THIAGO RODRIGO CICOGNA

\title{
Identificação de matrizes de funções de resposta em freqüência multidirecionais em estruturas complexas
}

Tese apresentada à Escola de
Engenharia de São Carlos da
Universidade de São Paulo, como
parte dos requisitos para a obtenção
do Título de Doutor em Engenharia
Mecânica

Orientador: Prof. Tit. Paulo Sergio Varoto

SÃO CARLOS 



\section{Dedicatória}

Aos meus queridos pais, ao meu irmão e à minha esposa, com amor, admiração e eterna gratidão. 



\section{AGRADECIMENTOS}

Agradeço a Deus pela saúde física e mental e por ter colocado em meu caminho pessoas que auxiliaram em muito para a minha formação.

Meu agradecimento especial ao Prof. Tit. Paulo Sergio Varoto pela amizade, orientação, pelo incentivo e pelo total apoio dispensado durante a elaboração desse trabalho.

Ao Prof. Dr. Marcelo Areias Trindade pela amizade, confiança e inestimáveis contribuições ao longo do desenvolvimento dessa tese.

Agradeço a minha família, simplesmente por tudo que fizeram e fazem ao longo de minha vida e a minha esposa pelo amor e o apoio constante.

Aos colegas de laboratório pelo companheirismo e em especial aos amigos Marcelo, Heinsten, Denis e Carlos, pelas contribuições em muitas etapas desse trabalho. Aos amigos Paulo Caixeta, Guilherme (Nauta) e Peronti pela amizade sincera e presença mesmo em momentos difíceis e muitas vezes incertos.

Meus sinceros agradecimentos aos funcionários do Laboratório de Dinâmica, Cristina, Xina, Diego, Sergio e Leandro, por todo o apoio e amizade.

Aos colegas do Laboratoire de Mécanique des Structures et des Systèmes Couplés por todo o apoio durante minha estadia no Conservatoire National des Arts e Métiers (CNAM/Paris) e em especial, ao Prof. Tit. Roger Ohayon.

À Fundação de Amparo à Pesquisa do Estado de São Paulo (FAPESP) pela bolsa de doutorado direto concedida.

E a todos que acreditam, torcem e contribuem para o meu crescimento. 



\section{RESUMO}

CICOGNA, T. R. Identificação de matrizes de funções de resposta em freqüência multidirecionais em estruturas complexas. 2008. 215 p. Tese (Doutorado) - Escola de Engenharia de São Carlos, Universidade de São Paulo, São Carlos-SP.

Este trabalho apresenta o desenvolvimento de uma metodologia para a estimativa de funções de resposta em freqüência angulares (FRFAs). Trata-se de uma técnica que utiliza transdutores piezelétricos $(\mathrm{PZT})$ do tipo bimorph para a medição da curvatura local da estrutura através do potencial elétrico induzido pela extensão e compressão do sensor. A partir da estimativa da curvatura, a rotação pode ser obtida diretamente através de várias técnicas de interpolação (polinomial, formas modais, etc.). Apresenta-se a modelagem teórica da qual se deriva as equações que governam a dinâmica de estruturas uni-dimensionais, do tipo viga, e estruturas bidimensionais, do tipo placa, ambas isotrópicas, onde se incorpora o sensor bimorph. Modelos em elementos finitos foram propostos no intuito de avaliar a utilização destes sensores (bimorphs) aplicados à estimativa das FRFAs. Apresentam-se também resultados numéricos e experimentais considerando-se uma viga engastada-livre (cantilever) e resultados numéricos considerando-se uma placa simplesmente apoiada. Um algoritmo genético foi ainda desenvolvido no intuito de determinar a posição e dimensão ótimas dos bimorphs em estruturas do tipo viga.

Palavras-chave: FRF Angular, Bimorph, Material piezelétrico, Movimentos angulares 



\section{ABSTRACT}

CICOGNA, T. R. Multidirectional frequency response functions matrices assessment in complex structures. 2008. 215 p. Thesis (Doctoral) - São Carlos School of Engineering, University of São Paulo, São Carlos-SP, Brazil.

The present work aims to perform the development of an attractive approach for accurate measurement of angular frequency response functions (AFRFs). It uses bimorph piezoceramic patches to measure the structure's local curvature through the measurement of the electric potential induced by the extension and compression of the patch's top and bottom stripes, respectively. From this curvature, rotation can be obtained directly by several interpolation techniques (single polynomial, modes basis). Theoretical modeling of the vibration incorporating piezoelectric bimorph sensor is presented and equations governing the dynamics for one-dimensional structures, like a beam, and for two-dimensional structures, like a plate, are derived for isotropic structures. Finite element model for the dynamic analysis were proposed to evaluate bimorphs patches applied to the measurement of angular FRFs. Numerical and experimental results are presented considering a cantilever beam and numerical results for a simply supported plate as tested structured. Also, in this work, a genetic algorithm was used as an adaptive heuristic search algorithm for optimal placement and sizing of the bimorph sensor into beam like structures.

Keywords: Angular FRF, Bimorph, Piezoelectric material, Angular motions 


\section{SUMÁRIO}

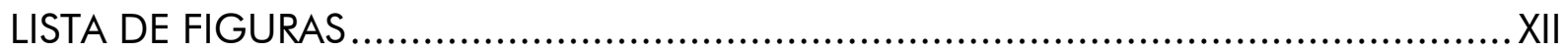

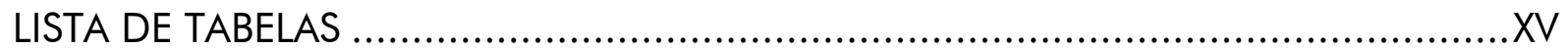

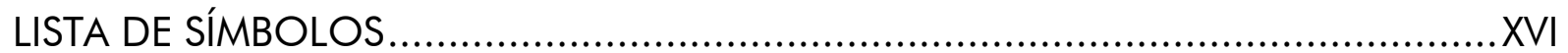

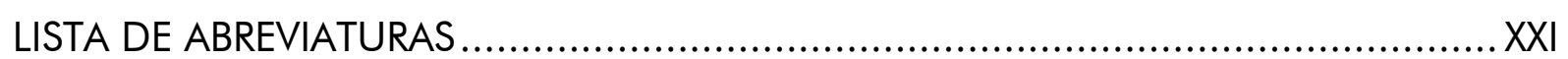

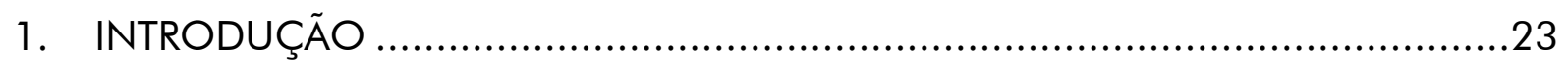

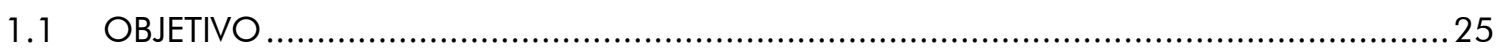

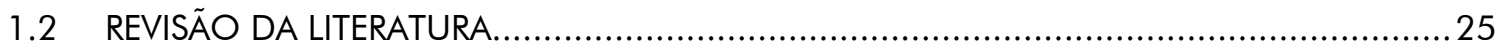

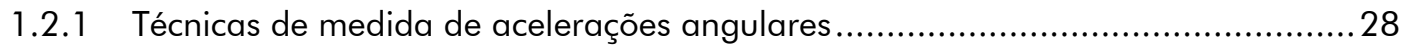

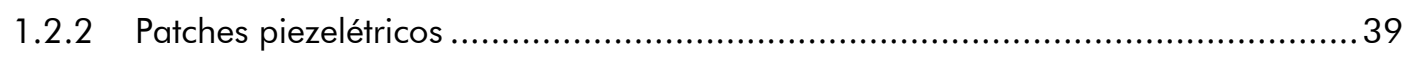

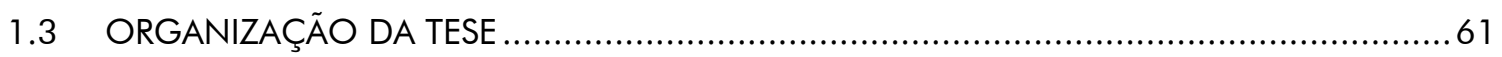

2. DESENVOLVIMENTO DE UM TRANSDUTOR DE ROTAÇÃO .......................63

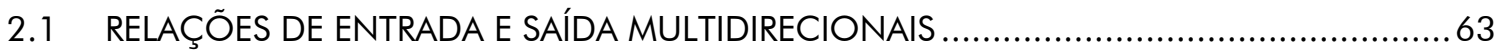

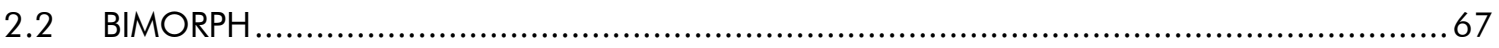

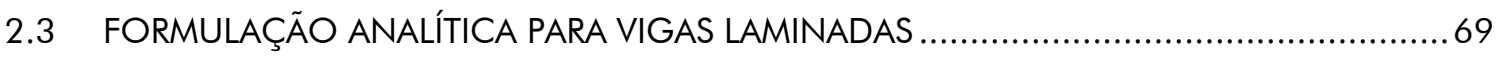

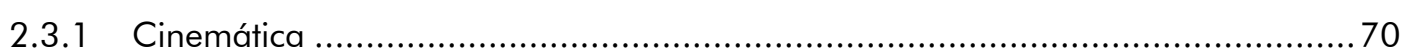

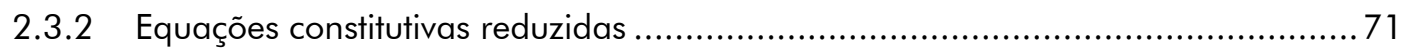

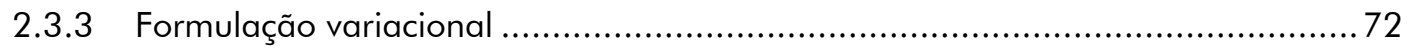

2.3.4 Equações de movimento e determinação da curvatura local ...............................76

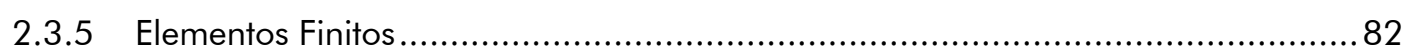

2.4 FORMULAÇÃO ANALÍTICA PARA PLACAS FINAS E ISOTRÓPICAS ….............................. 83

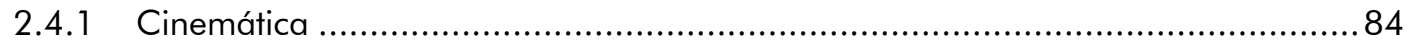

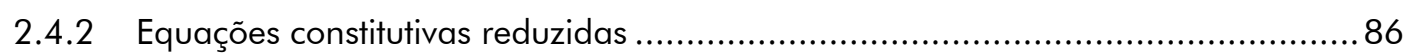

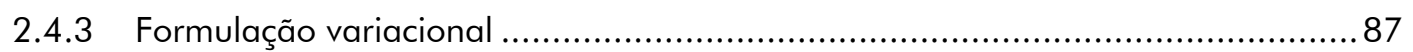

2.4.4 Equações de movimento e determinação da curvatura local ..............................89

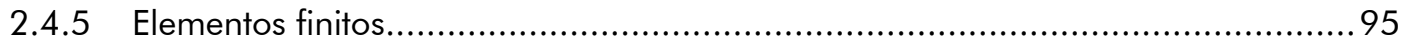

3. OTIMIZAÇÃO GEOMÉTRICA DOS SENSORES BIMORPHS ..........................98

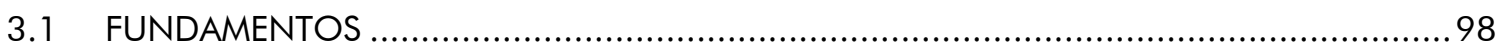

3.2 TERMOS E OPERADORES TÍPICOS EM ALGORITIMOS GENÉTICOS................................99

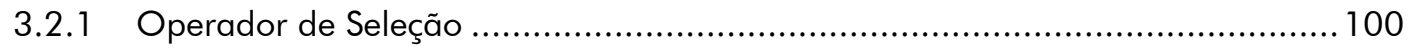

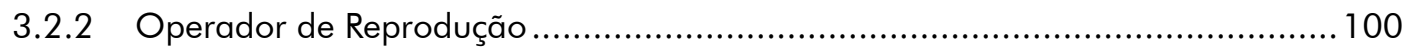

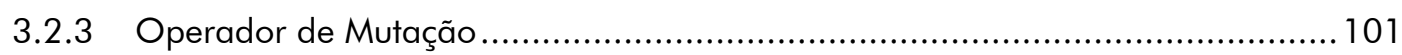

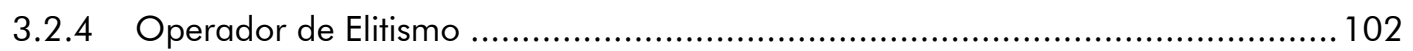

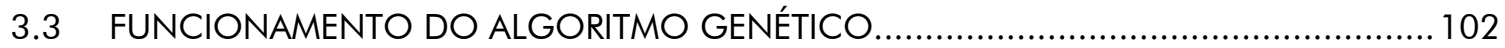

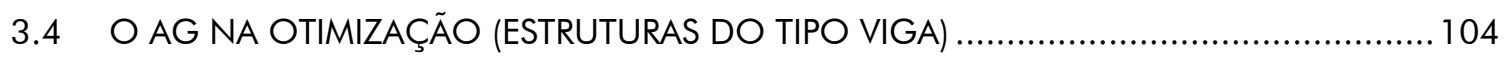

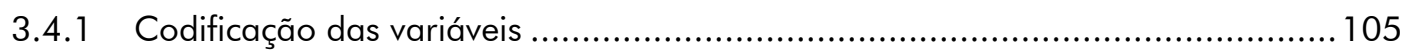

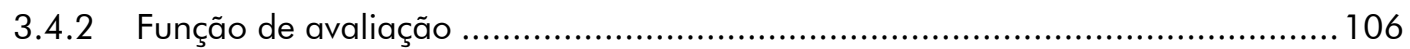




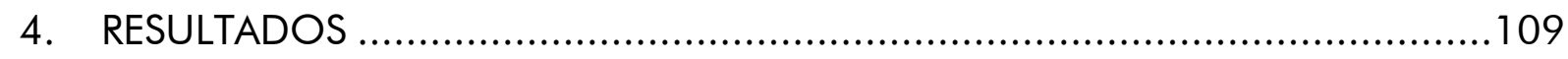

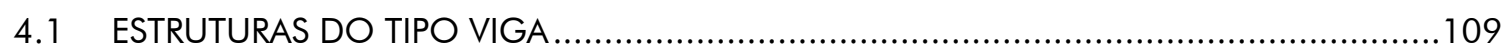

4.1.1 Avaliação dos métodos de aproximação ....................................................112

4.1.2 Comparação entre modos não corrigidos e modos corrigidos ........................118

4.1.3 Avaliação dos parâmetros de desempenho do AG .............................................123

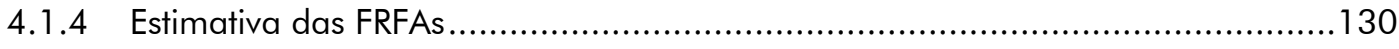

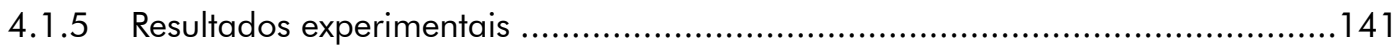

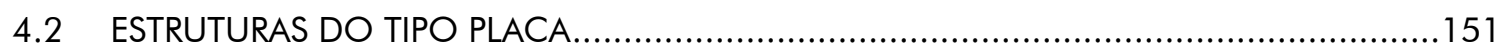

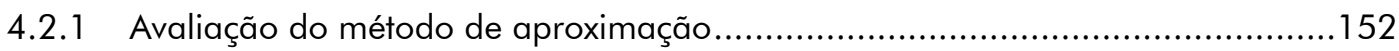

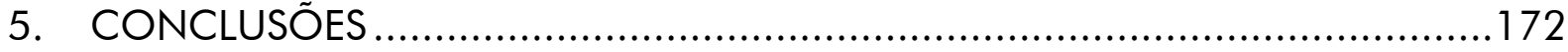

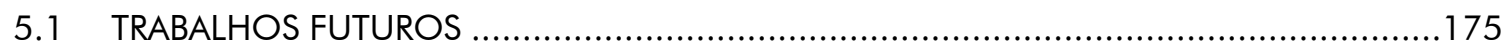

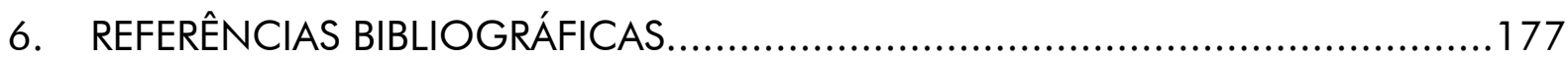

A. CÓDIGO EM MATLAB ${ }^{\circledR}$ PARA ESTRUTURAS DO TIPO VIGA...........................185

B. CÓDIGO EM ANSYS ${ }^{\circledR}$ PARA ESTRUTURAS DO TIPO PLACA ….......................196 


\section{LISTA DE FIGURAS}

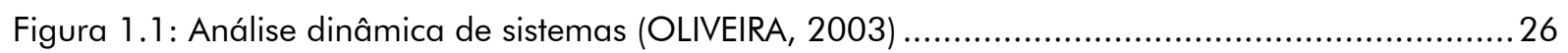

Figura 1.2: Crescimento do número de publicações nas últimas décadas ........................................2 27

Figura 1.3: Medição de aceleração angular através do bloco T ..................................................... 30

Figura 1.4: Configuração experimental (MOTTERSHEAD et al., 2005) ........................................... 33

Figura 1.5: Determinação das componentes de aceleração através de lasers ................................... 37

Figura 1.6: Transdutor de 6 GDL constituído por acelerômetros lineares .........................................37

Figura 1.7: Sensor com posicionamento e orientação dos acelerômetros (HELDERWEIRT et al. 2001). 38

Figura 1.8. Dispositivo VSM - Vibrating Sample Magnetometer - (MONTURET; NOGAREDE, 2002) .. 44

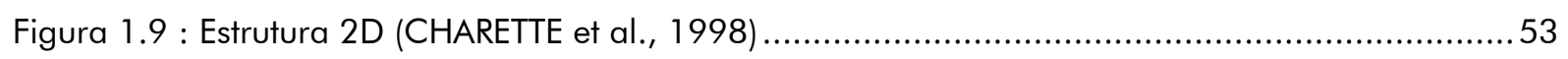

Figura 1.10: Patches piezelétricos na supressão de vibração em placas (QIU et al., 2007) ...............60

Figura 1.11: Múltiplos patches de PVDF no controle modal em placas (Tanaka e Sanada, 2007).......60

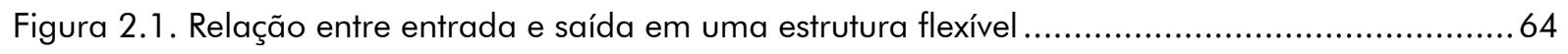

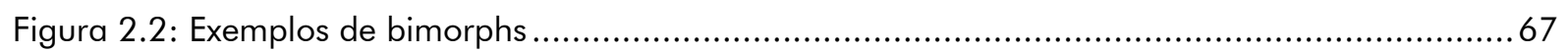

Figura 2.3: Montagem do sensor bimorph em paralelo (a e c) e em série (b e d) (DAS-GUPTA, 1998)68

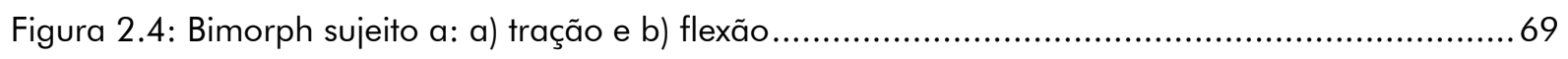

Figura 2.5: Representação cinemática para uma viga laminada .................................................... 70

Figura 2.6: Polarização e numeração das camadas piezelétricas ..................................................78

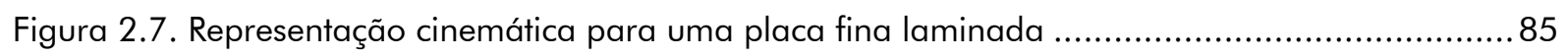

Figura 2.8: Variação da deformação, campo elétrico e tensão em uma placa fina laminada ..............87

Figura 2.9: Polarização e numeração das camadas piezelétricas para placas .................................. 90

Figura 2.10: Elemento SHELL99 utilizado na modelagem via elementos finitos................................96

Figura 2.1 1: Elemento SOLID226 utilizado na modelagem via elementos finitos .............................96

Figura 3.1: Funcionamento do operador de reprodução (crossover) ............................................ 101

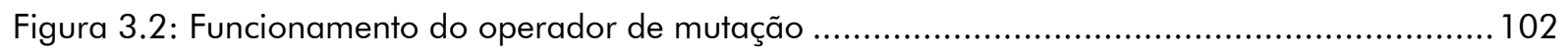

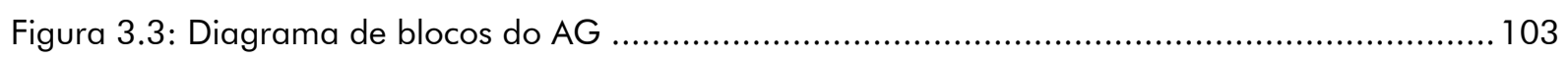

Figura 3.4: Parâmetros de otimização em estruturas do tipo viga ................................................ 104

Figura 3.5: Codificação utilizada na montagem dos cromossomos.............................................. 105

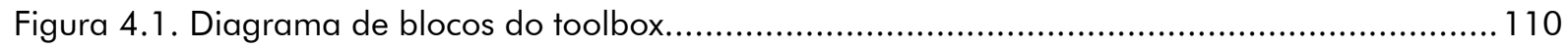

Figura 4.2: Resposta no tempo de cada pastilha cerâmica de um bimorph e a voltagem resultante a ser medida.

Figura 4.3. Configuração numérica adotada nas simulações 
Figura 4.4: Variação do erro para $n=1$ e $x_{\text {out }}=50 \mathrm{~mm}$

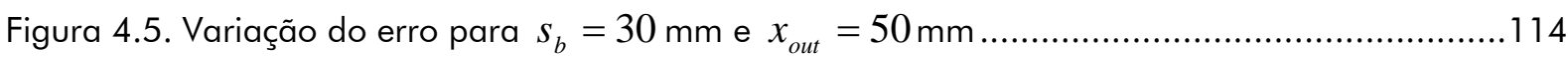

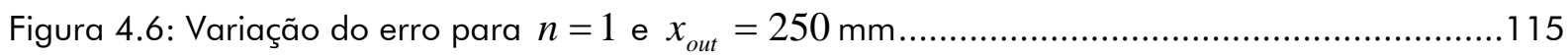

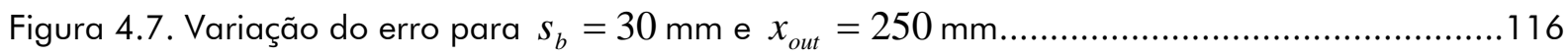

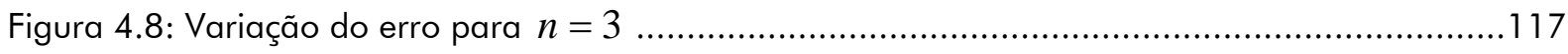

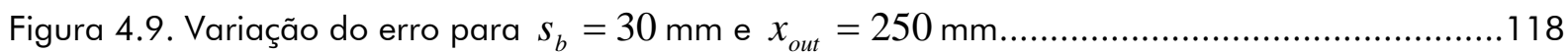

Figura 4.10: Comparação entre os 5 primeiros modos de vibrar (não corrigidos e corrigidos) no caso

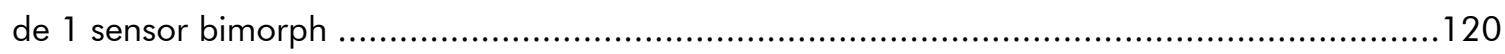

Figura 4.11: Comparação entre os 5 primeiros modos de vibrar (não corrigidos e corrigidos) no caso

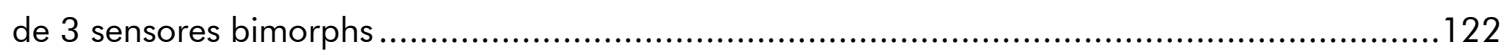

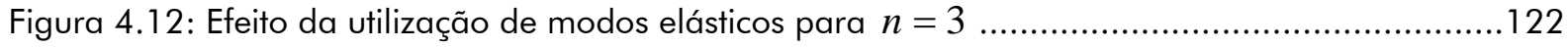

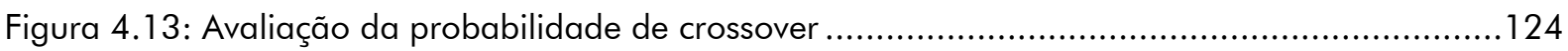

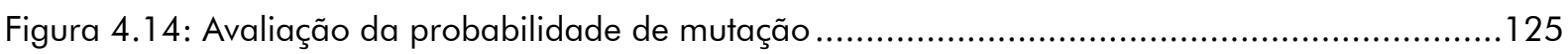

Figura 4.15: Considerações a respeito do tamanho da população ...........................................127

Figura 4.16: Distribuição dos indivíduos no domínio das soluções ..............................................128

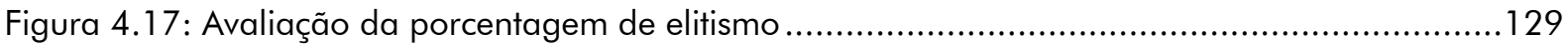

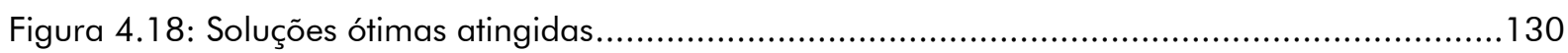

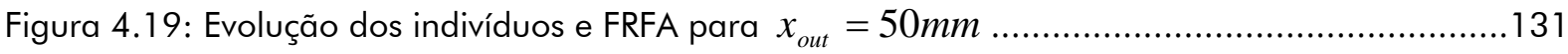

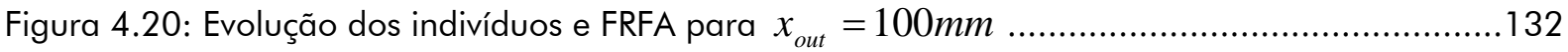

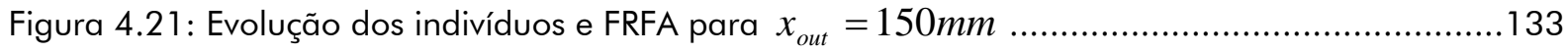

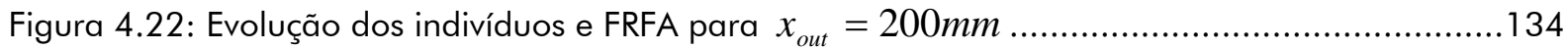

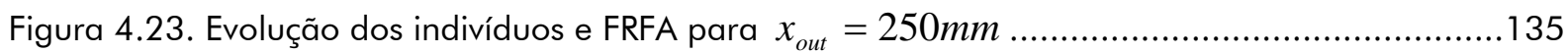

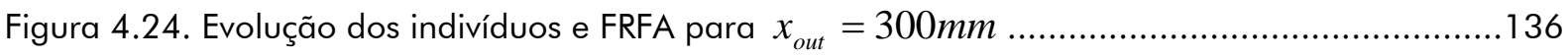

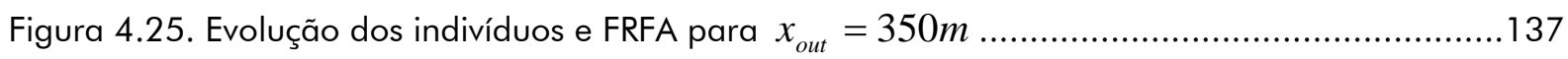

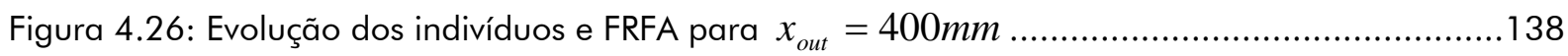

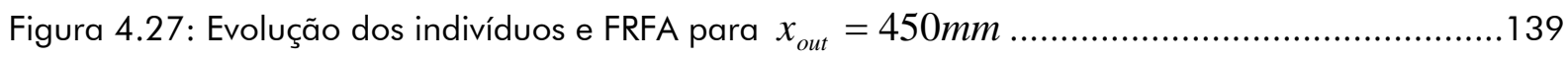

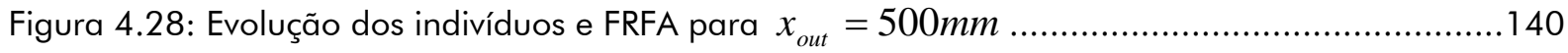

Figura 4.29: Dimensões da pastilha cerâmica piezelétrica (PZT-5H) e procedimento de corte e remoção das pastilhas do suporte de fixação 
Figura 4.30: Materiais utilizados na confecção dos bimorphs

Figura 4.31: Sensor bimorph confeccionado

Figura 4.32: Sensores bimorphs posicionados sobre a viga

Figura 4.33: Aparato experimental.

Figura 4.34: Resultado experimental: $x_{\text {out }}=150 \mathrm{~mm}$

Figura 4.35: Resultado experimental: $x_{\text {out }}=200 \mathrm{~mm}$ 148

Figura 4.36: Resultado experimental: $x_{\text {out }}=300 \mathrm{~mm}$ 148

Figura 4.37: Correção da estimativa numérica $\left(x_{\text {out }}=150 \mathrm{~mm}\right)$. 149

Figura 4.38: Correção da estimativa numérica $\left(x_{\text {out }}=200 \mathrm{~mm}\right.$ ). 150

Figura 4.39: Correção da estimativa numérica $\left(x_{\text {out }}=300 \mathrm{~mm}\right)$. 150

Figura 4.40: Dimensões principais na modelagem da placa 151

Figura 4.41: 4 bimorphs dispostos sobre a placa 153

Figura 4.42: Modos de vibrar para placa com 4 bimorphs (Rayleigh-Ritz) 156

Figura 4.43: Respostas no domínio da freqüência para cada bimorph $(n=4)$. 157

Figura 4.44: Estimativa da FRFA: ponto $1(x=200, y=25)$ e $n=4$. 158

Figura 4.45: Estimativa da FRFA: ponto $2(x=100, y=50)$ e $n=4$ 159

Figura 4.46: Estimativa da FRFA: ponto $3(x=220, y=250)$ e $n=4$ 160

Figura 4.47: Estimativa da FRFA: ponto $4(x=90, y=210)$ e $n=4$. 161

Figura 4.48: 4 bimorphs dispostos sobre a placa. 162

Figura 4.49: Modos de vibrar para placa com 12 bimorphs (Elementos finitos) 164

Figura 4.50: Respostas no domínio da freqüência para cada bimorph $(n=12)$. 164

Figura 4.51: Estimativa da FRFA: ponto $1(x=200, y=25)$ e $n=12$ 165

Figura 4.52: Estimativa da FRFA: ponto $2(x=100, y=50)$ e $n=12$. 166

Figura 4.53: Estimativa da FRFA: ponto $3(x=220, y=250)$ e $n=12$. 167

Figura 4.54: Estimativa da FRFA: ponto $4(x=90, y=210)$ e $n=12$ 168 


\section{LISTA DE TABELAS}

Tabela 4.1. Propriedades do material da placa

151

Tabela 4.2. Comparação entre as freqüências naturais $(n=4)$ 153

Tabela 4.3. Comparação entre as freqüências naturais $(n=12)$ 163

Tabela 4.4. Freqüências naturais da placa sob condições de contorno elétricas diferentes .171 


\section{LISTA DE SÍMBOLOS}

\section{Romanas Maiúsculas}
$A_{j} \quad$ Área da $j$-ésima camada
$D_{E} \quad$ Constante elástica
$D_{\text {posição }} \quad$ Número de bits para o gene "posição"
$D_{\text {tamanho }} \quad$ Número de bits para o gene "tamanho"
$D_{3} \quad$ Deslocamento elétrico transveral
E Módulo de Young
$E_{3} \quad$ Campo elétrico na direção $Z$
F Força de excitação
$F_{Q} \quad$ Excitação estrutural linear associada à coordenada estrutural $Q$
$\{F\} \quad$ Vetor de excitação linear
$\{F\}_{Q} \quad$ Vetor de excitação linear associada à coordenada estrutural $Q$
$\{\mathfrak{J}\} \quad$ Vetor de excitação estrutural ao longo das direções ortogonais
$H_{P Q} \quad$ FRF relacionada às coordenadas estruturais $P$ e $Q$
$\left[H_{X F}\right] \quad$ Sub-matriz de FRFs envolvendo a relação de GDL linear/linear
$\left[H_{\theta F}\right]$ Sub-matriz de FRFs envolvendo a relação de GDL angular/linear
$\left[H_{X M}\right]$ Sub-matriz de FRFs envolvendo a relação de GDL linear/angular
$\left[H_{\theta M}\right] \quad$ Sub-matriz de FRFs envolvendo a relação de GDL angular/angular
$I_{j} \quad$ Segundo momento de inércia da seção transversal ( $j$-ésima camada)
$I_{0}^{j} \quad$ Área da $j$-ésima camada
$I_{1}^{j} \quad$ Primeiro momento de inércia da seção transversal ( $j$-ésima camada)
$I_{2}^{j} \quad$ Segundo momento de inércia da seção transversal ( $j$-ésima camada)
$\bar{I}_{j} \quad$ Primeiro momento de inércia da seção transversal ( $j$-ésima camada)
[K] Matriz de rigidez
$L_{j} \quad$ Comprimento da $j$-ésima camada
$L_{x} \quad$ Dimensão da placa na direção $x$
$L_{y} \quad$ Dimensão da placa na direção $y$ 
$L_{p x} \quad$ Dimensão do sensor bimorph na direção $x$

$L_{p y} \quad$ Dimensão do sensor bimorph na direção $y$

M Momento resultante aplicado

$\{M\} \quad$ Vetor de excitação angular

$\{M\}_{Q} \quad$ Vetor de excitação angular associada à coordenada estrutural $Q$

[M] Matriz de massa

N

Número de camadas em estruturas compostas (piezelétricas e não piezelétricas)

$N \quad$ Resultante normal aplicada

$N \quad$ Número de pontos calculados no domínio da frequência

$P \quad$ Coordenada do ponto de resposta estrutural

Q Coordenada do ponto de aplicação do vetor de forças

$Q_{i} \quad i$-ésima força generalizada

$\left[Q_{M}\right] \quad$ Matriz de interpolação para a aproximação por formas modais

$\left\lfloor Q_{p}\right\rfloor \quad$ Matriz de interpolação para a aproximação polinomial

$\left[Q_{R R}\right] \quad$ Matriz de interpolação para a aproximação por formas modais (Ritz)

RFRF FRF angular

$R F R F_{i}^{\text {bimorph }}$ Valor pontual para FRF angular (bimorph)

$R F R F_{i}{ }^{\text {fem }} \quad$ Valor pontual para FRF angular (elementos finitos)

$T \quad$ Energia cinética

U Energia potencial

$V \quad$ Resultante transversal aplicada

$V \quad$ Unidade de tensão elétrica (Volts)

$V \quad$ Tensão elétrica

$V_{j} \quad$ Diferença de potencial elétrico para a $j$-ésima camada piezelétrica

$V_{j}^{+} \quad$ Potencial elétrico medido na face superior da $j$-ésima camada piezelétrica

$V_{j}^{-} \quad$ Potencial elétrico medido na face inferior da $j$-ésima camada piezelétrica

$V_{\text {posição }} \quad$ Intervalo de valores para o cromossomo "posição"

$V_{\text {tamanho }} \quad$ Intervalo de valores para o cromossomo "tamanho"

$X_{P} \quad$ Resposta estrutural linear associada à coordenada estrutural $P$

$\{X\} \quad$ Vetor de movimentos lineares 
$\{X\}_{P} \quad$ Vetor de resposta linear associada à coordenada estrutural $P$

$\{N\} \quad$ Vetor de resposta estrutural ao longo das direções ortogonais

\section{Romanas Minúsculas}

$a_{i} \quad$ Parâmetros de deslocamentos

$a_{k}(t) \quad$ Coeficientes temporais (aproximação polinomial)

$\{a\} \quad$ Vetor de coeficientes $a_{k}$

$b_{j} \quad$ Largura da $j$-ésima camada

$c_{i j} \quad$ Constantes elásticas

$\bar{c}_{11}^{j} \quad$ Constante elástica corrigida para a $j$-ésima camada

$\{c\}$ Vetor de curvaturas estimadas a partir de cada sensor bimorph

$e_{l j} \quad$ Constantes piezelétricas

$\bar{e}_{31}^{j} \quad$ Constante piezelétrica corrigida para a $j$-ésima camada

g Aceleração da gravidade $\left(g=9,81 \mathrm{~m} / \mathrm{s}^{2}\right)$

$h \quad$ Espessura da viga (placa)

$h_{j} \quad$ Espessura da $j$-ésima camada

$h_{p} \quad$ Espessura de cada camada piezelétrica

m Massa

$m \quad$ Número de modos utilizados na aproximação por formas modais

$m \quad$ Ordem da maior derivada do funcional

$n \quad$ Número de sensores bimorph distribuídos sob a estrutura

p Ordem do polinômio de aproximação para o campo de deslocamentos

$q_{i} \quad i$-ésima coordenada generalizada

$s_{b i} \quad$ Dimensão do $i$-ésimo sensor bimorph

$t_{i} \quad$ Instante de tempo

$u \quad$ Deslocamento axial local (linha média)

$u_{, x} \quad$ Primeira derivada do deslocamento axial $u$ em relação à $x$

$u_{, y} \quad$ Primeira derivada do deslocamento axial $u$ em relação à $y$

$\bar{u} \quad$ Campo de deslocamento axial 


$\begin{array}{ll}v_{, y} & \text { Primeira derivada do deslocamento axial } v \text { em relação à } y \\ v_{, x} & \text { Primeira derivada do deslocamento axial } v \text { em relação à } x \\ \bar{v} & \text { Campo de deslocamento axial } \\ x & \text { Eixo do sistema de coordenada } \\ x_{b i} & \text { Posição do } i \text {-ésimo sensor bimorph ao longo do eixo } x \\ x_{i n} & \text { Posição da excitação impulsiva ao longo do eixo } x \\ x_{\text {out }} & \text { Ponto de resposta na viga (coordenada } x \text { ) } \\ \dot{x} & \text { Derivada primeira em relação ao tempo } \\ \ddot{x} & \text { Derivada segunda em relação ao tempo } \\ y & \text { Eixo do sistema de coordenada } \\ y_{\text {in }} & \text { Posição da excitação impulsiva ao longo do eixo } y \\ y_{\text {out }} & \text { Ponto de resposta na viga (coordenada } y \text { ) } \\ z & \quad \text { Eixo do sistema de coordenada } \\ w & \text { Deslocamento axial local (linha média) } \\ \bar{w} & \text { Campo de deslocamento transversal }\end{array}$

\section{Grega Maiúscula}

$\Delta D \quad$ Média entre os erros locais

$\Delta D_{i} \quad i$-ésimo erro

$\nabla^{2} \quad$ Laplaciano

$\in_{l l} \quad$ Constantes dielétricas

$\{\Theta\} \quad$ Vetor de movimentos angulares

$\Omega_{j} \quad$ Volume da $j$-ésima camada

\section{Grega Minúscula}

$\alpha_{i}(t) \quad$ Coeficientes temporais (aproximação por formas modais)

$\alpha_{i}(\omega) \quad$ Coeficientes de forma no domínio da frequência

$\{\alpha\} \quad$ Vetor de coeficientes $\alpha_{i}$ 
$\beta \quad$ Primeira derivada do deslocamento transversal $w$ em relação ao eixo $x$

$\beta_{, x} \quad$ Primeira derivada do deslocamento transversal $w$ em relação à $x$

$\beta_{, y} \quad$ Primeira derivada do deslocamento transversal $w$ em relação à $y$

$\varepsilon^{b} \quad$ Deformação do tipo flexão

$\varepsilon^{m} \quad$ Deformação do tipo membrana

$\varepsilon_{1} \quad$ Deformação axial em $x$

$\varepsilon_{2} \quad$ Deformação axial em $y$

$\varepsilon_{6} \quad$ Deformação em cisalhamento

$\delta H \quad$ Trabalho virtual das forças eletromecânicas

$\delta T \quad$ Trabalho virtual das forças de inércia

$\delta W \quad$ Trabalho virtual das forças externas

$\phi_{i}(x) \quad$ Descrição geométrica do $i$-ésimo modo de vibrar

$\phi(x, y) \quad$ Função de forma ou função de Ritz

$\phi_{r}(x, y) \quad r$-esima forma modal

$\gamma \quad$ Cisalhamento

$v \quad$ Coeficiente de Poisson

$\theta \quad$ Rotação angular

$\dot{\theta} \quad$ Velocidade angular (derivada primeira em relação ao tempo)

$\rho_{j} \quad$ Densidade em massa por volume da $j$-ésima camada

$\sigma_{x} \quad$ Tensão normal em $x$

$\sigma_{y} \quad$ Tensão normal em $y$

$\sigma_{z} \quad$ Tensão normal em $z$

$\sigma_{1} \quad$ Tensão mecânica axial (direção $x$ )

$\sigma_{2} \quad$ Tensão mecânica axial (direção $y$ )

$\sigma_{6} \quad$ Tensão mecânica em cisalhamento (plano $x y$ )

$\sigma_{3} \quad$ Tensão mecânica na direção $Z$

$\omega \quad$ Freqüência

$\omega_{O C}^{2} \quad$ Frequência de ressonância em circuito aberto

$\omega_{S C}^{2} \quad$ Frequência de ressonância em curto-circuito 


\section{LISTA DE ABREVIATURAS}

AG Algoritmo Genético

AM Assumed Modes method

ASAC Active Structural Acoustic Control

CC Clamped edges

CF Clamped and free edges

CLT Classical Laminated Theory

CNAM Conservatoire National des Arts et Métiers

DC Transverse electric displacement constant

EAM Enhanced Assumed Modes method

EMCC Coeficiente Efetivo de Acoplamento Eletromecânico

ESL Equivalent Single Layer

FE Finite Element method

FRF Função de Resposta em Freqüência

FRFA Função de Resposta em Freqüência Angular

FRFM Função de Resposta em Freqüência Multidirecional

GB Gigabytes

GDL Graus de Liberdade

GDLR Graus de Liberdade Rotacionais

GDLT Graus de Liberdade de Translação

$\mathrm{GHz} \quad$ Giga-Hertz

LEN Last Energy Norm method

LMSSC Laboratoire de Mécanique des Structures et des Systèmes Couplés

LW Layerwise

MEC Método dos Elementos de Contorno

MEF Método dos Elementos Finitos

MEMS Microelectromechanical Systems

MSM Método dos Sistemas Multicorpos

OC Open circuit (circuito aberto)

PVDF Polyvinylidenefluoride

PVF Polyvinyfluoride

PZT Titanato ou Zirconato de Chumbo

RR Rayleigh-Ritz

SEREP System Equivalent Reduction Expansion Technique

SC Short circuit (curto-circuito) 
SS Simply Supported edges

VLD Vibrômetro a Laser Doppler

2D Bi-dimensional

3D Tri-dimensional 


\section{INTRODUÇÃO}

Durante a década de 90 os recursos computacionais e experimentais destinados à análise modal experimental de estruturas flexíveis alcançaram um avanço significativo com o surgimento de novos sensores e técnicas de medida que visam, principalmente, aumentar a precisão dos dados experimentais. Novos sensores, dentre os quais se destacam os piezelétricos têm surgido mais leves e menores, o que contribui de forma decisiva para a redução da influência destes nos dados experimentais. As técnicas de medição de vibração sem contato, principalmente aquelas baseadas no uso de interferômetros à laser mereceram uma atenção maior e igualmente avançaram nos últimos anos.

Em relação aos mecanismos de excitação estrutural, prepondera ainda a utilização de duas técnicas já consagradas no contexto da análise modal experimental: os excitadores' eletromagnéticos e os martelos impulsivos. Embora estas duas técnicas possuam vantagens e desvantagens conforme estabelecido em diversas publicações importantes na área (VAROTO, 1994; OLIVEIRA; VAROTO, 2002; ZHU et al., 2006), os shakers e martelos de impacto ainda são utilizados na grande maioria dos ensaios com o objetivo de se levantar modelos modais de resposta da estrutura sob estudo. Em estudos recentes, considerou-se a possibilidade

\footnotetext{
${ }^{1}$ O termo shaker é também comumente utilizado.
} 
de se utilizar fontes acústicas calibradas como mecanismos de excitação estrutural (BRUNSKOG, 2002). Esta técnica, embora também possua algumas desvantagens, apresenta-se como uma opção promissora, tanto na análise modal estrutural quanto acústica, principalmente pelo fato de não requerer, a princípio, que acoplamentos mecânicos sejam realizados com a estrutura sob estudo, como é o caso dos shakers.

Embora as considerações feitas nos dois parágrafos precedentes permitam uma idéia de que avanços importantes foram atingidos, existe ainda uma deficiência tanto nos mecanismos de excitação quanto na captação da resposta estrutural no que diz respeito à identificação de grandezas angulares. $\bigcirc$ conhecimento de tais grandezas é de fundamental importância para a estimativa das chamadas Funções de Resposta em Freqüência Multidirecionais (FRFMs) e, por sua vez, das Funções de Resposta em Freqüência Angulares (FRFAs), que desempenham um papel importante, pois estão presentes em $75 \%$ da matriz de resposta estrutural completa.

O sucesso no desenvolvimento de produtos consiste primordialmente em introduzir no mercado produtos cada vez mais baratos, duráveis, leves e principalmente ainda mais confiáveis e que agridam o mínimo possível o meio ambiente. Por sua vez, um fator fundamental no desenvolvimento de produtos é o estudo do seu comportamento dinâmico. Do ponto de vista da análise modal experimental, os ensaios em vibração são realizados atualmente considerando-se somente grandezas lineares em excitação e resposta. Contudo, a não consideração de grandezas angulares na determinação da resposta dinâmica de um produto empobrece os resultados obtidos (AVITABILE; O'CALLAHAN, 2003), com conseqüente perda de informações que venham a ser importantes para o seu completo entendimento. 


\subsection{OBJETIVO}

O objetivo desta tese é realizar um estudo aprofundado de técnicas analíticas e experimentais para a identificação de matrizes de FRFM, em especial, na identificação das FRFs envolvendo grandezas angulares. Para tal, o presente trabalho apresenta $\circ$ desenvolvimento analítico, numérico e experimental de um transdutor piezelétrico (bimorph) voltado para a estimativa de FRFs do tipo $\theta / F$, onde $\theta$ é a rotação angular local de algum ponto em particular da estrutura em estudo e $F$ a força de excitação aplicada à mesma.

\subsection{REVISÃO DA LITERATURA}

A análise dinâmica de sistemas pode ser realizada através de dois procedimentos diferentes (EWINS, 1984). O primeiro é denominado de Análise Modal Teórica e consiste na formulação de um modelo matemático da estrutura em estudo através de alguma técnica de discretização: o Método dos Elementos Finitos (MEF) ou - Método dos Sistemas Multicorpos (MSM), como também, o Método dos Elementos de Contorno (MEC). O MEF é largamente utilizado na obtenção das matrizes físicas de massa e rigidez da estrutura. Estas matrizes são então utilizadas na formulação de um problema de autovalores e autovetores cuja solução fornece as freqüências naturais e modos normais de vibrar da estrutura. Estes resultados constituem o chamado modelo modal teórico e podem ser posteriormente utilizados na obtenção de níveis de resposta a carregamentos dinâmicos conhecidos, na determinação de características de resposta em freqüência e impulsiva e na correlação com dados experimentais (EWINS, 1984). 
O segundo procedimento é denominado de Análise Modal Experimental. Neste tipo de análise dados experimentais são obtidos e utilizados na determinação das características dinâmicas da estrutura em estudo (freqüências naturais, fatores de amortecimento modais e modos de vibrar). Dentre as aplicações da análise modal experimental, a mais comum é a validação de um modelo teórico para uma dada estrutura. Através de ensaios experimentais obtêm-se as características de resposta do sistema, que são geralmente apresentadas no domínio da freqüência através de Funções de Respostas em Freqüência (FRFs) ou então através da resposta impulsiva (MAIA et al., 1997).

A Figura 1.1 ilustra ambos os procedimentos que podem ser adotados em uma análise dinâmica de sistemas (OLIVEIRA, 2003).

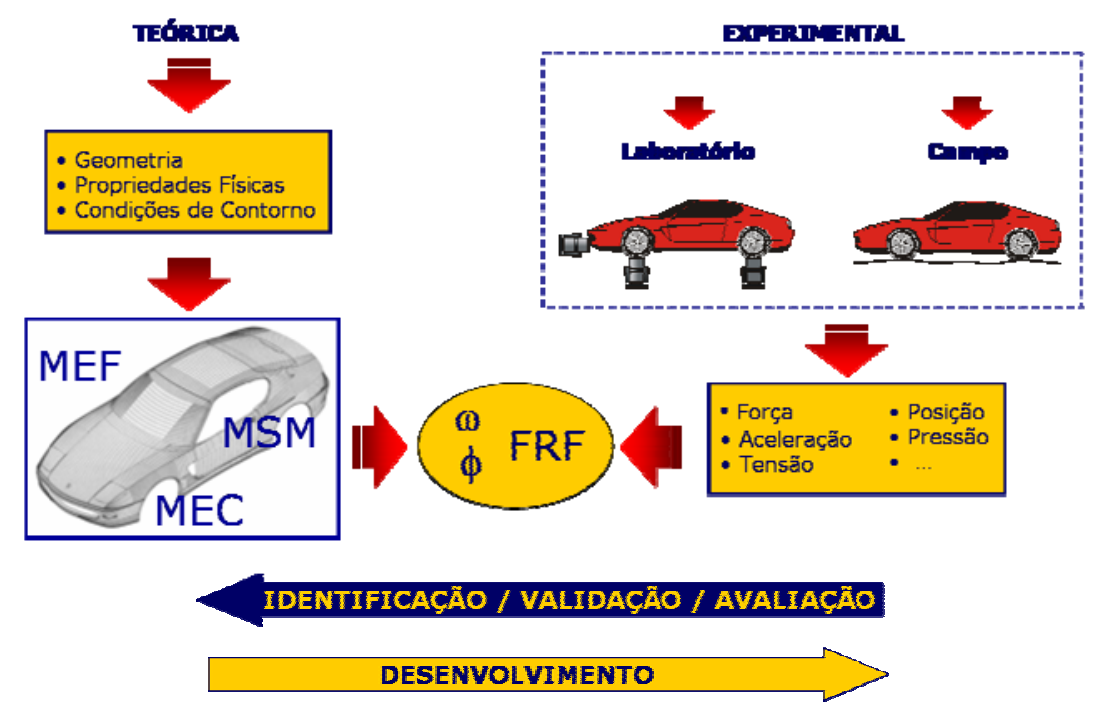

Figura 1.1: Análise dinâmica de sistemas (OLIVEIRA, 2003)

No entanto, um dos maiores desafios da análise modal experimental é a identificação com precisão de FRFs angulares cujas entradas e saídas do sistema são dadas através de grandezas angulares. Da mesma forma, as medidas de binários 
também representam um grande desafio no contexto da análise modal experimental. Por muitos anos este problema não tem sido de fácil solução e as medidas têm se limitado à excitação com forças lineares e a resposta em aceleração apenas translacional. O resultado destas medidas conduz a um modelo experimental incompleto, onde a falta de informação das grandezas angulares pode representar mais da metade do modelo de resposta completo do sistema (VAROTO, 1996). Contudo, a necessidade de maior precisão nos modelos de resposta vem contribuindo para uma crescente importância e melhoria nas técnicas de medida de grandezas angulares (MAIA et al., 1997).

A Figura 1.2 ilustra o crescimento do número de publicações diretamente relacionadas à obtenção de grandezas angulares e mais amplamente, na medição de FRFs multidirecionais.
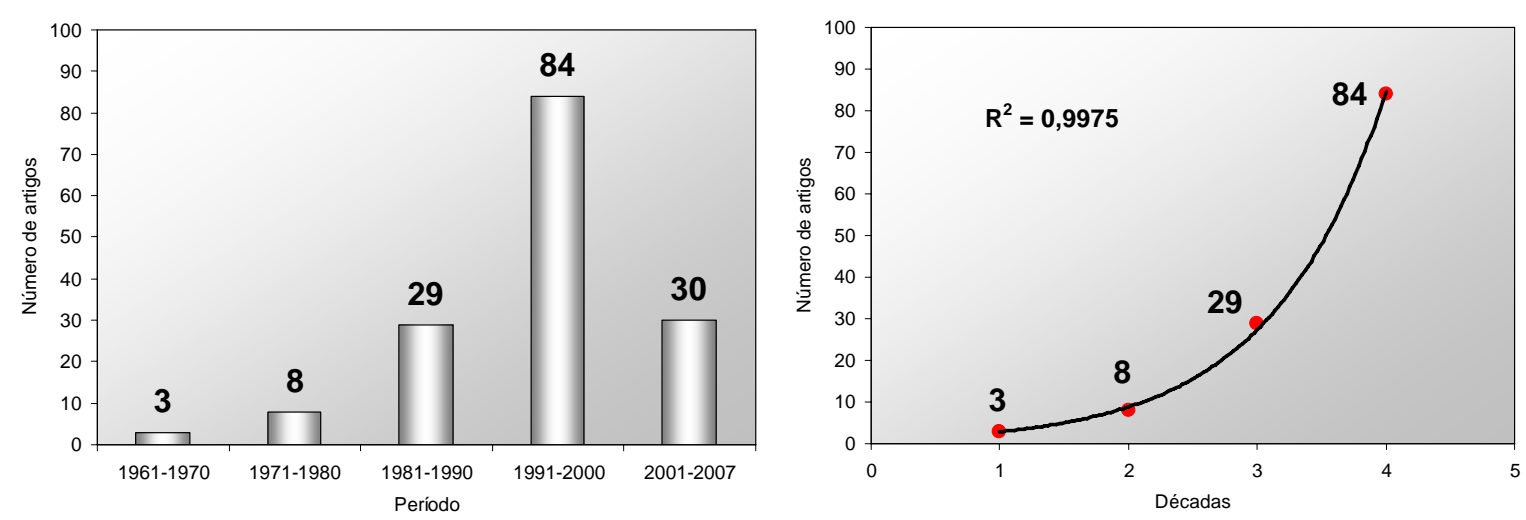

Figura 1.2: Crescimento do número de publicações nas últimas décadas

Seguindo a mesma divisão de conteúdo feita por Bregant e Sanderson (2000), os tópicos a seguir apresentam uma descrição das principais contribuições científicas e tecnológicas relacionada às técnicas e métodos de medição e aplicação de FRFs multidirecionais, com maior enfoque aos métodos experimentais para determinação dos graus de liberdade rotacionais (GDLR). 


\subsubsection{TÉCNICAS DE MEDIDA DE ACELERAÇÕES ANGULARES}

O estudo experimental de vibração estrutural tem proporcionado uma grande contribuição para a identificação e também para a solução de problemas de engenharia. Neste contexto, a Análise Modal Experimental tornou-se uma poderosa ferramenta de análise para a determinação de características dinâmicas das estruturas a partir de medidas da resposta em freqüência da estrutura sob estudo. Desta forma, a pesquisa em Análise Modal Experimental está relacionada a um conjunto de técnicas que possibilitam a obtenção de modelos matemáticos para uma determinada estrutura através de dados experimentais (EWINS; INMAN, 2000).

De acordo com Maia et al. (1997), a análise modal foi aplicada pela primeira vez com sucesso em 1940 em um estudo que proporcionou o entendimento do comportamento dinâmico de uma estrutura aeronáutica. Atualmente, a aplicação da análise modal cobre uma vasta área: desde a identificação e avaliação dos fenômenos de vibração, como também na validação e ajuste de modelos dinâmicos computacionais e na modificação estrutural e detecção de falhas. Salienta-se também que a análise modal é parte integrante do processo de desenvolvimento de novos produtos bem como na avaliação de seu comportamento dinâmico. A análise modal também possui uma estreita relação com temas de pesquisa em acústica estrutural e análise vibro acústica de sistemas mecânicos (HEYLEN et al., 2000).

De acordo com Bregant e Sanderson (2000), medidas e excitações que considerem graus de liberdade de rotação (GDLR) têm um histórico relativamente curto se comparado com os graus de liberdade de translação (GDLT), devendo-se isto principalmente a dois motivos: (i) GDLR não eram considerados importantes e estes 
não eram vistos como necessários para o enriquecimento do modelo de resposta da estrutura. Isto poderia, em princípio, ser considerado verdade na determinação das freqüências naturais e fatores de amortecimento modais, mas não representa uma hipótese apropriada em termos de acoplamento estrutural e (ii) GDLR apresentam maior complexidade em termos de medição em comparação aos GDLT, pois estas medidas requerem um grande esforço experimental e apresentam pouca precisão se comparado com as medidas diretas dos movimentos dos GDLT. Técnicas e métodos para medir GDLR vêm ganhando muita importância pela necessidade de maior precisão nas FRFs experimentais.

\subsubsection{MEDIDAS ANGULARES BASEADAS NA UTILIZAÇÃO DE "BLOCOS T"}

A obtenção de dados de posição, velocidade ou aceleração angular pode ser feita de diferentes maneiras, (EWINS, 2000; MAIA et al., 1997; McCONNELL, 1995). As mais comuns são baseadas na utilização de dois ou mais acelerômetros de medidas lineares fixados diretamente sobre a estrutura ou utilizando um corpo rígido auxiliar na forma de um T conectado a mesma (EWINS, 2000; MAIA et al., 1997; MCCONNELL, 1995; YOSHIMURA; HOSOYA, 2000).

A técnica do bloco $T$ baseia-se na medição da resposta de acelerômetros lineares montados em um bloco T conectado à estrutura no ponto de interesse como mostrado na Figura 1.3 (URGUEIRA, 1989). O bloco é assumido como sendo rígido na faixa de freqüências de interesse e a sensibilidade cruzada dos acelerômetros tem que ser baixa (BREGANT; SANDERSON, 2000). 


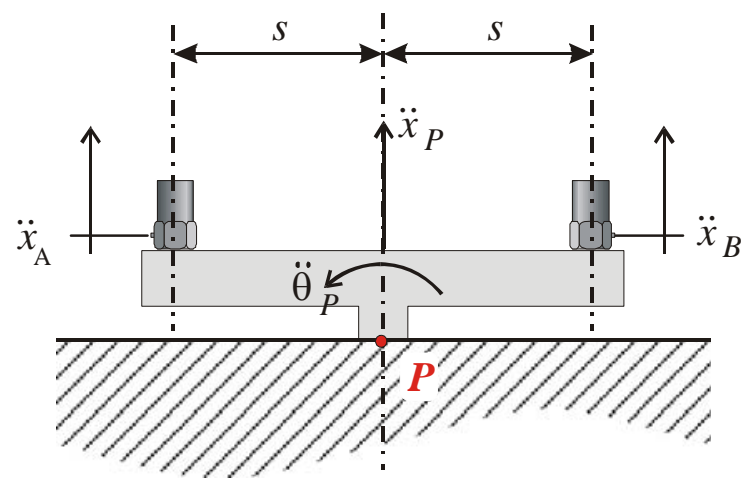

Figura 1.3: Medição de aceleração angular através do bloco $T$

A principal vantagem dessa técnica é que o aparato experimental é relativamente simples e barato, já que faz uso somente de acelerômetros lineares convencionais durante as medidas. Porém, uma grande desvantagem desta técnica é a presença de massa adicional (do bloco $\mathrm{T}$ e dos acelerômetros) adicionada à estrutura sob estudo e que pode alterar as medidas significativamente em alguns casos. Outra desvantagem desta técnica é a presença de elevados níveis de ruído, já que a determinação da aceleração angular nesta técnica requer que os sinais dos acelerômetros sejam subtraídos um do outro.

Yoshimura e Hosoya (2000) utilizam o bloco T em estruturas tipo viga para estimar FRFs angulares. Primeiramente, o bloco é fixado na estrutura no ponto de interesse e então excitado por um martelo de impacto convencional em três pontos diferentes, onde são então introduzidas na estrutura uma força e um momento para se obter as acelerações dos GDLR como resposta do sistema. Após um procedimento numérico, são estimadas as forças e os momentos aplicados no ponto onde o bloco T foi instalado bem como os movimentos lineares e angulares resultantes nestes pontos. Finalmente, as FRFs angulares e lineares são obtidas. 
Silva (2003) desenvolveu um método baseado em técnicas de acoplamento em que se estimam termos rotacionais sem que seja necessária a aplicação de um binário, introduzindo-se uma modificação estrutural obtida pela rotação de um bloco em forma de T. A força é aplicada em seu centróide. Alguns exemplos numéricos e experimentais são apresentados de modo a ilustrar o procedimento e procedendo-se à sua discussão de modo a verificar as vantagens do método e evidenciar as dificuldades que surgem na sua aplicação prática. $\bigcirc$ trabalho também aborda técnicas de cancelamento de massa e medições por laser.

Neste mesmo ano, Lofrano (2003) realizou uma investigação sobre técnicas experimentais para a determinação de FRFs angulares com aplicação em estruturas do tipo viga. Foram feitas várias constatações e dentre elas destacam-se resultados onde as FRFs angulares/lineares resultantes podem sofrer alterações significativas dependendo das dimensões dos blocos $T$, forma de fixação do mesmo, bem como, os dados experimentais são processados.

De acordo com Montalvão et al. (2004), um método alternativo baseado em técnicas de acoplamento é desenvolvido. Este método permite a obtenção de receptâncias que envolvam grandezas angulares sem que haja a necessidade de se aplicar uma excitação do tipo binário, porém, ainda sendo passível de medição. Isto é alcançado introduzindo-se uma inércia de rotação oriunda de um bloco rígido no formato de um T. Alguns exemplos numéricos e experimentais são apresentados a título de demonstração da aplicabilidade e do desempenho do método. As limitações do método proposto são exploradas de maneira que sejam explicitadas as origens de resultados pobres. O método explora ainda o que é chamado de "terceira" função do bloco T: a introdução de uma modificação na inércia de rotação devido à rotação em 
$90^{\circ}$ do bloco sobre um de seus eixos de simetria. Respostas em translação são realizadas sem contato através de dois vibrômetros a laser, resultando em respostas rotacionais por subtração. O método envolve ainda um procedimento de cancelamento de massas adicionais e a inércia residual devido à rotação do bloco $\mathrm{T}$. Fica evidente ainda da análise de alguns resultados, que o procedimento de cancelamento de massa é muito sensível a erros. Embora bons resultados sejam obtidos no caso de um exemplo numérico, os autores salientam a necessidade da utilização de dados reais, oriundos de experimentos. Para dados com certo nível de ruído (simulação de dados reais), observa-se a propagação e a amplificação de erros devido à subtração de quantidades que são similares. Em vista de suprimir esse fato, os autores propõem a regeneração das FRFs através da identificação dos parâmetros modais.

Por fim, Mottershead et al. (2005), descrevem uma técnica de processamento de sinais e uma metodologia experimental baseada também na utilização de um bloco T para a obtenção da matriz completa de receptância, incluindo a estimativa de FRFAs. O trabalho se diferencia dos demais na inclusão da rigidez e massa do bloco T em sua modelagem, representando uma melhora nos resultados decorrente do pósprocessamento dos dados. As equações resultantes geradas são mal condicionadas, porém, os autores propõem com sucesso a regularização através de poucas medidas independentes da estrutura sob investigação sem a presença do bloco T. Um exemplo experimental é apresentado no intuito de demonstrar a aplicabilidade do método proposto (ver Figura 1.4). 


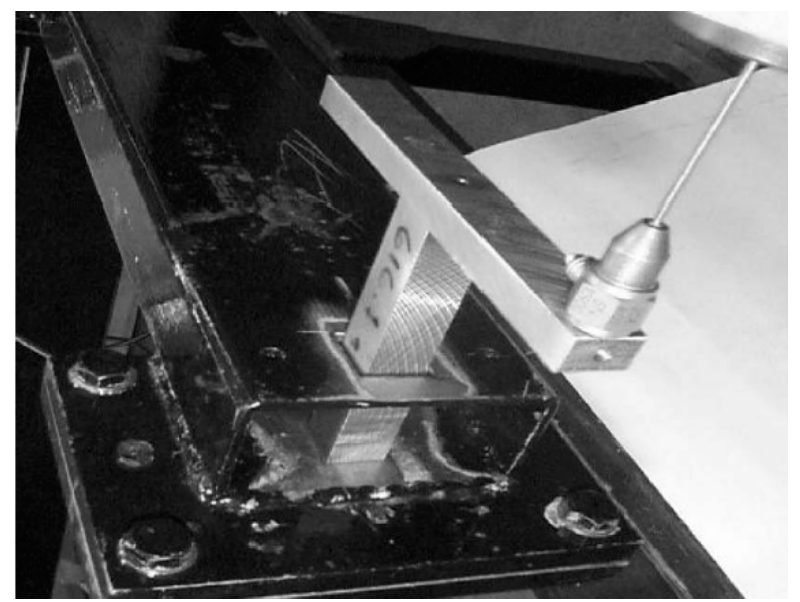

Figura 1.4: Configuração experimental (MOTTERSHEAD et al., 2005)

\subsubsection{MEDIDAS ANGULARES BASEADAS NA UTILIZAÇÃO DE DIFERENÇAS FINITAS}

Um método relativamente simples quanto à aplicação prática para solucionar o problema da falta de medidas de graus de liberdade de rotação é apresentado por Ashory (1999). Em seu trabalho, a técnica das diferenças finitas é apresentada, juntamente com um método de correção, para estimar FRFs. Para aplicar a técnica de diferenças finitas, dois ou três acelerômetros convencionais (de acordo com a formulação de diferenças finitas empregada) são colocados próximos uns aos outros, com uma distância entre eles constante. Medem-se os movimentos nos GDLT e a partir das formulações dessa técnica, as FRFs angulares são obtidas. Um método de correção é proposto, pois as FRFs angulares de transferência podem não apresentar bons resultados. A principal vantagem em se obter FRFs angulares baseadas na técnica de diferenças finitas se deve ao fato de as FRFs serem diretamente obtidas. Além disso, nenhum aparato experimental especial é necessário, pois, somente os transdutores convencionais são utilizados. Porém alguns problemas são associados no uso dessa técnica e alguns cuidados devem ser tomados para se minimizar 
influências que empobreçam os resultados. O primeiro problema é estabilizar o espaçamento entre os acelerômetros. A distância entre os acelerômetros tem uma relação direta na freqüência das anti-ressonâncias (ASHORY, 1999). Outro problema é a ordem da aproximação utilizada. Para um dado espaçamento, a aproximação de segunda ordem é geralmente melhor que a aproximação de primeira ordem para as FRFs. O mesmo não ocorre para as FRFs angulares que relacionam entrada e resposta do tipo angular (DUARTE, 1996).

Duarte e Ewins (2000) em seu trabalho também utilizaram a técnica das diferenças finitas. Por se tratar de uma técnica da qual se obtém movimentos nos GDLR com boa qualidade, os autores consideram seu uso como uma boa alternativa para se aplicar também na análise do acoplamento estrutural. A compensação residual na obtenção desses graus de liberdade é cuidadosamente tratada neste trabalho junto com a melhor técnica de aproximação. Os autores demonstraram também que a qualidade das medidas depende diretamente do espaçamento entre os acelerômetros, e propõem que para aumentar a ordem de aproximação das FRFs é necessária que a distância entre os acelerômetros seja a menor possível.

Lofrano (2003) também fez uso da formulação de diferenças finitas na estimativa de FRFAs, cujos resultados numéricos e experimentais obtidos, reforçam os a eficiência da técnica via diferenças finitas em comparação ao bloco T.

\subsubsection{MEDIDAS UTILIZANDO TECNOLOGIA À LASER}

A utilização de vibrômetros a laser em medidas de vibração vem ganhando popularidade tanto no meio acadêmico quanto nas empresas. Esta tecnologia teve seu início de forma mais acentuada no início da década de 1990 com os vibrômetros 
baseados em métodos interferométricos e pontuais; a varredura na estrutura em estudo ocorria de forma manual. $\bigcirc$ uso destes instrumentos tem-se difundido bastante, principalmente no setor acadêmico, especialmente devido à redução de seu custo. Em contrapartida, novas tecnologias surgiram nesta área, e hoje os vibrômetros de varredura (scanning laser vibrometers) já equipam a maioria dos laboratórios de análise modal das grandes empresas (montadoras automobilísticas, empresas aeronáuticas, etc.).

O funcionamento do vibrômetro à laser Doppler (VLD) se baseia no efeito Doppler, ou seja, quando a luz entra em contato com uma superfície em movimento, a freqüência do feixe de luz refletida é alterada de uma determinada quantidade e o feixe de luz é então dividido em duas partes: uma delas é guiada em direção a estrutura em um determinado ponto e a outra parte é usada como feixe de luz de referência para a formação de interferência construtiva ou destrutiva com relação ao feixe de luz medido, o qual é refletido pela estrutura (RATCLIFFE; LIEVEN, 1996).

Ziaei-Rad et al. (2000) utilizaram o vibrômetro Doppler para obter movimentos angulares da estrutura. Os autores descrevem o funcionamento dessa técnica levando em consideração os métodos discretos, lineares e circulares de medidas. Desta forma, o vibrômetro pode mapear continuamente a superfície de uma estrutura vibrante ao longo de uma linha reta ou ao redor de um círculo e responder com uma saída modulada que pode ser usada para analisar a vibração de uma estrutura com mais de um grau de liberdade. $O$ vibrômetro é um instrumento que mede a componente da velocidade de vibração do ponto na direção do laser e, a partir de uma formulação algébrica, podem-se derivar os movimentos nos GDL. 
A principal vantagem dessa técnica é a ausência de contado com a estrutura sob teste, o qual permite desconsiderar o efeito de carregamento de massa (diferente da maioria das técnicas que utiliza transdutores convencionais). As medidas são relativamente rápidas e fáceis, como também, a resolução e a precisão das medidas são elevadas. Qualquer superfície pode ser medida, independentemente da temperatura ou da presença de altos campos eletromagnéticos. Até o presente momento, a principal desvantagem se deve ao custo do equipamento, pois dentre todas as técnicas de obtenção de GDLR o uso do laser é o que apresenta a maior inviabilidade econômica por ainda possuir um elevado custo dos equipamentos (ZIAEI-RAD et al., 2000).

Outra técnica que se baseia na utilização de lasers é apresentada por Bokelberg et al. (1994a, 1994b) e consiste no posicionamento de um conjunto de vibrômetros de tal maneira que o feixe de luz possa incidir sobre um alvo tetraédrico localizado numa superfície vibrante. Cada feixe de luz refletida intercepta um fotodetector capaz de determinar as coordenada $x$ e y do alvo. Com alguns procedimentos algébricos é possível determinar a posição inicial do alvo em forma de tetraedro e seu movimento em seis direções (ver Figura 1.5). Esse sistema possui um alto custo devido ao fato de se utilizar mais de um laser no aparato experimental. Outra desvantagem é a sobrecarga computacional e problemas relacionados ao posicionamento do alvo na estrutura. 


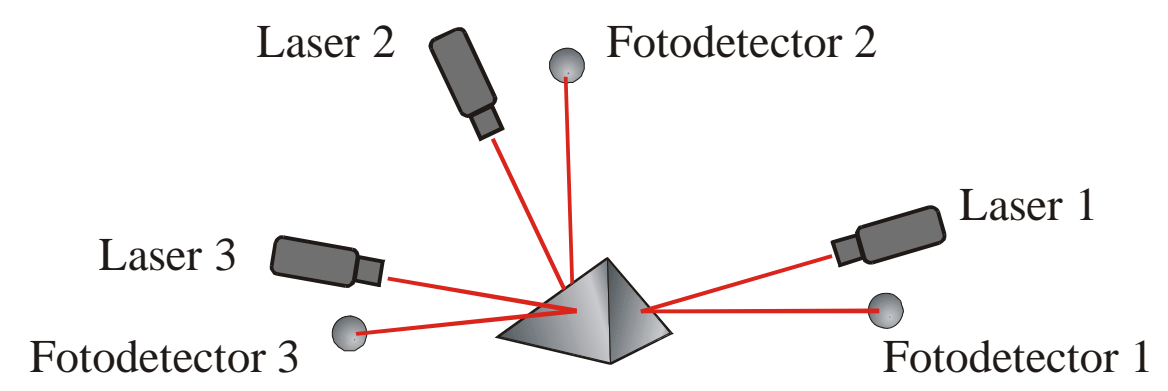

Figura 1.5: Determinação das componentes de aceleração através de lasers

\subsubsection{MEDIDAS UTILIZANDO SENSORES DEDICADOS}

Ivarsson et al. (2000) utilizaram um corpo rígido na forma de triângulo com uso de acelerômetros lineares e desenvolveram um transdutor para medir simultaneamente todos os seis graus de liberdade de um corpo rígido. Esse mecanismo conta com seis acelerômetros convencionais devidamente posicionados em uma peça triangular com um orifício em seu centro e este sendo o ponto de medição, como mostra a Figura 1.6.

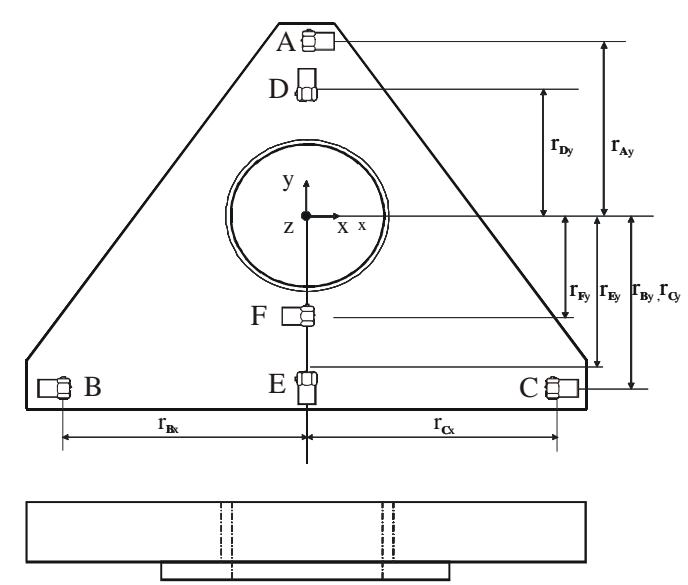

Figura 1.6: Transdutor de 6 GDL constituído por acelerômetros lineares

O orifício na peça possibilita a medida de excitação e resposta no mesmo ponto, além de diminuir a massa do transdutor, minimizando o problema de 
carregamento de massa. Também para evitar este problema, os acelerômetros adotados apresentam massa pequena (cada acelerômetro possui cerca de $2 \mathrm{~g}$ ). Apesar de esse transdutor conter seis acelerômetros, ele foi projetado para ter pouca massa, o que não leva a considerar o carregamento de massa na estrutura. Assumindo que o transdutor de 6 GDL se comporta como corpo rígido, as equações ordinárias para análise cinética dos corpos rígidos podem ser utilizadas.

Helderweirt et al. (2001) utilizaram técnicas indiretas e uma massa adicional para propor um método de obtenção de movimentos nos GDLR. Os autores propuseram uma técnica que utiliza vários acelerômetros lineares em uma massa adicional para derivar os correspondentes movimentos dos GDLR no ponto de excitação. Para essa finalidade, um sensor especial foi desenvolvido. Esse sensor consiste em um corpo rígido em forma de cruz onde são conectados acelerômetros lineares em diversas direções (ver Figura 1.7). Este trabalho também aborda a técnica de cancelamento de massa para a eliminação de erros.

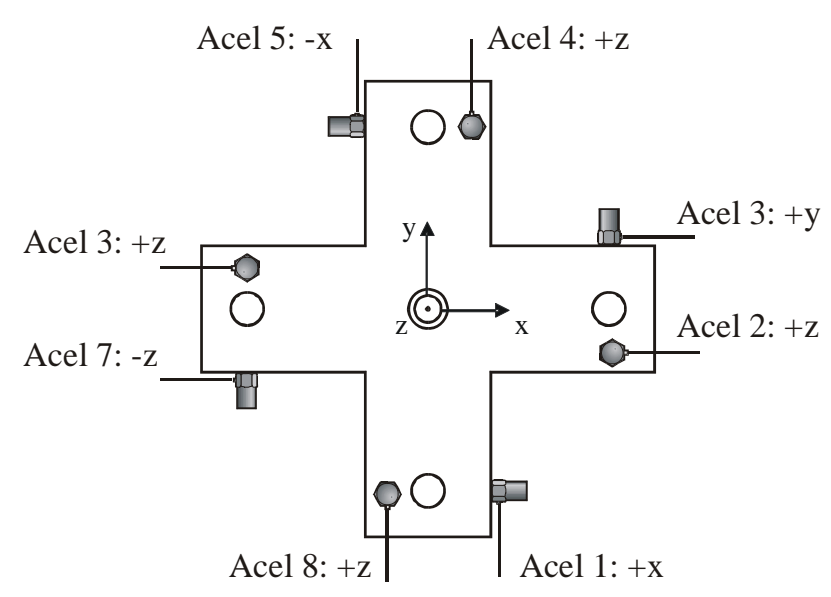

Figura 1.7: Sensor com posicionamento e orientação dos acelerômetros (HELDERWEIRT et al. 2001) 
Ainda utilizando a tecnologia de materiais piezelétricos, a empresa Kistler disponibilizou recentemente no mercado dois acelerômetros angulares: K-Shear ${ }^{\top M}$ Type 8838 e 8840 . O primeiro mede acelerações angulares axiais e o segundo acelerações angulares laterais. Estes sensores representam a evolução de um sensor dedicado a medidas de aceleração angular denominado TAP (Translational Angular Piezobeam) que foi comercializado em meados da década de 1990. McCONNELL (1995) descreve o modelo mecânico e elétrico deste sensor que é bastante similar aos atuais.

\subsubsection{PATCHES PIEZELÉTRICOS}

Bello et al. (2003) considera em seu trabalho a possibilidade de uso de pastilhas piezelétricas de baixo custo como transdutores para medidas de grandezas rotacionais. Como referência, utiliza-se bimorphs, pois estes são capazes de medir a curvatura local da estrutura, possuem baixo custo e pouca interferência na estrutura sob teste. A partir da curvatura, a rotação pode ser obtida tanto por integração quanto por métodos de interpolação. Diversas dificuldades devem ser superadas, como: i) uma montagem apropriada sobre a estrutura em análise; ii) o problema de sensibilidade cruzada, especialmente para medições em placas e iii) um procedimento de calibração, pois tais pastilhas piezelétricas não possuem cartas de calibração. O trabalho apresenta também algumas comparações entre FRFs rotacionais obtidas através de um sensor de aceleração angular e estimativas baseadas na aplicação do método de redução/expansão SEREP (System Equivalent Reduction Expansion Technique). Uma forma encontrada para a redução do efeito da sensibilidade cruzada foi o uso de uma pastilha esbelta, com uma razão de 
comprimento/largura da ordem de 10/1. Além disso, a pastilha é colada a uma camada de material deformável (no caso, poliestireno), possibilitando assim, a sua fixação à estrutura de calibração e à estrutura sob estudo de maneira intercambiável. Para obtenção das rotações, optou-se por uma interpolação polinomial cujo grau é da ordem de $n+3$, onde $n$ é o número de sensores distribuídos ao longo da estrutura. Os resultados apresentados encontram-se em uma faixa que vai de 0 a $800 \mathrm{~Hz}$ com 5 sensores (pastilhas piezelétricas+base para fixação) ao longo de uma viga simplesmente apoiada. Apesar de certo nível de ruído presente nas curvas oriundas do método proposto, a comparação com as demais técnicas mostra bons resultados.

\subsubsection{ESTRUTURAS DO TIPO VIGA}

Benjeddou et al. (1997) apresenta um modelo em elementos finitos para vigas sanduíches capaz de representar tanto o mecanismo de extensão e atuação convencional, quanto o mecanismo de atuação por cisalhamento utilizando-se materiais piezelétricos. No primeiro mecanismo, um núcleo elástico é coberto por duas camadas piezelétricas transversamente polarizadas (uma camada inferior e outra superior), constituindo a parte ativa do mecanismo. Na segunda forma de atuação, um núcleo piezelétrico polarizado axialmente é coberto por duas camadas de material elástico. O modelo mecânico se baseia na teoria de Euler-Bernoulli para as camadas superficiais e na teoria de Timoshenko para o núcleo do sanduíche. Os resultados apresentados mostram que o desvio a partir do modelo de Euler-Bernoulli ocorre de maneira significativa para atuadores pequenos e espessos, assim como, para vigas espessas onde a influência do cisalhamento do material é grande. Em 
termos de controle de vibração, o trabalho mostra que o mecanismo de atuação por cisalhamento é promissor em comparação ao mecanismo convencional de extensãoatuação e mais adequado em altas freqüências e pequenas amplitudes. Para baixas freqüências, os atuadores posicionados sobre a estrutura fornecem melhores resultados, fato este, já comprovado anteriormente através de uma formulação teórica apresentado por Zhang e Sun (1996).

Em 1999, Benjeddou et al. apresenta um novo modelo para o mecanismo de atuação por cisalhamento. Em seu trabalho anterior, a descrição cinemática do modelo permitia a presença do fenômeno conhecido por "shear locking", pois não considerava uma adição no cisalhamento devido ao escorregamento das camadas em vista do núcleo piezelétrico. Comparações teóricas e numéricas para situações estáticas e dinâmicas são apresentadas, comprovando a aplicabilidade do novo modelo desenvolvido. Mostra-se ainda que o mecanismo de atuação por cisalhamento é mais eficiente em comparação ao mecanismo de extensão, pois este último está limitado a espessuras reduzidas para produzir bons resultados. Além disso, mostra-se também que para estruturas com rigidez elevada, novamente o mecanismo por cisalhamento apresenta melhores resultados. Em ambos os modelos os modos de vibrar obtidos são equivalentes, embora os atuadores cisalhantes apresentem menos deformação e freqüências naturais mais altas.

Gopinathan et al. (2000) apresenta uma revisão a cerca das diferentes teorias utilizadas na modelagem e análise de vigas e placas laminadas. O trabalho atenta para o fato de não haverem estudos e simulações documentados em termos das variações dinâmicas do campo eletromecânico ao longo da espessura de estruturas laminadas. O mesmo considera este efeito essencial no entendimento e 
aplicabilidade da hipótese de modelos que tratam de placas finas no controle ativo de estruturas. Um campo de soluções tridimensional para camadas ativas baseado em soluções por séries de Fourier é desenvolvido para o cálculo de todos os campos eletromecânicos nas proximidades das freqüências de ressonância no caso de vigas e placas considerando duas camadas piezelétricas (sensor e atuador) e uma única camada estrutural. Desta forma, o cálculo ao longo da espessura de componentes não nulos em termos do campo eletromecânico é viável. Conclui-se ainda que para estruturas com razão de aspecto moderadas, muitas das aproximações consideradas nos modelos de deformação em primeira ordem para o cisalhamento são questionáveis nas proximidades das freqüências de ressonância.

No trabalho desenvolvido por Trindade et al. (2001a), uma formulação em elementos finitos para a análise de vigas do tipo sanduíche é apresentada. Neste trabalho, vigas do tipo multicamadas podem ser modeladas considerando um controle ativo-passivo. Suas multicamadas podem ser constituídas de materiais elásticos e piezelétricos (Euler-Bernoulli), de maneira que apenas a camada central pode ser modelada como um material viscoelástico (Timoshenko). O material viscoelástico é ainda modelado considerando sua dependência em relação à freqüência (Anelastic Displacement Field - Lesieutre's ADF). O modelo em elementos finitos foi programado considerando funções de forma lineares (Lagrange) no caso dos deslocamentos axiais principais e relativos e através de funções cúbicas (hermitianas) no caso da deflexão transversal. As diferenças de potenciais elétricos nas camadas piezelétricas foram assumidas constantes, constituindo um elemento com 8 graus de liberdade mecânicos e 1 grau de liberdade elétrico. A validação do modelo é apresentada na segunda parte do trabalho (TRINDADE et al., 2001b) em 
três exemplos: 1) uma viga composta por material elástico, um adesivo e uma camada piezelétrica; 2) uma viga feita de materiais compostos e 3) uma viga sanduíche com atuadores piezelétricos. Os resultados oriundos das análises mostram a acuracidade do modelo quando comparado a resultados numéricos.

Uma análise aprimorada do comportamento de estruturas do tipo bimorph é apresentada por Beckert e Pfundtner (2002) ao combinar uma análise teórica de materiais compostos em flexão a uma aproximação analítica detalhada para a transferência de tensão gradual das extremidades da face piezelétrica induzida por uma deformação desigual entre as camadas. Os resultados são validados através de análises em um modelo em elementos finitos e revelam uma influência significativa das suposições para o estado de deformação transversal. O estudo é complementado por análises experimentais que investigam a influência da rigidez e da espessura da camada adesiva na eficiência do atuador piezelétrico. Mostra-se que para camadas finas e rígidas, a transferência de tensões entre as camadas se aproxima de um estado plano de tensões, enquanto que para camadas adesivas pouco rígidas um comportamento não linear pode ser evidenciado, gerando discrepâncias entre os resultados numéricos e experimentais.

artigo escrito por Monturet e Nogarede (2002) propõe uma metodologia de projeto voltada para o dimensionamento ótimo de atuadores piezelétricos. $\bigcirc$ estudo trata do funcionamento de uma barra bimorph heterogênea em flexão quaseestática. Primeiro, um modelo analítico é estabelecido baseando-se em suposições clássicas para vigas e materiais piezelétricos. O campo de validade do modelo proposto é então avaliado através de comparações com um modelo em elementos finitos. O modelo desenvolvido é explorado, desta forma, dentro de um procedimento 
de dimensionamento automatizado via otimização. São ilustradas as possibilidades do método desenvolvido no dimensionamento de um atuador piezelétrico voltado para um equipamento vibratório (ver Figura 1.8).

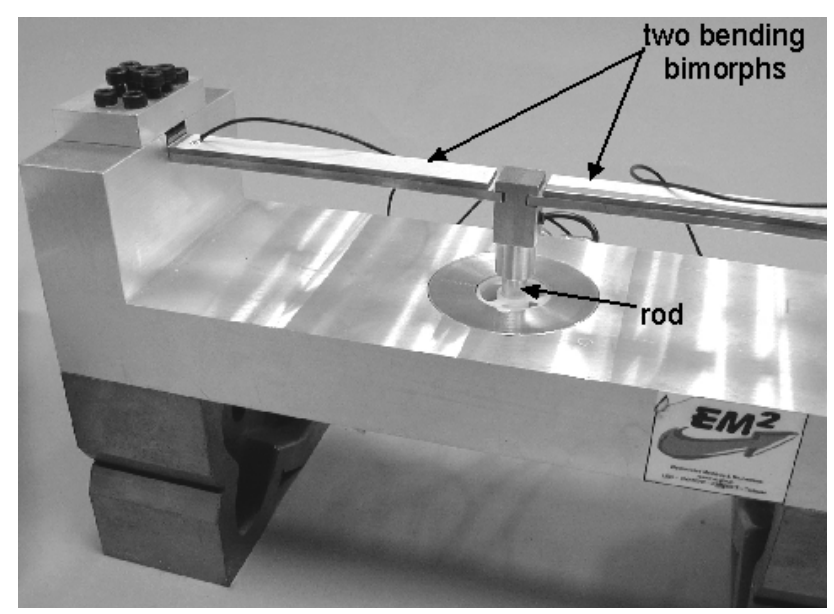

Figura 1.8. Dispositivo VSM - Vibrating Sample Magnetometer - (MONTURET; NOGAREDE, 2002)

O trabalho de Brissaud (2004) trata da modelagem de bimorphs nãosimétricos utilizados em sistemas micro-eletro mecânicos (sigla em inglês: MEMS). Um modelo analítico incluindo os parâmetros elásticos e geométricos da estrutura elástica, da camada adesiva, dos eletrodos e da camada piezelétrica é apresentado. Este modelo foi aplicado a bimorphs em tipos diferentes de condições de contornos: bi-engastada (CC), cantilever (CF) e simplesmente apoiada (SS). Adota-se para o modelo analítico a teoria clássica de lâminas, onde a flexão e as deformações são as mesmas para todas as camadas. Quando o bimorph é usado como atuador, a freqüência de ressonância e o deslocamento de diferentes tipos de bimorphs são calculados. A voltagem em circuito aberto, o deslocamento e freqüência de ressonância são determinados quando o bimorph é utilizado como sensor. A influência dos parâmetros da camada de cola também é avaliada. Um método para 
calcular o fator de qualidade global considerando os bimorphs versus um fator de qualidade aplicado a cada camada é proposto. Este método pode ser aplicado facilmente a todos os tipos de bimorphs (CC, CF, SS). A forma analítica da evolução da freqüência de ressonância e a sensibilidade são deduzidas do modelo geral e modelos teóricos são comparados com o método dos elementos finitos.

O artigo escrito por Costa Branco e Dente (2004) apresenta um estudo analítico, numérico e experimental de um atuador/sensor piezelétrico assimétrico aplicado a vigas engastadas (cantilever). A estrutura consiste de três camadas laminadas: uma camada piezelétrica representado um atuador, uma camada de material elástico e uma segunda camada de piezelétrica que pode operar como um sensor ou atuador. $\bigcirc$ acoplamento entre os movimentos de extensão e flexão é resolvido analiticamente, de forma que as equações eletromecânicas que governam a expansão e a flexão são obtidas. Soluções analíticas em termos dos deslocamentos longitudinais e transversais, assim como, a resposta em freqüência da estrutura é calculada. O modelo teórico é formulado baseando-se em pequenas deformações, o que garante que os materiais sejam considerados dentro de seus regimes lineares e desconsidera-se qualquer efeito de histerese. Um modelo em elementos finitos é desenvolvido e o mesmo é utilizado para avaliar a precisão do modelo analítico. Utilizam-se ainda resultados experimentais na verificação da resposta em freqüência da estrutura como forma de validar os dois modelos precedentes: teórico e em elementos finitos.

Huang et al. (2004) desenvolve em seu artigo um novo modelo aplicado a vigas multicamadas. Expressões analíticas para a curvatura, deslocamento e o deslocamento da ponta da viga são apresentadas em diversas situações. Através do 
modelo proposto é possível ainda avaliar o efeito dos eletrodos na deflexão da viga. Para um mesmo módulo de Young e uma mesma espessura da camada piezelétrica, os autores mostram em seus resultados que a deflexão na ponta da viga para um bimorph montado em paralelo é o dobro em comparação a um bimorph montado em sua configuração em série e que não há nenhuma interferência significativa quando se altera a largura dos atuadores.

Um método analítico é introduzido por Li et al. (2004) no intuito de determinar - campo de deslocamentos em uma viga bimorph heterogênea. Um modelo tridimensional é comparado a um modelo em elementos finitos e os resultados obtidos mostram diferenças inferiores a $3 \%$ para as condições examinadas. Baseando-se nestas comparações, os autores deduzem que o modelo analítico, o qual não considera efeitos secundários como cisalhamento e tensão residual, pode ser utilizado como uma ferramenta para aperfeiçoar o projeto de vigas bimorph dentro de uma gama específica de materiais e espessuras. Para ilustrar a utilidade do modelo, vários tipos de vigas foram parametricamente estudados monitorando-se o comportamento da deflexão das mesmas. Baseado no estudo paramétrico determinou-se que a espessura da viga é um parâmetro crítico na obtenção da deflexão desejada e, em contra partida, o mesmo não ocorre em termos da sua largura. A rigidez, por sua vez, indica ter uma influência modesta na deflexão em metais típicos e uma influência significativa em materiais menos rígidos como polímeros.

Um modelo em elementos finitos dedicado somente ao elemento piezelétrico do tipo bimorph é apresentado no trabalho de Wang (2004). O modelo combina elementos 2D (uma única camada) com elementos piezelétricos 3D (subcamadas) 
para análises do tipo estática e dinâmica. Os resultados mostram que a distribuição de potencial elétrico ao longo da espessura do bimorph pode ser obtida com acuracidade através da suposição de uma distribuição linear para cada subcamada. De acordo ainda com o modelo proposto, os efeitos não lineares relacionados aos potenciais elétricos, para os sensores piezelétricos em circuito fechado, são insignificantes para bimorphs finos ou de moderada espessura.

Maxwell e Asokanthan (2004) trazem em seu trabalho as características modais de vigas flexíveis com múltiplos atuadores (PZTs) distribuídos ao longo da mesma. A estrutura, assim como, as pastilhas piezocerâmicas foram modeladas através da teoria de vigas por Timoshenko. Os atuadores foram considerados perfeitamente aderidos à estrutura, não havendo interferência do adesivo na atuação. As formas dos modos, bem como, as respectivas freqüências naturais foram computadas para diversas configurações de posicionamento das pastilhas. Como conclusão do trabalho, tem-se como efeito direto do posicionamento dos PZTs o aumento de rigidez local, bem como, a variação do parâmetro de cisalhamento.

Wu e Ro (2004) apresentam um cálculo analítico do desempenho dinâmico para estruturas do tipo bimorph. Simulações em elementos finitos foram efetuadas para validar a estratégia proposta. Os resultados mostram que o método de determinação do pico pela amplitude apresenta aptidão suficiente para predizer o desempenho dinâmico de bimorphs. A colagem de camadas e seus efeitos também foram analisados através de métodos estáticos e dinâmicos. O comprimento do bimorph, assim como a espessura e a rigidez da cola devem ser consideradas ao se tentar minimizar o efeito da colagem, pois estes se apresentam como os parâmetros 
de maior relevância. Concluiu-se o trabalho apontando para a utilização de estruturas longas e camadas finas de cola com alta rigidez.

Na área de supressão de vibração em estruturas, alguns parâmetros como a localização de atuadores e sensores possuem influência decisiva no melhoramento do desempenho do sistema de controle. Bruant e Proslier (2005) apresentam um critério de otimização modificado que visa garantir bons níveis de observabilidade e controlabilidade da estrutura. Considera ainda o efeito de modos residuais como forma de limitar o efeito de spill-over. Dois exemplos são colocados para ilustrar a eficiência do critério proposto utilizando para tal uma viga simplesmente apoiada e uma placa retangular. Os resultados apontam para a importância do critério de otimização e sua influência no controle da estrutura. Outro fator importante do critério proposto reside na simplicidade computacional.

Nesta mesma área, o trabalho proposto por Dhuri e Seshu (2006) tem por objetivo determinar o melhor local e o melhor tamanho para um atuador piezelétrico responsável pelo controle da estrutura. Propõem também que o atuador altere o mínimo possível as características originais do sistema, pois este foi projetado para atuar dentro de um determinado espectro em freqüência em relação às excitações externas. Os exemplos se baseiam em estruturas do tipo viga e em duas condições distintas: estacionária e em rotação. Com isso, pode-se concluir que os parâmetros referentes ao atuador (tamanho e posição) podem ser distintos nestas duas condições.

Maurini et al. (2006) analisa em seu trabalho métodos numéricos para análise modal de vigas e pastilhas piezelétricas. As análises recaem em modelos lineares (Euler-Bernoulli) com a inclusão de efeitos tridimensionais. Quatro diferentes técnicas 
foram testadas: LEN (Last Energy Norm method), AM (Assumed Modes method), EAM (Enhanced Assumed Modes method) o qual inclui funções especiais para capturar descontinuidades na curvatura dos modos de vibrar e por fim, o método dos elementos finitos (FE method). O método dos modos assumidos não produziu resultados satisfatórios em termos de propriedades modais. $O$ método dos modos assumidos melhorado, no entanto, conseguiu gerar resultados mais precisos, além de apresentar os efeitos de segmentação da viga. Segundo os autores, o método dos elementos finitos apresenta bons resultados em termos de freqüências, porém, mesmo com um alto número de graus de liberdade, as estimativas para altas freqüências ficam abaixo das obtidas pelo método EAM, pois este último contém as funções de descontinuidades. Por fim, o método LEN tem como aliado a sua fácil programação computacional, porém, é restrito a problemas unidimensionais.

No trabalho apresentado por Zabihollah et al. (2006) uma análise da sensibilidade de vigas laminadas considerando sensores e atuadores embebidos ou colados sobre a superfície é apresentada utilizando-se um modelo em elementos finitos baseado na teoria de deslocamentos de estruturas laminadas. A formulação em elementos finitos também incorpora a interação entre campos elétricos e mecânicos. $\bigcirc$ artigo mostra ainda que o modelo em elementos finitos aliado a uma técnica de programação quadrática seqüencial produz um algoritmo eficiente em termos de otimização do conjunto estrutura e atuadores/sensores. Exemplos numéricos são apresentados para demonstrar a capacidade e a eficiência da análise de sensibilidade desenvolvida pelo algoritmo de otimização tanto em problemas estáticos quanto em dinâmicos. A posição dos sensores/atuadores e as condições de 
contorno da estrutura contribuem decisivamente para a escolha entre a melhor espessura das camadas elásticas e piezelétricas e suas massas, respectivamente.

Outro trabalho também relacionado ao estudo da otimização no posicionamento de sensores e atuadores piezelétricos pode ser encontrado no artigo escrito por Zhang e Erdman (2006). Primeiro, introduz-se um modelo de controle de vibração de mecanismos flexíveis. Em seguida, o modelo ótimo é projetado visando o máximo em controlabilidade e o observabilidade a partir dos modos sob controle e a minimização dos modos residuais. Um exemplo numérico é apresentado para demonstrar a aplicabilidade do método proposto.

Carbonari et al. (2007) propõe nessa mesma linha de otimização uma formulação que permite a distribuição simultânea de materiais não piezelétricos e piezelétricos no intuito de se obter movimentos de atuação específicos. $\bigcirc$ problema de otimização é colocado como a procura simultânea por uma ótima topologia da estrutura flexível e a ótima posição para o atuador piezelétrico, assim como, ótimos ângulos de rotação que maximizem os deslocamentos ou as forças em certa direção especificada. Uma função multi-objetiva é definida para permitir o controle da flexibilidade, dureza e deslocamento na estrutura. Alguns exemplos são apresentados para ilustrar o potencial do método. Considerando o ângulo de rotação como uma variável de projeto o deslocamento em determinados pontos podem ser minimizados fortemente com o método proposto.

\subsubsection{ESTRUTURAS DO TIPO PLACA}

Steel et al. (1978) apresenta em seu trabalho um estudo teórico e experimental da resposta quase-estática de uma placa de cerâmica piezelétrica de $150 \mu \mathrm{m}$ de 
espessura colada sobre uma placa de cobre. O comportamento eletromecânico é avaliado considerando a direção polarização da cerâmica, assim como, um estudo a cerca das deformações longitudinais e transversais. $\bigcirc$ tratamento teórico é apresentado como um método para interpretar os resultados. Para o bimorph de cerâmica/metal as medidas estão em acordo com as predições da análise teórica, respeitando a dependência com a espessura da placa. Uma pequena relação com a largura da placa é observada e atribui-se o fato às restrições presentes nas condições de contorno. Para o bimorph de cerâmica/plástico também se buscou identificar a relação com a espessura da placa, no entanto, os resultados demonstram apenas uma equivalência qualitativa com a teoria. Os benefícios práticos do bimorph heterogêneo estático remetem a sua habilidade para produzir deflexões milimétricas e aceitar voltagens até $100 \mathrm{~V}$.

Usando combinações de ângulos e padrões de eletrodos diferentes, uma fina placa bimorph de polímero piezocerâmico e metal foi construída apresentando ambos os fenômenos de flexão e torção quando sujeita a um campo elétrico (Lee e Moon, 1989). Os resultados experimentais mostram grande concordância com as previsões teóricas. Os autores ainda sugerem que tais dispositivos podem encontrar aplicação no controle de micro-atuadores ou talvez no controle modal de estruturas contínuas de maiores dimensões.

Lee (1990) novamente faz uso da teoria de placas laminadas com a presença de camadas piezelétricas no controle e observação da flexão, torção, compressão e extensão. $\bigcirc$ aprimoramento em relação ao seu trabalho anterior permite a modelagem eletromecânica (atuação) e mecânico-elétrico (sensoriamento) em termos do comportamento da placa. Atenta-se para o fato de uma rigorosa formulação para 
a presença de sensores e atuadores distribuídos. As equações de movimento no caso dos atuadores incluem a força de cisalhamento equivalente para as condições de contorno, pois se baseiam na formulação de Kirchhoff. Observa-se também uma relação recíproca entre os sensores e atuadores piezelétricos ao se utilizar funções generalizadas, o que permite, segundo o autor, atestar a vantagem de algoritmos de controle que combinam sensores e atuadores piezelétricos.

Incorporando o efeito piezelétrico na teoria clássica de placas laminadas, sensores e atuadores distribuídos capazes de sensoriar e controlar a vibração modal de uma placa cantilever são apresentados teoricamente e verificados experimentalmente por Lee et al. (1991). Mostra-se que o amortecimento crítico de um modo em particular pode ser alcançado usando a combinação sensor/atuador modal contanto que a amplitude de vibração da estrutura controlada não sature o atuador modal. Considerando ainda que o sinal do sensor seja proporcional à coordenada modal, um controlador de avaliação de velocidade pode ser empregado sem o uso de qualquer elemento ajustado à freqüência de ressonância no controlador. Utilizando-se um sensor/atuador de $\mathrm{PVF}_{2}$ e eliminando-se a interferência eletromagnética e o ruído de base no controlador em circuito fechado, demonstra-se experimentalmente um amortecimento crítico para o primeiro modo de uma placa cantilever.

Um conjunto completo de equações que descrevem o comportamento mecânico e elétrico de um componente piezelétrico é desenvolvido no artigo de Koshigoe e Murdock (1993). Destas equações, obtêm-se as equações eletromecânicas que descrevem o comportamento dinâmico de elementos piezelétricos aplicados a estruturas do tipo placa. As equações eletromecânicas são utilizadas para explicar o 
amortecimento ativo introduzido por PZTs funcionando como atuadores e sensores. $\mathrm{O}$ modelo de amortecimento ativo é aplicado a um caso mais realístico. $O$ deslocamento transversal e os coeficientes de amortecimento da placa são calculados fazendo-se uso das equações eletromecânicas e os mesmos são comparados com resultados experimentais. $O$ amortecimento alcançado é de aproximadamente $20 \mathrm{~dB}$ em ambos os casos, numérico e experimental, excitando a placa em uma freqüência correspondente ao seu primeiro modo de vibrar. Usando a equação de sensor, uma concisa aproximação é desenvolvida tendo em vista a construção de métodos de amortecimento ativo e passivo.

Charette et al. (1998) descreve em seu artigo um sensor de deslocamento volumétrico feito de filme PVDF cortado em tiras moldadas. A estratégia é projetar um sensor que traduza o deslocamento volumétrico induzido pela vibração de uma estrutura 2D. A técnica se baseia na representação modal da resposta da placa utilizando para tal um sensor composto de várias tiras de PVDF coladas à superfície da estrutura, capaz de emitir um sinal de saída diretamente proporcional ao deslocamento volumétrico (ver Figura 1.9).

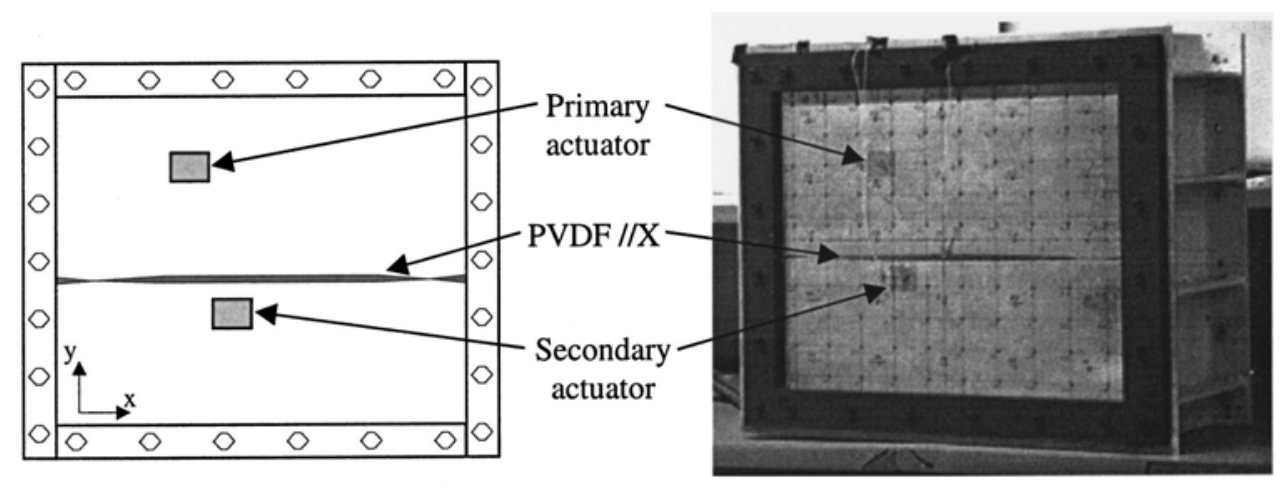

Figura 1.9 : Estrutura 2D (CHARETTE et al., 1998) 
A aplicação experimental deste sensor é voltada para sistemas com controle ativo. O campo de deslocamento transversal e os níveis de pressão obtidos experimentalmente antes e depois de aplicado o controle validam o uso do filme de PVDF como um sensor de deslocamento volumétrico voltado para o controle acústico estrutural ativo (ASAC). Sugere-se o uso deste tipo de sensor para bandas de excitação ainda maiores se um controlador digital apropriado for implementado.

Em paralelo ao ocorrido às estruturas do tipo viga, os trabalhos relacionados às estruturas bidimensionais também se voltaram para o campo da otimização. Utilizando um algoritmo genético, Han e Lee (1999), propõem um método para a determinação dos locais ótimos para o posicionamento de sensores e atuadores em placas. Os conceitos de observabilidade, controlabilidade e prevenção de spill-over formam a base para a função custo dentro da otimização. Os resultados experimentais mostram redução de vibração significante para os modos controlados com pequeno efeito nos modos residuais. Além disso, observa-se que o sistema em circuito fechado é robusto o suficiente às variações dos parâmetros do sistema.

Sadri et al. (1999) apresenta em seu trabalho a modelagem teórica de estruturas do tipo placa que incorporam atuadores piezelétricos. As equações que governam a dinâmica da estrutura, relacionando as deformações nos elementos piezelétricos às deformações induzidas no sistema, são obtidas através do método de Rayleigh-Ritz para placas isotrópicas. Todo o desenvolvimento foi feito para placas simplesmente apoiadas. Dois critérios de otimização para o posicionamento dos atuadores piezelétricos são apresentados: um utilizando controlabilidade modal e outro utilizando controlabilidade via Grammian. Ambos os critérios foram testados utilizando-se novamente um algoritmo genético. Como resultado, observou-se que o 
modelo foi capaz de determinar com acuracidade as freqüências naturais, assim como, os critérios utilizados na determinação do melhor posicionamento/dimensão do atuador proporcionaram consideráveis níveis de amortecimento para uma considerável faixa de freqüência.

A solução analítica exata para placas piezelétricas adaptativas simplesmente apoiadas é trazida no artigo escrito por Benjeddou et al. (2002). O estudo se baseia na formulação original voltada a estruturas do tipo sanduíche. Nenhuma simplificação na modelagem é feita em termos do campo elétrico e de deslocamentos. Desta forma, a equação de conservação da carga elétrica é satisfeita e o potencial elétrico induzido é corretamente representado no acoplamento eletromecânico. Pela primeira vez, equações de movimento eletromecânicas bidimensionais e equações constitutivas piezeoelétricas generalizadas correspondentes às tensões e deslocamentos elétricos resultantes são introduzidos. $O$ método proposto é validado numericamente através da análise modal de placas híbridas de carbono-epoxy e camadas piezelétricas embebidas ou coladas sobre a superfície. Os resultados mostram a aplicabilidade da formulação proposta ao serem confrontados com modelos elásticos tridimensionais acoplados ou desacoplados e a modelos em elementos finitos de camada equivalente ou sanduíche.

Utilizando as definições de Reissner para cinemática de placas espessas, Barut et al. (2002) aproxima os componentes de deslocamento em qualquer ponto de uma placa em termos da ponderação das quantidades médias, deslocamentos e rotações, funções estes das coordenadas no plano. As equações de equilíbrio e as condições de contorno de uma placa sanduíche são apresentadas empregando-se o princípio de deslocamentos virtuais. A solução para uma carga arbitrariamente distribuída é 
obtida empregando-se séries de Fourier na representação das variáveis desconhecidas. A teoria apresentada é validada comparando-a a uma solução analítica para uma placa sanduíche quadrada simplesmente apoiada sob pressão em uma pequena região e a outras teorias de camada equivalente.

Um modelo em elementos finitos para estruturas do tipo placa em material composto é proposto no artigo de Ferrario et al. (2003) como um aprimoramento nas modelagens de membranas piezelétricas. Demonstra-se a validade da teoria através da simulação de um sensor no monitoramento de viscosidade de alimentos. A motivação do trabalho reside no fato de que modelos precisos voltados a membranas piezelétricas multicamadas não estavam disponíveis em pacotes comerciais de softwares de elementos de finitos. $O$ modelo proposto se comporta como uma placa bidimensional considerando-se os graus de liberdade mecânicos e como um prisma tridimensional para os graus de liberdade elétricos. $\bigcirc$ modelo proposto, denominado Argyris, juntamente com as equações piezelétricas habilitam uma representação satisfatória da teoria de placas sanduíche de Kirchhoff-Love em análises termomecânicas.

Sze et al. (2004) aborda a freqüente adoção em análises computacionais de estruturas compostas por camadas piezelétricas e não-piezelétricas do campo elétrico ser constante ao longo da direção transversal. Esta suposição convencional pode conduzir a erros significantes a menos que a camada piezelétrica seja consideravelmente fina em comparação as demais camadas. Dois métodos alternativos, denominados EL e DC, são propostos para representar a distribuição espacial das variáveis elétricas. Em EL, o campo elétrico é adotado linear ao longo da direção transversal e em DC, o deslocamento elétrico é tomado como constante ao 
longo da direção transversal. Os resultados indicam que os métodos alternativos propostos são notadamente mais precisos que o convencional. Porém, em EL, os resultados perdem acuracidade quando se adota o campo elétrico constante ao longo de mais de uma camada ao mesmo tempo. Por outro lado, em DC, ocorre um consumo menor de graus de liberdade elétricos e o mesmo se mostra mais eficiente ao compará-lo a EL.

A representação exata de movimentos de corpo-rígido no padrão de deslocamentos em elementos de camada equivalente (ESL) e sanduíche (LW) é abordada por Kulikov e Plotnikova (2005). Esta consideração exigiu o desenvolvimento das relações de deslocamento-deformação para ESL e LW com respeito à consistência dos movimentos de corpo-rígido. As variáveis fundamentais desconhecidas consistem em seis deslocamentos das superfícies na teoria de camada equivalente $(E S L)$ e $3(N+1)$ deslocamentos das superfícies em $L W$, onde $N$ representa o número de camadas. Tal escolha de deslocamentos permite deduzir as relações deslocamento-deformação, invariantes sob movimentos de corpo-rígido.

Lee et al. (2005) trata em seu artigo da determinação de respostas estáticas e dinâmicas de estruturas laminadas (multimorphs). Determina-se baseado na teoria de Euler-Bernoulli as freqüências naturais, o deslocamento máximo e a força que pode ser produzida por uma estrutura multimorph cantilever simétrica. $\bigcirc$ modelo inclui a dinâmica dos piezelétricos, eletrodos e da camada elástica. O modelo teórico proposto é verificado experimentalmente utilizando-se um multimorph com 20 camadas piezelétricas e o mesmo é comparado a um modelo de estrutura bimorph convencional. Os resultados experimentais concordam com as predições analíticas em termos das freqüências naturais e do deslocamento vertical. Através da solução 
analítica, os efeitos do número e da espessura de camadas piezelétricas são demonstrados. Mostra-se que existe um número ótimo de camadas piezelétricas (6 ou 8) na maximização da deflexão transversal, assim como, há um valor específico na relação entre a espessura das camadas piezelétricas e da camada estrutural $(0,88$ para 6 e 0,275 para 8 camadas piezelétricas) que maximiza tanto a deflexão quanto a força produzida.

Recentemente, um modelo reduzido voltado a estruturas piezelétricas do tipo placa é trazido por Costa et al. (2007). O foco inicial do trabalho é a modelagem de uma placa fina composta de camadas de materiais piezelétricos distintos. Segundo o modelo proposto, as variáveis mecânicas e elétricas mostram-se parcialmente desacopladas. O modelo é avaliado do ponto de vista da sua capacidade de representar um atuador e um sensor e ambos os problemas são resolvidos através de um algoritmo genético. No caso do atuador, altera-se a localização de aplicação do potencial elétrico em busca do maior deslocamento possível como resposta e do menor número de regiões com potenciais elétricos não-nulos (regiões de excitação). Para o sensor, altera-se a localização de aplicação dos carregamentos mecânicos buscando-se o maior potencial elétrico induzido na placa e um número mínimo de regiões de excitação. Observa-se que em ambos os casos, a solução ótima é alcançada quando certo número máximo de regiões é excitado e que existe interferência nos resultados quanto à diferença de discretização da estrutura.

Pietrzakowski (2007) trata em seu artigo da análise vibratória de placas retangulares ativas. As placas são constituídas de camadas piezelétricas que atuam como sensores/atuadores em um controle de supressão de vibração do movimento transversal. As camadas piezelétricas são polarizadas transversalmente e equipadas 
com eletrodos sobre as suas superfícies. Para satisfazer as equações eletrostáticas de Maxwell, o modelo considera que a distribuição do potencial elétrico no caso dos atuadores se trata de uma combinação de senos e co-senos na direção transversal. A variação espacial no plano do potencial é determinada pela solução das equações eletromecânicas acopladas em conjunto com as condições de contorno correspondentes à flexão e ao potencial elétrico. A análise é executada em placas simplesmente apoiadas. Consideram-se dois modelos de placa: no primeiro caso, o campo de deslocamento baseia-se nas hipóteses de Kirchhoff e, no segundo, no modelo de Mindlin. A influência da distribuição do potencial elétrico, assim como, a espessura das camadas piezelétricas na dinâmica da placa, incluindo a modificação nas freqüências naturais é numericamente investigada e discutida. Observa-se que as freqüências naturais aumentam em função do aumento da espessura da camada piezelétrica referente ao atuador. Este efeito fica mais evidente no modelo de Mindlin devido à inclusão dos efeitos de cisalhamento. Em placas relativamente finas, a inércia de rotação ligeiramente modifica as freqüências naturais.

Motivado pelo problema de estruturas espaciais tais como, painéis solares e antenas, Qiu et al. (2007) propõe a utilização de patches piezelétricos no controle da vibração em placas engastadas (ver Figura 1.10). Primeiramente, o artigo apresenta as equações modais e de controle. Em seguida, um método de determinação dos pontos ótimos de aplicação dos sensores e atuadores piezelétricos é desenvolvido baseado nos índices de observabilidade e controlabilidade da estrutura. $\bigcirc$ método propõe ainda o desacoplamento dos modos de torção e flexão através do filtro de Butterworth. Os resultados analíticos referentes às freqüências modais, respostas transientes e controle são apresentados, assim como, os resultados experimentais 
voltados para o controle da vibração referente aos modos de flexão e torção. Os resultados numéricos e experimentais apresentados mostram que o método de controle e o método de identificação dos locais ótimos propostos são adequados.

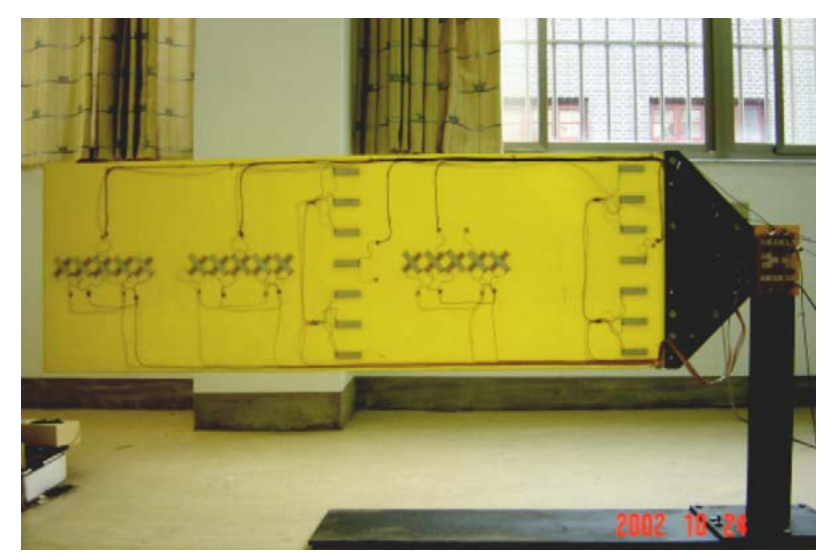

Figura 1.10: Patches piezelétricos na supressão de vibração em placas (QIU et al., 2007)

Na mesma linha de pesquisa, Tanaka e Sanada (2007) apresentam um controle modal voltado a placas retangulares através do uso de sensores e atuadores piezelétricos do tipo PVDF. O controle modal é discutido teoricamente, assim como, investigado experimentalmente utilizando sensores/atuadores bidimensionais (ver Figura 1.11).
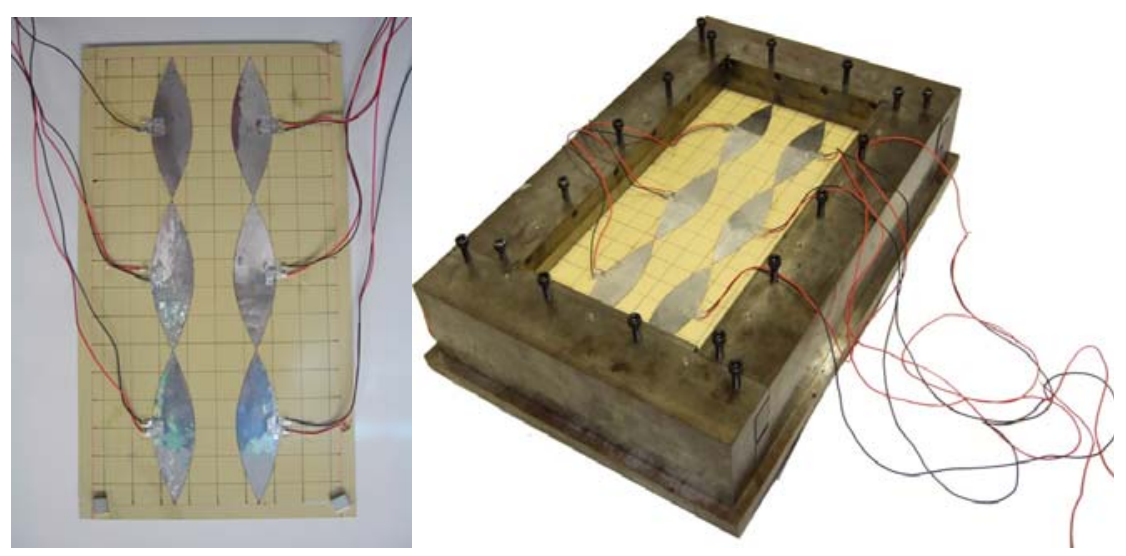

Figura 1.11: Múltiplos patches de PVDF no controle modal em placas (Tanaka e Sanada, 2007) 
Os resultados mostram que a supressão de vibração é alcançada combinandose múltiplos sensores/atuadores sem que haja a presença do fenômeno de spill-over.

\subsection{ORGANIZAÇÃO DA TESE}

Esta tese apresenta-se organizada da seguinte maneira:

- no Capítulo 2 introduz-se a formulação matemática para estruturas do tipo viga e placa de um novo sensor capaz de medir grandezas angulares. Trata-se de um sensor composto por duas pastilhas piezelétricas, denotado aqui por sensor bimorph. Sua aplicação tem grande motivação ao se considerar a sua facilidade de integração com a estrutura e a qualidade dos resultados obtidos dentro da metodologia proposta;

- no Capítulo 3 apresenta-se a formulação do problema de otimização do sensor bimorph para o caso de estruturas do tipo viga. O problema é tratado do ponto de vista dos algoritmos genéticos;

- no Capítulo 4 trata-se dos resultados numéricos obtidos, da comparação entre os métodos de aproximação (no caso de vigas) propostos e da avaliação de parâmetros correspondentes ao algoritmo genético. Trata ainda dos resultados numéricos obtidos no caso de estruturas do tipo placa, bem como, do método de aproximação proposto;

- no Capítulo 5 contemplam-se as conclusões finais decorrentes dos estudos desenvolvidos ao longo deste trabalho;

- no Capítulo 6 trazem-se as referências bibliográficas deste trabalho; 
- no Apêndice A descreve-se as rotinas desenvolvidas em ambiente Matlab ${ }^{\circledR}$ na modelagem numérica do transdutor bimorph e do algoritmo genético desenvolvido e, - no Apêndice B apresenta-se o código desenvolvido para o estudo de estruturas do tipo placa+bimorph do ponto de vista do software Ansys ${ }^{\circledR}$. 


\section{DESENVOLVIMENTO DE UM TRANSDUTOR DE ROTAÇÃO}

A possibilidade de medição de Graus de Liberdade Rotacionais (GDLR) e conseqüentemente de Funções de Resposta em Freqüência Angulares (FRFAs) limitamse atualmente à utilização de técnicas numéricas e experimentais restritas a poucos tipos de estruturas e condições de contorno. Este capítulo apresenta uma técnica de baixo custo, voltada para a utilização de materiais piezelétricos (PZTs) como uma forma alternativa às técnicas e sensores dedicados já existentes. Trata-se da utilização de sensores do tipo bimorph, capazes de medirem a curvatura local da estrutura em condições dinâmicas. A partir desta curvatura, a rotação em qualquer ponto da estrutura pode ser obtida tanto via integração quanto via interpolação (BELLO et al., 2003).

\subsection{RELAÇÕES DE ENTRADA E SAÍDA MULTIDIRECIONAIS}

Considere a estrutura flexível mostrada na Figura 2.1. Comum a análise modal de estruturas, a notação aqui utilizada, corresponde ao domínio da freqüência. As relações entradas/saídas são dadas como funções da freqüência $\omega$ e estas, são chamadas de funções de resposta em freqüência, ou simplesmente, FRFs (MCCONNELL, 1995).

A entrada aplicada no ponto de coordenada $Q$ é representada pelo vetor $\{\mathfrak{J}\}=\{\mathfrak{J}(\omega)\}_{Q}$, o qual pode ser constituído por seis componentes: três componentes 
que representam forças lineares ao longo das direções ortogonais 1, 2 e 3 e três binários em torno dos respectivos eixos, indicados por 4, 5 e 6 na figura.

Em um único ponto da estrutura, portanto, o vetor excitação pode ser decomposto em potencialmente seis entradas aplicadas à estrutura, sendo que destas, três são forças e as três restantes, binários.

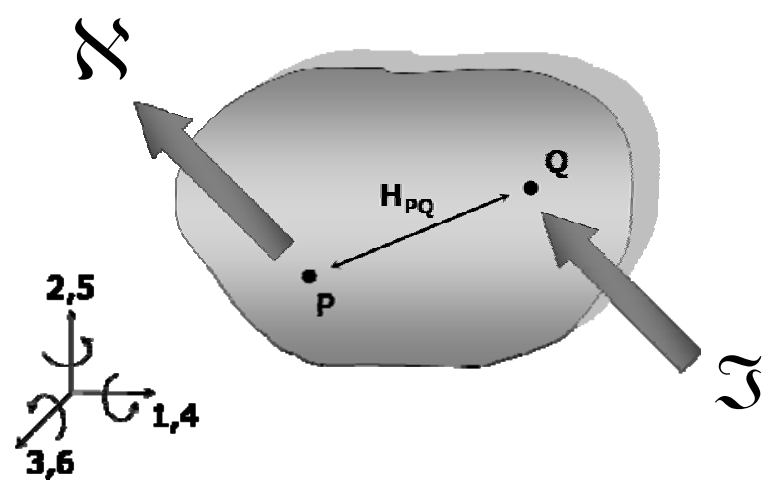

Figura 2.1. Relação entre entrada e saída em uma estrutura flexível

De maneira inteiramente análoga, a resposta da estrutura $\{\aleph\}=\{\aleph(\omega)\}_{P}$ no ponto de coordenada $P$ pode ser decomposta também em seis movimentos, sendo três movimentos lineares ao longo dos eixos ortogonais e três movimentos angulares em torno destes mesmos eixos. Desta forma, sabendo-se que uma dada FRF é definida como a razão da resposta em um determinado ponto pela excitação aplicada em outro ponto, tem-se então que para dois pontos não coincidentes na mesma estrutura existem potencialmente 36 FRFs a serem determinadas.

As equações de movimento para qualquer estrutura e em especial à ilustrada na Figura 2.1 podem então ser escritas no domínio da freqüência da seguinte maneira (MCCONNELL, 1995): 


$$
\{\mathfrak{\aleph}\}_{P}=[\mathrm{H}(\omega)]_{P Q}\{\mathfrak{I}\}_{Q}
$$

Reescrevendo a equação acima em termos dos vetores de força e binário como entrada e os vetores de movimento linear e angular como saída, obtém-se

$$
\left\{\begin{array}{l}
\{X\} \\
\{\Theta\}
\end{array}\right\}_{P}=\left[\begin{array}{ll}
{\left[H_{X F}\right]} & {\left[H_{X M}\right]} \\
{\left[H_{\theta F}\right]} & {\left[H_{\theta M}\right]}
\end{array}\right]_{P Q}\left\{\begin{array}{l}
\{F\} \\
\{M\}
\end{array}\right\}_{Q}
$$

Os vetores $\{X\}=\{X(\omega)\}_{P}$ e $\{\Theta\}=\{\Theta(\omega)\}_{P}$ representam os movimentos lineares e angulares associados ao $P$-ésimo grau de liberdade da estrutura (GDL), bem como, $\{F\}=\{F(\omega)\}_{Q}$ e $\{M\}=\{M(\omega)\}_{Q}$ representam as entradas lineares e angulares aplicadas ao $Q$-ésimo grau de liberdade da estrutura, respectivamente.

A matriz de FRF do sistema, por sua vez, aparece escrita de forma particionada em quatro sub-matrizes. A sub-matriz $\left[H_{X F}\right]=\left[H_{X F}(\omega)\right]$ contém apenas as FRFs relacionando graus de liberdade lineares (tanto para entrada quanto para saída).

A sub-matriz $\left[H_{\theta F}\right]=\left[H_{\theta F}(\omega)\right]$, por outro lado, relaciona a resposta angular da estrutura a uma entrada do tipo força através da sub-matriz e, como visto na revisão da literatura, a maioria das técnicas de estimativa de FRFAs tem concentrado esforços na identificação desta sub-matriz (BREGANT; SANDERSON, 2000).

Pela lei da reciprocidade, a sub-matriz que relaciona as entradas angulares com as saídas lineares $\left[H_{X M}\right]$ deve ser idêntica à sub-matriz que relaciona as saídas angulares por entradas lineares $\left[H_{\theta F}\right]$. Sendo assim, tem-se que $\left[H_{X M}(\omega)\right]=\left[H_{\theta F}(\omega)\right]$. Por último, a sub-matriz $\left[H_{\theta M}\right]=\left[H_{\theta M}(\omega)\right]$ contém as FRFs que relacionam saídas angulares com suas respectivas entradas angulares aplicadas à estrutura. 
A importância da Eq. (2.2) pode ser vista quando um de seus elementos é escrito explicitamente:

$$
\{X\}_{P}=\left[H_{X F}\right]_{P Q}\{F\}_{Q}+\left[H_{\theta F}\right]_{P Q}\{M\}_{Q}
$$

A resposta linear no ponto de coordenada $P$ recebe a contribuição dos esforços lineares e das FRFs contidas em $\left[H_{X F}\right]$, assim como, dos esforços angulares e das FRFs contidas na matriz $\left[H_{\theta F}\right]$. Entretanto, na prática experimental, onde se utiliza comumentemente acelerômetros translacionais, é comum fazer-se a seguinte simplificação:

$$
X_{P}=H_{P Q} F_{Q}
$$

de maneira que os demais termos que aparecem na Eq. (2.3) são simplesmente desprezados, o que pode, em determinados casos afetar de maneira substancial os modelos de resposta da estrutura sob estudo.

Do ponto de vista matemático, o desconhecimento de tais informações pode representar cerca de $75 \%$ do modelo completo (VAROTO, 1996). Então, torna-se de grande importância a correta estimativa dos movimentos angulares e as respectivas FRFs.

Desta forma, propõe-se a seguir o desenvolvimento de um sensor angular baseado na utilização de pastilhas piezelétricas capaz de estimar rotações em qualquer ponto da estrutura, e assim, ser possível determinar as FRFs do tipo $H(\omega)=\theta(\omega) / F(\omega)$ que relacionam respostas angulares devido a entradas do tipo força. 


\subsection{BIMORPH}

Por bimorph entende-se um elemento composto por duas camadas de material piezelétrico ligadas a um painel metálico flexível (SAWYER, 1931). Exemplos deste componente podem ser vistos na Figura 2.2.

Sua utilização é extensa, podendo ser encontrado desde aplicações em microválvulas (MORRIS; FORSTER, 2000) quanto como fontes geradoras de eletricidade (AJITSARIA et al., 2007) entre outras (TAl et al., 2004; GONG et al., 2005; JIANG et al., 2005; LIM; CHOI, 2007).
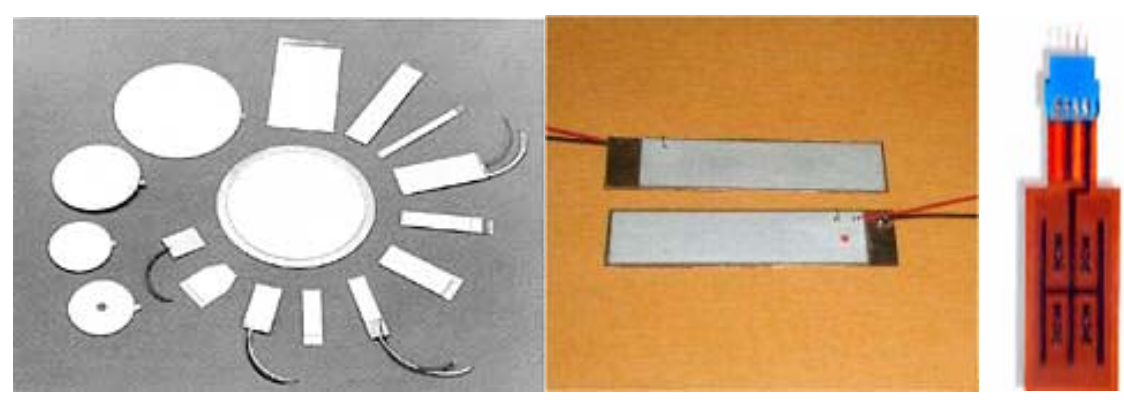

Figura 2.2: Exemplos de bimorphs

Bimorphs podem ser utilizados como atuadores, quando alimentados por uma tensão elétrica (efeito piezelétrico inverso), ou como sensores, quando as tensões elétricas são medidas em seus terminais (efeito piezelétrico direto). Seu funcionamento se baseia na utilização das duas camadas piezelétricas conectadas de tal maneira que se tenha um circuito em paralelo ou em série (ver Figura 2.3). 

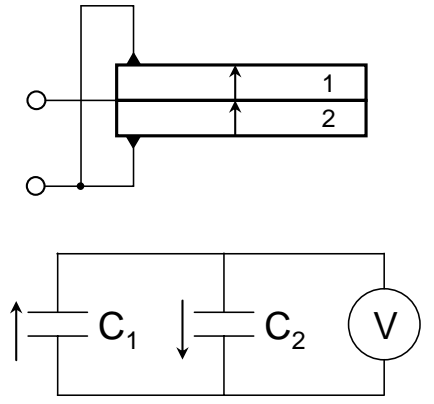

a)
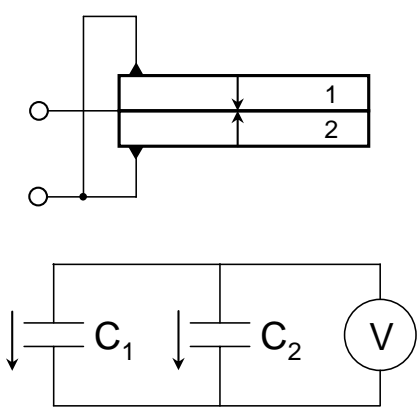

c)
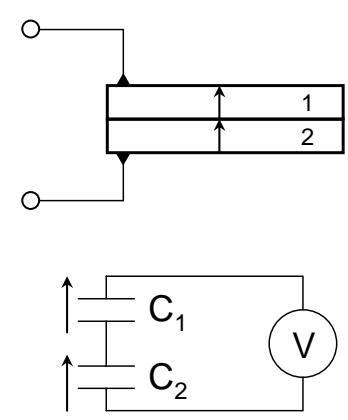

b)
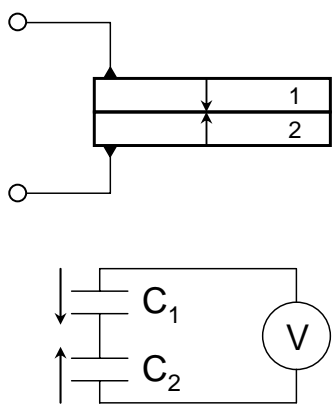

d)

Figura 2.3: Montagem do sensor bimorph em paralelo (a e c) e em série (b e d) (DASGUPTA, 1998)

A razão em se utilizar duas e não apenas uma única pastilha piezelétrica na confecção de um bimorph se deve ao fato de que quando este é sujeito a uma tração, ambas as camadas também estarão sob tração. Logo, a tensão elétrica na extremidade do circuito é nula (ver Figura 2.4a). Semelhantemente, se aplicada uma flexão, a camada piezelétrica superior estará sob tração enquanto que a inferior sob compressão. Desta maneira, a tensão elétrica $(V)$ na extremidade do circuito será proporcional ao efeito de tração na camada superior e ao efeito de compressão na camada inferior, ou seja, ter-se-á uma tensão elétrica não nula e proporcional à curvatura (ver Figura 2.4b). 


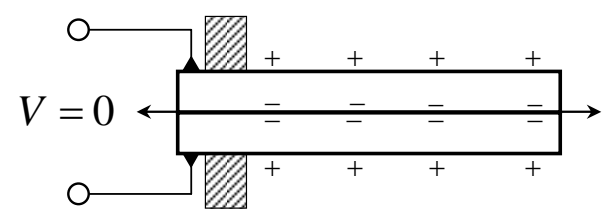

a)

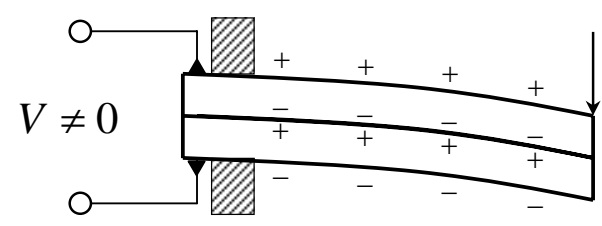

b)

Figura 2.4: Bimorph sujeito a: a) tração e b) flexão

Sendo assim, sugere-se a utilização de bimorphs na estimativa da curvatura local da estrutura, como também, uma estimativa da rotação em um ponto qualquer da estrutura a ser identificada através de um método de aproximação (polinomial, formas modais, etc.).

\subsection{FORMULAÇÃO ANALÍTICA PARA VIGAS LAMINADAS}

Apresenta-se a seguir a formulação teórica de uma viga laminada composta de materiais elásticos/piezelétricos. A viga é modelada utilizando-se a teoria clássica de lâminas ou, em inglês, Classical Laminate Theory (CLT), onde todas as camadas estão sujeitas ao mesmo campo de deslocamento e às hipóteses de Euler-Bernoulli.

As camadas piezelétricas são consideradas transversalmente polarizadas e sujeitas também a um campo elétrico transversal. Por outro lado, a camada elástica é considerada isolada das demais. Todas as camadas são assumidas perfeitamente aderidas e no mesmo estado plano de tensão. O comprimento, largura e espessura da viga laminada são denotadas por $L_{j}, b_{j}$ e $h_{j}$, respectivamente. 


\subsubsection{CINEMÁTICA}

Os deslocamentos axiais $\bar{u}(x, z, t)$ foram assumidos lineares ao longo da espessura, enquanto que os deslocamentos transversais $\bar{w}(x, z, t)$ foram supostos constantes (TRINDADE et al., 2001a).

$$
\begin{gathered}
\bar{u}(x, z, t)=u(x, t)+z \beta(x, t) \\
\bar{w}(x, z, t)=w(x, t)
\end{gathered}
$$

A descrição cinemática da viga laminada está esquematizada na Figura 2.5.

Observa-se que foram considerados os mesmos campos de deslocamentos $(u)$ para todas as camadas. A partir da hipótese de Euller-Bernoulli, $\beta=-w^{\prime}$, tal que, -' foi utilizado para denotar $\partial \bullet / \partial x$.

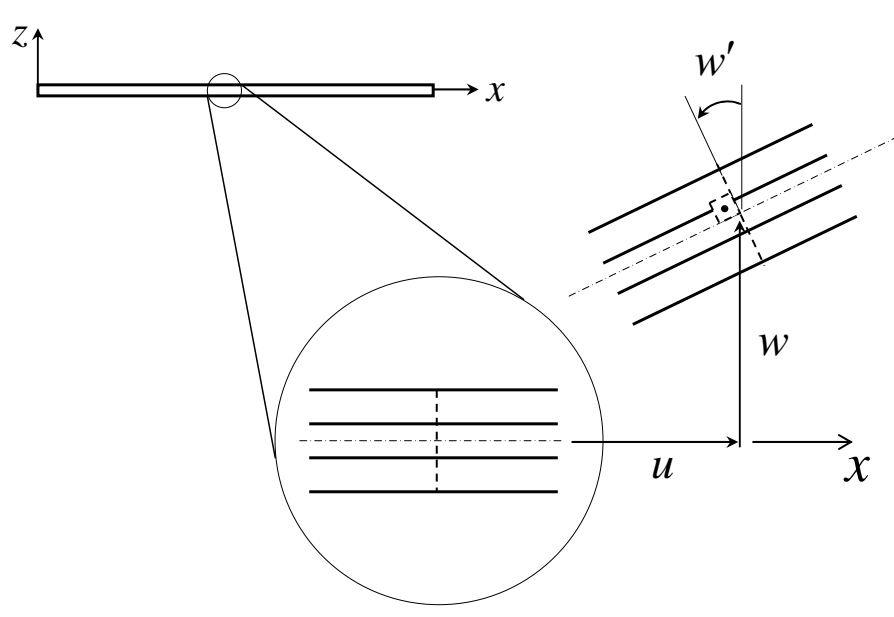

Figura 2.5: Representação cinemática para uma viga laminada

Desta forma, considerando-se as relações usuais de deslocamento e deformação para cada camada, a deformação axial $\varepsilon_{1}$ pode ser escrita da seguinte maneira: 


$$
\varepsilon_{1}=\varepsilon^{m}+\mathrm{z} \varepsilon^{f}
$$

onde $\varepsilon^{m}=u^{\prime}, \varepsilon^{f}=-w^{\prime \prime}$ e os índices $m$ e $f$ remetem às deformações do tipo membrana e flexão.

Supõe-se um campo elétrico transverso constante para as camadas piezelétricas enquanto que as componentes no mesmo plano são supostas nulas. Embora a equação de equilíbrio eletrostático seja satisfeita apenas com a adoção de um campo elétrico linear (RAHMOUNE et al., 1998; WANG, 2004), observou-se que a parte linear pode ser desconsiderada para o problema tratado neste modelo (TRINDADE et al., 2001). Conseqüentemente, para $j$-ésima camada de material piezelétrico, tem-se que:

$$
E_{3}^{j}=-\frac{V_{j}}{h_{j}}
$$

onde $V_{j}$ é a diferença de potencial elétrico para a $j$-ésima camada, definida por $V_{j}=V_{j}^{+}-V_{j}^{-}$, de maneira que, $V_{j}^{+}$e $V_{j}^{-}$referem-se aos potenciais elétricos medidos nas faces superior e inferior da $j$-ésima camada de material piezelétrico.

Considera-se ainda, que os materiais piezelétricos estão completamente cobertos em suas superfícies superiores e inferiores por eletrodos, onde um campo elétrico na direção $z\left(E_{3}\right)$ pode ser aplicado (GODOY, 2008).

\subsubsection{EQUAÇÕES CONSTITUTIVAS REDUZIDAS}

Para a modelagem dos materiais piezelétricos, adotou-se materiais ortotrópicos lineares cujos eixos de simetria são paralelos aos da viga em estudo. Os 
termos $c_{i j}, \quad e_{l j}$ e $\in_{l l} \quad(i, j=1, \ldots, 6 ; \quad l=1,2,3)$ denotam as constantes elásticas, piezelétricas e dielétricas, respectivamente. Para simplificar a notação, todas as camadas foram consideradas piezelétricas. A camada elástica (viga), por sua vez, é obtida fazendo-se com que a constante piezelétrica seja nula.

Assim, as equações constitutivas tridimensionais para uma camada de material piezelétrico ortotrópico podem ser reduzidas a (RAHMOUNE et al., 1998)

$$
\left[\begin{array}{l}
\sigma_{1}^{j} \\
D_{3}^{j}
\end{array}\right]=\left[\begin{array}{cc}
\bar{c}_{11}^{j} & -\bar{e}_{31}^{j} \\
\bar{e}_{31}^{j} & \bar{\epsilon}_{33}^{j}
\end{array}\right]\left[\begin{array}{c}
\varepsilon_{1} \\
E_{3}^{j}
\end{array}\right]
$$

onde

$$
\bar{c}_{11}^{j}=c_{11}-\frac{c_{13}^{2}}{c_{33}}, \bar{e}_{31}^{j}=e_{31}-\frac{c_{13}}{c_{33}} e_{33}, \bar{\epsilon}_{33}^{j}=\epsilon_{33}+\frac{e_{33}^{2}}{c_{33}}
$$

e $\sigma_{1}$ e $D_{3}$ referem-se às componentes de tensão axial e deslocamento elétrico transversal.

A correção das constantes $c_{11}, e_{31}$ e $\in_{33}$ em (2.8b) deve-se à hipótese de que a tensão $\left(\sigma_{3}\right)$ na direção $z$ é nula (RAHMOUNE et al., 1998) - tensões planas.

Observa-se que o acoplamento eletromecânico nas camadas piezelétricas ocorre devido à deformação axial e ao campo elétrico transversal, ou seja, o mecanismo de extensão e atuação convencional para materiais piezelétricos.

\subsubsection{FORMULAÇÃO VARIACIONAL}

Utilizando o princípio de d'Alembert, a seguinte equação variacional pode ser escrita: 


$$
\delta T-\delta H+\delta W=0, \forall \delta u, \delta w, \delta V_{k}
$$

onde $\delta T, \delta H$ e $\delta W$ remetem ao trabalho virtual das forças de inércia, eletromecânicas e externas, respectivamente.

Por sua vez, estes três termos podem ser descritos de acordo com as variáveis principais $u, w$ e $V_{j}$.

O trabalho virtual das forças eletromecânicas pode ser escrito da seguinte forma para uma viga laminada:

$$
\delta H=\int_{\Omega}(\sigma \delta \varepsilon-D \delta E)
$$

ou então, como um somatório das contribuições de cada camada

$$
\delta H=\sum_{j} \delta H_{j}
$$

tal que

$$
\delta H_{j}=\int_{\Omega_{j}}\left(\sigma_{1}^{j} \delta \varepsilon_{1}-D_{3}^{j} \delta E_{3}^{j}\right) d \Omega_{j}
$$

com $\Omega_{j}$ sendo o volume da $j$-ésima camada.

Fazendo uso das equações constitutivas (2.8) e (2.8b) pode-se escrever que

$$
\delta H_{j}=\int_{\Omega_{j}}\left(\varepsilon_{1} \bar{c}_{11}^{j} \delta \varepsilon_{1}-E_{3}^{j} \bar{e}_{31}^{j} \delta \varepsilon_{1}-\varepsilon_{1} \bar{e}_{31}^{j} \delta E_{3}^{j}-E_{3}^{j} \bar{\epsilon}_{33}^{j} \delta E_{3}^{j}\right) d \Omega_{j}
$$

Substituindo a equação referente ao campo de deslocamentos (2.5) e ao compo elétrico (2.7), o trabalho virtual dos esforços eletromecânicos pode ser descrito e decomposto de acordo com as seguintes contribuições: mecânica $\delta H_{j}^{m}$, piezelétricas $\delta H_{j}^{m e}$ e $\delta H_{j}^{e m}$ e dielétrica $\delta H_{j}^{e}$. Logo, 


$$
\delta H_{j}=\delta H_{j}^{m}-\delta H_{j}^{m e}-\delta H_{j}^{e m}+\delta H_{j}^{e}
$$

onde

$$
\begin{gathered}
\delta H_{j}^{m}=\int_{0}^{L} \bar{c}_{11}^{j}\left(\varepsilon^{m} A_{j} \delta \varepsilon^{m}+\varepsilon^{f} \bar{I}_{j} \delta \varepsilon^{m}+\varepsilon^{m} \bar{I}_{j} \delta \varepsilon^{f}+\varepsilon^{f} I_{j} \delta \varepsilon^{f}\right) d x \\
\delta H_{j}^{m e}=-\int_{0}^{L}\left(A_{j} \delta \varepsilon^{m}+\bar{I}_{j} \delta \varepsilon^{f}\right) \bar{e}_{31}^{j} \frac{V_{j}}{h_{j}} d x \\
\delta H_{j}^{e m}=-\int_{0}^{L} \bar{e}_{31}^{j}\left(A_{j} \varepsilon^{m}+\bar{I}_{j} \varepsilon^{f}\right) \frac{\delta V_{j}}{h_{j}} d x \\
\delta H_{j}^{e}=-\int_{0}^{L} \bar{\epsilon}_{33}^{j} A_{j} \frac{V_{j}}{h_{j}} \frac{\delta V_{j}}{h_{j}} d x
\end{gathered}
$$

$A_{j}, \bar{I}_{j}$ e $I_{j}$ simbolizam, respectivamente, a área, o primeiro e o segundo momento de inércia da seção transversal da j -ésima camada. Logo,

$$
\left[A_{j}, \bar{I}_{j}, I_{j}\right]=\int_{-b / 2}^{b / 2} \int_{-z_{j}-h_{j} / 2}^{z_{j}+h_{j} / 2_{j}}\left[1, z, z^{2}\right] d z d y
$$

Observa-se das expressões em (2.15) que existem termos de acoplamento entre flexão e membrana devido à característica de múltiplas camadas. O eixo local $z$ da $j$-ésima camada situa-se no plano médio, de forma que

$$
z_{j}=\frac{h_{j}^{\text {piezo }}+h^{\text {viga }}}{2}+\sum_{r=1}^{j-1} h_{r}^{\text {piezo }}
$$

O trabalho virtual dos esforços eletromecânicos (2.14) pode ser expresso em termos das variáveis $u, w$ e $V_{j}$, logo, 


$$
\begin{aligned}
& \delta H_{j}=\int_{0}^{L}\left\{\delta u^{\prime}\left[\bar{c}_{11}^{j} A_{j} u^{\prime}-\bar{c}_{11}^{j} \bar{I}_{j} w^{\prime \prime}+\bar{e}_{31}^{j} A_{j} \frac{V_{j}}{h_{j}}\right]+\delta w^{\prime \prime}\left[-\bar{c}_{11}^{j} \bar{I}_{j} u^{\prime}+\bar{c}_{11}^{j} I_{j} w^{\prime \prime}+\bar{e}_{31}^{j} \bar{I}_{j} \frac{V_{j}}{h_{j}}\right]\right. \\
& \left.+\frac{\delta V_{j}}{h_{j}}\left[\bar{e}_{31}^{j} A_{j} u^{\prime}-\bar{e}_{31}^{j} \bar{I}_{j} w^{\prime \prime}-\bar{\epsilon}_{33}^{j} A_{j} \frac{V_{j}}{h_{j}}\right]\right\} d x
\end{aligned}
$$

Integrando por parte uma vez em $\delta u^{\prime}$ e duas vezes em $\delta w^{\prime \prime}$, pode-se escrever

que

$$
\delta H_{j}=\delta H_{j}^{l m}+\delta H_{j}^{v l}
$$

onde

$$
\begin{aligned}
& \delta H_{j}^{l m}=\left\{\delta u\left[\bar{c}_{11}^{j} A_{j} u^{\prime}-\bar{c}_{11}^{j} \bar{I}_{j} w^{\prime \prime}+\bar{e}_{31}^{j} A_{j} \frac{V_{j}}{h_{j}}\right]\right. \\
& +\delta w^{\prime}\left[-\bar{c}_{11}^{j} \bar{I}_{j} u^{\prime}+\bar{c}_{11}^{j} I_{j} w^{\prime \prime}+\bar{e}_{31}^{j} \bar{I}_{j} \frac{V_{j}}{h_{j}}\right] \\
& \left.-\delta w\left[-\bar{c}_{11}^{j} \bar{I}_{j} u^{\prime \prime}+\bar{c}_{11}^{j} I_{j} w^{\prime \prime \prime}+\bar{e}_{31}^{j} \bar{I}_{j} \frac{V_{j}^{\prime}}{h_{j}}\right]\right\}_{0}^{L} \\
& \delta H_{j}^{v l}=-\int_{0}^{L}\left\{\delta u\left[\bar{c}_{11}^{j} A_{j} u^{\prime \prime}-\bar{c}_{11}^{j} \bar{I}_{j} w^{\prime \prime \prime}+\bar{e}_{31}^{j} A_{j} \frac{V_{j}^{\prime}}{h_{j}}\right]\right. \\
& -\delta w\left[-\bar{c}_{11}^{j} \bar{I}_{j} u^{\prime \prime \prime}+\bar{c}_{11}^{j} I_{j} w^{\prime \prime \prime}+\bar{e}_{31}^{j} \bar{I}_{j} \frac{V_{j}^{\prime \prime}}{h_{j}}\right] \\
& \left.-\frac{\delta V_{j}}{h_{j}}\left[\bar{e}_{31}^{j} A_{j} u^{\prime}-\bar{e}_{31}^{j} \bar{I}_{j} w^{\prime \prime}-\bar{\epsilon}_{33}^{j} A_{j} \frac{V_{j}}{h_{j}}\right]\right\} d x
\end{aligned}
$$

trabalho virtual das forças inerciais pode ser escrito da seguinte maneira:

$$
\delta T=-\sum_{j} \int_{\Omega_{j}}\left(\delta u \rho_{j} \ddot{u}+\delta w \rho_{j} \ddot{w}\right) d \Omega_{j}
$$

onde $\rho_{j}$ representa a densidade em massa por volume da $j$-ésima camada e $\bullet$ remete à $\partial \bullet / \partial t$. 
Utilizando as relações de deslocamento (2.5) e promovendo uma integração ao longo da área transversal, tem-se que:

$$
\delta T_{j}=-\int_{0}^{L} \rho_{j} A_{j}(\delta u \ddot{u}+\delta w \ddot{w}) d x
$$

É importante salientar que os termos inerciais de acoplamento translacionalrotacional desta modelagem foram desconsiderados para efeitos de simplificação do modelo, sem a perda de acuracidade do mesmo. Assim, em vista da definição do campo de deslocamentos, a equação (2.21) pode ser expressa em função das variáveis $u$ e $w$ de tal forma que

$$
\delta T_{j}=-\int_{0}^{L}\left(\delta u \rho_{j} A_{j} \ddot{u}+\delta w \rho_{j} A_{j} \ddot{w}\right) d x
$$

O trabalho virtual das forças axiais e transversais aplicadas em cada camada pode ser escrito da seguinte forma:

$$
\delta W=\sum_{j} \delta W_{j}
$$

onde

$$
\delta W_{j}=\int_{0}^{L}\left(\delta u N+\delta w V-\delta w^{\prime} M\right) d x
$$

e $N, V$ e $M$ representam as resultantes totais normal, transversal e o momento aplicadas às camadas.

\subsubsection{EQUAÇÕES DE MOVIMENTO E DETERMINAÇÃO DA CURVATURA LOCAL}

As equações de movimento para toda a viga podem ser escritas da seguinte maneira: 


$$
\sum_{j}\left(\delta T_{j}-\delta H_{j}+\delta W_{j}\right)=0, \forall \delta u, \delta w, \delta V_{j}
$$

Utilizando as relações vistas em (2.18), (2.22), e (2.24), pode-se reescrever a equação acima supondo em relação às variáveis independentes $u, w$ e $V_{j}$ a diferença de potencial elétrico $V_{j}$, constante ao longo da direção $x$ (condição de equipotencialidade atribuída à camada piezelétrica devido à hipótese de eletrodos recobrindo a mesma), tal como:

$$
\begin{aligned}
& \int_{0}^{L}\left\{\delta u\left[\left(-\sum_{j} \rho_{j} A_{j}\right) \ddot{u}+\left(\sum_{j} \bar{c}_{11}^{j} A_{j}\right) u^{\prime \prime}-\left(\sum_{j} \bar{c}_{11}^{j} \bar{I}_{j}\right) w^{\prime \prime \prime}+N\right]\right. \\
& +\delta w\left[\left(-\sum_{j} \rho_{j} A_{j}\right) \ddot{w}+\left(\sum_{j} \bar{c}_{11}^{j} \bar{I}_{j}\right) u^{\prime \prime \prime}-\left(\sum_{j} \bar{c}_{11}^{j} I_{j}\right) w^{\prime \prime \prime}+V-M^{\prime}\right] \\
& \left.-\sum_{j} \frac{\delta V_{j}}{h_{j}}\left(\bar{e}_{31}^{j} A_{j} u^{\prime}-\bar{e}_{31}^{j} \bar{I}_{j} w^{\prime \prime}-\bar{\epsilon}_{33}^{j} A_{j} \frac{V_{j}}{h_{j}}\right)\right\} d x=0
\end{aligned}
$$

Observa-se que embora considerando as hipóteses de Euler-Bernoulli, onde $u$ e $w$ são iguais para cada camada, a diferença de potencial elétrico $V_{j}$ é independente e pode variar de acordo com cada camada. Desta maneira, das equações de movimento pode-se dizer que:

$$
\begin{gathered}
\left(\sum_{j} \rho_{j} A_{j}\right) \ddot{u}-\left(\sum_{j} \bar{c}_{11}^{j} A_{j}\right) u^{\prime \prime}+\left(\sum_{j} \bar{c}_{11}^{j} \bar{I}_{j}\right) w^{\prime \prime \prime}=N \\
\left(\sum_{j} \rho_{j} A_{j}\right) \ddot{w}+\left(\sum_{j} \bar{c}_{11}^{j} I_{j}\right) w^{\prime \prime \prime}-\left(\sum_{j} \bar{c}_{11}^{j} \bar{I}_{j}\right) u^{\prime \prime \prime}=V-M^{\prime} \\
\bar{e}_{31}^{j} A_{j} u^{\prime}-\bar{e}_{31}^{j} \bar{I}_{j} w^{\prime \prime}-\bar{\epsilon}_{33}^{j} A_{j} \frac{V_{j}}{h_{j}}=0
\end{gathered}
$$


A Eq. (2.27c) pode ser resolvida em termos de $V_{j}$, pois o interesse aqui é justamente avaliar a diferença de potencial elétrico induzido em cada camada piezelétrica devido à vibração da estrutura. Logo,

$$
V_{j}=\frac{\bar{e}_{31}^{j}}{\bar{\epsilon}_{33}^{j}} h_{j}\left(u^{\prime}-\frac{\bar{I}_{j}}{A_{j}} w^{\prime \prime}\right)
$$

A Eq. (2.28) mostra a razão da utilização de sensores bimorph. Com apenas uma única camada piezelétrica não seria possível a determinação da voltagem apenas conhecendo-se a curvatura $w^{\prime \prime}$, pois esta é dependente também do deslocamento axial $u^{\prime}$. No entanto, se for utilizado um par de pastilhas piezelétricas idênticas coladas uma sobre a outra (bimorph), é possível se obter a seguinte expressão:

$$
V_{2}-V_{1}=\frac{\bar{e}_{31}}{\bar{\epsilon}_{33}} \frac{h_{p}}{A_{p}}\left(\bar{I}_{1}-\bar{I}_{2}\right) w^{\prime \prime}
$$

A partir da Eq. (2.16) e da Figura 2.6 pode se escrever que

$$
\bar{I}_{1}=\int_{h / 2}^{h / 2+h_{p}} z d A \text { e } \bar{I}_{2}=\int_{h / 2+h_{p}}^{h / 2+2 h_{p}} z d A
$$

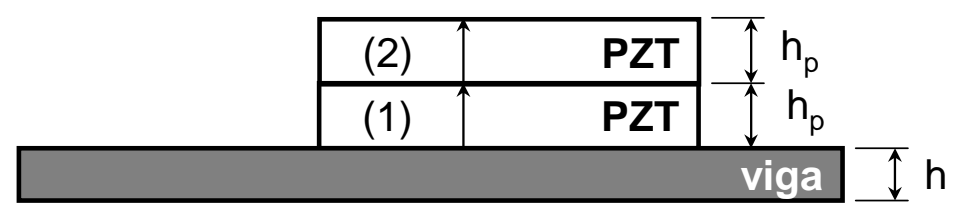

Figura 2.6: Polarização e numeração das camadas piezelétricas

Logo, considerando-se pastilhas com seção transversal retangular e de mesma largura $b$ da viga, tem-se que: 


$$
V_{2}-V_{1}=-h_{p}^{2} \frac{\bar{e}_{31}}{\bar{\epsilon}_{33}} w^{\prime \prime}
$$

Desta forma, a curvatura local pode ser associada com a voltagem medida diretamente de cada bimorph através da seguinte relação:

$$
w^{\prime \prime}(x, t)=-\frac{\bar{\epsilon}_{33}}{\bar{e}_{31} h_{p}^{2}}\left[V_{2}(t)-V_{1}(t)\right]
$$

De acordo com a Eq. (2.31), o princípio básico de funcionamento do transdutor bimorph consiste na obtenção da diferença entre as voltagens oriundas de cada pastilha piezelétrica. Logo, a determinação da rotação para um determinado ponto $\left(x_{\text {out }}\right)$ de resposta na viga, por sua vez, ocorre através de um processo de aproximação. Dois métodos são propostos: polinomial e formas modais.

\subsubsection{APROXIMAÇÃO POLINOMIAL}

Neste tipo de aproximação o campo de deslocamentos e suas derivadas podem ser escritos da seguinte forma:

$$
\begin{aligned}
& w(x, t)=a_{p}(t) x^{p}+a_{p-1}(t) x^{p-1}+\cdots+a_{3}(t) x^{3}+a_{2}(t) x^{2}+a_{1}(t) x+a_{0}(t) \\
& w^{\prime}(x, t)=a_{p}(t) p x^{p-1}+a_{p-1}(t)(p-1) x^{p-2}+\cdots+3 a_{3}(t) x^{2}+2 a_{2}(t) x+a_{1}(t) \\
& w^{\prime \prime}(x, t)=a_{p}(t) p(p-1) x^{p-2}+a_{p-1}(t)(p-1)(p-2) x^{p-3}+\cdots+6 a_{3}(t) x+2 a_{2}(t) \\
& w^{\prime \prime \prime}(x, t)=a_{p}(t) p(p-1)(p-2) x^{p-3}+a_{p-1}(t)(p-1)(p-2)(p-3) x^{p-4}+\cdots+6 a_{3}(t)
\end{aligned}
$$

Os coeficientes $a_{k}(t)(k=0, \ldots, p)$ podem ser determinados impondo-se as condições de contorno e as curvaturas locais obtidas de (2.31) para cada instante de tempo $t_{i}$. Para uma viga engastada-livre (cantilever), as quatro condições de contorno são: deslocamento $(w)$ e rotação $\left(w^{\prime}\right)$ nulos em $x=0$ e momento ou 
curvatura $\left(w^{\prime \prime}\right)$ e força de cisalhamento $\left(w^{\prime \prime \prime}\right)$ nulos para a extremidade oposta $(x=L)$.

Cada condição de contorno fornece uma equação em vista dos coeficientes $a_{k}$. Logo, para uma viga cantilever, tem-se que $a_{0}=a_{1}=0$, enquanto que os $p-1$ coeficientes $\left(a_{2}, \ldots, a_{p}\right)$ restantes devem ser determinados a partir das duas condições naturais de contorno em $x=L$ e as respectivas curvaturas locais, obtidas a partir da equação (2.31), extraídas em cada um dos $n$ sensores bimorphs.

Desta forma, a solução exata do sistema de equações em termos dos coeficientes $\left(a_{2}, \ldots, a_{p}\right)$ pode ser encontrada caso a ordem do polinômio seja dada pela relação $p=n+3$, de tal forma que

$$
\left\lfloor Q_{p}\{a\}=\{c\}\right.
$$

onde

$$
\begin{aligned}
& Q_{P}=\left[\begin{array}{cccc}
(n+3)(n+2)\left(x_{b 1}\right)^{n+1} & (n+2)(n+1)\left(x_{b 1}\right)^{n} & \cdots & 2 \\
\vdots & \vdots & \vdots & \vdots \\
(n+3)(n+2)\left(x_{b n}\right)^{n+1} & (n+2)(n+1)\left(x_{b n}\right)^{n} & \cdots & 2 \\
(n+3)(n+2)(L)^{n+1} & (n+3)(n+2)(L)^{n} & \cdots & 2 \\
(n+3)(n+2)(n+1)(L)^{n} & (n+3)(n+2)(n+1)(n)(L)^{n-1} & \cdots & 0
\end{array}\right] \\
& \{a\}^{T}=\left\{\begin{array}{llll}
a_{p}\left(t_{i}\right) & \cdots & a_{3}\left(t_{i}\right) & a_{2}\left(t_{i}\right)
\end{array}\right\} \\
& \{c\}^{T}=\left\{\begin{array}{lllll}
w_{b 1}^{\prime \prime}\left(t_{i}\right) & \cdots & w_{b n}^{\prime \prime}\left(t_{i}\right) & 0 & 0
\end{array}\right\}
\end{aligned}
$$

tal que $x_{b}$ representa a posição de cada bimorph em relação ao eixo longitudinal $x$ da viga. 
Utilizando os coeficientes $a_{k}$ para cada instante de tempo $t_{i}$, os deslocamentos $w\left(x, t_{i}\right)$ e as rotações $w^{\prime}\left(x, t_{i}\right)$ são obtidos considerando-se o campo de deslocamentos adotado em (2.32).

\subsubsection{APROXIMAÇÃO POR FORMAS MODAIS}

Utilizando formas modais, tem-se que o campo de deslocamentos pode ser aproximado da seguinte forma:

$$
w(x, t)=\sum_{i=1}^{m} \phi_{i}(x) \alpha_{i}(t)
$$

onde $\phi_{i}(x)$ representa a descrição geométrica do $i$-ésimo modo de vibrar para uma viga cantilever do tipo Euler-Bernoulli. Observa-se ainda que qualquer função $\phi_{i}(x)$ pode ser utilizada neste caso, incluindo funções polinomiais de alta ordem.

Os coeficientes temporais $\alpha_{i}(t)$ podem ser determinados impondo-se novamente as quatro condições de contorno naturais, bem como, as curvaturas locais obtidas através das voltagens induzidas em cada bimorph, em um total de $n$ pontos de medidas, para cada instante de tempo $t_{i}$.

Desta forma, tendo assumido a presença de $n$ bimorphs, o número de modos que devem utilizados nesta aproximação é igual a $m=n+2$, dado que as condições de contorno já foram inicialmente incluídas na definição das formas modais.

De acordo com (2.37), o seguinte sistema pode ser escrito:

$$
\left[Q_{M}\right]\{\alpha\}=\{c\}
$$

onde 


$$
Q_{M}=\left[\begin{array}{cccc}
\phi_{1}^{\prime \prime}\left(x_{b 1}\right) & \phi_{2}^{\prime \prime}\left(x_{b 1}\right) & \cdots & \phi_{M}^{\prime \prime}\left(x_{b 1}\right) \\
\vdots & \vdots & \vdots & \vdots \\
\phi_{1}^{\prime \prime}\left(x_{b n}\right) & \phi_{2}^{\prime \prime}\left(x_{b n}\right) & \cdots & \phi_{M}^{\prime \prime}\left(x_{b n}\right) \\
\phi_{1}^{\prime \prime}(L) & \phi_{2}^{\prime \prime}(L) & \cdots & \phi_{M}^{\prime \prime}(L) \\
\phi^{\prime \prime \prime}(L)_{1} & \phi_{2}^{\prime \prime \prime}(L) & \cdots & \phi_{M}^{\prime \prime \prime}(L)
\end{array}\right]
$$

e

$$
\begin{gathered}
\{\alpha\}^{T}=\left\{\begin{array}{llll}
\alpha_{p}\left(t_{i}\right) & \cdots & \alpha_{M}\left(t_{i}\right)
\end{array}\right\} \\
\{c\}^{T}=\left\{\begin{array}{lllll}
w_{b 1}^{\prime \prime}\left(t_{i}\right) & \cdots & w_{b n}^{\prime \prime}\left(t_{i}\right) & 0 & 0
\end{array}\right\}
\end{gathered}
$$

Logo, a rotação $w^{\prime}(x, t)$ pode ser aproximada neste caso considerando-se a Eq. (2.37)

Finalmente, comparando-se o método de aproximação por formas modais ao método de aproximação polinomial, este último apresenta um polinômio de ordem $n+2$ referente à rotação, enquanto que o primeiro utiliza $n+2$ modos de vibrar de ordem $p-1$ em sua aproximação.

\subsubsection{ELEMENTOS FINITOS}

Um modelo em elementos finitos foi elaborado em conjunto com o Prof. Dr. Marcelo Areias Trindade do Departamento de Engenharia Mecânica da Escola de Engenharia de São Carlos. O modelo tem por objetivo simular a utilização do bimorph, bem como, prover subsídios de projeto para a integração deste tipo de sensor a estruturas do tipo viga.

A partir da formulação variacional e das expressões de trabalho virtual, desenvolveu-se um modelo em elementos finitos para a viga incluindo-se os sensores bimorphs. Funções de forma lineares (Lagrange) foram adotadas no caso dos 
deslocamentos principais $(\bar{u})$ e funções cúbicas (Hermitianas) para a deflexão transversal $\bar{w}$. $\bigcirc$ modelo ainda considera uma condição de equipotencialidade, o que equivale a uma rede de eletrodos interconectados cobrindo a superfície superior e inferior de cada pastilha. A descrição completa deste modelo pode ser encontrada em Trindade (2000).

\subsection{FORMULAÇÃO ANALÍTICA PARA PLACAS FINAS E ISOTRÓPICAS}

De maneira semelhante ao que foi visto para estruturas do tipo viga, apresenta-se a seguir, a formulação teórica para estruturas do tipo placa. $\bigcirc$ objetivo final é relacionar novamente a leitura da tensão elétrica resultante no bimorph à curvatura local da estrutura e, assim, estimar a rotação em qualquer ponto da estrutura.

As equações descrevendo o modelo de placa são obtidas a partir da equação geral de movimento de casca, em coordenadas curvilíneas, com a escolha apropriada dos parâmetros de Lamé e dos respectivos raios de curvatura (LIMA JR., 1999).

Neste trabalho, foi adotado o modelo de Kirchhoff, onde as normais à superfície de referência permanecerão perpendiculares à superfície de referência deformada, ou seja, $\gamma_{x z}=\gamma_{y z}=0$, como também, não há variação de espessura durante a deformação.

Considera-se ainda que a tensão normal $\sigma_{z}$, perpendicular a superfície da placa, é pequena, podendo ser desprezada quando comparada às outras tensões normais $\sigma_{x}$ e $\sigma_{y}$. Além disso, as deformações ocorrem no campo das pequenas 
deformações, o que permite desprezar os termos de segunda ordem e superiores. A espessura da placa $h$ é muito pequena em comparação às outras dimensões, condição esta, fundamental para a formulação da teoria de placas finas.

As camadas piezelétricas são supostas novamente transversalmente polarizadas e sujeitas também a um campo elétrico transversal. A camada elástica é novamente considerada isolada e, todas as camadas são assumidas perfeitamente aderidas e no mesmo estado plano de tensão.

\subsubsection{CINEMÁTICA}

Os deslocamentos axiais $\bar{u}(x, y, z, t)$ e $\bar{v}(x, y, z, t)$ foram assumidos lineares ao longo da espessura, enquanto que os deslocamentos transversais $\bar{w}(x, y, z, t)$ foram supostos constantes, logo:

$$
\begin{gathered}
\bar{u}(x, y, z, t)=u(x, y, t)+z \beta_{x}(x, y, t) \\
\bar{v}(x, y, z, t)=v(x, y, t)+z \beta_{y}(x, y, t) \\
\bar{w}(x, y, z, t)=w(x, y, t)
\end{gathered}
$$

O símbolo - indica a quantidade num ponto arbitrário $(x, y, z)$ da placa e as variáveis sem o traço são definidas no plano médio da placa. Desta forma, os deslocamentos $(\bar{u}, \bar{v})$ dependem apenas da localização do ponto $(x, y)$ e da rotação do plano médio em relação aos eixos $x$ e $y$.

A descrição cinemática da placa fina laminada está esquematizada na Figura 2.7 .

Observa-se que foram considerados os mesmos campos de deslocamentos $(u, v)$ para todas as camadas. A partir da hipótese de Euller-Bernoulli, $\beta_{, x}=-\partial w / \partial x$ e 
$\beta_{, y}=-\partial w / \partial y$. O plano inferior da camada mais inferior (placa) foi ajustado para coincidir com a origem do eixo $z$.

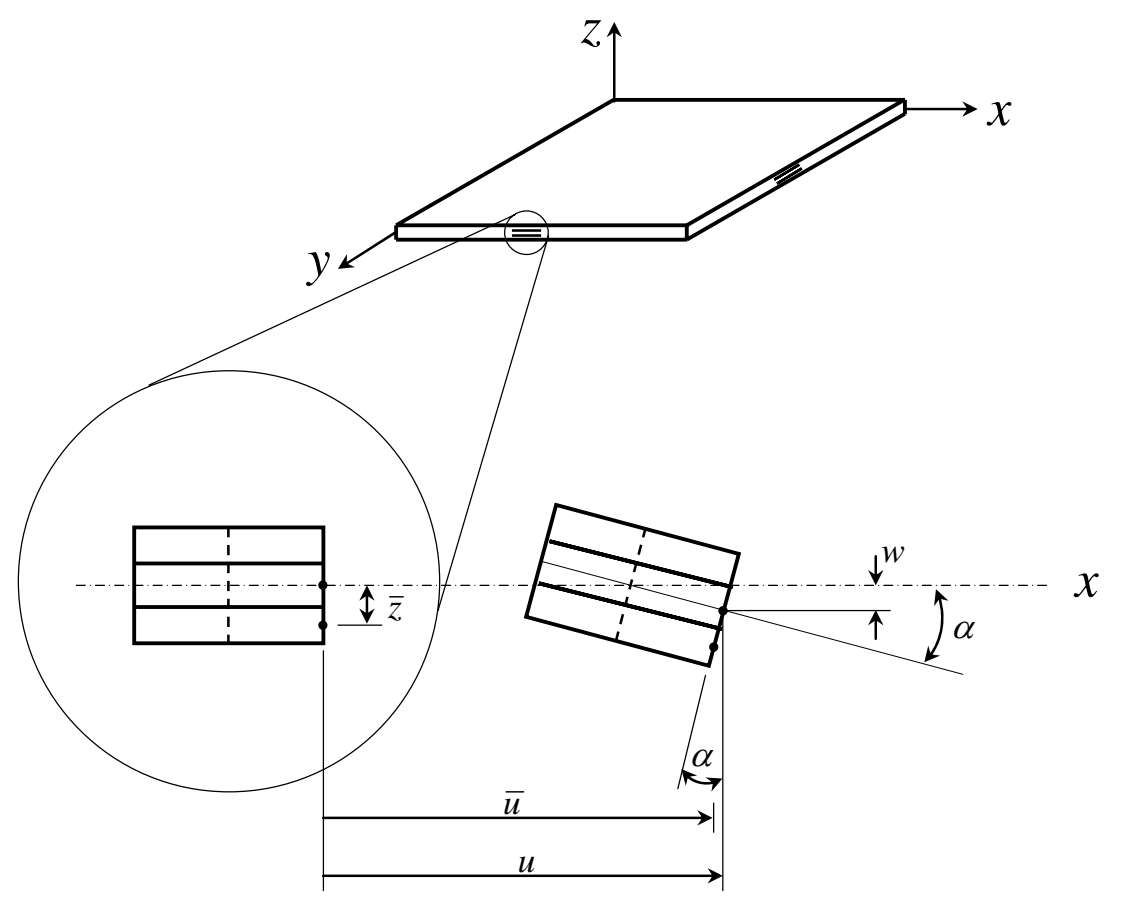

Figura 2.7. Representação cinemática para uma placa fina laminada

Considerando-se as relações usuais de tensão e deformação para cada camada, as deformações axiais $\varepsilon_{1}$ e $\varepsilon_{2}$ e cisalhamento $\varepsilon_{6}$ podem ser escritas da seguinte maneira:

$$
\begin{gathered}
\varepsilon_{1}=\frac{\partial u}{\partial x}-z \frac{\partial^{2} w}{\partial x^{2}}=u_{, x}+z \beta_{, x} \\
\varepsilon_{2}=\frac{\partial v}{\partial y}-z \frac{\partial^{2} w}{\partial y^{2}}=v_{, y}+z \beta_{y} \\
\varepsilon_{6}=\frac{\partial u}{\partial y}+\frac{\partial v}{\partial x}-2 z \frac{\partial^{2} w}{\partial x \partial y}=u_{, y}+v_{, x}+2 z \beta_{x y}
\end{gathered}
$$

Da mesma forma que foi adotada para a viga, supõe-se um campo elétrico transverso constante para as camadas piezelétricas enquanto que as componentes no mesmo plano são supostas nulas. 


\subsubsection{EQUAÇÕES CONSTITUTIVAS REDUZIDAS}

Novamente para a modelagem dos materiais piezelétricos, considerou-se materiais ortotrópicos lineares cujos eixos de simetria são paralelos aos da placa em estudo. Para simplificar a notação, todas as camadas foram consideradas piezelétricas. A camada elástica (placa), por sua vez, é obtida fazendo-se com que a constante piezelétrica seja nula.

Desta maneira, as equações constitutivas tridimensionais para uma camada de material piezelétrico ortotrópico podem ser reduzidas a (RAHMOUNE et al., 1998)

$$
\left\{\begin{array}{l}
\sigma_{1}^{j} \\
\sigma_{2}^{j} \\
\sigma_{6}^{j} \\
D_{3}^{j}
\end{array}\right\}=\left[\begin{array}{cccc}
\bar{c}_{11}^{j} & \bar{c}_{12}^{j} & 0 & -\bar{e}_{31}^{j} \\
\bar{c}_{12}^{j} & \bar{c}_{22}^{j} & 0 & -\bar{e}_{32}^{j} \\
0 & 0 & c_{66}^{j} & 0 \\
\bar{e}_{31}^{j} & \bar{e}_{32}^{j} & 0 & \bar{\epsilon}_{33}^{j}
\end{array}\right]\left\{\begin{array}{c}
\varepsilon_{1} \\
\varepsilon_{2} \\
\varepsilon_{6} \\
E_{3}^{j}
\end{array}\right\}
$$

onde

$$
\bar{c}_{11}=c_{11}-\frac{c_{13}^{2}}{c_{33}}, \bar{c}_{12}=c_{12}-\frac{c_{23}}{c_{33}} c_{13}, \bar{c}_{22}=c_{22}-\frac{c_{23}^{2}}{c_{33}}, \bar{e}_{31}=e_{31}-\frac{c_{13}}{c_{33}} e_{33}, \bar{\epsilon}_{33}=\epsilon_{33}+\frac{e_{33}^{2}}{c_{33}}
$$

tal que $\sigma_{1}, \sigma_{2}, \sigma_{6}$ referem-se às componentes de tensão axiais e cisalhamento no plano e $\varepsilon_{1}, \varepsilon_{2}, \varepsilon_{6}$ e $D_{3}$ às componentes de deformação axiais e cisalhamento e ao deslocamento elétrico transversal, respectivamente.

Ocoplamento eletromecânico nas camadas piezelétricas ocorre novamente entre às deformações axiais e o campo elétrico transversal o que caracteriza o mecanismo de extensão e atuação convencional para materiais piezelétricos. 
Observa-se que embora as deformações variem linearmente ao longo da espessura, o campo elétrico e as tensões não serão contínuos, no entanto, estas ainda assim variam linearmente a cada camada.
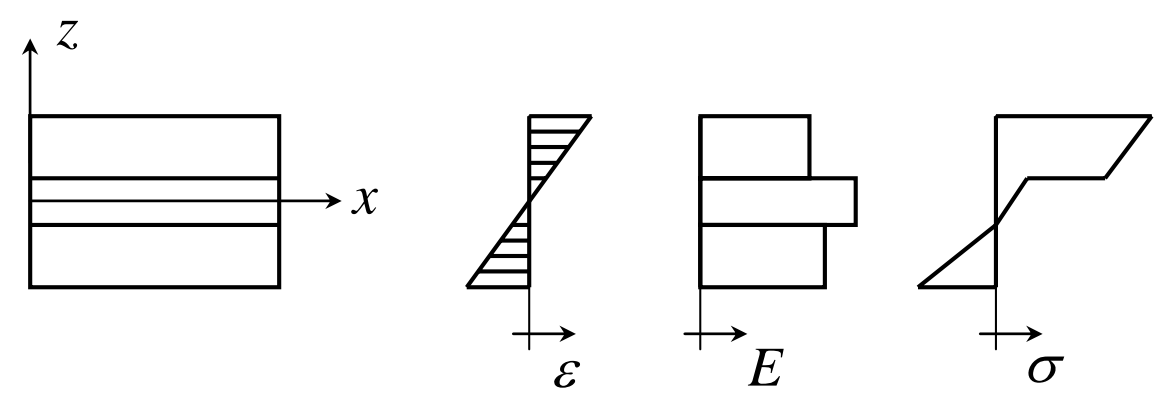

Figura 2.8: Variação da deformação, campo elétrico e tensão em uma placa fina laminada

\subsubsection{FORMULAÇÃO VARIACIONAL}

Utilizando mais uma vez o princípio de d'Alembert, a equação variacional pode ser escrita como:

$$
\delta T-\delta H+\delta W=0, \forall \delta u, \delta v, \delta w, \delta V_{j}
$$

onde $\delta T, \delta H$ e $\delta W$ referem-se ao trabalho virtual das forças de inércia, eletromecânicas e externas, respectivamente.

O trabalho virtual das forças eletromecânicas pode ser escrito da seguinte forma para uma placa laminada:

$$
\delta H=\sum_{j} \delta H_{j}
$$

tal que 


$$
\delta H_{j}=\int_{\Omega_{j}}\left(\sigma_{1}^{j} \delta \varepsilon_{1}+\sigma_{2}^{j} \delta \varepsilon_{2}+\sigma_{6}^{j} \delta \varepsilon_{6}-D_{3}^{j} \delta E_{3}^{j}\right) d \Omega_{j}
$$

e $\Omega_{j}$ simboliza o volume da $j$-ésima camada.

Fazendo uso das equações de deformação (2.43), constitutivas (2.44) e campo elétrico (2.7) e integrando-as ao longo eixo $z$, obtêm-se as seguintes equações para a $j$-ésima camada piezelétrica:

$$
\begin{aligned}
& \delta H_{j}=\int_{A_{j}}\left[\delta u_{, x}\left(\bar{c}_{11}^{j} I_{0}^{j} u_{, x}+\bar{c}_{11}^{j} I_{1}^{j} \beta_{, x}+\bar{c}_{12}^{j} I_{0}^{j} v_{, y}+\bar{c}_{12}^{j} I_{1}^{j} \beta_{, y}+\bar{e}_{31}^{j} I_{0}^{j} \frac{V_{j}}{h_{j}}\right)\right. \\
& +\delta v_{, y}\left(\bar{c}_{12}^{j} I_{0}^{j} u_{, x}+\bar{c}_{12}^{j} I_{1}^{j} \beta_{, x}+\bar{c}_{22}^{j} I_{0}^{j} v_{, y}+\bar{c}_{22}^{j} I_{1}^{j} \beta_{, y}+\bar{e}_{32}^{j} I_{0}^{j} \frac{V_{j}}{h_{j}}\right) \\
& +\delta \beta_{, x}\left(\bar{c}_{11}^{j} I_{1}^{j} u_{, x}+\bar{c}_{11}^{j} I_{2}^{j} \beta_{, x}+\bar{c}_{12}^{j} I_{1}^{j} v_{, y}+\bar{c}_{12}^{j} I_{2}^{j} \beta_{, y}+\bar{e}_{31}^{j} I_{1}^{j} \frac{V_{j}}{h_{j}}\right) \\
& +\delta \beta_{, y}\left(\bar{c}_{12}^{j} I_{1}^{j} u_{, x}+\bar{c}_{12}^{j} I_{2}^{j} \beta_{, x}+\bar{c}_{22}^{j} I_{1}^{j} v_{, y}+\bar{c}_{22}^{j} I_{2}^{j} \beta_{, y}+\bar{e}_{32}^{j} I_{1}^{j} \frac{V_{j}}{h_{j}}\right) \\
& +\delta u_{, y}\left(c_{66}^{j} I_{0}^{j} u_{, y}+c_{66}^{j} I_{0}^{j} v_{, x}+2 c_{66}^{j} I_{1}^{j} \beta_{x y}\right)+\delta v_{, x}\left(c_{66}^{j} I_{0}^{j} u_{, y}+c_{66}^{j} I_{0}^{j} v_{, x}+2 c_{66}^{j} I_{1}^{j} \beta_{x y}\right) \\
& +2 \delta \beta_{x y}\left(c_{66}^{j} I_{1}^{j} u_{, y}+c_{66}^{j} I_{1}^{j} v_{, x}+2 c_{66}^{j} I_{2}^{j} \beta_{x y}\right) \\
& \left.+\frac{\delta V_{j}}{h_{j}}\left(\bar{e}_{31}^{j} I_{0}^{j} u_{, x}+\bar{e}_{32}^{j} I_{0}^{j} v_{, y}+\bar{e}_{31}^{j} I_{1}^{j} \beta_{, x}+\bar{e}_{32}^{j} I_{1}^{j} \beta_{, y}-\bar{\epsilon}_{33}^{j} I_{0}^{j} \frac{V_{j}}{h_{j}}\right)\right] d A_{j}
\end{aligned}
$$

de maneira que

$$
\left[I_{0}^{j}, I_{1}^{j}, I_{2}^{j}\right]=\int_{z_{j}-h_{j} / 2}^{z_{j}+h_{j} / 2}\left[1, z, z^{2}\right] d z
$$

O eixo local $z$ da $j$-ésima camada situa-se no plano médio, de forma que

$$
Z_{j}=\frac{h_{j}^{\text {piezo }}+h^{\text {placa }}}{2}+\sum_{r=1}^{j-1} h_{r}^{\text {piezo }}
$$

Utilizando as relações de deslocamento (2.42) tem-se que: 


$$
\delta T_{j}=-\int_{\Omega_{j}} \rho_{j}(\delta \ddot{u} \ddot{\bar{u}}+\delta \bar{v} \ddot{\bar{v}}+\delta \bar{w} \ddot{\bar{w}}) d \Omega_{j}
$$

Os termos inerciais de acoplamento translacional-rotacional novamente nesta modelagem foram desconsiderados para efeitos de simplificação do modelo.

Por fim, o trabalho virtual das forças axiais e transversais aplicadas em cada camada pode ser escrito novamente da seguinte forma:

$$
\delta W=\sum_{j} \delta W_{j}
$$

\subsubsection{EQUAÇÕES DE MOVIMENTO E DETERMINAÇÃO DA CURVATURA LOCAL}

A partir da Eq. (2.47) é possível observar que para uma diferença de potencial elétrico $V_{j}$ medida na $j$-ésima camada piezelétrica, o variacional $\delta V_{j}$ anula-se, o que resulta em:

$$
\bar{e}_{31}^{j} I_{0}^{j} u_{, x}+\bar{e}_{32}^{j} I_{0}^{j} v_{, y}+\bar{e}_{31}^{j} I_{1}^{j} \beta_{, x}+\bar{e}_{32}^{j} I_{1}^{j} \beta_{, y}-\bar{\epsilon}_{33}^{j} I_{0}^{j} \frac{V_{j}}{h_{j}}=0
$$

Logo, considerando o material piezelétrico transversalmente isotrópico $\left(\bar{e}_{31}^{j}=\bar{e}_{32}^{j}\right)$, a diferença de potencial pode ser escrita da seguinte maneira:

$$
V_{j}=\frac{\bar{e}_{31}^{j}}{\bar{\epsilon}_{33}^{j}} h_{j}\left(u_{, x}+v_{, y}\right)+\frac{\bar{e}_{31}^{j}}{\bar{\epsilon}_{33}^{j}} \frac{I_{1}^{j}}{I_{0}^{j}} h_{j}\left(\beta_{, x}+\beta_{, y}\right)
$$

ou então,

$$
V_{j}=\frac{\bar{e}_{31}^{j} h_{j}}{\bar{\epsilon}_{33}^{j}}\left(u_{, x}+v_{, y}-\frac{I_{1}^{j}}{I_{0}^{j}} \nabla^{2} w\right)
$$

onde $\nabla^{2} w$ representa o Laplaciano de $w$, ou seja: $\nabla^{2} w=\partial^{2} w / \partial x^{2}+\partial^{2} w / \partial y^{2}$. 
A Eq. (2.54) explicita a razão da utilização de sensores bimorph. Com apenas uma única camada piezelétrica não seria possível a determinação da voltagem apenas conhecendo-se a curvatura média local $\nabla^{2} w$, pois esta é dependente também dos deslocamentos axiais. No entanto, utilizando-se um par de pastilhas piezelétricas idênticas $\left(\bar{e}_{31}^{j}=\bar{e}_{31}\right.$ e $\left.\bar{\epsilon}_{33}^{j}=\bar{\epsilon}_{33}\right)$, coladas uma sobre a outra, é possível assumir que

$$
V_{2}-V_{!}=-\frac{\bar{e}_{31} h_{p}}{\bar{\epsilon}_{33}}\left(\frac{I_{1}^{1}}{I_{0}^{1}}-\frac{I_{1}^{2}}{I_{0}^{2}}\right) \nabla^{2} w
$$

Considera-se ainda que as camadas piezelétricas possuam as mesmas espessuras e dimensões laterais (ver Figura 2.9).

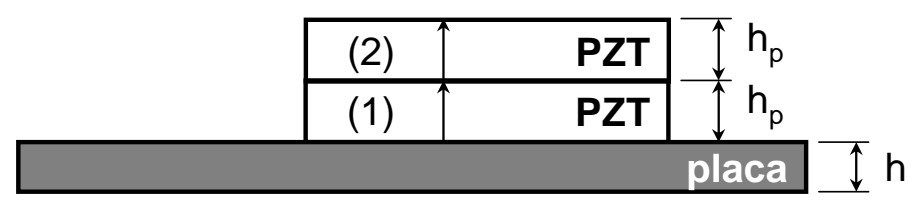

Figura 2.9: Polarização e numeração das camadas piezelétricas para placas

A partir da Eq. (2.48) e da suposição acima, pode se escrever que

$$
\begin{gathered}
I_{0}^{1}=\int_{h / 2}^{h / 2+h_{p}} 1 d z=h_{p} \text { e } I_{0}^{2}=\int_{h / 2+h_{p}}^{h / 2+2 h_{p}} 1 d z=h_{p} \\
I_{1}^{1}=\int_{h / 2}^{h / 2+h_{p}} z d z=\frac{h_{p}}{2}\left(h+h_{p}\right) \text { e } I_{1}^{2}=\int_{h / 2+h_{p}}^{h / 2+2 h_{p}} z d z=\frac{h_{p}}{2}\left(h+3 h_{p}\right)
\end{gathered}
$$

Logo,

$$
V_{2}-V_{1}=-\frac{\bar{e}_{31} h_{p}^{2}}{\bar{\epsilon}_{33}} \nabla^{2} w
$$

Finalmente, a curvatura média local pode ser associada com a voltagem resultante medida diretamente de cada bimorph através da seguinte relação: 


$$
\nabla^{2} w(x, y, t)=-\frac{\bar{\epsilon}_{33}}{\bar{e}_{31} h_{p}^{2}}\left[V_{2}(t)-V_{1}(t)\right]
$$

Novamente, o princípio básico de funcionamento do transdutor bimorph consiste na obtenção da diferença entre os potencias elétricos oriundos de cada pastilha piezelétrica. A determinação da rotação, por sua vez, para um determinado ponto $(x, y)=\left(x_{\text {out }}, y_{\text {out }}\right)$ de interesse na placa ocorre através de um processo de ajuste considerando o respectivo campo de deslocamentos.

\subsubsection{DETERMINAÇÃO DAS FORMAS MODAIS POR RAYLEIGH-RITZ}

No cálculo variacional, procura-se a função $y(x, y)$ que dentre todas as funções admissíveis é a solução exata para minimizar um determinado funcional.

No método de Rayleigh-Ritz, a função $y(x, y)$ (suposta exata) propõe uma solução aproximada, formada por uma combinação linear de funções $\bar{\phi}_{i}(x, y)$ para resolver o problema de elasticidade em sua formulação energética.

Neste trabalho, a determinação das formas modais para a estrutura do tipo placa será dada através do método de Rayleigh-Ritz da seguinte forma:

$$
\phi(x, y)=\sum_{i=1}^{k} a_{i} \bar{\phi}_{i}(x, y)=\{a\}^{T}\{\bar{\phi}\}
$$

As funções $\bar{\phi}_{i}(x, y)$, denominadas funções de forma ou funções de Ritz, devem ser linearmente independentes e satisfazerem individualmente as condições de contorno, além de serem contínuas até o grau $m-1$, sendo $m$ a ordem da maior derivada do funcional. Os coeficientes $a_{i}$, a serem determinados, são denominados parâmetros de deslocamentos. 
Esta solução em conjunto com as equações de Lagrange pode ser utilizada para obter uma formulação aproximada da equação do movimento do sistema. Logo, a energia potencial $U$ e cinética $T$ devem ser determinadas.

A energia potencial pode ser escrita da seguinte forma (MEIROVITCH, 1970):

$$
U=\frac{1}{2} \int_{\Omega} D_{E}\left\{\left(\nabla^{2} w\right)^{2}+2(1-v)\left[\left(\frac{\partial^{2} w}{\partial x \partial y}\right)^{2}-\frac{\partial^{2} w}{\partial x^{2}} \frac{\partial^{2} w}{\partial y^{2}}\right]\right\} d \Omega
$$

onde $D_{E}=E h^{3} / 12\left(1-v^{2}\right)$ e $v$ o coeficiente de Poisson.

Considerando a aproximação por Rayleigh-Ritz, pode-se escrever a energia potencial da seguinte maneira:

$$
U=\frac{1}{2} D_{E}\{a\}^{T}\left[\iint \nabla^{2}\{\bar{\phi}\} \nabla^{2}\{\bar{\phi}\}^{T} d x d y\right]\{a\}=\frac{1}{2}\{a\}^{T}[K]\{a\}
$$

A energia cinética pode ser escrita simplesmente da seguinte forma (MEIROVITCH, 1970)

$$
T=\frac{1}{2} \int_{\Omega} m \dot{w}^{2} d \Omega
$$

ou então

$$
T=\frac{1}{2} \rho h\{a\}^{T}\left[\iint\{\bar{\phi}\}\{\bar{\phi}\}^{T} d x d y\right]\{a\}=\frac{1}{2}\{a\}^{T}[M]\{a\}
$$

Como os modos normais de vibração por definição estão associados a um sistema conservativo, podem-se considerar as equações de Lagrange para tais sistemas como:

$$
\frac{d}{d t}\left(\frac{\partial T}{\partial \dot{q}_{i}}\right)-\frac{\partial T}{\partial q_{i}}+\frac{\partial U}{\partial q_{i}}=Q_{i}
$$


onde $q_{i}$ representa a $i$-ésima coordenada generalizada e $Q_{i}$ a $i$-ésima força generalizada.

Logo, substituindo as equações (2.60) e (2.62) na equação (2.63)(2.72), obtém-se as equações do movimento escritas na forma matricial:

$$
[M]\{\ddot{q}\}+[K]\{q\}=\{0\}
$$

Além disso, lembrando que para o modo normal de vibração, a dependência temporal de $\{q(t)\}$ é harmônica, tem-se um problema de autovalor dado por

$$
\{a\}^{T}\left([K]-\omega^{2}[M]\right)=0
$$

A solução do autoproblema resulta em $k$ autovalores $\omega_{r}^{2}$, vistos como as freqüências naturais estimadas, e seus $k$ autovalores associados $\{a\}_{r}(r=1,2, \ldots, k)$.

Assim, as formas modais podem ser descritas da seguinte maneira:

$$
\phi_{r}(x, y)=\{a\}_{r}^{T}\{\bar{\phi}\}
$$

A escolha adequada das funções $\bar{\phi}_{i}(x, y)$ é determinante para se obter uma boa aproximação para a solução do problema. As funções aproximadoras mais comumente utilizadas são polinomiais e trigonométricas.

Para o problema da placa aqui em estudo adotou-se funções de forma que representam a descrição geométrica do $i$-ésimo modo de vibrar para uma placa fina isotrópica simplesmente apoiada. Logo,

$$
\bar{\phi}_{i}(x, y)=\sin \left(\frac{m \pi}{L_{x}}\right) \sin \left(\frac{n \pi}{L_{y}}\right)
$$


onde $m$ e $n$ retratam o número de meias ondas, assim como, $L_{x}$ e $L_{y}$ remetem às dimensões da placa nas direções $x$ e $y$, respectivamente.

\subsubsection{APROXIMAÇÃO DO CAMPO DE DESLOCAMENTOS POR FORMAS MODAIS}

Utilizando formas modais, tem-se que o campo de deslocamentos pode ser aproximado da seguinte forma:

$$
w(x, y, \omega)=\sum_{i=1}^{m} \alpha_{i}(\omega) \phi_{i}(x, y)
$$

Os coeficientes $\alpha_{i}(\omega)$, descritos agora no domínio da freqüência $\omega$, podem ser determinados impondo-se as curvaturas locais obtidas através das voltagens induzidas em cada bimorph, em um total de $n$ sensores distribuídos sobre a placa, para cada incremento na freqüência $\omega_{i}$. Desta forma, tendo assumido a colocação de $n$ bimorphs, o número de modos a serem utilizados neste método de aproximação para o campo de deslocamentos é igual a $k=n$, dado que as condições de contorno já estão embutidas na definição dos modos aproximados $\phi_{i}(x, y)$ escolhidos.

Logo, de acordo com a equação (2.68), o seguinte sistema pode ser escrito:

$$
\left[Q_{R R}\right]\{\alpha\}=\{c\}
$$

onde 


$$
Q_{R R}=\left[\begin{array}{cccc}
\nabla^{2} \phi_{1}\left(x_{b 1}, y_{b 1}\right) & \nabla^{2} \phi_{2}\left(x_{b 1}, y_{b 1}\right) & \ldots & \nabla^{2} \phi_{n}\left(x_{b 1}, y_{b 1}\right) \\
\nabla^{2} \phi_{1}\left(x_{b 2}, y_{b 2}\right) & \nabla^{2} \phi_{2}\left(x_{b 2}, y_{b 2}\right) & \ldots & \nabla^{2} \phi_{n}\left(x_{b 2}, y_{b 2}\right) \\
\vdots & \vdots & \vdots & \vdots \\
\nabla^{2} \phi_{1}\left(x_{b n}, y_{b n}\right) & \nabla^{2} \phi_{2}\left(x_{b n}, y_{b n}\right) & \ldots & \nabla^{2} \phi_{n}\left(x_{b n}, y_{b n}\right)
\end{array}\right]
$$

e

$$
\begin{gathered}
\{\alpha\}^{T}=\left\{\begin{array}{llll}
\alpha_{1}\left(\omega_{i}\right) & \alpha_{2}\left(\omega_{i}\right) & \cdots & \alpha_{n}\left(\omega_{i}\right)
\end{array}\right\} \\
\{c\}^{T}=\left\{\begin{array}{llll}
\nabla^{2} w_{b 1}\left(\omega_{i}\right) & \nabla^{2} w_{b 2}\left(\omega_{i}\right) & \cdots & \nabla^{2} w_{b n}\left(\omega_{i}\right)
\end{array}\right\}
\end{gathered}
$$

Portanto, a rotação $w^{\prime}(x, y, \omega)$ pode ser aproximada neste caso considerandose a equação (2.68).

\subsubsection{ELEMENTOS FINITOS}

O software Ansys $^{\circledR}$ (Release 10.0) foi utilizado na modelagem estrutural, análise da resposta modal e tensões elétricas induzidas pelo acoplamento eletromecânico em um sistema do tipo placa-bimorphs. O modelo utilizado consiste de uma placa retangular e um conjunto de pastilhas cerâmicas piezelétricas coladas duas a duas entre elas constituindo os sensores bimorphs e à superfície da placa.

O elemento estrutural SHELL99 foi utilizado na modelagem da placa, na forma quadrangular em camada única. Este elemento apresenta propriedades de linearidade e isotropia, com oito nós no seu plano médio e seis graus de liberdade por nó: deslocamentos UX, UY e UZ e rotações ROTX, ROTY e ROTZ nas direções $x$, $y$ e $z$, respectivamente (Figura 2.10).

O elemento SOLID226 foi adotado na modelagem das pastilhas piezelétricas que constituem os sensores bimorph. Este elemento apresenta potencialidade de 
acoplamento estrutural-térmico, térmico-elétrico, estrutural-termoelétrico, térmicopiezelétrico ou puramente piezelétrico e piezoresistivo.
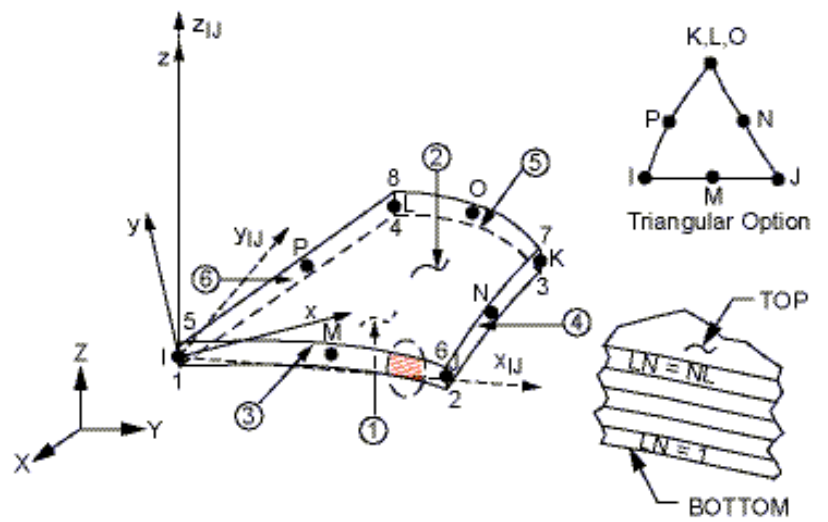

Figura 2.10: Elemento SHELL99 utilizado na modelagem via elementos finitos

No formato cúbico puramente piezelétrico aqui utilizado é composto por 20 nós, sendo 8 por face, com nós comuns nos vértices e quatro graus de liberdade por nó: deslocamentos UX, UY e UZ, tensão elétrica VOLT (Figura 2.11).
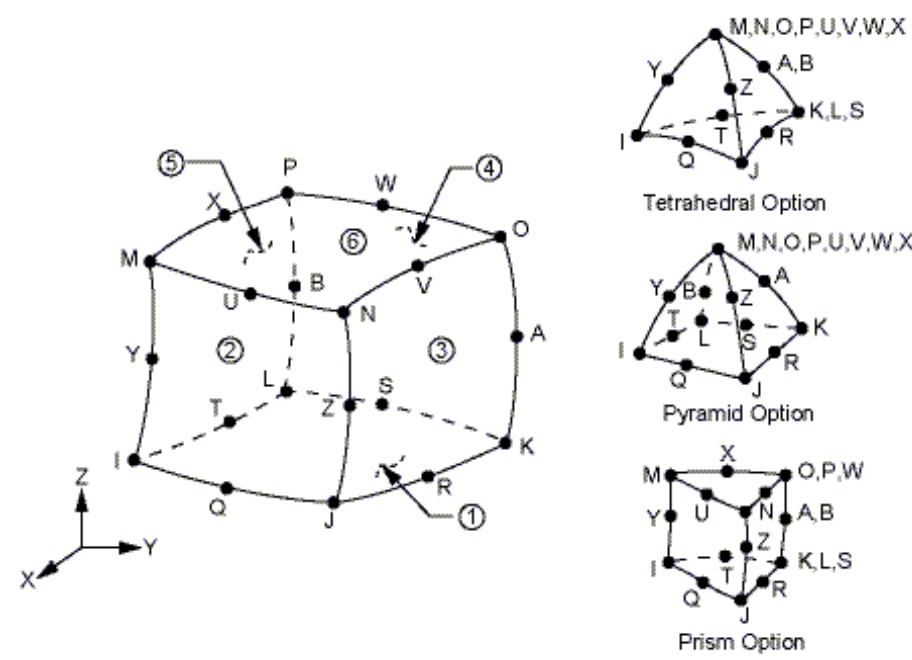

Figura 2. 11: Elemento SOLID226 utilizado na modelagem via elementos finitos

As malhas da placa e das pastilhas definem um reticulado uniforme de elementos com dimensões unitárias de $5 \times 5 \times 3 \mathrm{~mm}$ e $5 \times 5 \times 2,5 \mathrm{~mm}$, respectivamente. 
Observou-se que uma discretização ao longo da espessura das pastilhas em ao menos duas camadas de elementos sobrepostos propicia uma correta leitura da tensão elétrica (PAGANI JR; TRINDADE, 2007).

No modelo considerado, ambos os elementos possuem oito nós coplanares. elemento SHELL99 permite ainda que os nós, a partir de seu plano médio, sejam deslocados para a superfície do topo da placa, permanecendo assim, em um plano comum aos nós da base de cada pastilha em contato.

As pastilhas foram posicionadas de maneira que seus nós estejam verticalmente alinhados aos da placa, sendo possível a utilização do comando Merge. Este comando é responsável por acoplar mecanicamente cada nó do elemento SHELL99 ao nó adjacente do elemento SOLID226. Seu efeito prático é a colagem dos materiais, na medida em que transforma dois nós em um único e acopla os graus de liberdade comuns: as translações em $x, y$ e $z$.

Para a definição das condições elétricas dos sensores bimorphs, utilizou-se a configuração em paralelo, cuja leitura da tensão elétrica resultante é dada pelo eletrodo do meio (ver Figura 2.3a) com o aterramento dos nós das superfícies inferior e superior de cada bimorph. Deve-se considerar também que o potencial elétrico é invariante na superfície, o que é conseguido com a condição de equipotencialidade nas superfícies superior e inferior de cada camada piezelétrica. 


\section{OTIMIZAÇÃO GEOMÉTRICA DOS SENSORES BIMORPHS}

Este capítulo trata dos fundamentos, elementos e operadores utilizados no procedimento de otimização via Algoritmo Genético (AG) desenvolvido para a determinação do melhor posicionamento e dimensão de sensores bimorphs aplicados a estruturas do tipo viga.

\subsection{FUNDAMENTOS}

Algoritmos genéticos são ferramentas de busca baseadas em teorias de genética e da seleção natural de Charles Darwin. São técnicas de inteligência artificial utilizadas na pesquisa por soluções em domínios extensos para os quais uma busca através da varredura do domínio demandaria um grande esforço desnecessário (GOLDBERG, 1989).

Entre os métodos de otimização mais comuns pode-se dizer que as diferenças básicas são: i) AGs não trabalham com parâmetros de otimização em si, mas com uma codificação destes; ii) AGs não procuram um único ponto, mas sim uma população de pontos; iii) AGs utilizam informações de funções objetivo (fitness) e, finalmente, iv) AGs utilizam regras de transição probabilísticas e não determinísticas.

A otimização por AG parte de um conjunto inicial de soluções do problema proposto, as quais são codificadas para descrever as características do sistema. A manipulação desses elementos é feita de maneira a imitar os processos de seleção e 
evolução dos seres vivos na natureza, através de operadores típicos de genética, descritos a seguir.

\subsection{TERMOS E OPERADORES TíPICOS EM ALGORITIMOS GENÉTICOS}

Alguns termos são freqüentemente utilizados quando se trata de AGs por definirem os seus elementos de trabalho. Todos têm sua origem nas teorias de genética e entre eles destacam-se:

- População: conjunto de indivíduos que representam soluções para o problema a ser tratado;

- Indivíduo: um elemento da população descrito (codificado) através de um cromossomo;

- Cromossomo: código que descreve as características de cada indivíduo, sendo cada uma destas características relacionadas em um gene;

- Gene: trecho de um cromossomo ligado a uma característica do indivíduo;

- Função de avaliação (fitness): trata-se da função de custo no ambiente de otimização. Seu valor reproduz a aptidão e define o quanto o indivíduo é apto a sobreviver no meio em que vive.

Em todo processo de otimização através de algoritmos genéticos, seus elementos (indivíduos, genes e cromossomos) são manipulados através de operadores. O AG desenvolvido neste trabalho para a otimização dos sensores bimorph utiliza operadores baseados nos processos naturais da genética de seres vivos: seleção, reprodução, mutação e elitismo. 
Neste trabalho, pela simplicidade e capacidade de gerar bons, adotou-se uma codificação binária (0 ou 1) dos indivíduos.

\subsubsection{OPERADOR DE SELEÇÃO}

A seleção consiste na escolha de indivíduos (pais), representados por seus cromossomos, de acordo com seus valores da função custo, pois esta traduz a aptidão de cada solução (indivíduos). Os indivíduos mais aptos terão maiores probabilidades de contribuírem geneticamente para as gerações seguintes.

operador de seleção pode ser entendido como uma versão artificial da seleção natural das espécies de Darwin, onde os mais aptos tendem a permanecer e os menos aptos tendem a desaparecer com o decorrer das gerações.

Em termos computacionais, a maneira mais comum de se programar a seleção é através da chamada roda de roleta (roulette wheel). Conceitualmente, este mecanismo funciona como as rodas de roletas de cassinos. Os indivíduos pais são colocados na roda, para que esta, quando girada, pare em uma posição qualquer e defina qual será o pai escolhido (GOLDBERG, 1989). Na roda, a região ocupada por cada indivíduo é proporcional ao seu valor resultante da avaliação através da função de custo. Define-se assim, a probabilidade dos indivíduos serem escolhidos como pais para as próximas gerações (CAO e WU, 1999).

\subsubsection{OPERADOR DE REPRODUÇÃO}

A reprodução é um dos principais operadores em um algoritmo genético e para tal utiliza-se o cruzamento (crossover). Ele é o responsável por transmitir aos 
filhos características dos pais, uma vez que, divide os cromossomos dos pais, troca parte deles e os recombina gerando novos cromossomos (filhos). A Figura 3.1 ilustra o conceito deste operador.

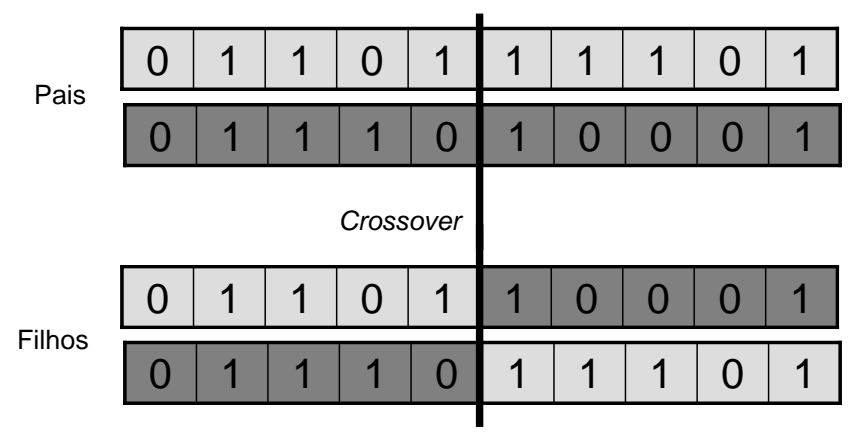

Figura 3.1: Funcionamento do operador de reprodução (crossover)

A seleção dos pais é feita através da roda de roleta, descrita anteriormente no operador de seleção. Optou-se aqui por uma seleção aleatória do ponto de troca do material genético e até o presente momento, 5 pontos de troca podem ser selecionados de acordo com o número de bimorphs: dois pontos de troca a cada bimorph presente na otimização.

\subsubsection{OPERADOR DE MUTAÇÃO}

A mutação é responsável pela diversificação da população, permitindo que se trabalhe com indivíduos de áreas distintas do domínio de soluções, o que adiciona robustez ao método de otimização. Através da mutação, pode-se também atenuar uma possível perda de material genético valioso que tenha ocorrido no decorrer da formação de novas gerações.

O funcionamento da mutação é bem simples no caso de indivíduos (cromossomos) codificados binariamente: a partir de uma probabilidade de 
ocorrência de mutação um elemento do cromossomo é escolhido aleatoriamente e este é trocado por zero (0) no caso de ser um (1) e vice versa (ver Figura 3.2).

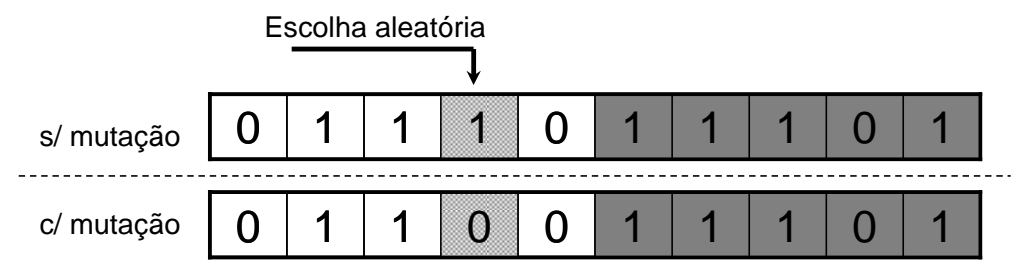

Figura 3.2: Funcionamento do operador de mutação

\subsubsection{OPERADOR DE ELITISMO}

operador de elitismo foi incluído, pois com a evolução das gerações, bons indivíduos pais podem gerar filhos piores que eles mesmos. Desta maneira, a nova geração pode deixar de herdar boas características. Pela simples geração de filhos através dos operadores descritos anteriormente, não se pode garantir que os melhores indivíduos permaneçam nas gerações futuras.

Por sua vez, o operador de elitismo tem por função manter os melhores indivíduos ao longo da evolução das gerações e, assim, melhorar o desempenho do algoritmo genético (DE JONG, 1975).

\subsection{FUNCIONAMENTO DO ALGORITMO GENÉTICO}

funcionamento do AG proposto neste trabalho parte de uma população inicial de soluções do problema, as quais são codificadas em cromossomos. 0 processo continua baseado em operações probabilísticas que lembram as etapas típicas da seleção, reprodução e por sua vez, evolução dos seres vivos. Cruzamentos entre indivíduos (pais) na geração de novos indivíduos (filhos) correspondem a um 
procedimento intrínseco da evolução. Como resultado, os filhos possuem em seus cromossomos as características genéticas de seus pais, que serão transmitidas para as futuras gerações, representadas aqui por iterações na busca pela solução ótima global. Na concepção dos filhos, tem-se ainda a importante presença do operador de mutação, responsável pela alteração dos genes do indivíduo.

No decorrer das gerações (iterações), os indivíduos mais aptos sobrevivem, ou seja, as melhores soluções permanecem na população, enquanto que os menos aptos são descartados. A Figura 3.3 ilustra a seqüência do AG.

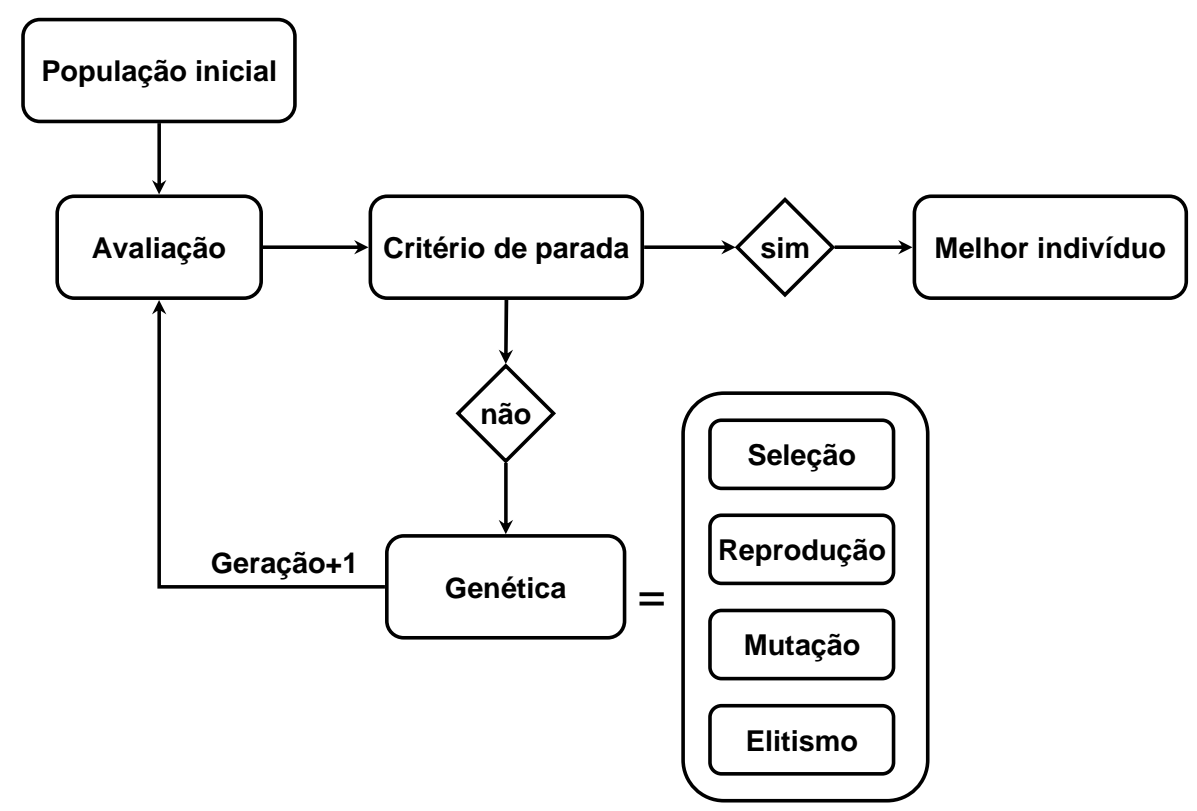

Figura 3.3: Diagrama de blocos do AG

Como visto anteriormente, a genética é responsável pela seleção, reprodução, mutação e elitismo dos indivíduos da população

A cada nova geração (processo evolutivo), uma nova população corresponde a uma busca no domínio das possíveis soluções. O AG pertence a uma categoria de métodos de busca que consegue um balanço necessário entre dois objetivos 
aparentemente dispares: i) obter as melhores soluções e ii) explorar o espaço de busca.

\subsection{O AG NA OTIMIZAÇÃO (ESTRUTURAS DO TIPO VIGA)}

A Figura 3.4 ilustra os parâmetros utilizados no algoritmo genético aplicado a estruturas do tipo viga: $n$ bimorphs posicionados em $x_{b 1}$ a $x_{b n}$ e dimensões $s_{b 1}$ a $s_{b n}$, respectivamente, podem ser dispostos ao longo da viga ( $x=0$ na região de engaste).

Fixado o número de bimorphs que se deseja para a análise, o algoritmo genético tem por objetivo determinar as posições e dimensões que representam um indivíduo com a melhor aptidão possível.

De acordo com os métodos de aproximação vistos, quanto maior o número de bimorphs, maior é o grau do polinômio na aproximação polinomial e maior é o número de modos utilizados na aproximação por formas modais.

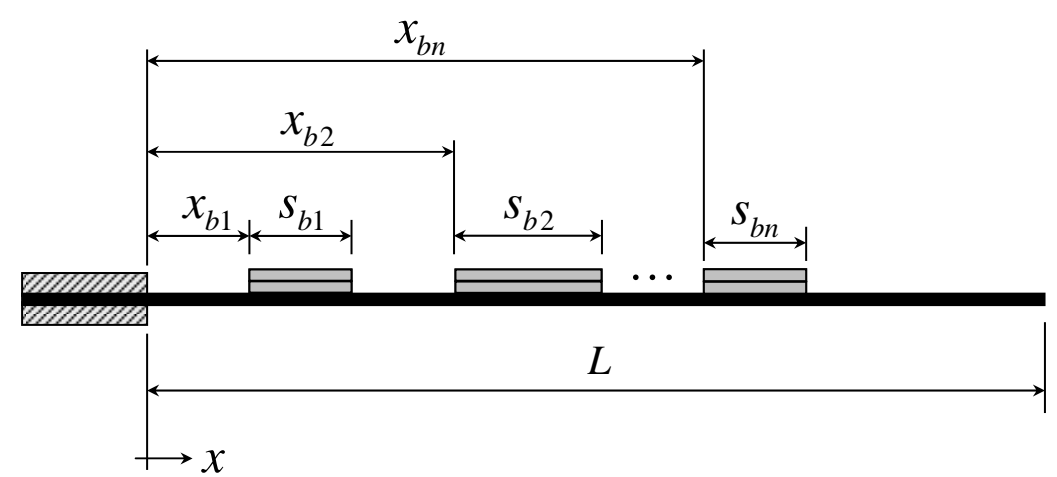

Figura 3.4: Parâmetros de otimização em estruturas do tipo viga 


\subsubsection{CODIFICAÇÃO DAS VARIÁVEIS}

A codificação destas variáveis pode ser feita de inúmeras maneiras, sendo que a mais comum delas é a representação através de uma base binária (GOLDBERG, 1989). Para este padrão de codificação, cada parâmetro é traduzido com um número binário e disposto seqüencialmente ao longo do cromossomo.

No caso deste algoritmo genético em específico, um cromossomo é composto pela seqüência dos valores relativos ao tamanho do transdutor e à posição do mesmo na viga. Cada um desses valores (genes) é incluído nos cromossomos como valores binários.

Experimentalmente, entende-se que a precisão de corte da pastilha piezelétrica e a unidade de posicionamento ao longo da viga não devam ser inferiores a $1 \mathrm{~mm}$. Sendo assim, o valor do tamanho de cada bimorph foi codificado com 6 dígitos e o valor da posição com 8 dígitos, totalizando um cromossomo de 14 dígitos por bimorph. Logo, o tamanho final do cromossomo é dado por 14n dígitos.

A Figura 3.5 apresenta uma ilustração de como os genes são organizados ao longo do cromossomo para um indivíduo arbitrário.

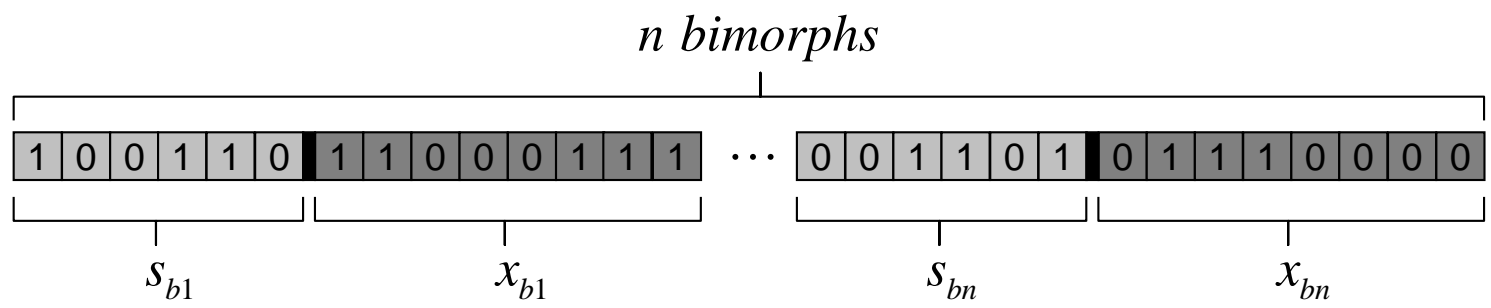

Figura 3.5: Codificação utilizada na montagem dos cromossomos

Desta forma, explica-se o motivo do número de bimorphs não fazer parte do processo de otimização, pois, se cada indivíduo representasse um número de 
bimorphs distinto dentro de uma mesma população, ocorreria durante as operações genéticas à troca de material genético entre cromossomos de tamanhos diferentes.

Para operar com os cromossomos durante as fases de avaliação do AG, é preciso decodificar os seus respectivos valores binários em grandezas físicas que correspondam aos intervalos de funcionamento dos parâmetros de otimização. Dentro desta metodologia, é possível estabelecer uma regra matemática que decodifique cada parâmetro em termos de valores reais (GOLDBERG, 1989). Logo, tem-se que:

$$
\begin{aligned}
& V_{\text {tamanho }}=\frac{(68-5)}{63} * D_{\text {tamanho }}+5=1 * D_{\text {tamanho }}+5 \\
& V_{\text {posição }}=\frac{(500-15)}{255} * D_{\text {posição }}+15=1,9 * D_{\text {posição }}+15
\end{aligned}
$$

onde $D_{\text {tamanho }}$ e $D_{\text {posição }}$ são os valores dos genes binários convertidos para a base decimal.

Os valores entre parênteses na Eq. (3.1) representam os intervalos de valores admissíveis para o problema, ou seja, no caso do tamanho do sensor um intervalo de 5 a $68 \mathrm{~mm}$ com uma variação de $1 \mathrm{~mm}$ e no caso da posição, um intervalo de 15 a $500 \mathrm{~mm}$ e um passo de aproximadamente $2 \mathrm{~mm}$.

\subsubsection{FUNÇÃO DE AVALIAÇÃO}

A avaliação de cada indivíduo durante o processo de otimização com o AG é dada através do cálculo da função de avaliação (fitness). Esta função deve ser definida visando privilegiar os indivíduos de uma população que tenham características desejáveis sobre os outros. Nela devem estar presentes as variáveis que 
resultam dos modelos matemáticos utilizados na avaliação. Em alguns casos, pode ser necessária também a criação de restrições de operação ou penalidades, para adequação aos modelos ou às condições de contorno do problema em estudo.

Buscou-se utilizar uma função de fitness que traduzisse a diferença (erro) entre a função de resposta em freqüência angular obtida através do sensor bimorph em comparação à FRFA oriunda do modelo em elementos.

Dois métodos são comumente referenciados na literatura ao se efetuar a comparação entre duas curvas: o método da área e o método do desvio (CHEN; WEI, 1984). Para o método da área, a diferença entre duas curvas é expressa pela distância média entre elas, porém, nenhuma informação a respeito da similaridade entre as formas é considerada. No segundo método, o valor do desvio expressa a similaridade das formas, ao passo que a distância é negligenciada. Desta forma, atribuindo-se características de ambos os métodos, um termo global (erro), onde a distância e a diferença de forma devem ser as mínimas possíveis pode ser escrito da seguinte maneira:

$$
\text { erro }=\frac{\left|\sum \Delta D_{i}\right|}{N}+\left[\frac{\sum\left(\left|\Delta D_{i}\right|-\Delta D\right)^{2}}{N-1}\right]^{1 / 2}
$$

onde $\Delta D_{i}=R F R F_{i}^{\text {bimorph }}-R F R F_{i}^{\text {fem }}, \Delta D=\left(\sum \Delta D_{i}\right) / N$ e $N$ representa o número de pontos calculados no domínio da freqüência e RFRF as funções de resposta em freqüência angulares.

Logo, cada indivíduo (cromossomo) da população será avaliado de acordo com a tradução de seus genes (dimensões e posições dos bimorphs ao longo da 
estrutura) e em curvas de funções de resposta em freqüência angulares, utilizadas no cálculo da função de fitness. 


\section{RESULTADOS}

Neste capítulo apresentam-se os resultados numéricos e experimentais da utilização de sensores bimorphs na determinação de funções de resposta em freqüência angulares (FRFAs), um estudo a cerca dos métodos de aproximação vistos anteriormente e a avaliação de parâmetros que afetam diretamente o desempenho do AG no caso de estruturas do tipo viga. Para a estrutura do tipo placa, apresentamse os resultados numéricos, bem como, uma avaliação do método de aproximação proposto.

\subsection{ESTRUTURAS DO TIPO VIGA}

Como visto anteriormente, é possível aproximar a rotação em um ponto qualquer $x_{\text {out }}$ utilizando-se um ou vários sensores bimorphs. Para tal, um programa denominado de bimorph foi elaborado em conjunto ao toolbox HDBT desenvolvido pelo Prof. Dr. Marcelo Areias Trindade em ambiente Matlab ${ }^{\circledR}$.

A Figura 4.1 traduz no formato de diagrama de blocos as etapas envolvidas no procedimento de cálculo que compõe o conjunto de funções desenvolvidas.

programa pode ser resumido da seguinte forma: os dados de entrada (propriedades físicas dos materiais e parâmetros de configuração), contidos em um arquivo de entrada, são lidos e analisados pelo programa. Após a leitura deste arquivo, o programa se encarrega de gerar a malha em elementos finitos automaticamente de 
acordo com a dimensão mínima adotada para os elementos e a calcular a resposta no tempo do bimorph para uma dada excitação.

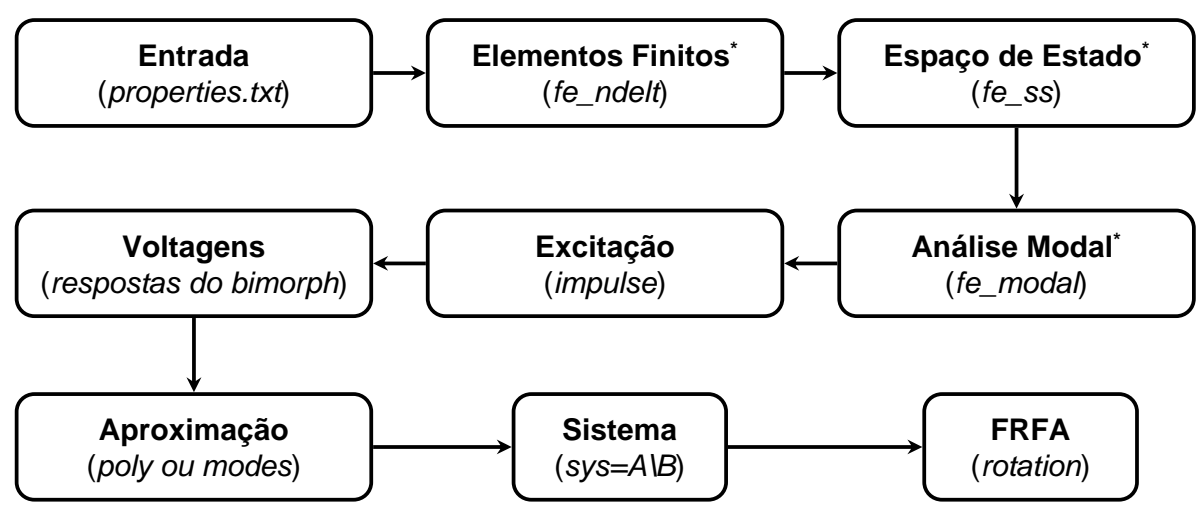

* Rotinas de cálculo do toolbox do Prof. Dr. Marcelo A. Trindade

Figura 4. 1. Diagrama de blocos do toolbox

Estas respostas são traduzidas em termos da variação no tempo da voltagem medida em cada bimorph. Por fim, através dos métodos de aproximação vistos (polinomial e formas modais), o programa estima as FRFs angulares para um determinado ponto da estrutura.

A Figura 4.2 ilustra as respostas no tempo em termos de voltagem de cada pastilha piezelétrica, assim como, a diferença entre as tensões fornecidas pelo sensor para uma entrada do tipo impacto na extremidade livre da viga.

A partir da resolução do sistema de equações (2.33) ou (2.38) torna-se possível obter o deslocamento transversal e a rotação para cada instante de tempo, de acordo com o modelo de aproximação adotado. Por fim, a determinação da correspondente FRFA ocorre com a transformação da resposta temporal da rotação e da excitação a qual a estrutura foi submetida para o domínio da freqüência através da transformada de Fourier. 


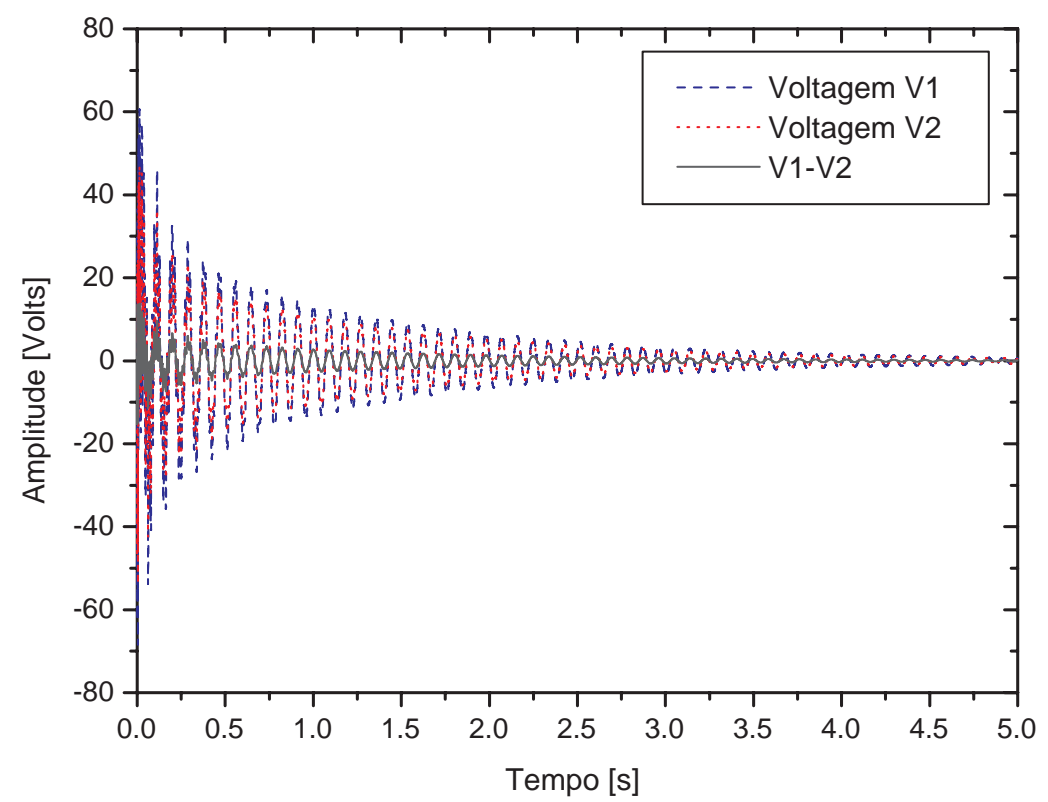

Figura 4.2: Resposta no tempo de cada pastilha cerâmica de um bimorph e a voltagem resultante a ser medida

Para todas as avaliações aqui apresentadas, considerou-se uma viga em alumínio $\left(E=69,9 G P a\right.$ e $\left.\rho=2400 \mathrm{~kg} / \mathrm{m}^{3}\right)$ de dimensões $500 \times 25 \times 3 \mathrm{~mm}^{3}$ na condição cantilever e cuja excitação ocorre na extremidade oposta à região de engaste (ver Figura 4.3).

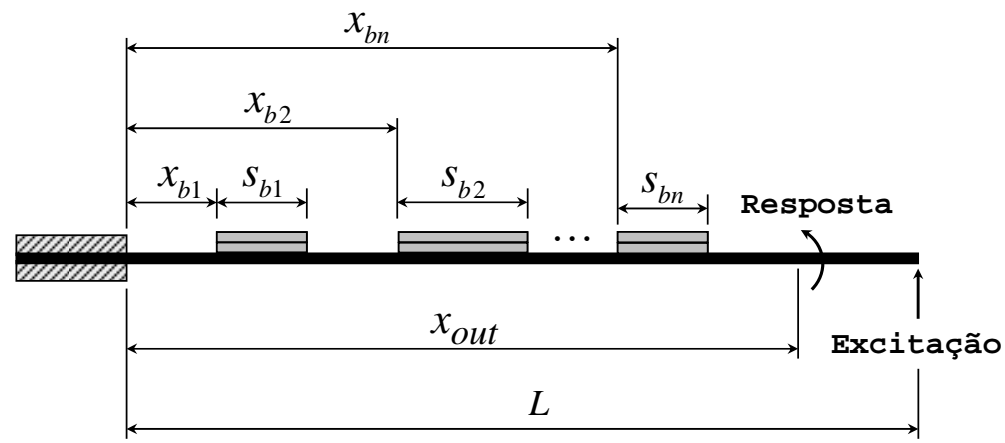

Figura 4.3. Configuração numérica adotada nas simulações

Como excitação para a estrutura, considerou-se sempre uma entrada do tipo impulsiva de valor unitário. 
Para o bimorph, fez-se uso de pastilhas piezelétricas do tipo PZT-5H cujas propriedades físicas são, respectivamente, $\bar{c}_{11}=65,5 G P a, \quad \rho=7500 \mathrm{~kg} / \mathrm{m}^{3}$, $\bar{e}_{31}=-23,2 C / \mathrm{m}^{2}$ e $\bar{\epsilon}_{33}=1,54 \times 10^{-8} \mathrm{~F} / \mathrm{m}$.

\subsubsection{AVALIAÇÃO DOS MÉTODOS DE APROXIMAÇÃO}

Como visto anteriormente, dois métodos de aproximação no estudo de estruturas do tipo viga foram propostos: polinomial e formas modais. No caso da aproximação polinomial, a ordem do polinômio que aproxima a rotação é igual $n+2$, enquanto que se utiliza para a aproximação por formas modais $n+2$ modos de vibrar traduzidos por polinômios de ordem $p-1$, onde $n$ é o número de bimorphs presentes.

É importante avaliar cada método de aproximação de maneira que seja possível explicitar o melhor, tendo em vista o processo de otimização. Para tal, inicialmente, fez-se uma varredura da viga e do posicionamento de um único bimorph. A Figura 4.4 ilustra no formato de superfícies a sensibilidade dos resultados em termos da variação do erro, Eq. (3.2), em termos da mudança de posição e tamanho do sensor bimorph para um ponto de leitura da resposta estrutural posicionado em $50 \mathrm{~mm}$. Nota-se que a diferença nos resultados para os dois métodos é sutil quando se analisa as superfícies. Desta forma, apresenta-se na Figura 4.5 uma secção da Figura 4.4 no intuito de comparar os dois métodos para o caso de um sensor com dimensão igual a $30 \mathrm{~mm}$. 


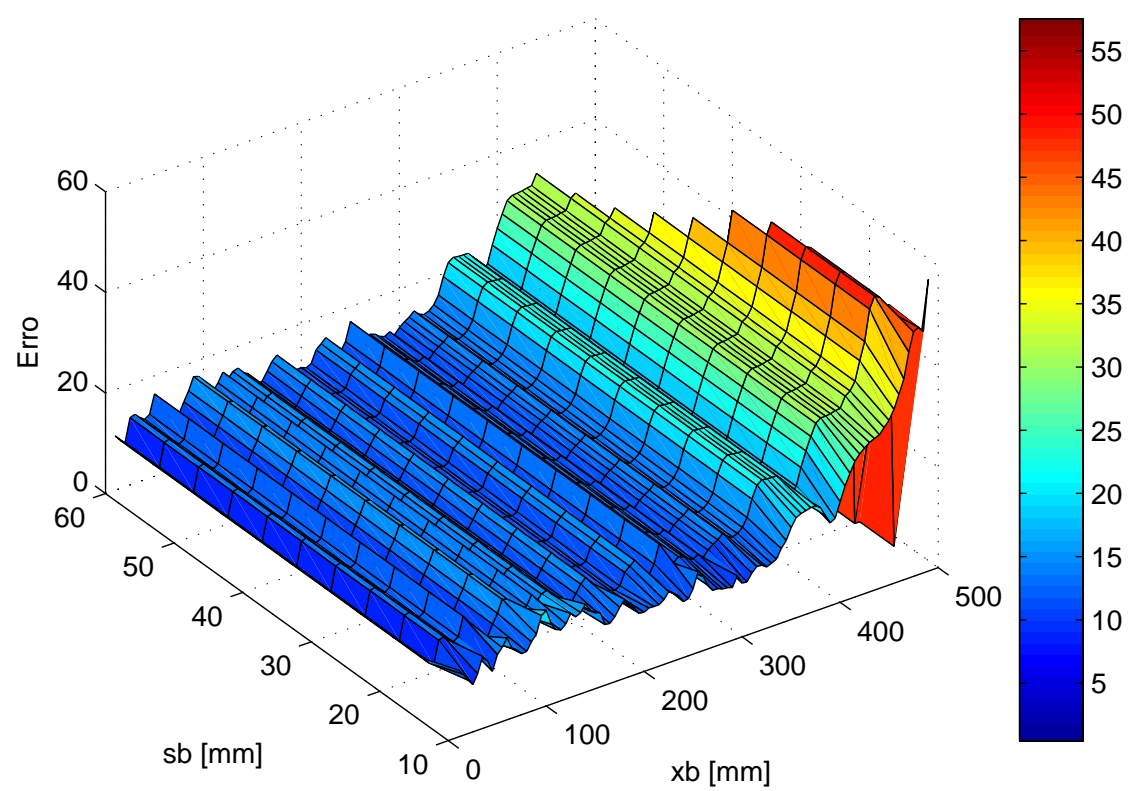

a) Aproximação polinomial

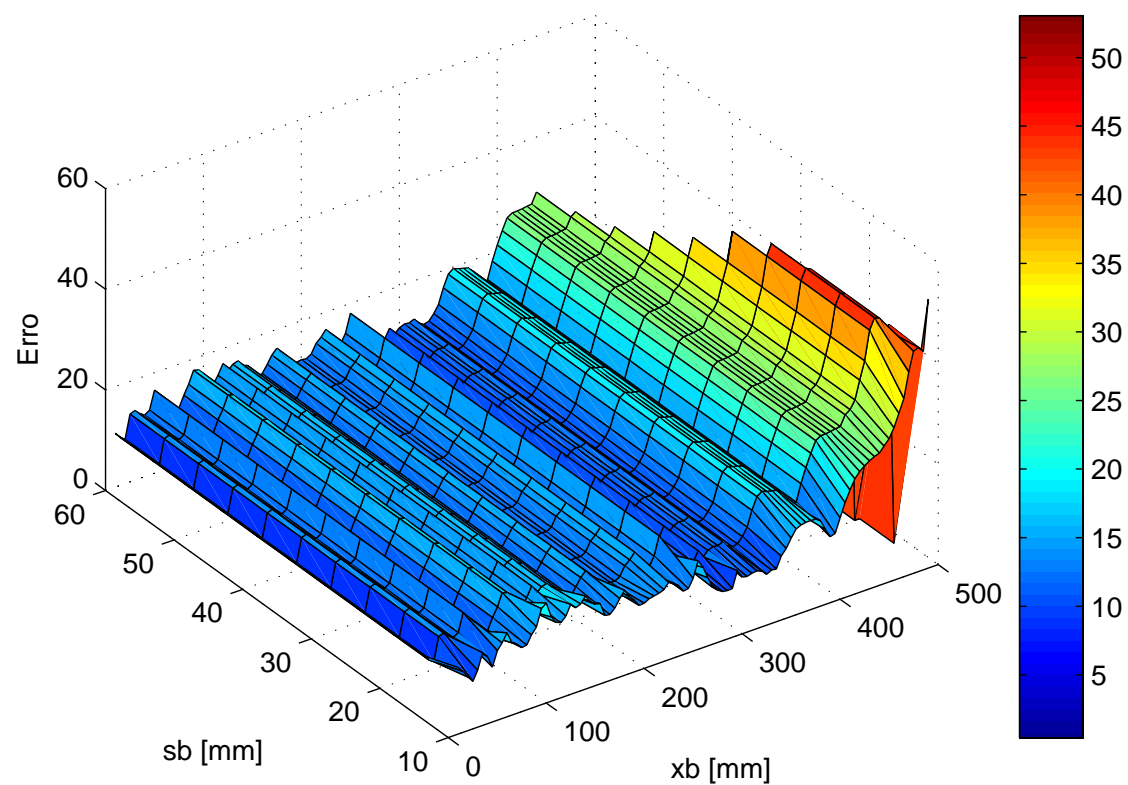

b) Aproximação por formas modais

Figura 4.4: Variação do erro para $n=1$ e $x_{\text {out }}=50 \mathrm{~mm}$ 
Observa-se que inicialmente ambas as aproximações apresentam resultados bem próximos, com ligeira vantagem em termos da aproximação polinomial. Com o incremento na posição do bimorph a caminho da extremidade livre da viga, ocorre um maior distanciamento entre as curvas, de tal forma que a partir da posição $x_{b} \geq L / 2$, ocorre uma inversão, de tal maneira que a aproximação por formas modais passa a reproduzir resultados melhores. $O$ mesmo ocorre para outras dimensões do bimorph.

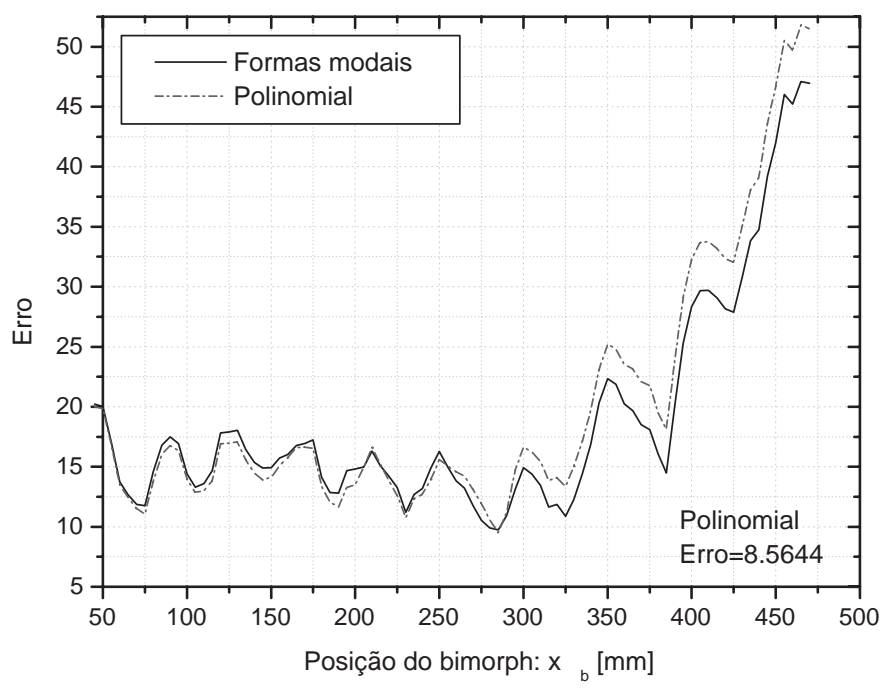

Figura 4.5. Variação do erro para $s_{b}=30 \mathrm{~mm}$ e $x_{\text {out }}=50 \mathrm{~mm}$

mesmo estudo é feito para outro ponto de estimativa da rotação, agora a 250mm do engaste (ver Figura 4.6). Nota-se novamente ao analisar as superfícies, uma ligeira diferença entre os resultados.

Na Figura 4.7, no entanto, a secção em $s_{b}=30 \mathrm{~mm}$ revela que não ocorre uma inversão entre o menor erro dentro da comparação entre os dois métodos. Isso é notado para todos os pontos de estimativa da rotação acima de $1 / 3 \mathrm{~L}$. 


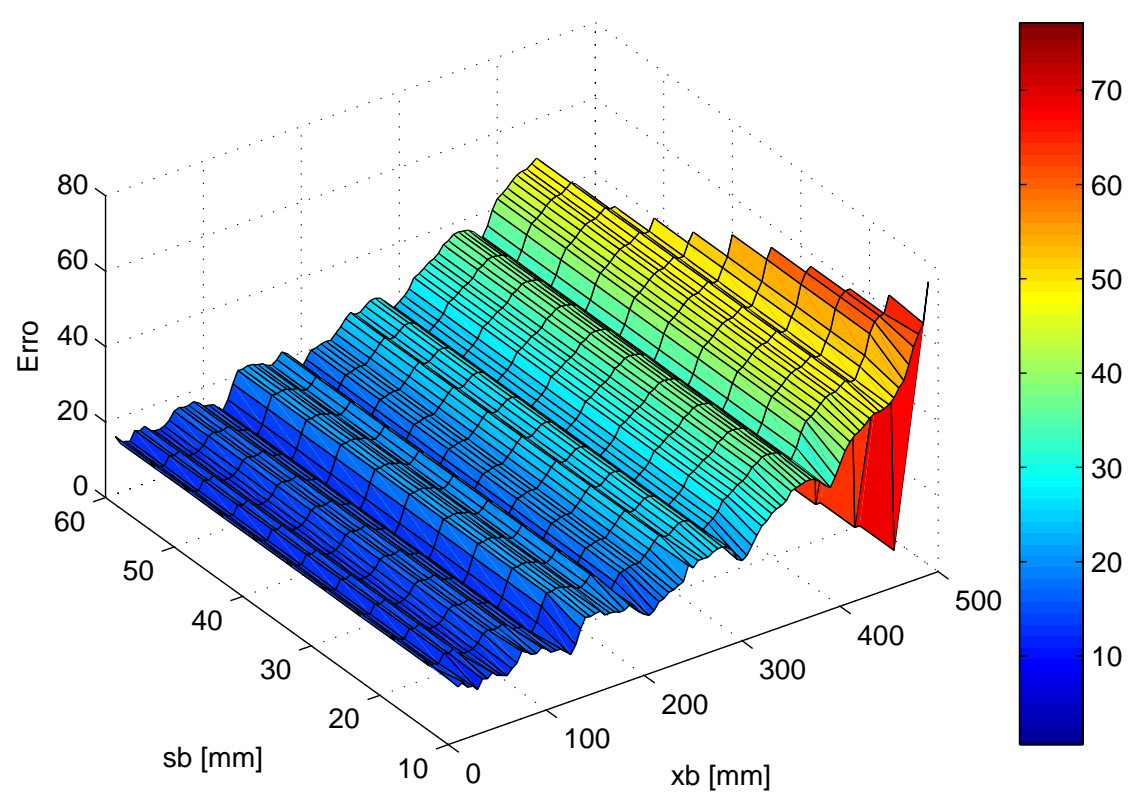

a) Aproximação polinomial

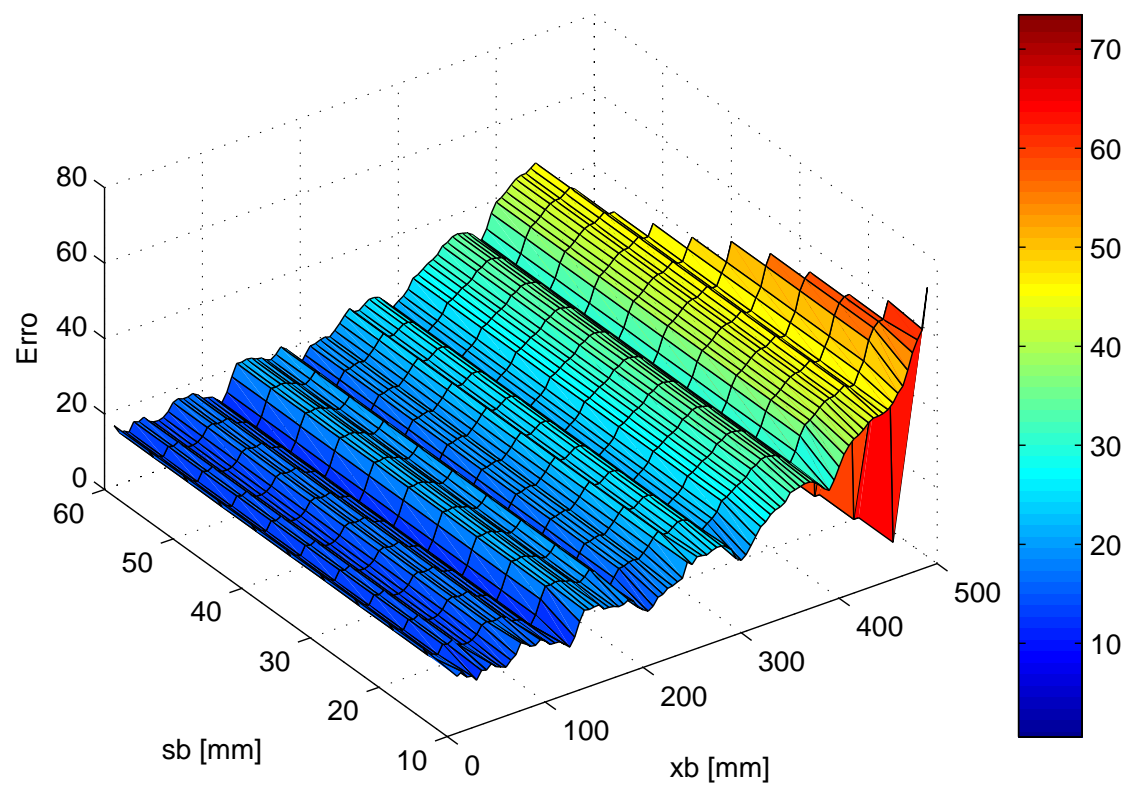

b) Aproximação por formas modais

Figura 4.6: Variação do erro para $n=1$ e $x_{\text {out }}=250 \mathrm{~mm}$ 


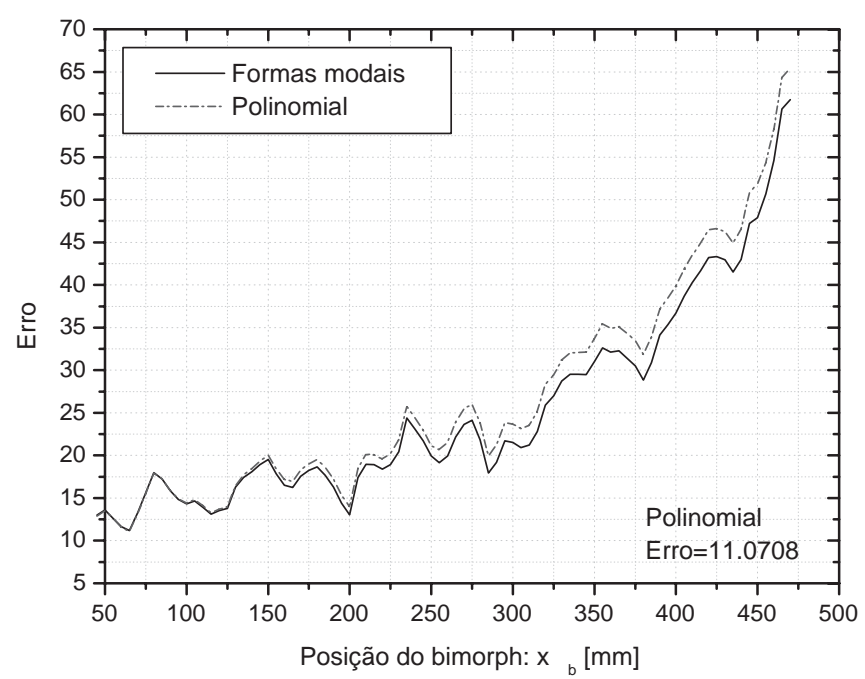

Figura 4.7. Variação do erro para $s_{b}=30 \mathrm{~mm}$ e $x_{\text {out }}=250 \mathrm{~mm}$

A Figura 4.8 apresenta o mesmo levantamento do erro, no entanto, considerando agora 3 bimorphs. Os dois primeiros bimorphs têm suas posições fixadas, respectivamente, em: $x_{b 1}=20 \mathrm{~mm}, x_{b 2}=50 \mathrm{~mm}$ e dimensões idênticas $\left(s_{b 1,2}=10 \mathrm{~mm}\right)$. Logo, somente ao terceiro bimorph é permitida a variação de posição e tamanho.

No caso de três bimorphs, os resultados são apresentados na faixa de 100 à $500 \mathrm{~mm}$, pois esta foi a faixa adotada para avaliação do posicionamento do terceiro bimorph. Nota-se ao analisar os resultados, um comportamento distinto em relação a um único bimorph.

Na Figura 4.9 é possível avaliar a distribuição dos valores de acordo com o método e o posicionamento para um bimorph de tamanho igual a $30 \mathrm{~mm}$. Na média dos resultados, a inclusão de mais bimorphs propicia uma redução no valor do erro. Caba ainda salientar que se trate de um caso não otimizado. Na otimização, se permite que tanto o tamanho como as posições dos três bimorphs variem. 


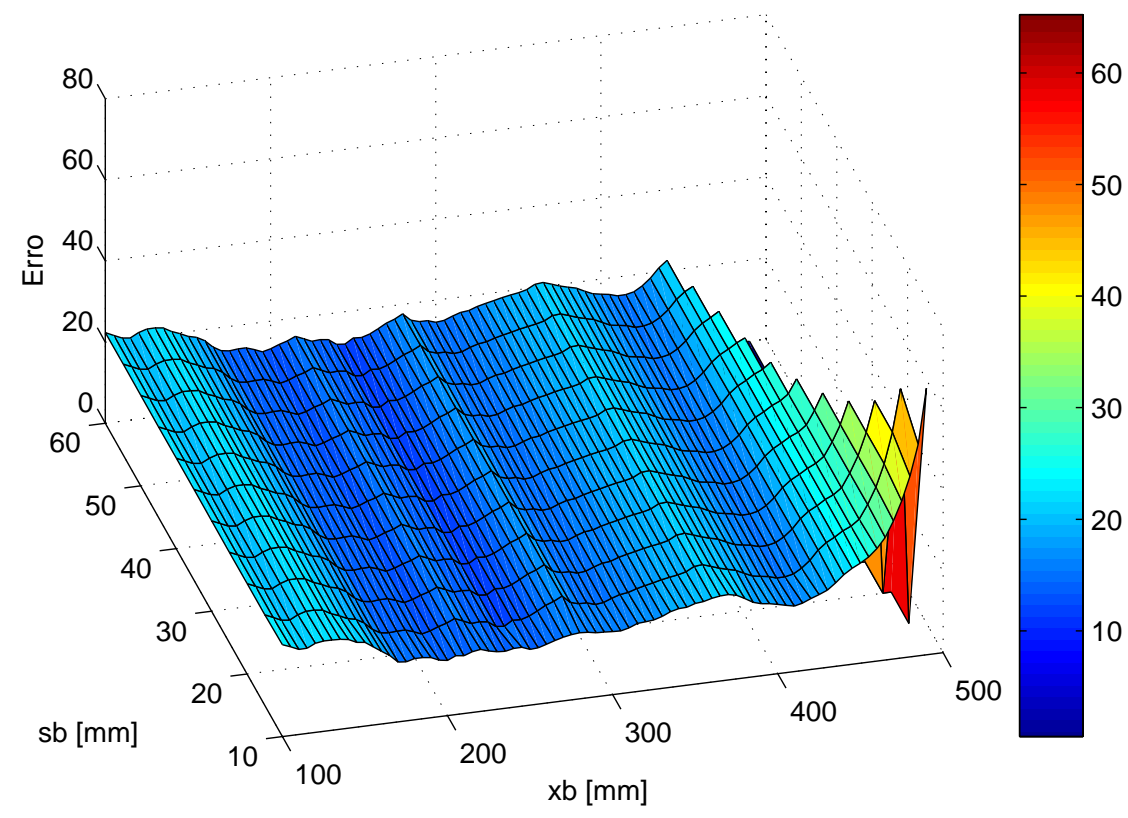

a) Aproximação polinomial

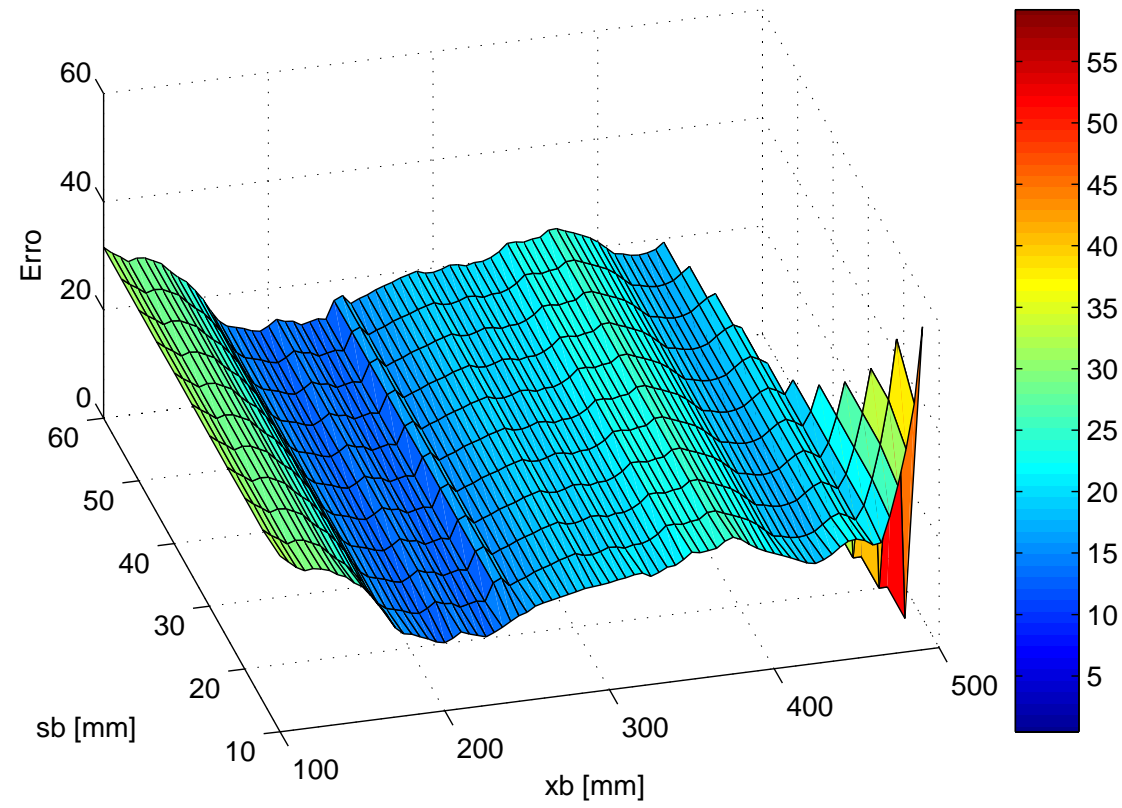

b) Aproximação por formas modais

Figura 4.8: Variação do erro para $n=3$ 


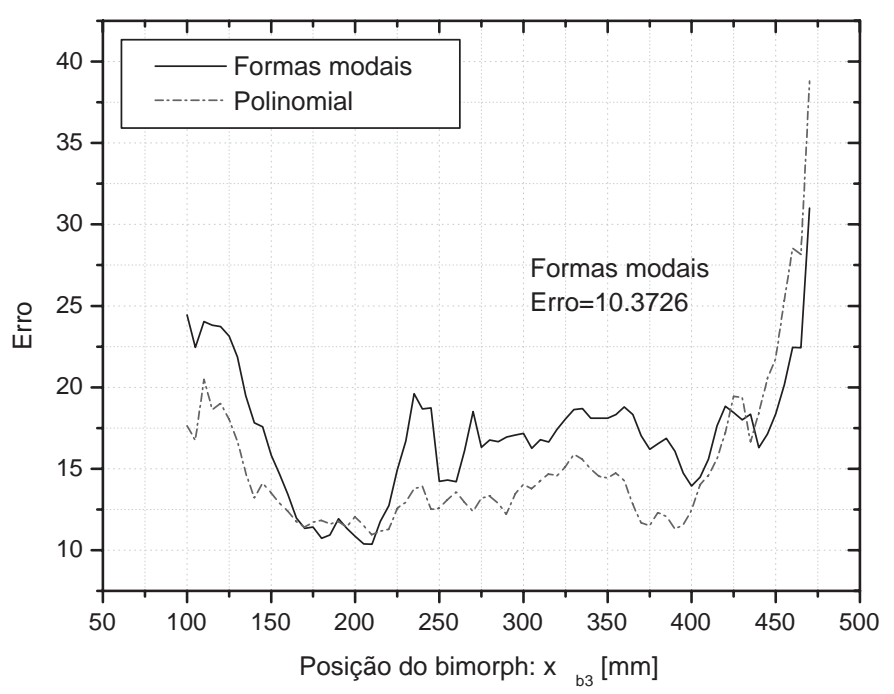

Figura 4.9. Variação do erro para $s_{b}=30 \mathrm{~mm}$ e $x_{\text {out }}=250 \mathrm{~mm}$

Decorrente destas análises, passou a se considerar o cálculo com ambas as aproximações no programa de otimização. $O$ processo todo se tornou mais oneroso em termos computacionais, porém, ainda assim, há um consumo menor de tempo ao se compará-lo com a execução de duas análises distintas, uma para cada aproximação em separado. Além disso, o ganho final em termos da determinação da solução ótima foi grande ao se permitir a escolha entre os métodos de aproximação.

\subsubsection{COMPARAÇÃO ENTRE MODOS NÃO CORRIGIDOS E MODOS CORRIGIDOS}

Uma consideração importante deve ser feita ao se utilizar a aproximação por formas modais: a presença do sensor ao longo da viga. A Figura 4.10 compara os cinco primeiros modos de vibrar oriundos de dois modelos de viga em elementos finitos: o primeiro retrata apenas a viga (modo não corrigido) e o segundo, quando um único sensor bimorph está presente (modo corrigido) à $50 \mathrm{~mm}$ do engaste $\left(x_{b}=50 \mathrm{~mm}\right)$. Nesta comparação, avalia-se ainda a importância da dimensão do 
sensor ao se comparar dois valores distintos: $s_{b}=10 \mathrm{~mm}$ (coluna da esquerda) e $s_{b}=50 \mathrm{~mm}$ (coluna da direita).

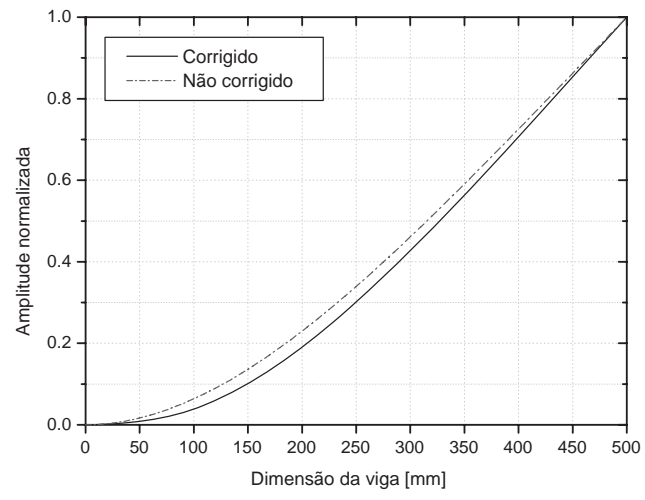

a)

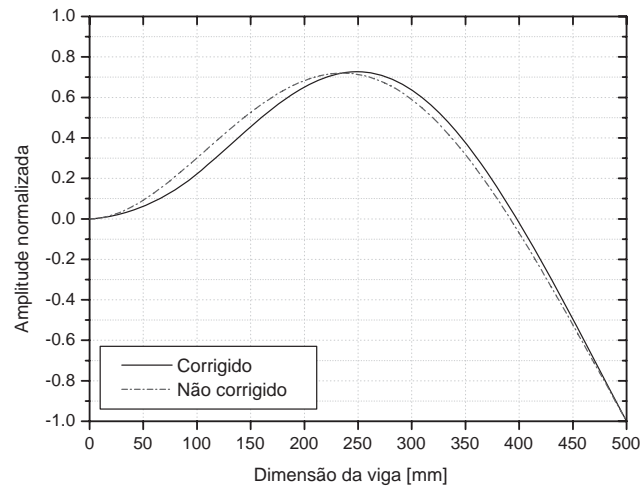

c)

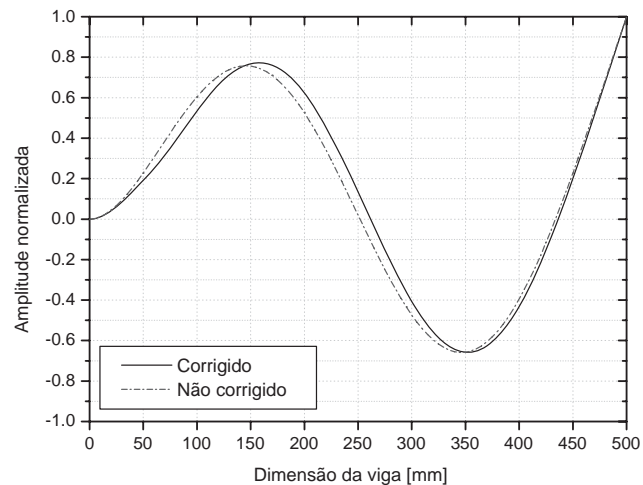

e)

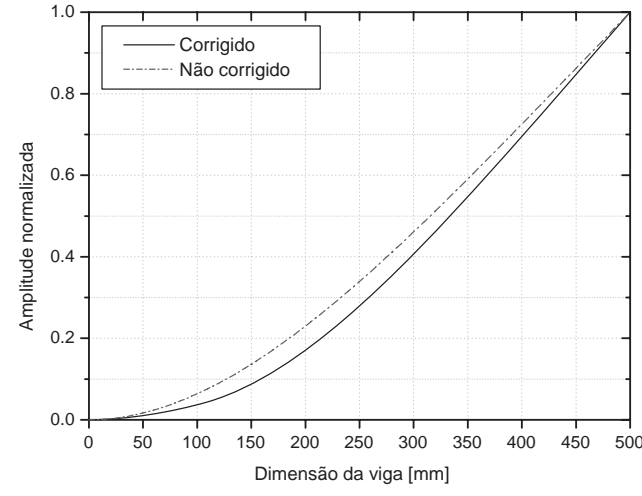

b)

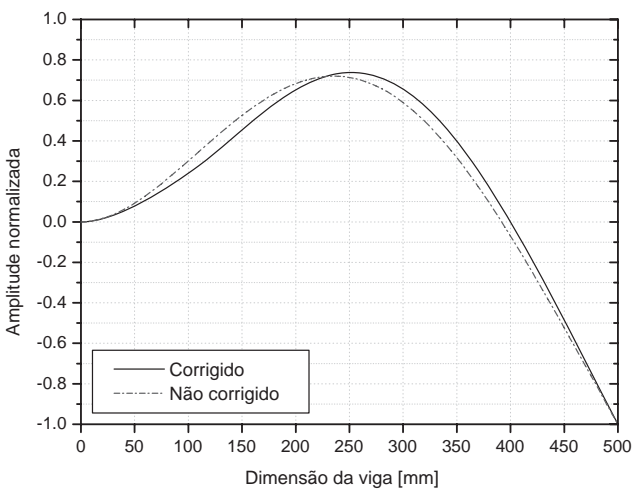

d)

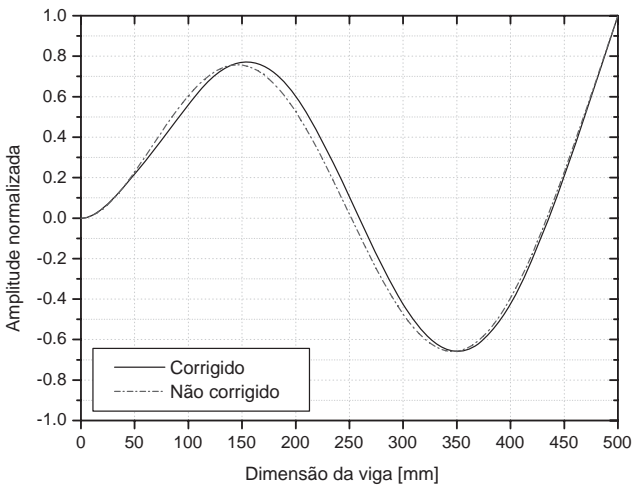




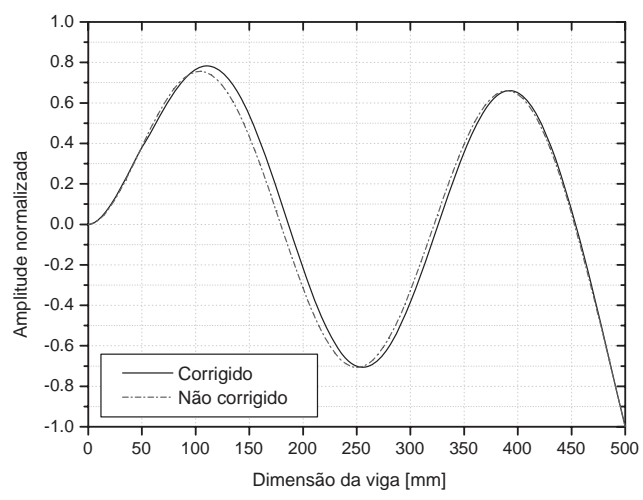

g)

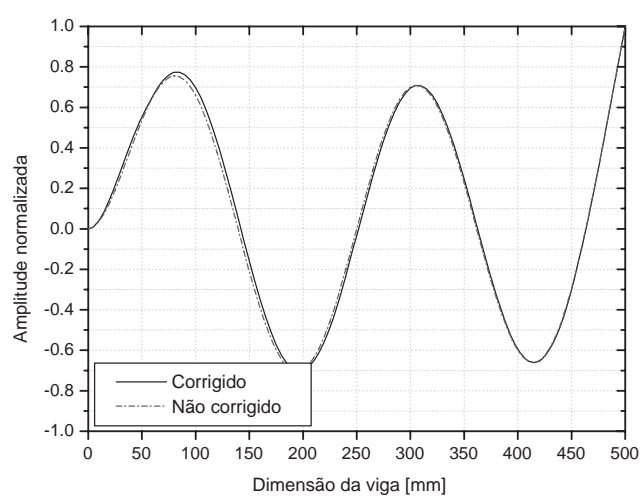

i)

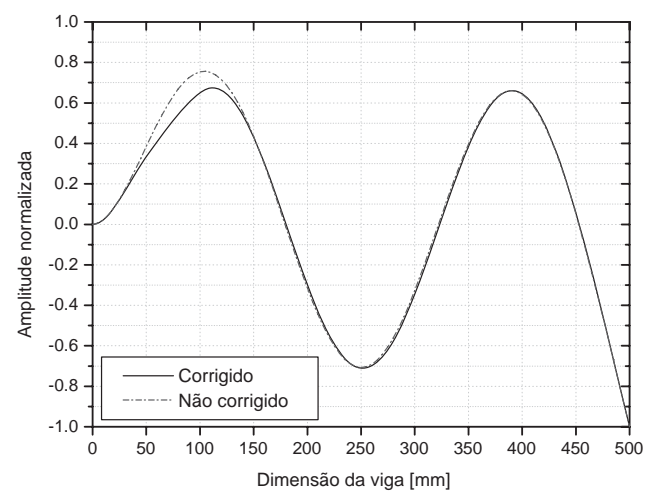

h)

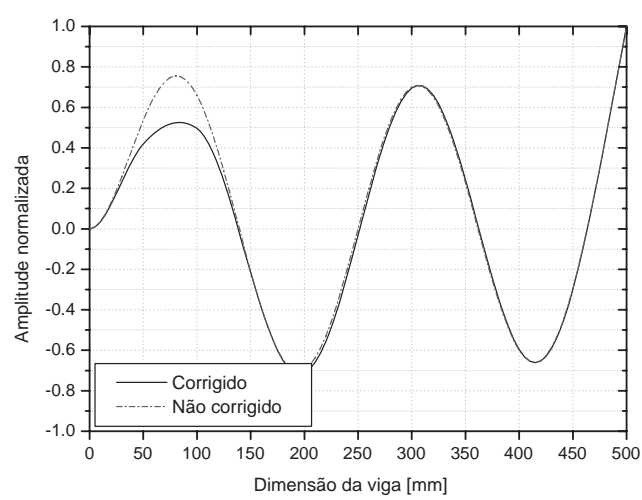

i)

Figura 4.10: Comparação entre os 5 primeiros modos de vibrar (não corrigidos e corrigidos) no caso de 1 sensor bimorph

Nota-se que para um único bimorph cuja dimensão pode ser considerada pequena $\left(s_{b}=10 \mathrm{~mm}\right)$, as diferenças entre os modos de vibrar são discretas. No entanto, o mesmo não pode ser dito para dimensões consideráveis como para um sensor de $50 \mathrm{~mm}$ de comprimento.

Logo, quanto maior a dimensão do sensor e quanto mais alto for o modo de vibrar, maiores serão as diferenças. Isso ocorre com os modos mais altos devido ao respectivo comprimento de onda destes modos serem menores, como também, à rigidez local que o bimorph impõe a estrutura. Porém, este efeito de correção não 
altera significativamente o resultado final na estimativa da FRFA no caso de um único bimorph, pois apenas os 3 primeiros modos $(m=n+2)$ serão utilizados na aproximação por formas modais.

No entanto, o efeito é evidenciado quando da presença de 2 ou mais bimorphs. A Figura 4.11 ilustra as diferenças no caso de 3 bimorphs posicionados em $x_{b 1}=50 \mathrm{~mm}, x_{b 2}=250 \mathrm{~mm}$ e $x_{b 3}=350 \mathrm{~mm}$ e dimensões $s_{1,2,3}=50 \mathrm{~mm}$.

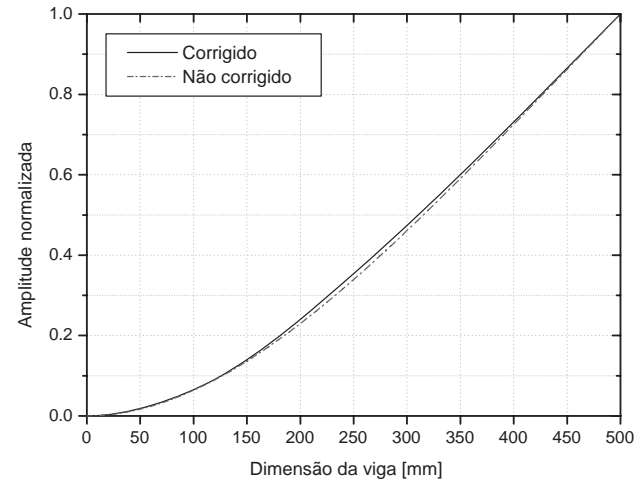

a)

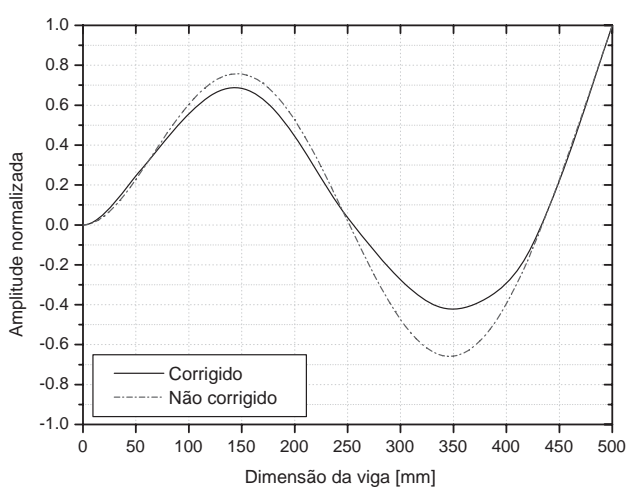

c)

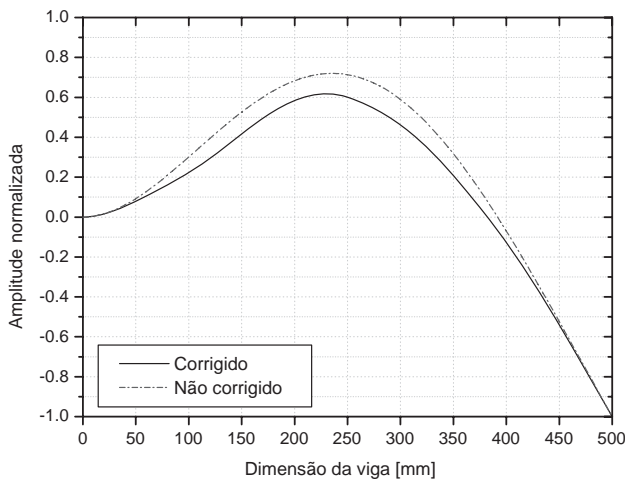

b)

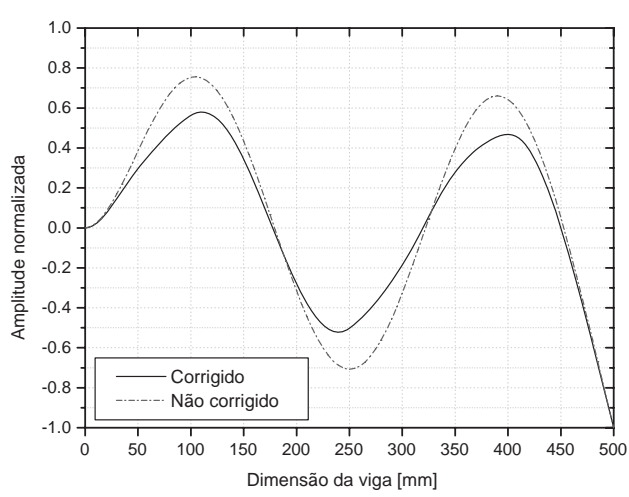

d) 


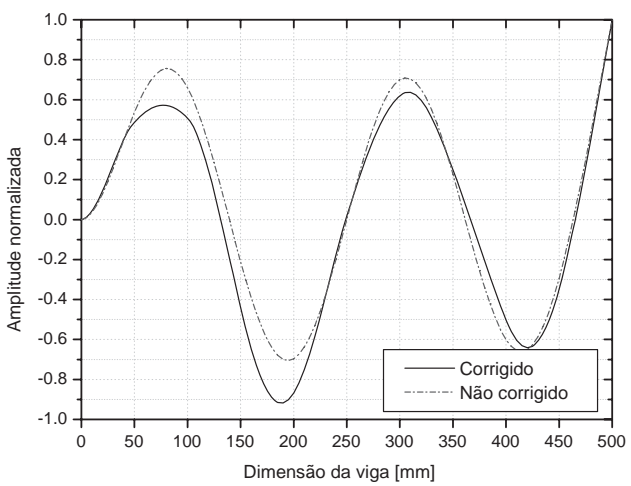

e)

Figura 4.11: Comparação entre os 5 primeiros modos de vibrar (não corrigidos e corrigidos) no caso de 3 sensores bimorphs

Esta correção é importante na estimativa das funções de resposta em freqüência angulares (FRFA) para 2 ou mais bimorphs $(n \geq 2)$, pois o número de modos utilizados é igual ou superior a 4 modos de vibrar e a importância na estimativa da FRFA é considerável (ver Figura 4.12).

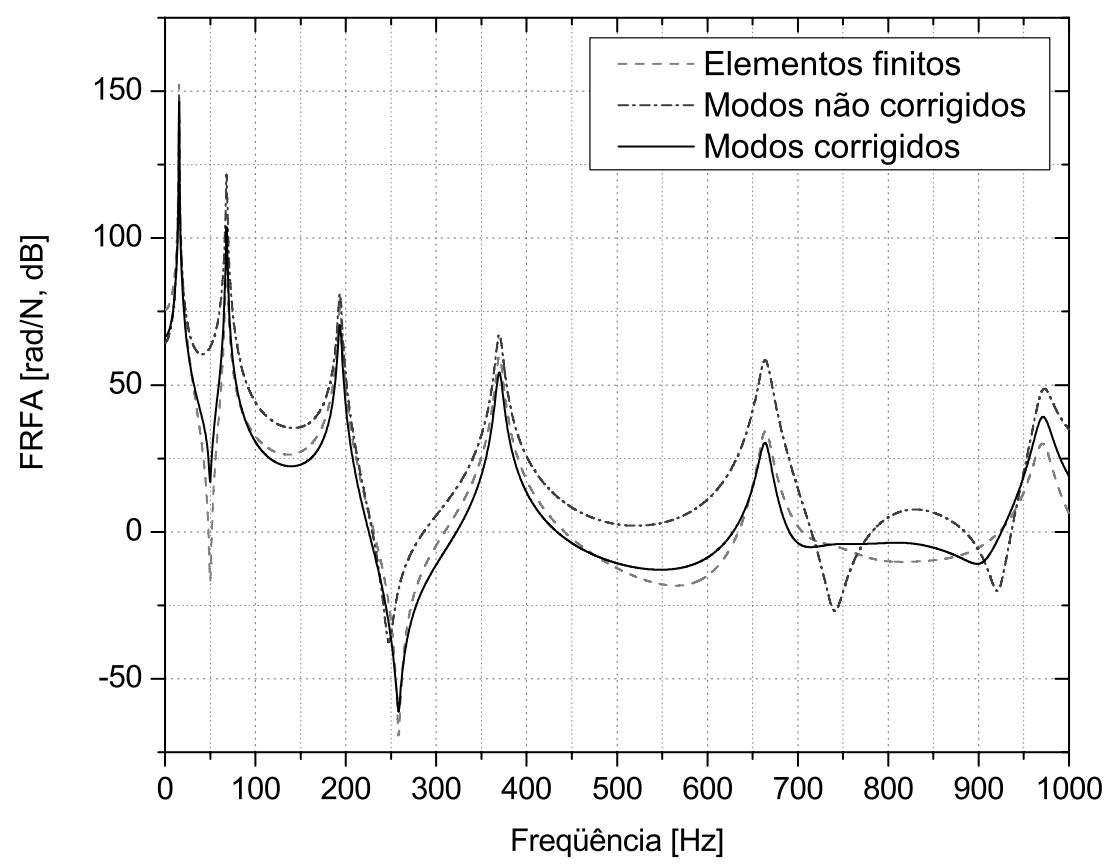

Figura 4.12: Efeito da utilização de modos elásticos para $n=3$ 
Nota-se uma substancial diferença entre os resultados. Com a utilização de 3 bimorphs $(n=3), 5$ modos de vibrar são utilizados de acordo com o modelo de aproximação por formas modais. Conseqüentemente, devido aos modos de vibrar mais altos terem suas formas significativamente alteradas, as funções de resposta em freqüência angulares (FRFA) estimadas nestes casos também são de fato influenciadas se os modos de vibrar não forem corrigidos.

\subsubsection{AVALIAÇÃO DOS PARÂMETROS DE DESEMPENHO DO AG}

Além da forma como o cromossomo é codificado e da definição do fitness (erro) escolhidos, existem vários parâmetros dentro de um algoritmo genético que podem ser escolhidos para melhorar o seu desempenho, adaptando-o às características particulares de determinadas classes de problemas. Entre eles os mais importantes são: o tamanho da população, o número de gerações, a probabilidade de crossover e a probabilidade de mutação. A influência de cada parâmetro no desempenho do algoritmo depende da classe de problemas em estudo. Assim, a determinação de um conjunto de valores otimizado para estes parâmetros dependerá da realização de experimentos e testes.

Dentro da literatura voltada a algoritmos genéticos, os valores encontrados estão na faixa de 60 a $65 \%$ para a probabilidade de crossover e entre 0,1 e 5\% para a probabilidade de mutação. O tamanho da população e o número de gerações dependem da complexidade do problema de otimização e devem ser determinados experimentalmente. No entanto, deve ser observado que o tamanho da população e o número de gerações definem diretamente o tamanho do espaço de busca a ser coberto. Existem estudos que utilizam um AG como método de otimização para a 
escolha dos parâmetros de outro AG, devido à importância da escolha correta destes parâmetros (MITCHELL, 1996).

O primeiro parâmetro de desempenho avaliado para o AG desenvolvido neste trabalho corresponde à probabilidade de ocorrência de crossover, ou seja, a probabilidade na qual o cruzamento pode ser realizado. Quando a probabilidade de cruzamento é igual a 1 (100\%) toda a descendência é produzida por cruzamento. Porém, quando a probabilidade é nula $(0 \%)$, a nova geração constitui-se pela cópia exata dos cromossomos da população antiga.

gráfico da Figura 4.13 foi construído a partir da realização de uma média entre 10 execuções do AG para cada conjunto de valores para uma população préestabelecida contendo 50 indivíduos: probabilidade de crossover de 0 a 100\% (em incrementos de 5\%), o número de bimorphs entre 1 e 3 e os pontos de resposta da estrutura de $50 \mathrm{~mm}$ a $500 \mathrm{~mm}$ (em incrementos de $50 \mathrm{~mm}$ ).

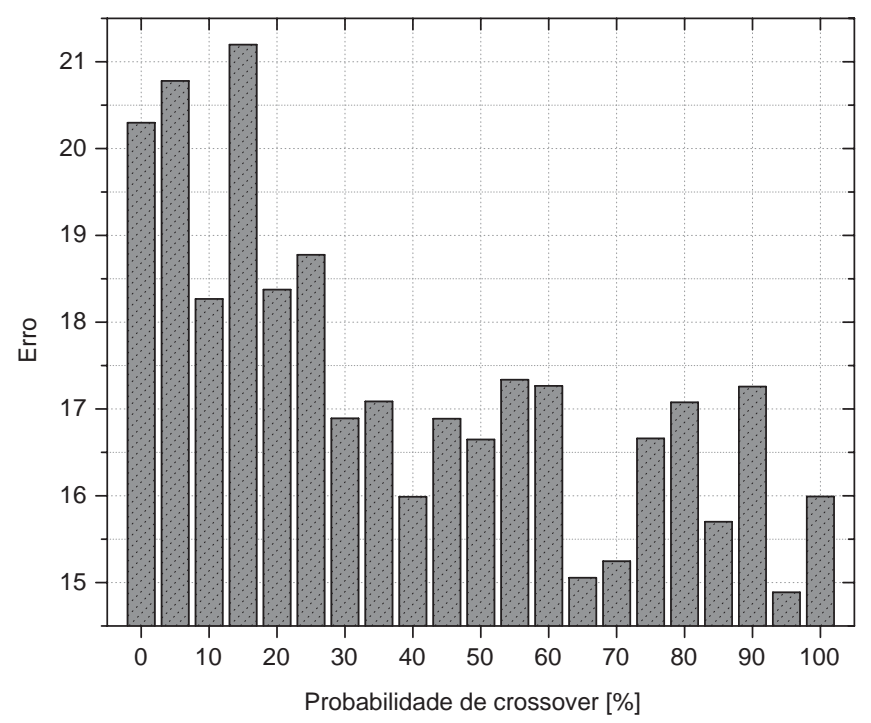

Figura 4.13: Avaliação da probabilidade de crossover 
Nota-se a partir dos resultados, que a probabilidade de ocorrência de $95 \%$ de crossover produz o menor erro na estimativa das FRFAs, na média das 10 execuções entre as três quantidades de bimorphs avaliada.

O segundo parâmetro de desempenho avaliado para o AG corresponde à probabilidade de ocorrência de mutação, ou seja, com qual freqüência os cromossomos sofrerão alteração. Se não houver mutação, a descendência gerada imediatamente após o cruzamento não sofre nenhuma alteração. Neste trabalho, optou-se pela alteração do cromossomo em um único ponto no caso de ocorrência de mutação.

Semelhante ao que foi feito na determinação da probabilidade de crossover, o gráfico da Figura 4.14 foi elaborado a partir de uma média entre 10 execuções do AG para uma população com 50 indivíduos com a seguinte variação de parâmetros: probabilidade de mutação de 0 a $5 \%$ (em incrementos de 1\%); número de bimorphs entre 1 e 3 ; pontos de resposta estrutural entre $50 \mathrm{~mm}$ e $500 \mathrm{~mm}$ (em incrementos de $50 \mathrm{~mm}$ ) e uma probabilidade de crossover de $95 \%$.

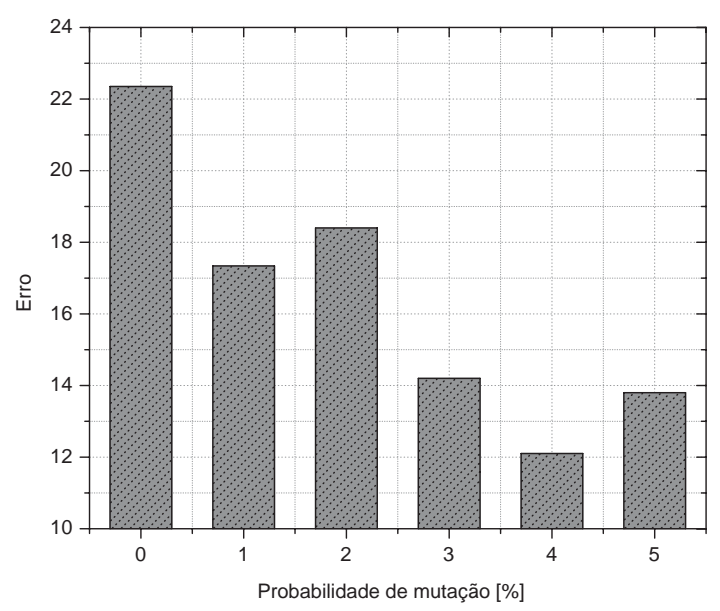

Figura 4.14: Avaliação da probabilidade de mutação 
Nota-se que com a probabilidade de ocorrência de mutação igual a $4 \%$ obtêm-se o menor erro médio na estimativa das FRFAs.

Outro fator importante no desempenho do AG é o tamanho da população, ou seja, quantos cromossomos existem em uma geração. Se houver poucos cromossomos, o AG terá poucas possibilidades de realizar cruzamentos e somente uma pequena parte do espaço de soluções será explorada. Por outro lado, se houver muitos indivíduos em uma população, o AG tornar-se-á extremamente lento. Pesquisas mostram que após determinado limite (que depende principalmente da codificação e do problema), não é conveniente aumentar a população porque isso não resolve o problema mais rapidamente se comparado a tamanhos moderados de população (MITCHELL, 1996).

A Figura 4.15 apresenta o tempo médio de execução do AG em função do número de bimorphs e do tamanho da população para um computador tipo desktop equipado com um processador Pentium $4^{\circledR}$ de $3,2 \mathrm{GHz}$ (single core) e 1 GB de memória $533 \mathrm{MHz}$ operando em dual channel.

Observa-se que ao mesmo passo que o tempo computacional médio aumenta com o tamanho da população, o erro obtido como solução ótima decai. No entanto, cabe ainda comentar sobre a figura a seguir, que o tempo apresentado é referente ao cálculo forçado do mesmo número de gerações (20) em todas as análises. No entanto, o AG pode interromper o processo em função do critério de parada de acordo com o valor da solução ótima obtida. 


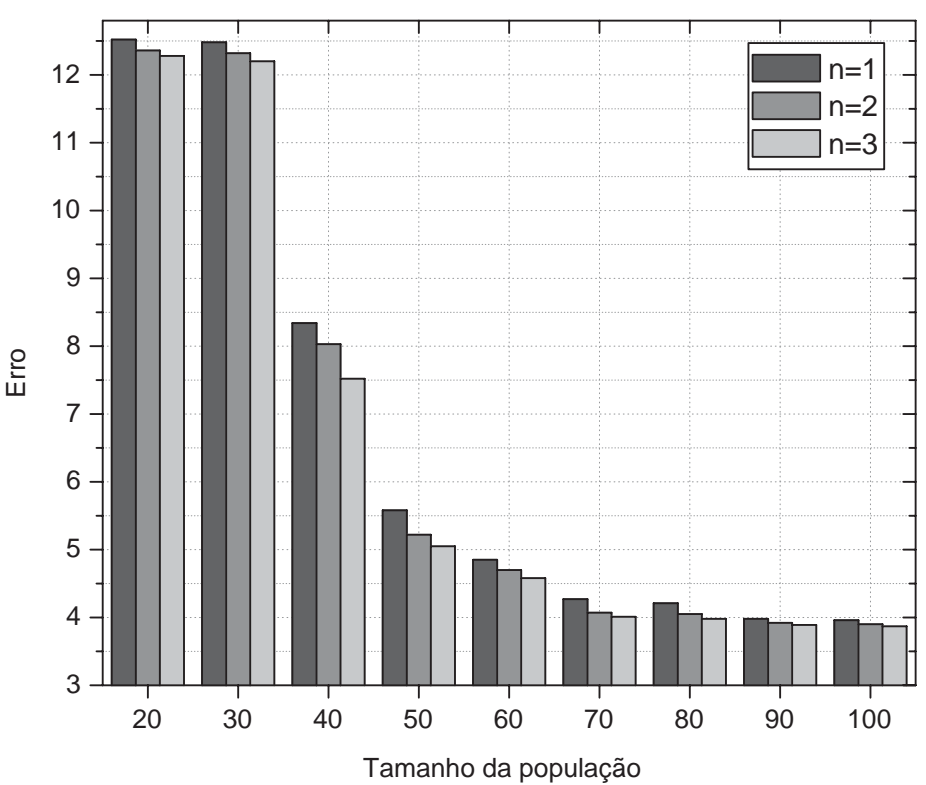

a) Tamanho da população versus erro

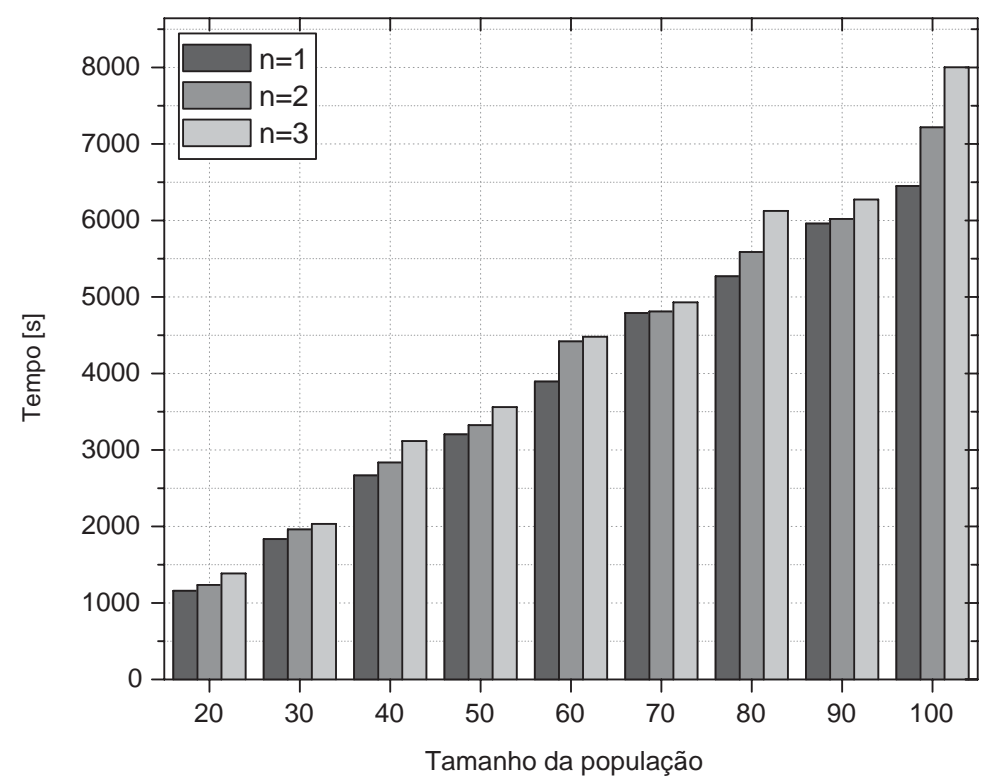

b) Tamanho da população versus tempo computacional

Figura 4.15: Considerações a respeito do tamanho da população

A Figura 4.16 ilustra a distribuição das possíveis soluções para a última geração de indivíduos dentro dos limites aceitáveis para dois tamanhos de população, 20 e 100, no caso de 3 bimorphs e $x_{\text {out }}=150 \mathrm{~mm}$. 


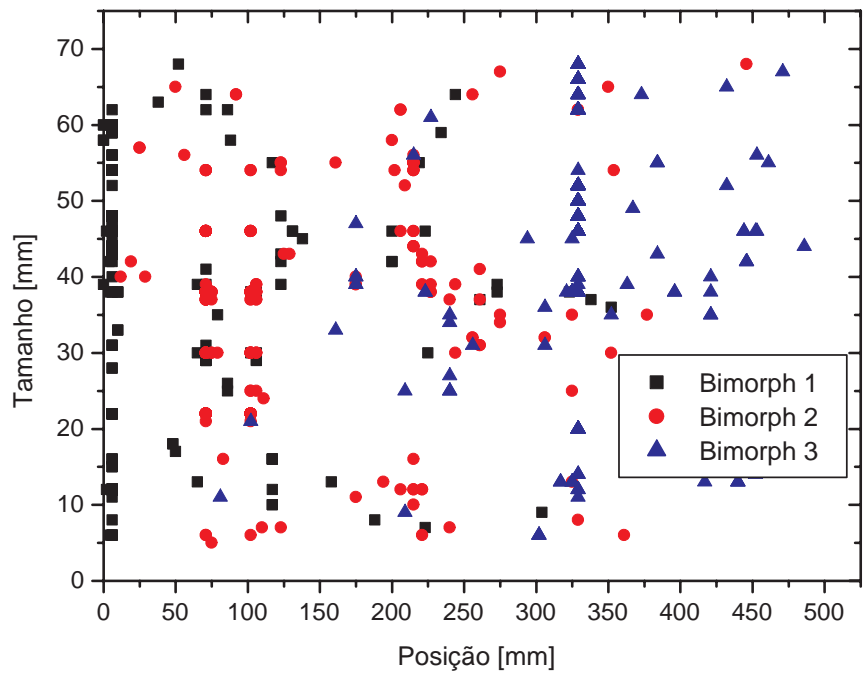

a) 20 indivíduos por população

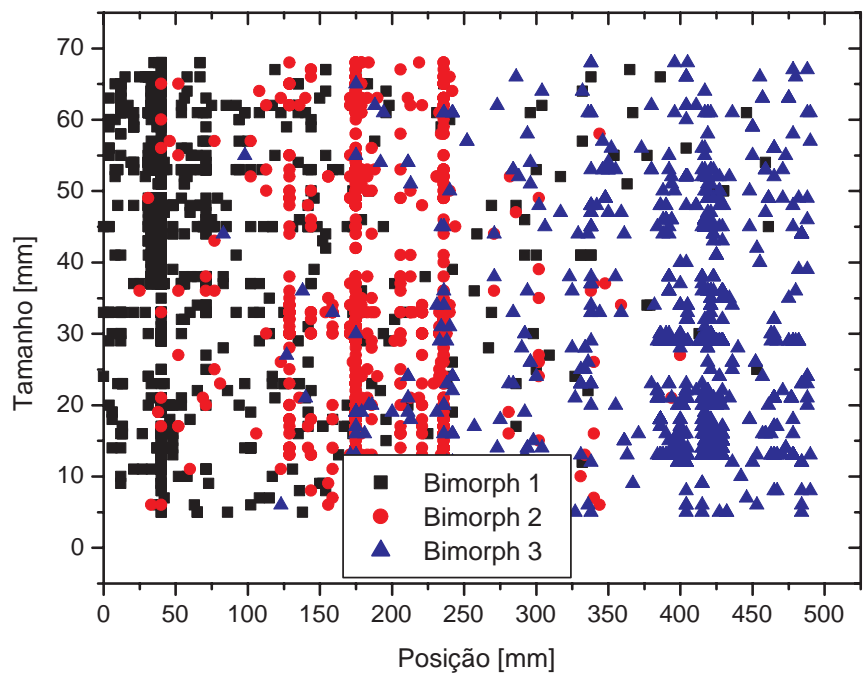

b) 100 indivíduos por população

Figura 4.16: Distribuição dos indivíduos no domínio das soluções

Ao se considerar a relação resultado/tempo computacional, pode-se dizer que grandes populações nem sempre reproduzem as melhores condições. Logo, como critério de projeto, decidiu-se adotar neste AG uma população com 50 indivíduos, por representar o caso médio em termos do tempo computacional e do erro alcançado nas soluções ótimas. 
A Figura 4.17 ilustra, por fim, o último parâmetro de desempenho analisado: o elitismo. Como dito anteriormente, pela simples geração de filhos através dos operadores de seleção, reprodução (crossover) e mutação, não se pode garantir que os melhores indivíduos permaneçam nas gerações futuras.

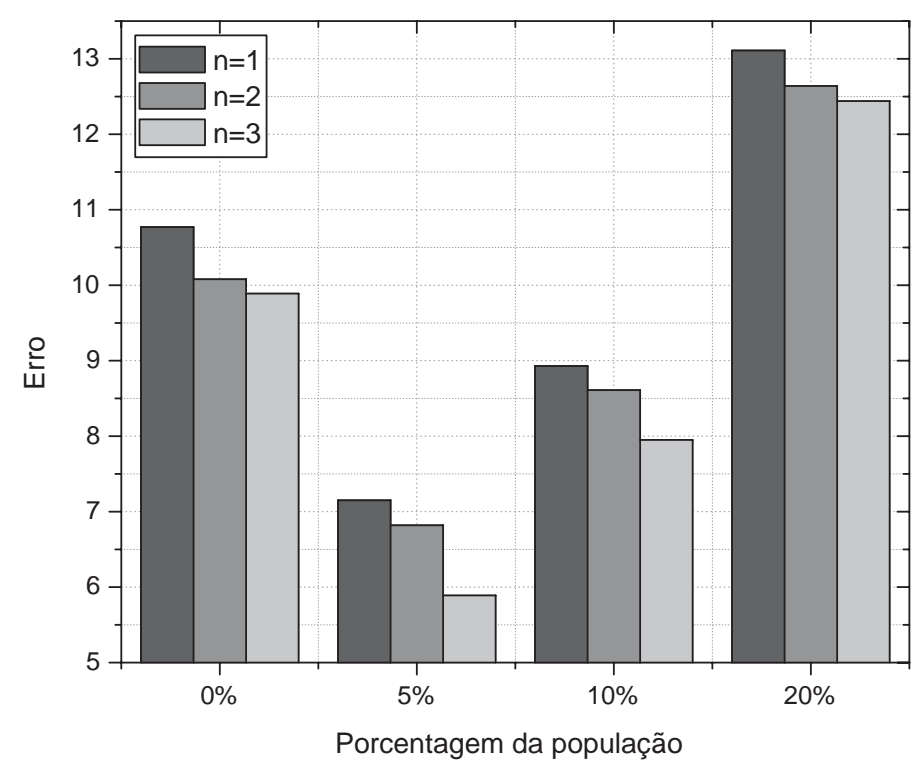

Figura 4.17: Avaliação da porcentagem de elitismo

gráfico da Figura 4.17 foi obtido a partir de uma média entre 10 execuções do AG para uma população com 50 indivíduos, probabilidade de mutação igual a $4 \%$, pontos de resposta estrutural $\left(x_{\text {out }}\right.$ ) entre $50 \mathrm{~mm}$ e $500 \mathrm{~mm}$ (em incrementos de $50 \mathrm{~mm}$ ) e uma probabilidade de crossover de 95\%. Logo, com 5\% de indivíduos destinados ao elitismo a média das soluções ótimas apresenta a menor faixa de valores entre 1 e 3 bimorphs, sendo esta a porcentagem de elitismo adotada. 


\subsubsection{ESTIMATIVA DAS FRFAS}

A Figura 4.18 ilustra os valores de fitness atingidos em cada solução ótima de acordo com o número de bimorphs $(n)$ utilizados na aproximação e o ponto de medição da resposta estrutural $\left(x_{\text {out }}\right)$ ao longo do comprimento da viga.

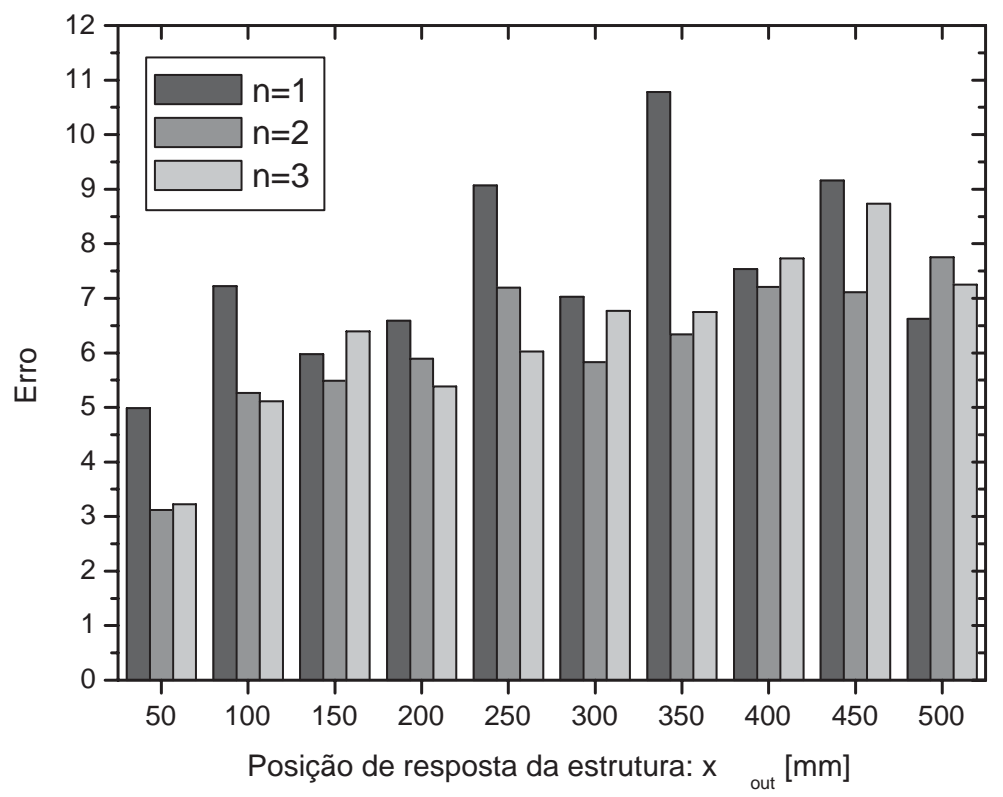

Figura 4.18: Soluções ótimas atingidas

As figuras 4.18 e 4.28 ilustram os resultados ótimos e a evolução do fitness de acordo com as gerações. Apresentam-se também os valores referentes às posições $\left(x_{b}\right)$ e dimensões $\left(s_{b}\right)$ ótimas dos respectivos sensores.

Os resultados mostram uma boa correlação entre o método dos elementos finitos, o qual possui inerente a sua formulação graus de liberdade referentes à rotação e o sensor bimorph desenvolvido e otimizado neste trabalho. 

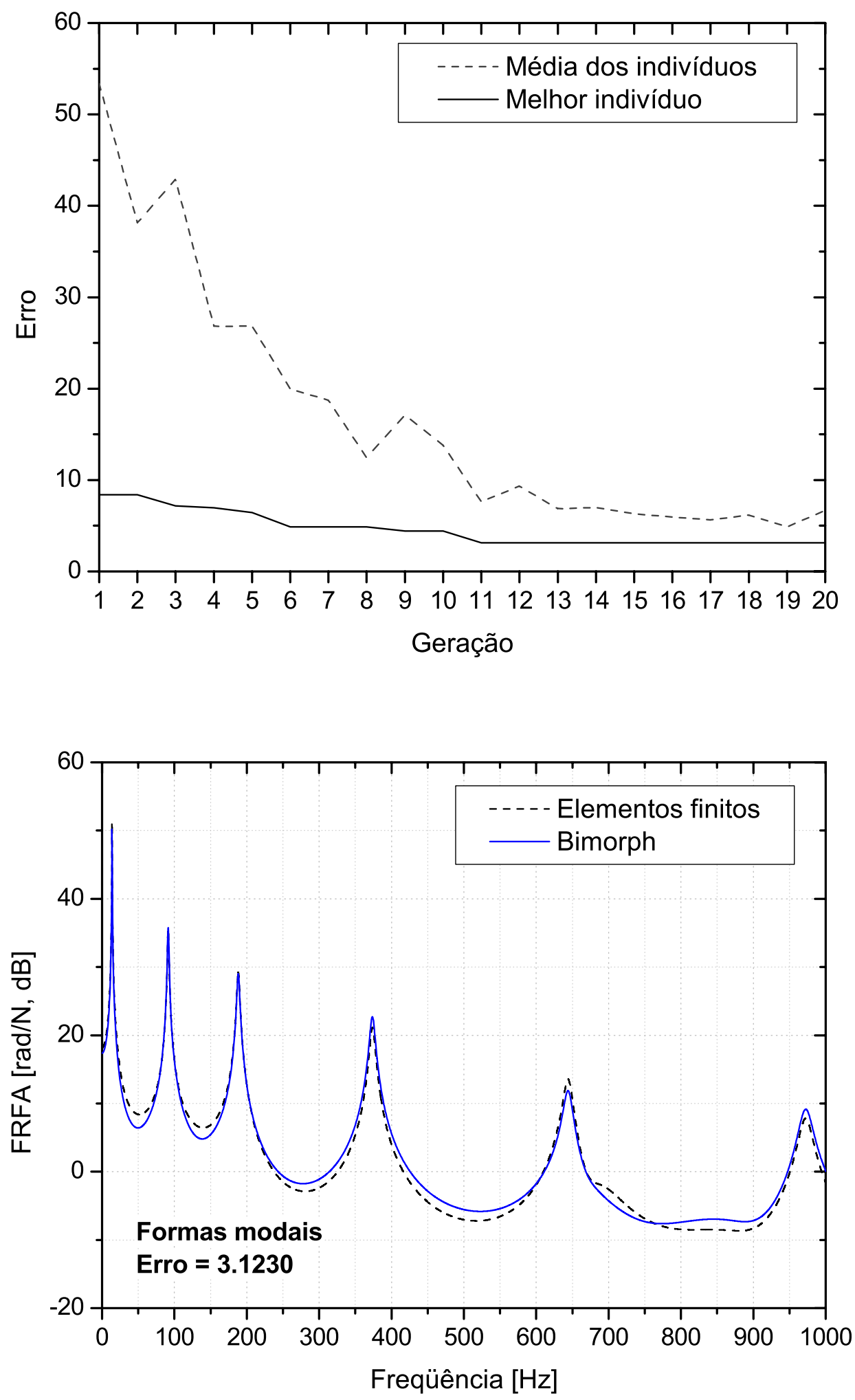

$n=3: x_{b 1}=10 \mathrm{~mm}, x_{b 2}=378 \mathrm{~mm}, x_{b 3}=432 \mathrm{~mm}$ e $s_{b 1}=30 \mathrm{~mm}, s_{b 2}=38 \mathrm{~mm} \mathrm{e}$ $s_{b 3}=42 \mathrm{~mm}$

Figura 4.19: Evolução dos indivíduos e FRFA para $x_{\text {out }}=50 \mathrm{~mm}$ 

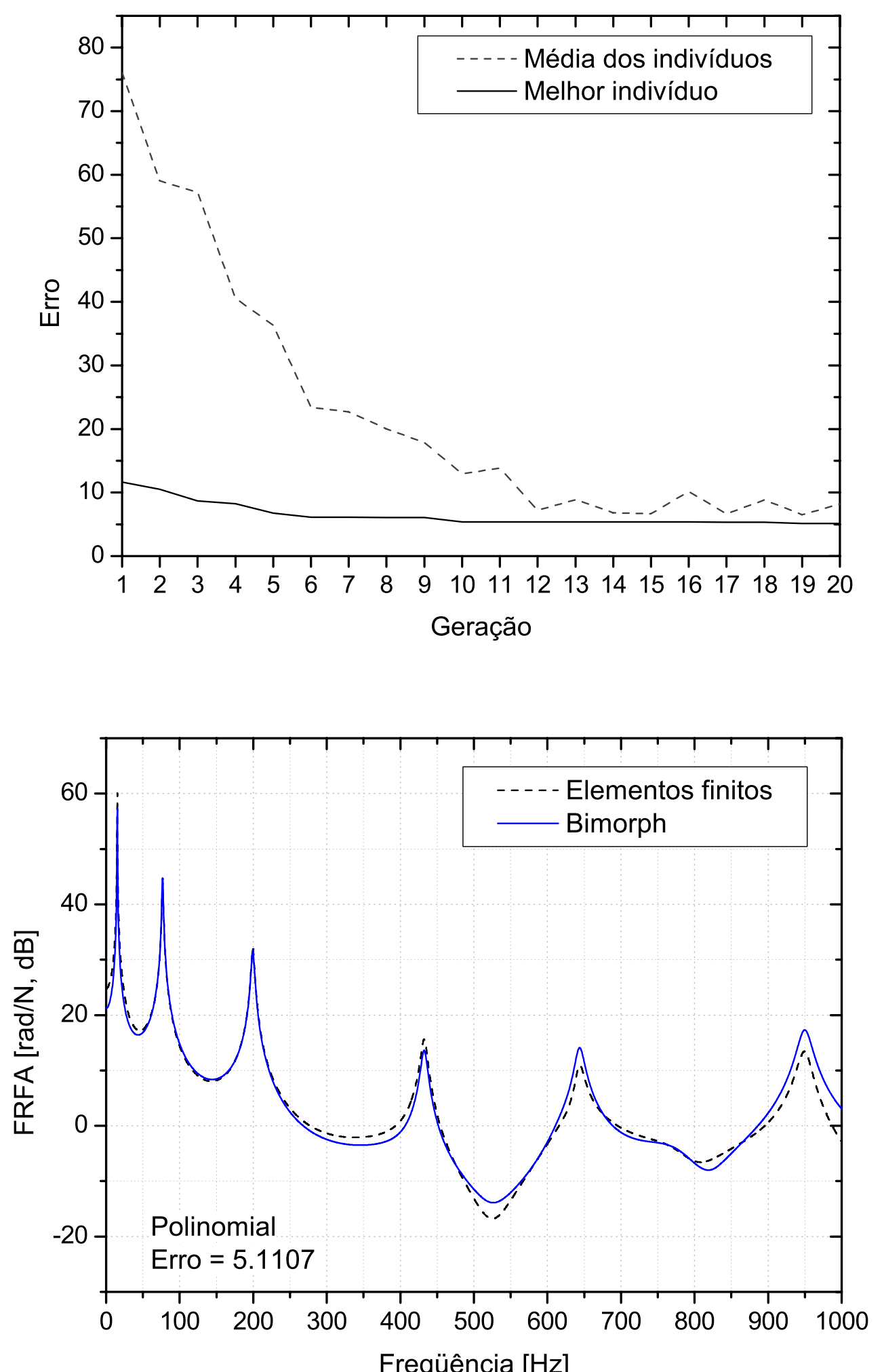

$n=3: x_{b 1}=10 \mathrm{~mm}, x_{b 2}=166 \mathrm{~mm}, x_{b 3}=450 \mathrm{~mm}$ e $s_{b 1}=22 \mathrm{~mm}, s_{b 2}=42 \mathrm{~mm} \mathrm{e}$ $s_{b 3}=45 \mathrm{~mm}$

Figura 4.20: Evolução dos indivíduos e FRFA para $x_{\text {out }}=100 \mathrm{~mm}$ 

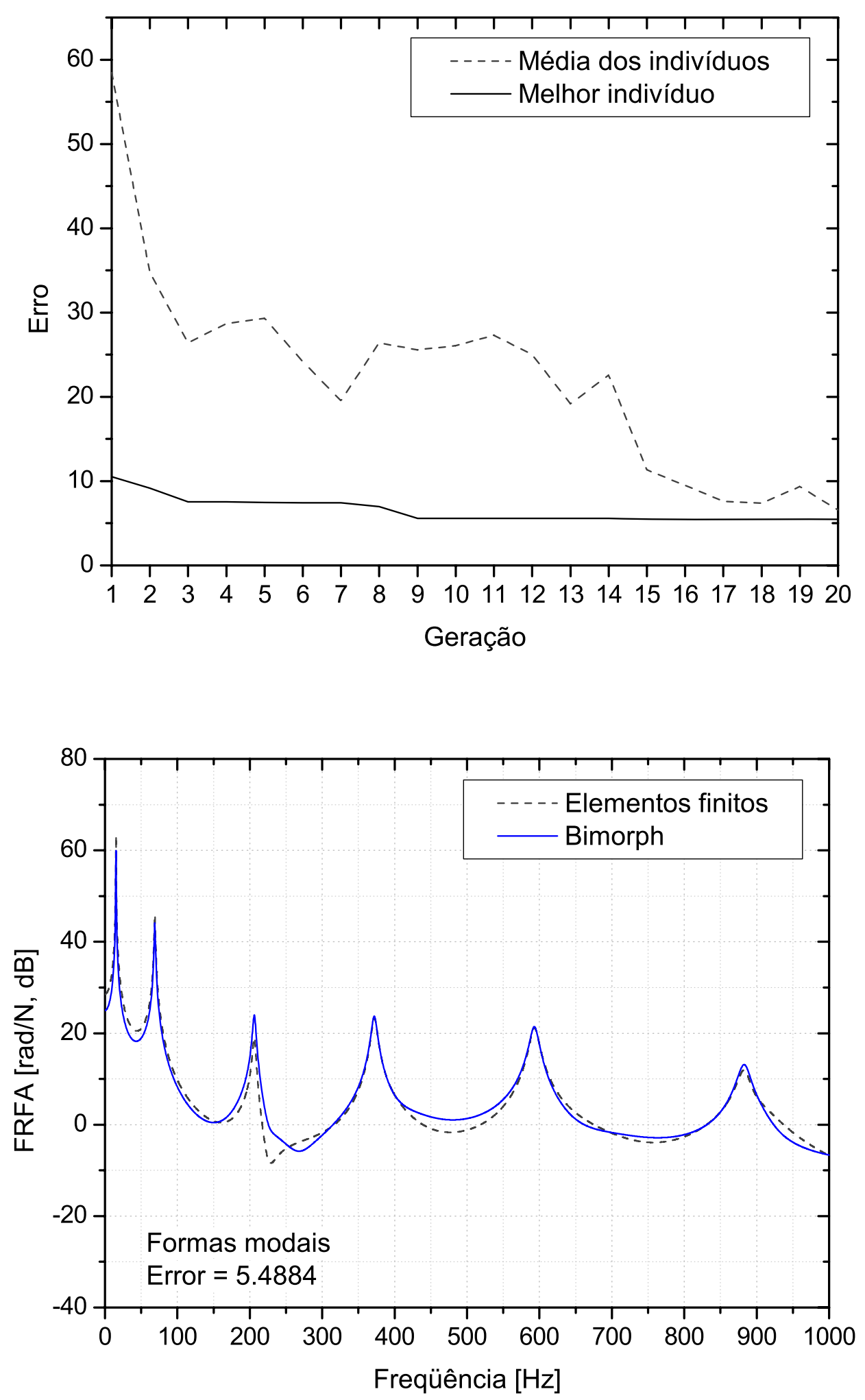

$n=3: x_{b 1}=428 \mathrm{~mm}, x_{b 2}=14 \mathrm{~mm}, x_{b 3}=120 \mathrm{~mm}$ e $s_{b 1}=37 \mathrm{~mm}, s_{b 2}=66 \mathrm{~mm} \mathrm{e}$ $s_{b 3}=42 \mathrm{~mm}$

Figura 4.21: Evolução dos indivíduos e FRFA para $x_{\text {out }}=150 \mathrm{~mm}$ 

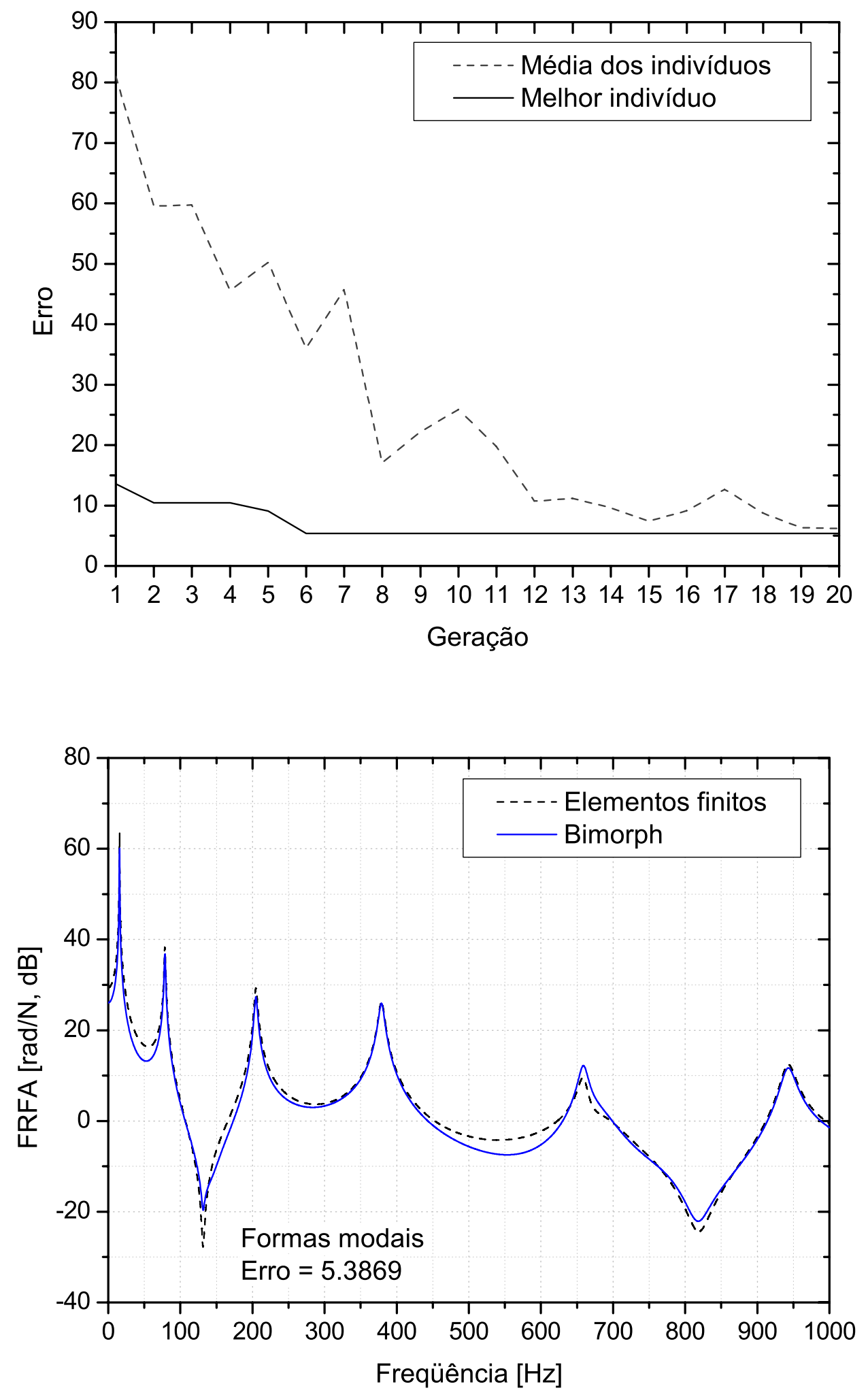

$n=2: x_{b 1}=28 \mathrm{~mm}, x_{b 2}=96 \mathrm{~mm}$ e $s_{b 1}=38 \mathrm{~mm}, s_{b 2}=24 \mathrm{~mm}$

Figura 4.22: Evolução dos indivíduos e FRFA para $x_{\text {out }}=200 \mathrm{~mm}$ 

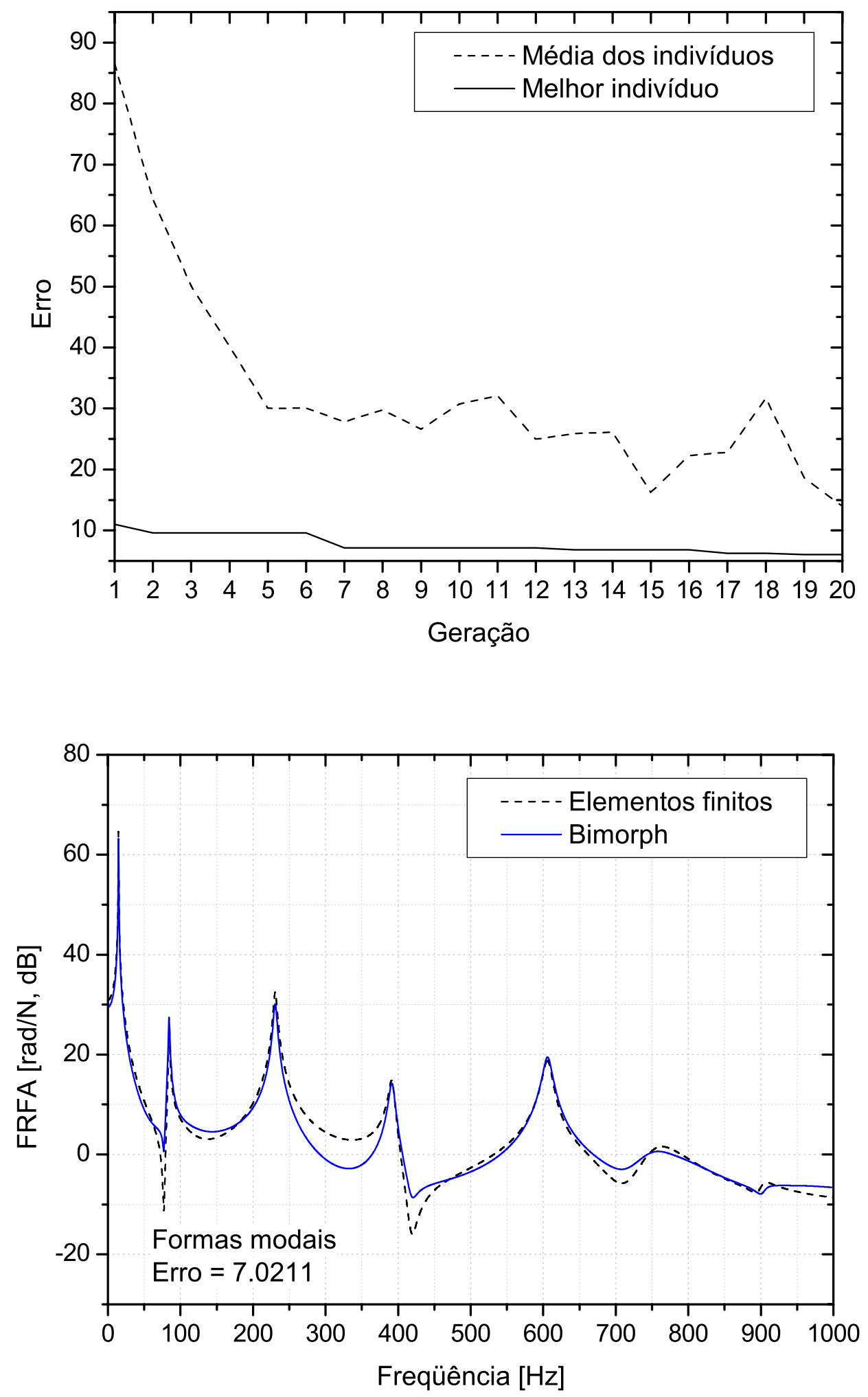

$n=3: x_{b 1}=408 \mathrm{~mm}, x_{b 2}=50 \mathrm{~mm}, x_{b 3}=170 \mathrm{~mm}$ e $s_{b 1}=29 \mathrm{~mm}, s_{b 2}=33 \mathrm{~mm} \mathrm{e}$ $s_{b 3}=60 \mathrm{~mm}$

Figura 4.23. Evolução dos indivíduos e FRFA para $x_{\text {out }}=250 \mathrm{~mm}$ 

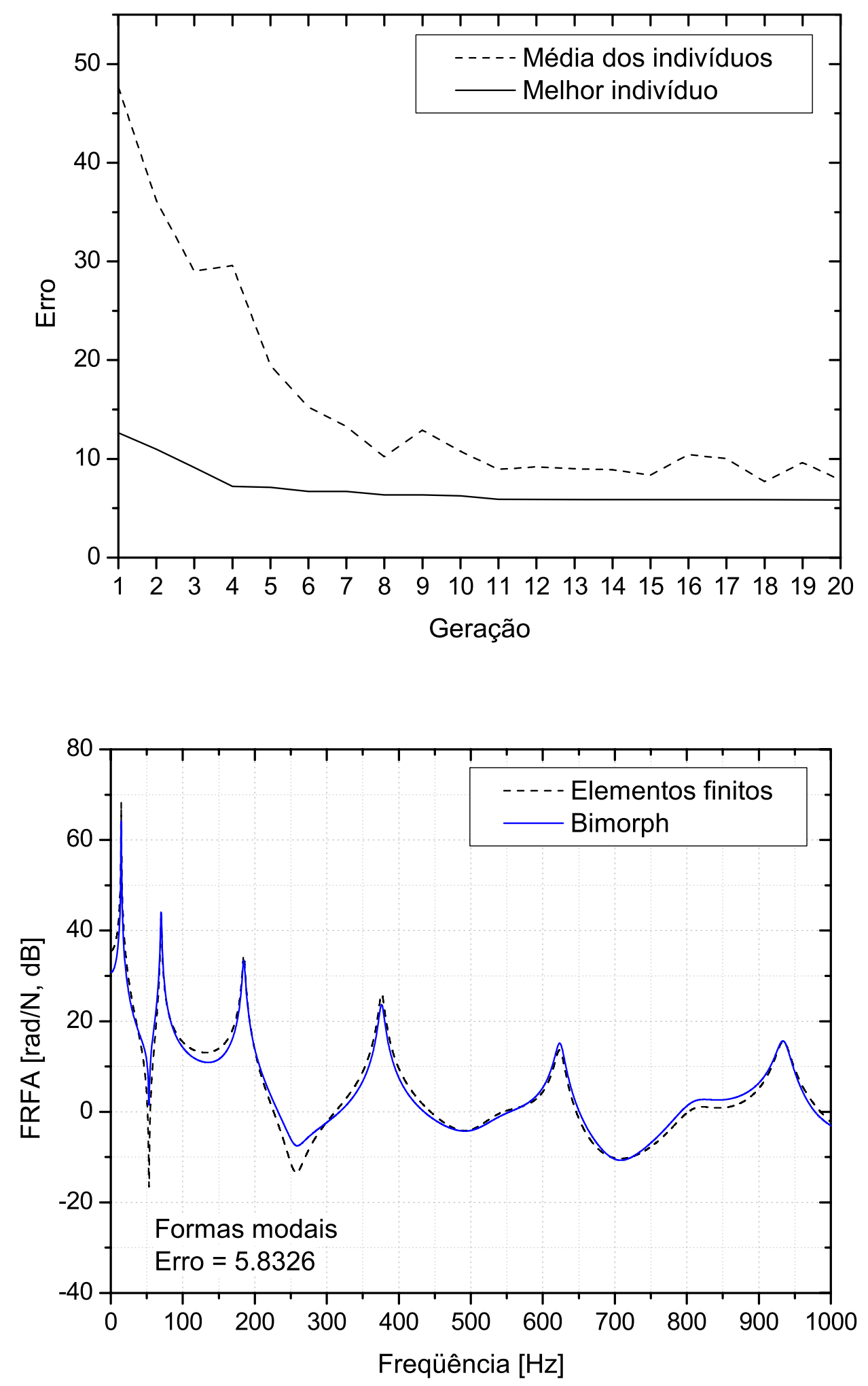

$n=2: x_{b 1}=8 \mathrm{~mm}, x_{b 2}=116 \mathrm{~mm}$ e $s_{b 1}=27 \mathrm{~mm}, s_{b 2}=56 \mathrm{~mm}$

Figura 4.24. Evolução dos indivíduos e FRFA para $x_{\text {out }}=300 \mathrm{~mm}$ 

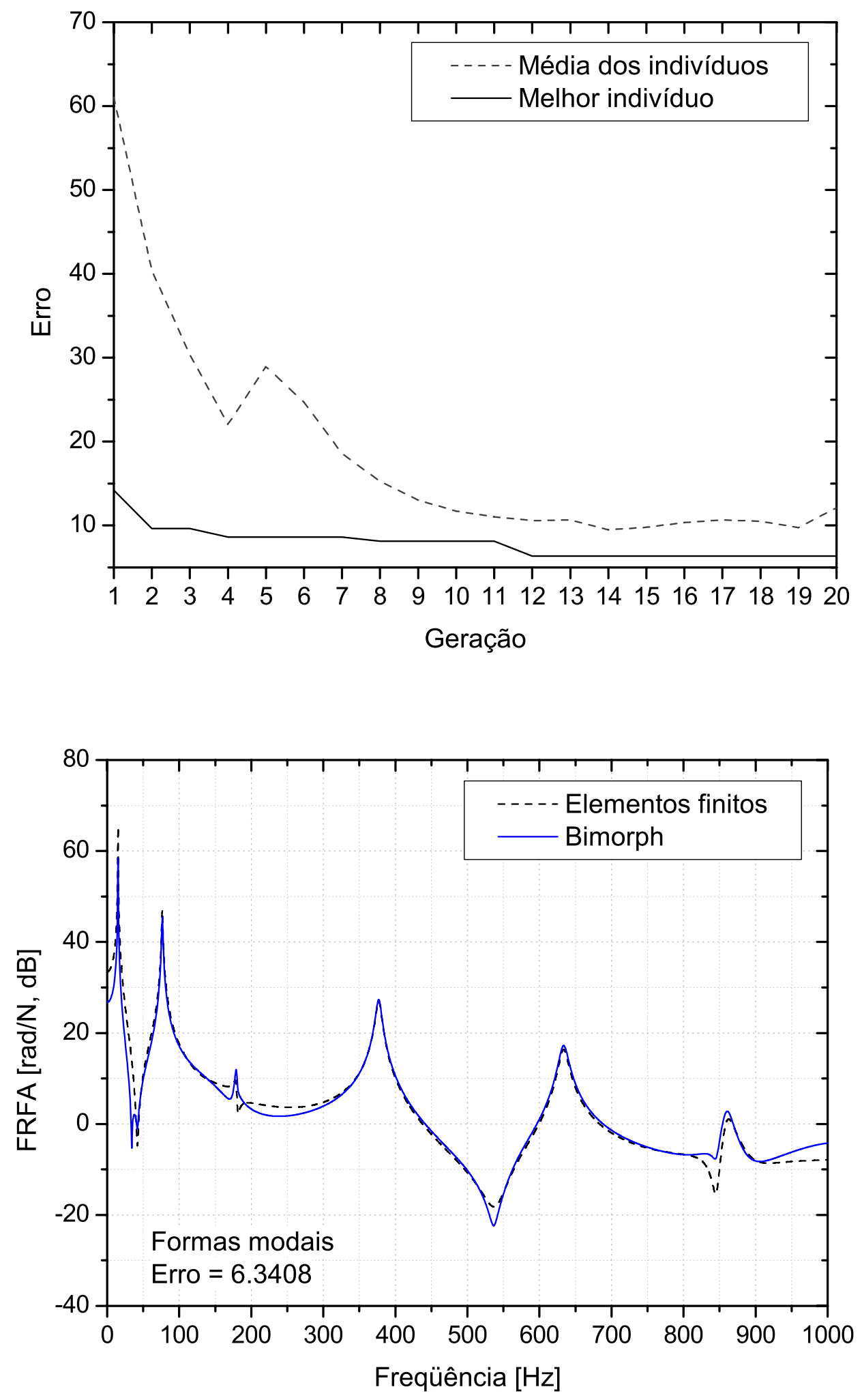

$n=3: x_{b 1}=30 \mathrm{~mm}, x_{b 2}=134 \mathrm{~mm}, x_{b 3}=190 \mathrm{~mm}$ e $s_{b 1}=17 \mathrm{~mm}, s_{b 2}=29 \mathrm{~mm} \mathrm{e}$ $s_{b 3}=64 \mathrm{~mm}$

Figura 4.25. Evolução dos indivíduos e FRFA para $x_{\text {out }}=350 \mathrm{~m}$ 

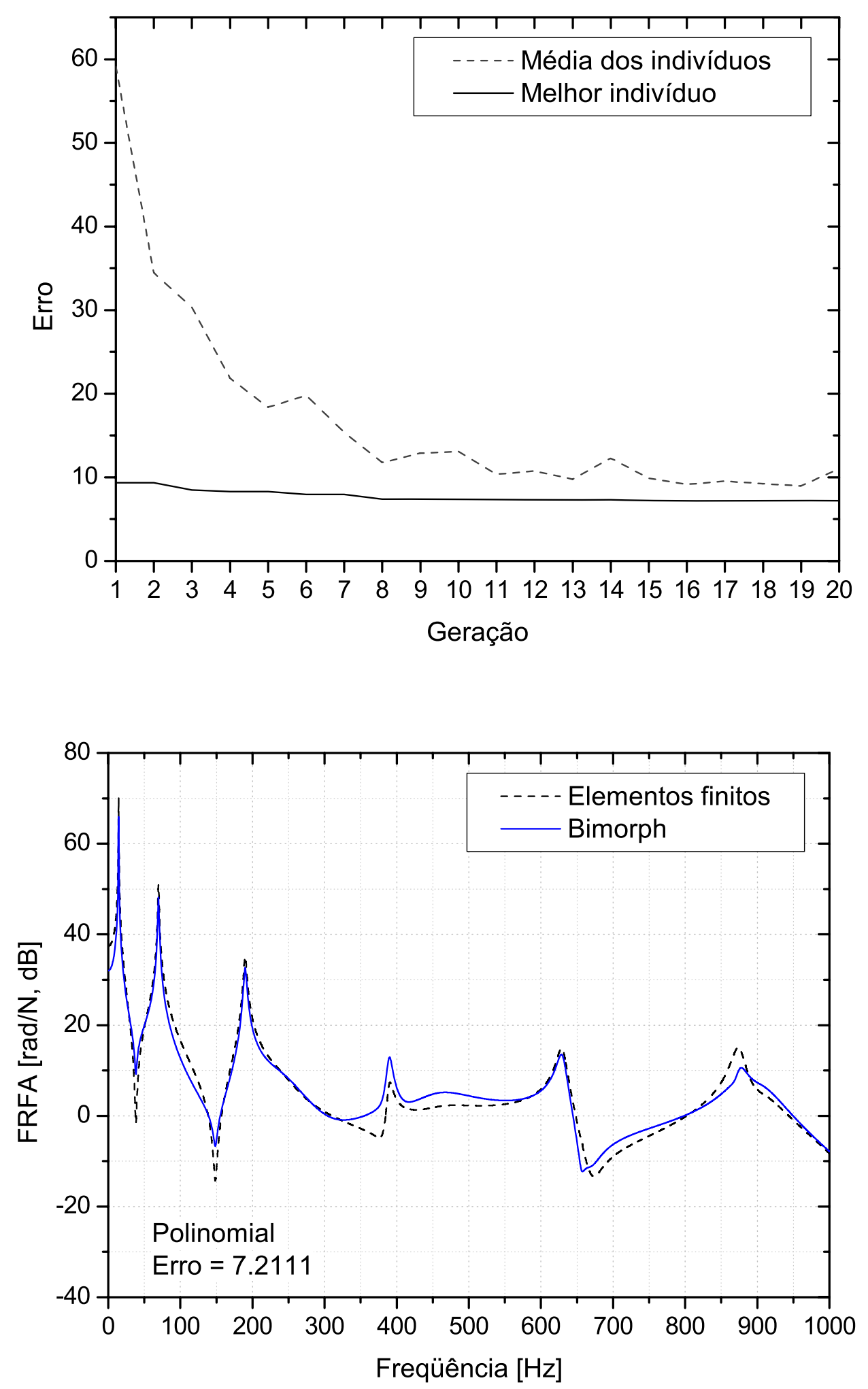

$n=3: x_{b 1}=30 \mathrm{~mm}, x_{b 2}=304 \mathrm{~mm}, x_{b 3}=152 \mathrm{~mm}$ e $s_{b 1}=18 \mathrm{~mm}, s_{b 2}=57 \mathrm{~mm} \mathrm{e}$ $s_{b 3}=34 \mathrm{~mm}$

Figura 4.26: Evolução dos indivíduos e FRFA para $x_{\text {out }}=400 \mathrm{~mm}$ 

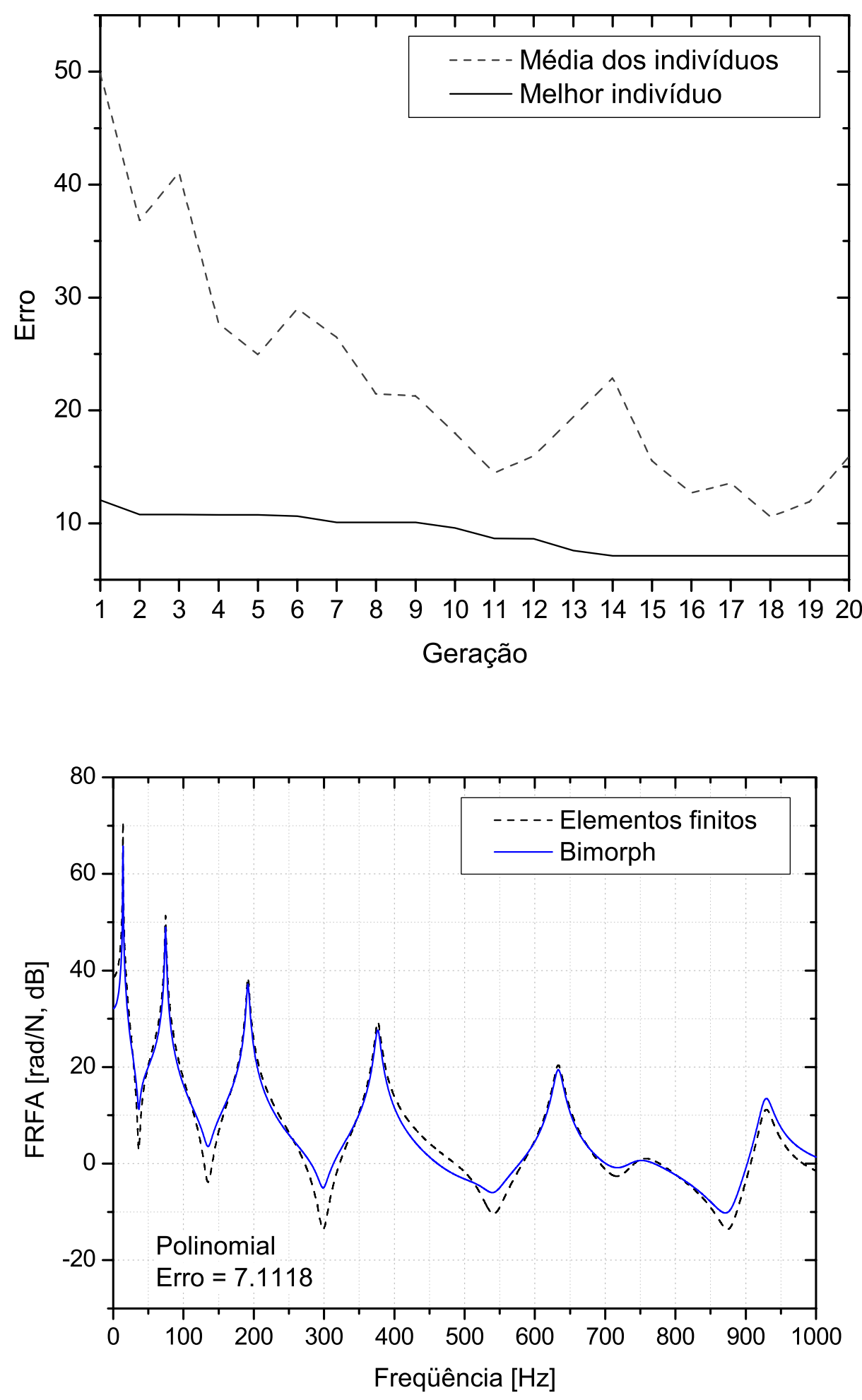

$$
n=1: x_{b 1}=8 \mathrm{~mm} \text { e } s_{b 1}=51 \mathrm{~mm}
$$

Figura 4.27: Evolução dos indivíduos e FRFA para $x_{\text {out }}=450 \mathrm{~mm}$ 

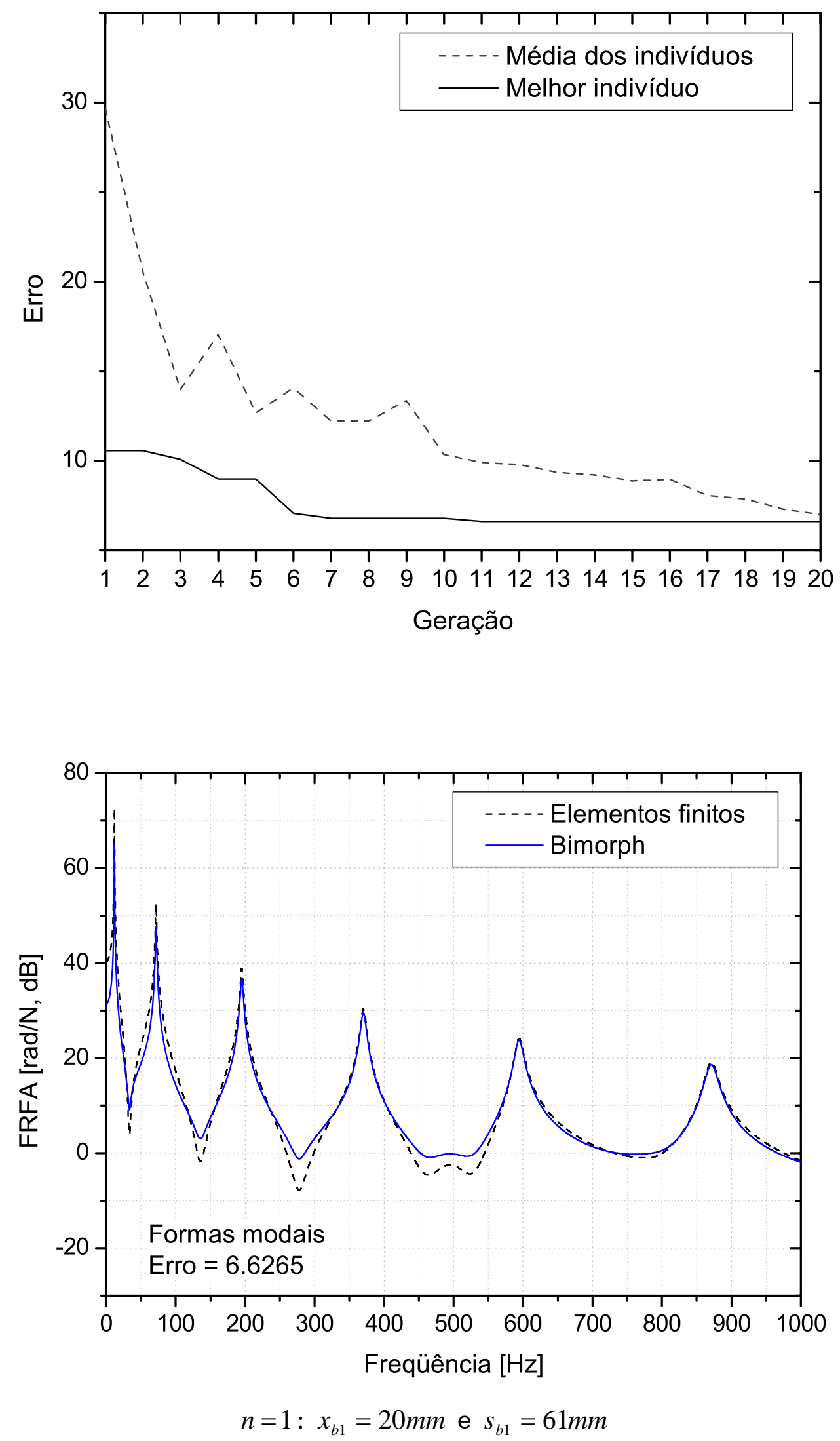

Figura 4.28: Evolução dos indivíduos e FRFA para $x_{\text {out }}=500 \mathrm{~mm}$ 


\subsubsection{RESULTADOS EXPERIMENTAIS}

Apresenta-se a seguir os resultados experimentais na determinação de FRFs angulares para estruturas do tipo viga através da utilização de sensores bimorphs.

Uma das dificuldades encontradas nesta etapa deveu-se a aquisição de pastilhas cerâmicas de tamanhos satisfatórios para o corte e montagem dos bimorphs de acordo com os resultados oriundos do procedimento evolutivo por algoritmos genéticos.

Optou-se pela construção de dois bimorphs de dimensão $s_{b}=25 \mathrm{~mm}\left(625 \mathrm{~mm}^{2}\right.$ cada pastilha piezelétrica), respeitando a condição de que cada sensor tivesse a mesma largura da viga $(25 \mathrm{~mm})$. A partir de uma placa de dimensões $60 \mathrm{~mm} \times 60 \mathrm{~mm}$ de PZT-5H, gentilmente cedida pelo Prof. Dr. Marcelo Areias Trindade, foi possível então construir os dois sensores, bem como, realizar testes de montagem com as sobras de materiais após o corte.

\subsubsection{MONTAGEM DOS SENSORES BIMORPH}

A seguir, descrevem-se os procedimentos empregados no corte, colagem e montagem dos contatos e de cada bimorph.

O primeiro passo foi realizar o corte da pastilha de $\mathrm{PZT}-5 \mathrm{H}$ em quatro pastilhas de $25 \mathrm{~mm} \times 25 \mathrm{~mm}$. Observa-se na Figura 4.29 que as linhas de corte foram demarcadas com $1 \mathrm{~mm}$ a mais em cada dimensão. Isso se deve ao tamanho do disco de corte disponível no laboratório do Grupo de Cerâmicas Ferroelétricas Departamento de Física - Universidade Federal de São Carlos (UFSCar), que também gentilmente cedeu o equipamento para o corte da pastilha cerâmica. 
As marcas no formato de " $X$ " indicam o sentido de polarização de cada pastilha, sentido este, muito importante na montagem dos bimorphs.

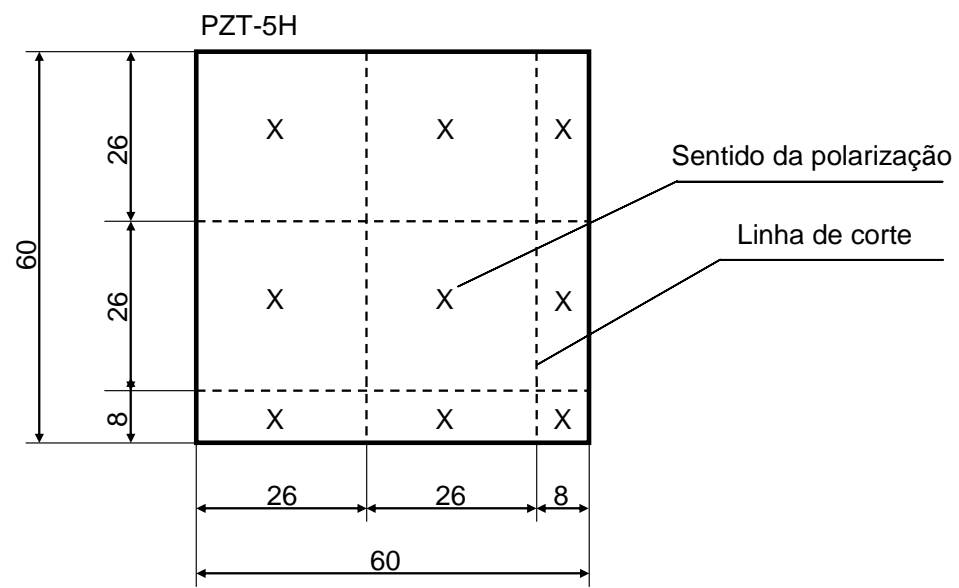

a) Linhas de corte da pastilha

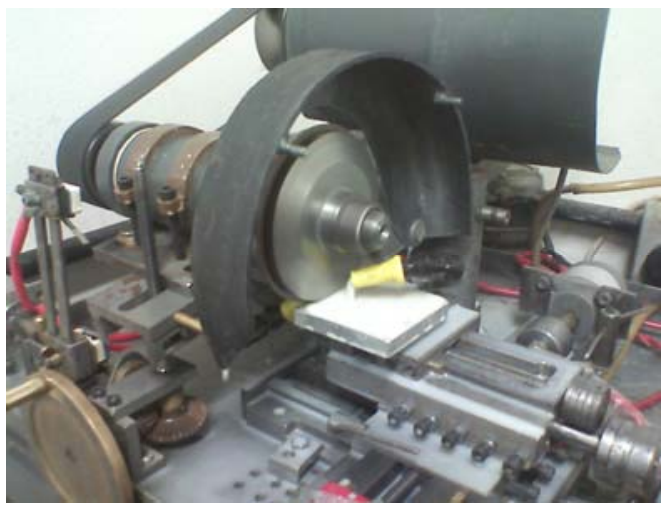

b) Corte da pastilha

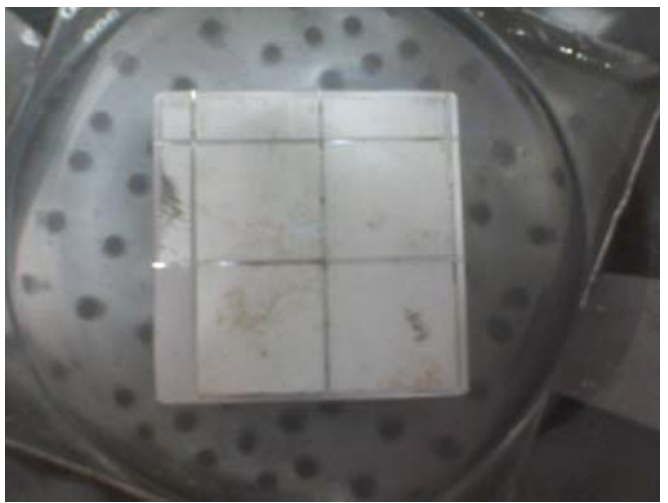

c) Remoção das pastilhas por ultra-som

Figura 4.29: Dimensões da pastilha cerâmica piezelétrica (PZT-5H) e procedimento de corte e remoção das pastilhas do suporte de fixação

As dimensões requeridas foram finalmente atingidas através do lixamento de cada aresta das pastilhas com lixas 400, 200 e 100, respectivamente.

Para realizar a colagem das pastilhas cerâmicas foram seguidos alguns procedimentos básicos como a limpeza mecânica das superfícies para a retirada de resíduos sólidos e poeira e a limpeza química (álcool isopropílico) para a retirada de graxas, gorduras e óleos. 
Como a montagem dos bimorphs segue a configuração em paralelo (Figura 2.3a), um cuidado especial foi tomado com relação aos contatos elétricos. Para tal, foram escolhidas lâminas de cobre com espessuras inferiores a 0,25mm. Estas lâminas foram coladas às camadas de eletrodos das pastilhas cerâmicas através de uma tinta condutiva adesiva utilizada na reconstrução de trilhas de circuitos impressos. Os fios utilizados são esmaltados e possuem aplicação comum em medições com strain-gages.
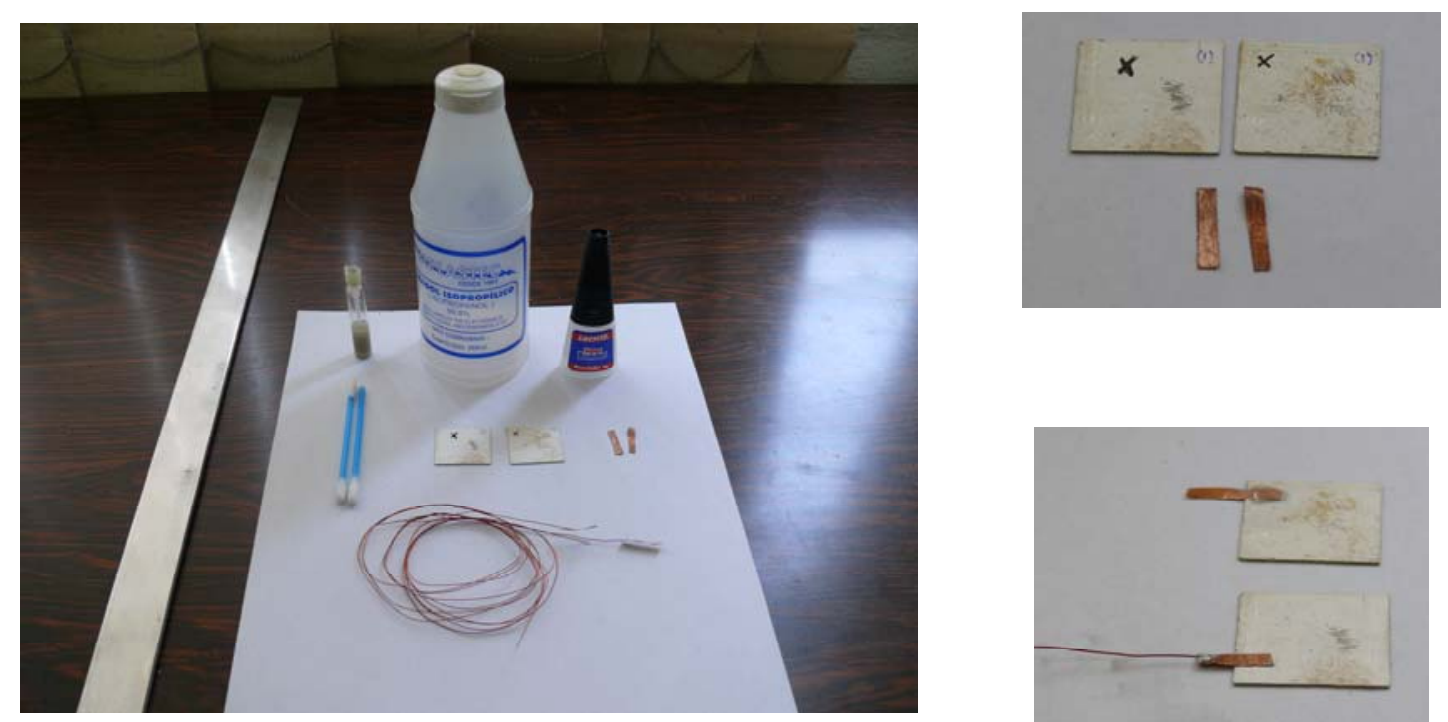

Figura 4.30: Materiais utilizados na confecção dos bimorphs

Para a colagem entre as duas camadas foi utilizada uma cola do tipo cianoacrilato - Loctite Super Bonder Precisão ${ }^{\circledR}$ (tubo de 5g). Para garantir o contato entre a pastilha inferior e a superior, distribuiu-se uma camada de tinta condutiva adesiva sobre o condutor de cobre (lâmina).

Após espalhar uma fina camada sobre o topo da pastilha inferior, deixando de cobrir apenas a região com a tira de cobre coberta pela tinta condutiva adesiva, a pastilha superior foi posicionada sobre a inferior e então logo pressionada. 
Ensaios mecânicos para assegurar a eficiência da colagem, bem como, a utilização da folha de cobre, foram realizados com os retalhos das cerâmicas piezelétricas em estruturas testes. Após diversos ciclos de excitação, a cola e a folha de cobre mostraram-se aptas na construção dos sensores bimorphs.

A Figura 4.31 ilustra um dos sensores bimorphs finalizado. No contato superior foi posto um pingo de cola para assegurar que o mesmo não se soltasse, bem como, no contato inferior, o mesmo foi recoberto com cola para evitar qualquer contato elétrico entre a viga e o bimorph.
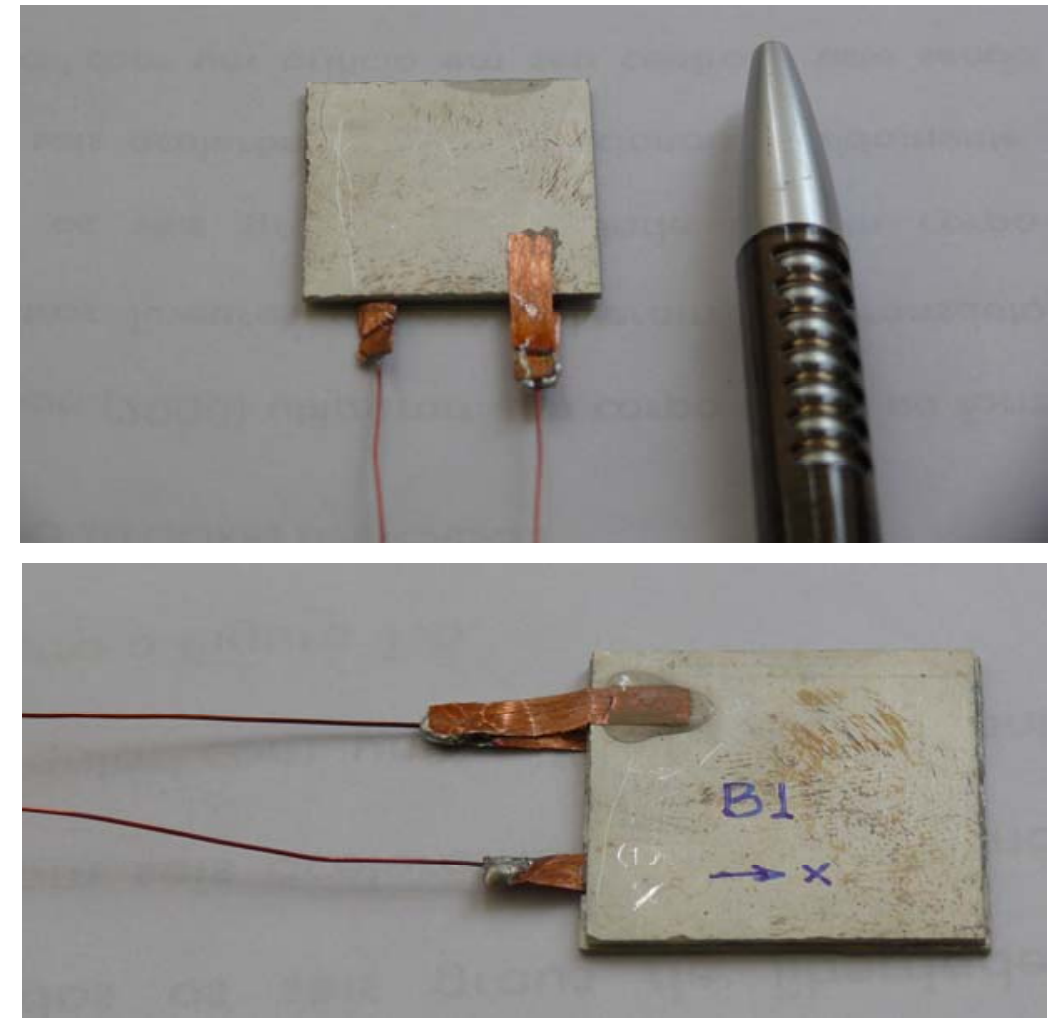

Figura 4.31: Sensor bimorph confeccionado

Para colagem dos bimorphs sobre a viga foram seguidos os mesmos procedimentos de limpeza e colagem. Além disso, demarcou-se o perímetro de cada sensor na superfície da viga. A Figura 4.32 ilustra a viga e os respectivos sensores 
bimorphs "B1" e "B2" após todo o procedimento de montagem e engaste da estrutura.
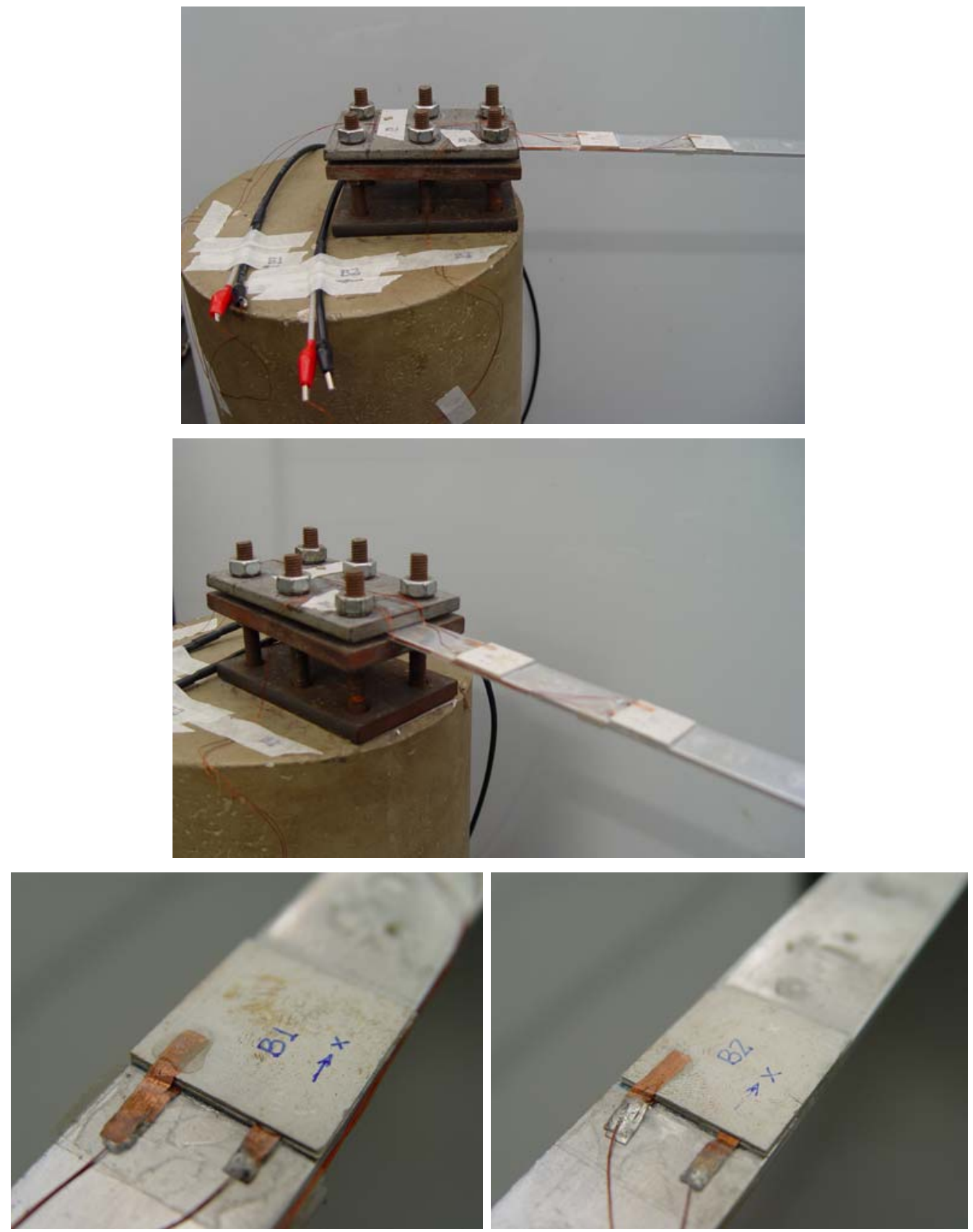

Figura 4.32: Sensores bimorphs posicionados sobre a viga

A escolha do posicionamento dos dois bimorphs foi obtida de acordo com o mesmo algoritmo genético visto anteriormente. No entanto, a otimização das dimensões não foi adotada em vista da limitação física durante a construção. Buscou- 
se encontrar um posicionamento que resultasse em boas estimativas para alguns pontos de leitura da resposta da estrutura. $O$ resultado encontrado foi: $x_{b 1}=42 \mathrm{~mm} \mathrm{e}$ $x_{b 2}=124 \mathrm{~mm}$ para os respectivos pontos de estimativa da rotação: 150, 200 e $300 \mathrm{~mm}$.

Após a colagem, fitas adesivas foram utilizadas para assegurar que os fios não vibrassem proporcionando uma possível fadiga e rompimento das folhas de cobre.

\subsubsection{FUNÇÕES DE RESPOSTA EM FREQUENCIA ANGULARES}

aparato experimental montado utilizou um analisador espectral Tectronix modelo 2630, um martelo de impacto PCB, dois amplificadores PCB modelo 478A01, um acelerômetro angular Kistler modelo $8840\left(34 \mu \mathrm{V} / \mathrm{rad} / \mathrm{s}^{2}\right)$, uma fonte de tensão/corrente elétrica ajustável e dois cabos BNC modificados para a captura da tensão elétrica resultante em cada bimorph (ver Figura 4.33).

Utilizou-se uma resolução em freqüência de $0,2441 \mathrm{~Hz}$ para um intervalo de análise de 0 à $1000 \mathrm{~Hz}$ tomando-se 4096 pontos neste intervalo para uma média entre 10 avaliações. Os sinais foram tratados utilizando-se o software Origin $7^{\circledR}$, assim como, o software Matlab $6.5^{\circledR}$.

Os resultados apresentados a seguir comparam, para cada ponto de estimativa na estrutura $\left(x_{\text {out }}\right)$, as FRFs angulares do modelo em elementos finitos, da estimativa numérica baseada na utilização dos bimorphs, assim como, para o acelerômetro angular, cuja integração numérica foi realizada através do software Origin $7^{\circledR}$. Salienta-se, assim como efetuado nas simulações numéricas, que o ponto de excitação é fixo, está localizado na extremidade livre da viga e ocorre na direção z. 


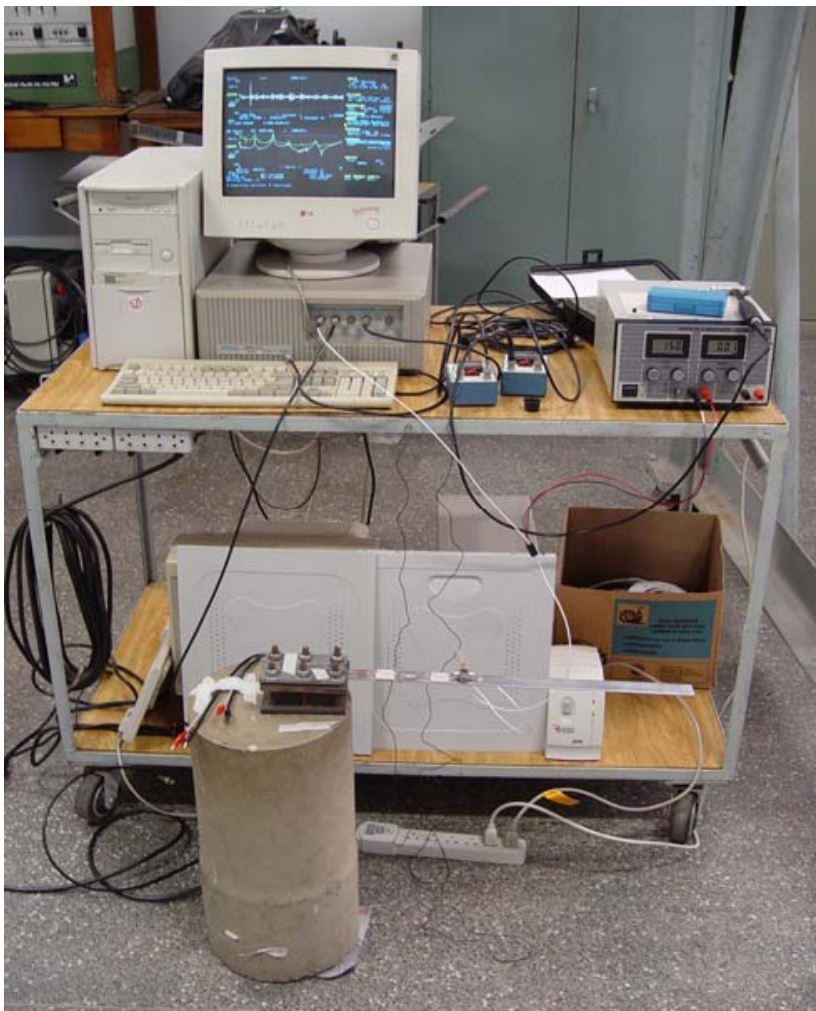

Figura 4.33: Aparato experimental

As figuras 4.34 a 4.36 ilustram os resultados obtidos.

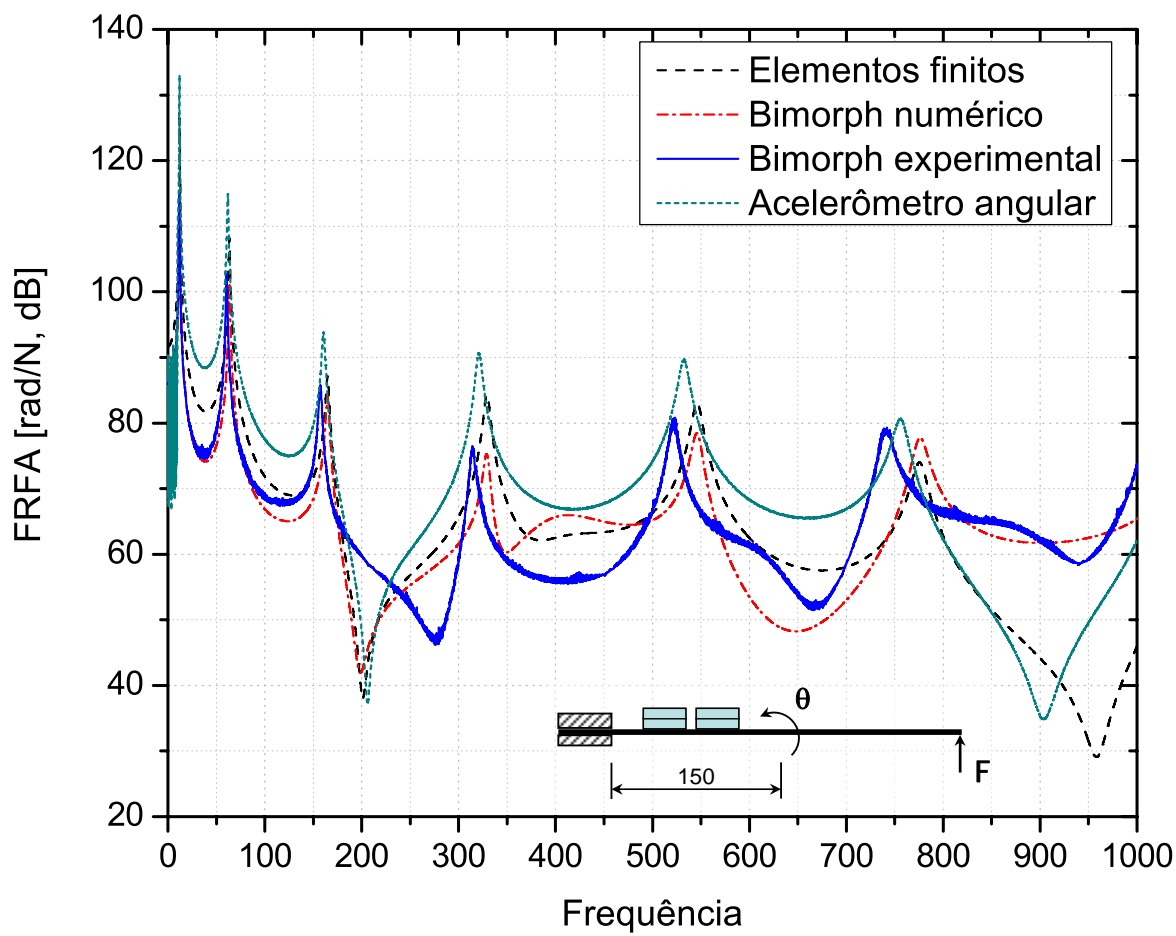

Figura 4.34: Resultado experimental: $x_{\text {out }}=150 \mathrm{~mm}$ 


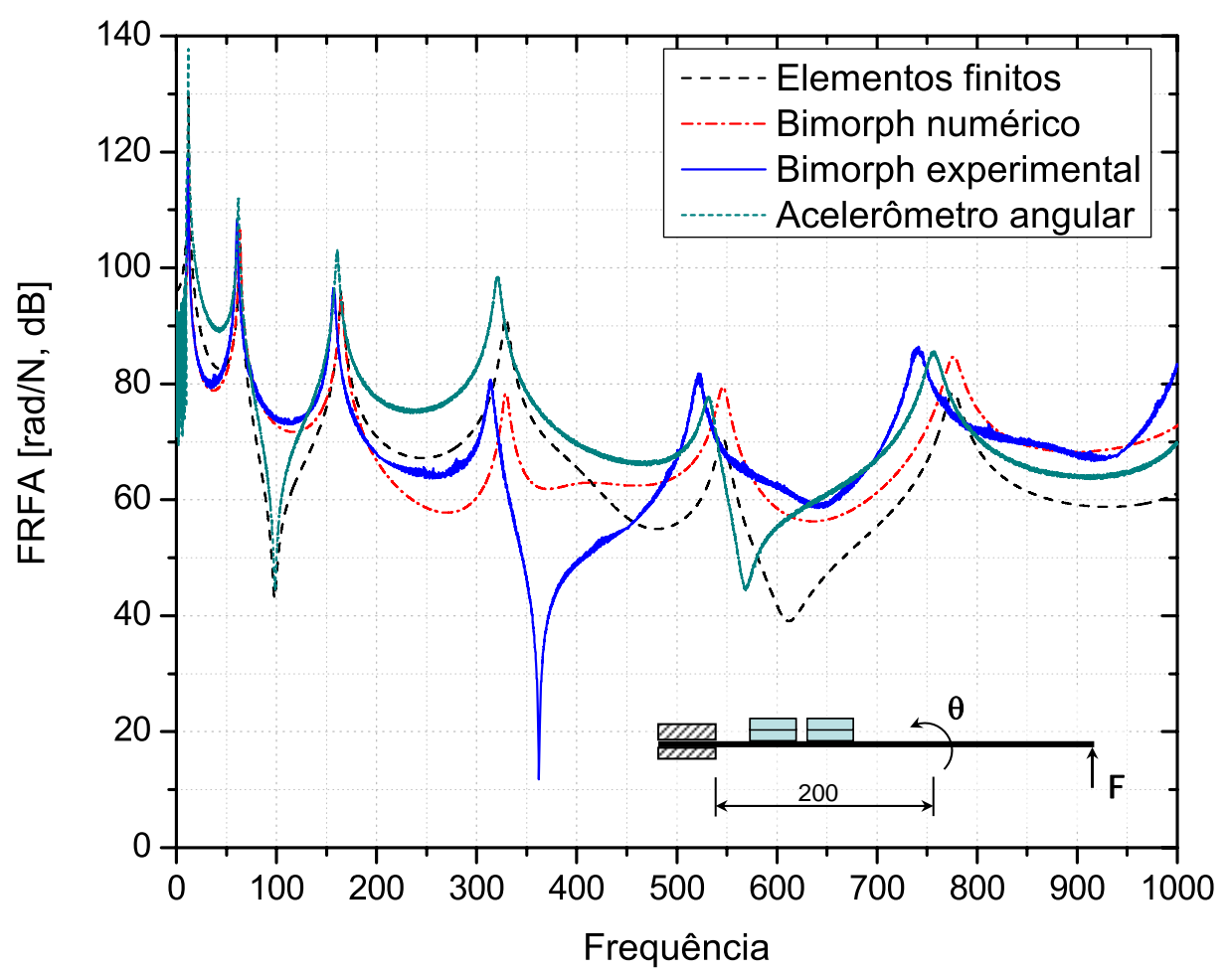

Figura 4.35: Resultado experimental: $x_{\text {out }}=200 \mathrm{~mm}$

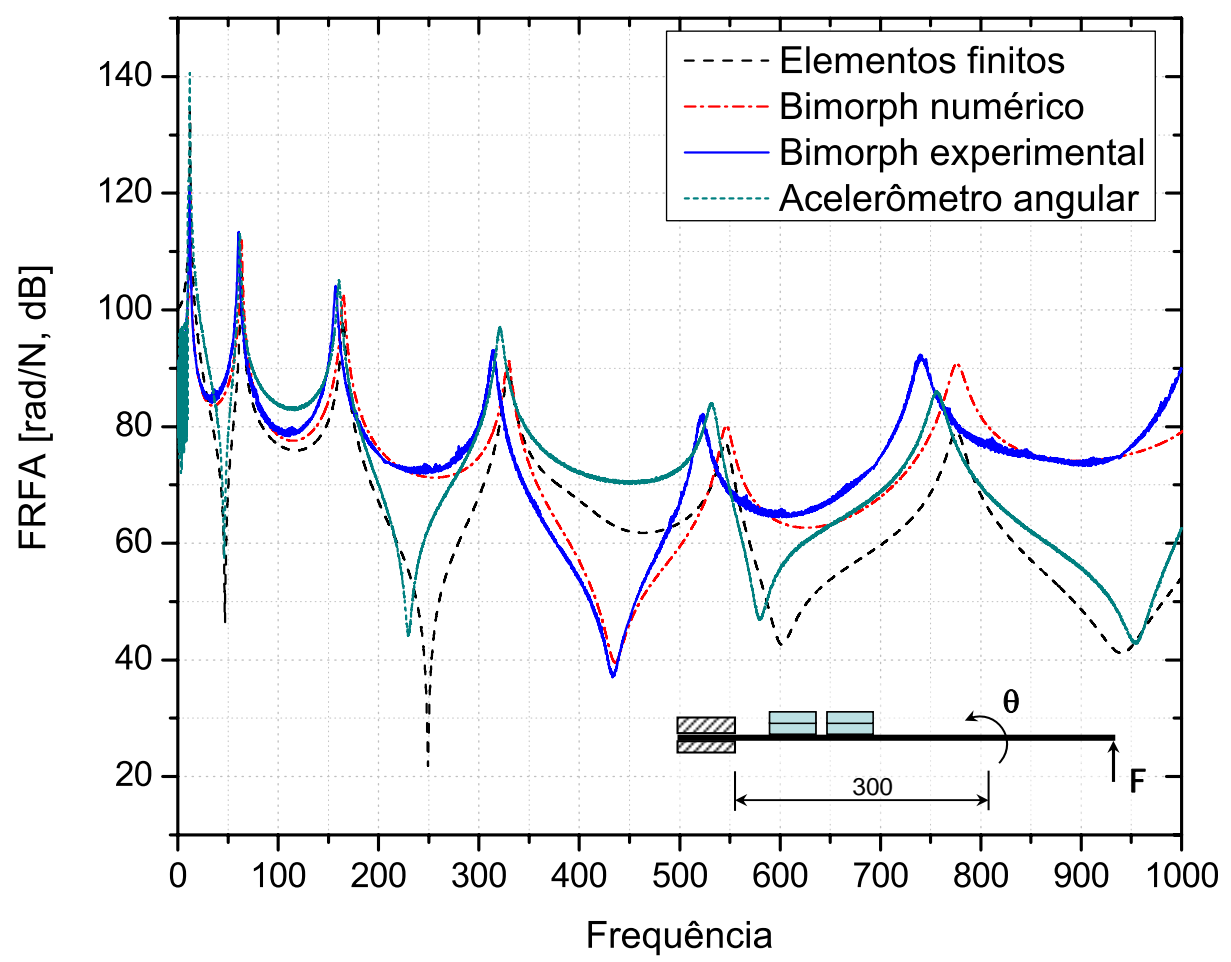

Figura 4.36: Resultado experimental: $x_{\text {out }}=300 \mathrm{~mm}$ 
Observa-se, primeiramente, que os resultados experimentais concordam satisfatoriamente com as estimativas numéricas em todos os pontos investigados. No entanto, em relação ao método dos elementos finitos, os resultados divergem tendo em vista que a otimização ocorreu apenas para o posicionamento de dois sensores bimorphs e para uma estimativa média entre os pontos selecionados.

Nota-se também uma divergência dos resultados em comparação ao acelerômetro angular. Em particular, este sensor não apresenta acuracidade para baixas freqüências, porém as freqüências de ressonância foram bem estimadas.

Para a divergência entre as freqüências de ressonâncias explica-se o fato das estimativas numéricas acima não considerarem a presença do acelerômetro angular. Tal efeito pode ser corrigido ao se considerar uma camada adicional sobre a viga equivalente ao acelerômetro angular em termos da sua inércia.

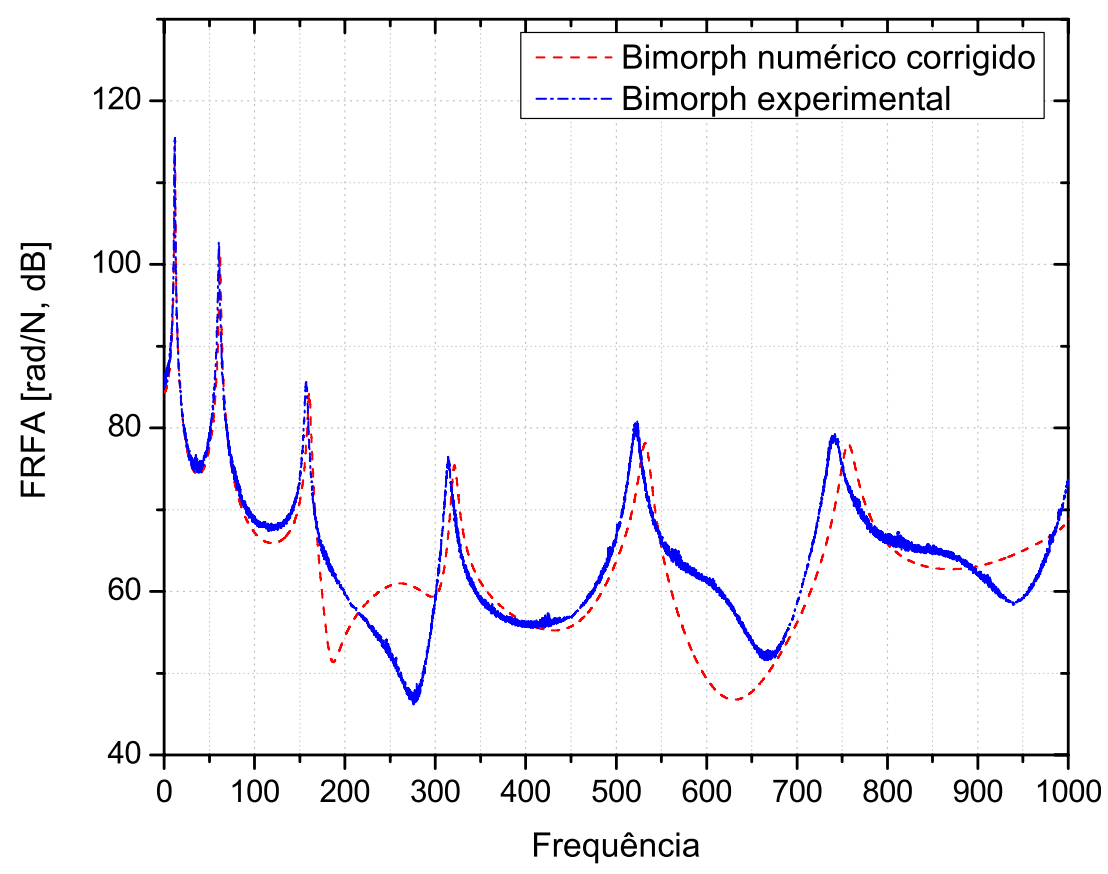

Figura 4.37: Correção da estimativa numérica $\left(x_{\text {out }}=150 \mathrm{~mm}\right)$ 


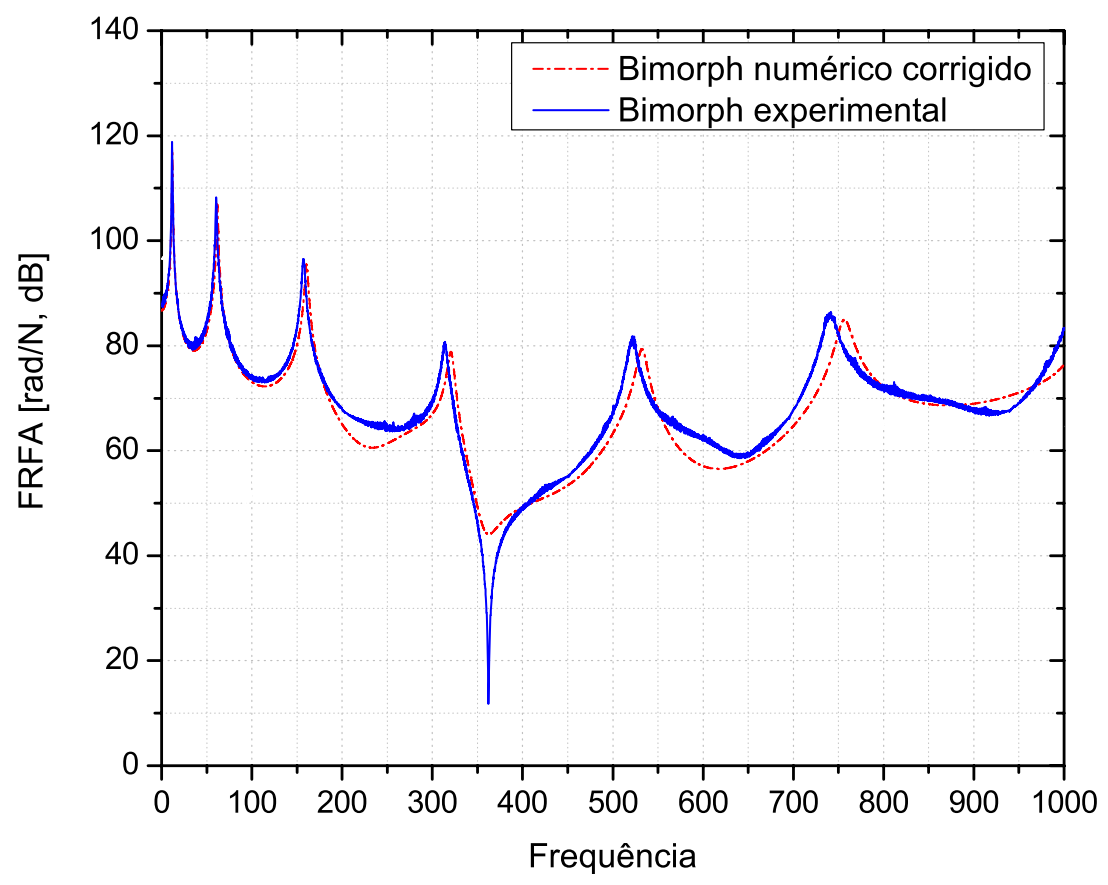

Figura 4.38: Correção da estimativa numérica $\left(x_{\text {out }}=200 \mathrm{~mm}\right)$

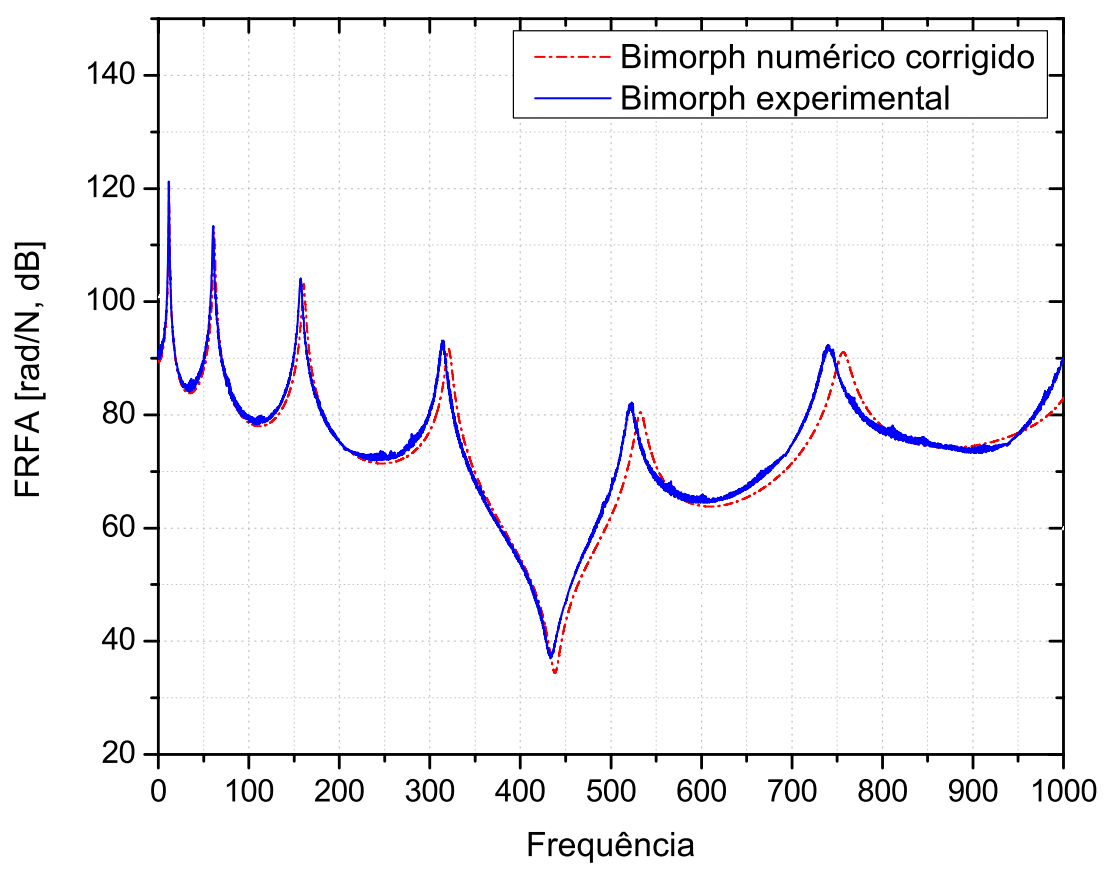

Figura 4.39: Correção da estimativa numérica $\left(x_{\text {out }}=300 \mathrm{~mm}\right.$ ) 
Nota-se que através da consideração da presença do acelerômetro angular, os resultados em termos das freqüências de ressonância melhoraram bastante, assim como, a proximidade entre os resultados numéricos e experimentais. Tais resultados, conseqüentemente, validam a técnica no caso de estruturas do tipo viga.

\subsection{ESTRUTURAS DO TIPO PLACA}

- modelo considerado nesta tese consiste de uma placa retangular de alumínio simplesmente apoiada em todas as extremidades com espessura de $3 \mathrm{~mm}$ cujas dimensões nas direções $x$ e $y$ são, respectivamente, $L_{x}=320 \mathrm{~mm}$ e $L_{y}=280 \mathrm{~mm}$. Adotou-se ainda pastilhas cerâmicas piezelétricas quadradas do tipo PZT-5H de espessura igual a $h_{p}=0,5 \mathrm{~mm}$ e dimensão $L_{p x}=L_{p y}=25 \mathrm{~mm}$.

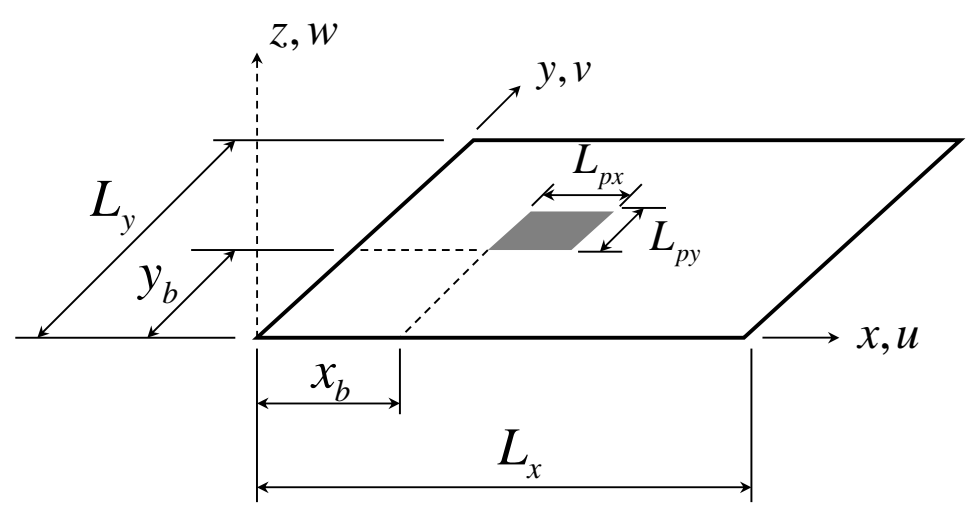

Figura 4.40: Dimensões principais na modelagem da placa

As propriedades consideradas para o material da placa encontram-se resumidas na Tabela 4.1 .

Tabela 4.1. Propriedades do material da placa

\begin{tabular}{ccc}
\hline$E\left(\times 10^{9} \mathrm{Nm}^{-2}\right)$ & $\rho\left(\mathrm{kg} \mathrm{m}^{-3}\right)$ & $v$ \\
\hline 70 & 2700 & 0.3 \\
\hline
\end{tabular}


As propriedades para o material das pastilhas (PZT-5H) são as seguintes:

$$
\begin{gathered}
S_{E}=\left[\begin{array}{cccccc}
16,5 & -4,78 & -8,45 & 0 & 0 & 0 \\
-4,78 & 16,5 & -8,45 & 0 & 0 & 0 \\
-8,45 & -8,45 & 20,7 & 0 & 0 & 0 \\
0 & 0 & 0 & 43,5 & 0 & 0 \\
0 & 0 & 0 & 0 & 43,5 & 0 \\
0 & 0 & 0 & 0 & 0 & 42,6
\end{array}\right] \frac{p m^{2}}{N} ; d=\left[\begin{array}{ccc}
0 & 0 & -274 \\
0 & 0 & -274 \\
0 & 0 & 593 \\
0 & 741 & 0 \\
741 & 0 & 0 \\
0 & 0 & 0
\end{array}\right] \frac{p C}{N} \\
\frac{\in_{T}}{\in_{0}}=\left[\begin{array}{ccc}
3130 & 0 & 0 \\
0 & 3130 & 0 \\
0 & 0 & 3400
\end{array}\right]
\end{gathered}
$$

onde $\epsilon_{0}=8,854 \mathrm{pFm}^{-1}$

Como excitação para a estrutura, considerou-se sempre uma entrada do tipo impulsiva de amplitude unitária no ponto $\left(x_{i n}, y_{\text {in }}\right)=(200,25) \mathrm{mm}$.

\subsubsection{AVALIAÇÃO DO MÉTODO DE APROXIMAÇÃO}

Como visto anteriormente, um método de aproximação para a determinação do campo de deslocamentos e, conseqüentemente, da curvatura em qualquer ponto da placa foi proposto: a aproximação por formas modais. Estas formas modais, por sua vez, são oriundas da aproximação pelo método de Rayleigh-Ritz (RR).

Como visto anteriormente, para cada bimorph disposto sobre a placa, um único modo de vibrar, traduzido por funções trigonométricas, será utilizado para aproximar o campo de deslocamentos $w(x, y)$ da placa. Dois casos foram estudados no intuito de avaliar a capacidade da técnica em estimar as FRFs angulares de acordo com o número de sensores utilizados. No primeiro caso, 4 sensores bimorphs $(n=4)$ foram dispostos sobre a placa (ver Figura 4.41). 

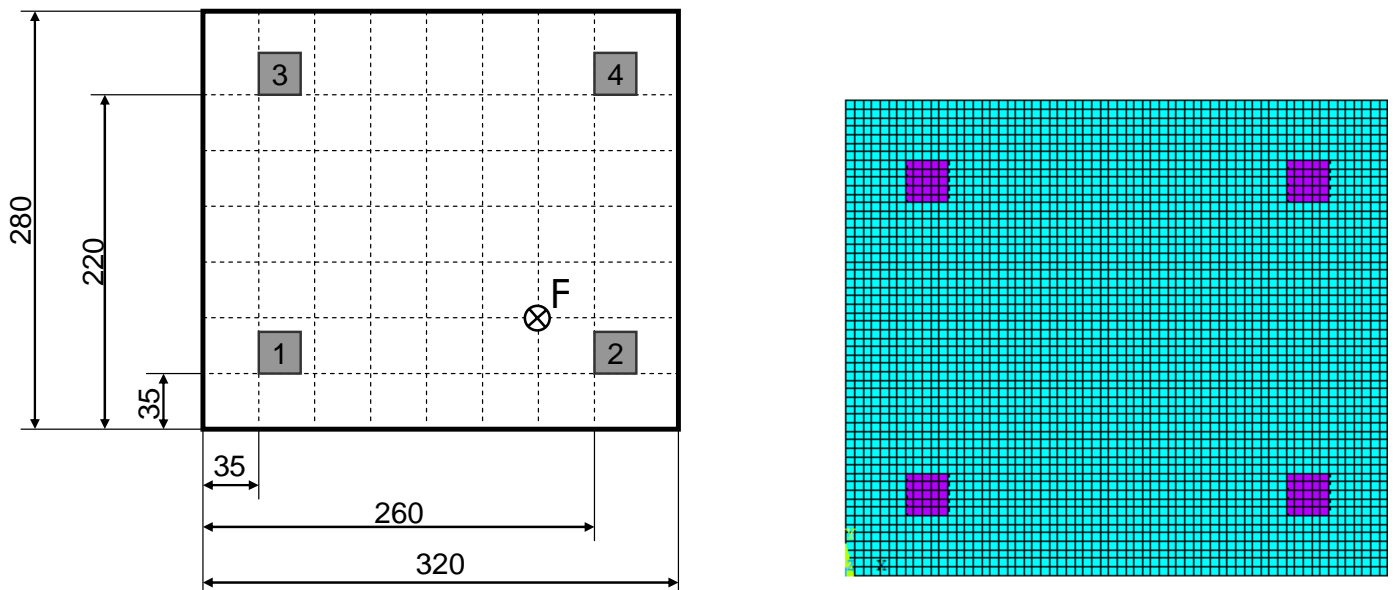

Figura 4.41: 4 bimorphs dispostos sobre a placa

método de Rayleigh-Ritz, por sua vez, possibilita a determinação das freqüências naturais aproximadas, bem como, os respectivos modos de vibrar da estrutura. Na Tabela 4.2 apresenta-se um comparativo entre as freqüências naturais oriundas do modelo em elementos finitos e do método de aproximação via RayleighRitz.

Tabela 4.2. Comparação entre as freqüências naturais $(n=4)$

\begin{tabular}{cccc}
\hline & Rayleigh-Ritz & Elem. Finitos & $(\%)$ \\
\hline 1 & 493,29 & 514,09 & 4,05 \\
2 & 1135,0 & 1176,0 & 3,49 \\
3 & 1331,4 & 1380,9 & 3,58 \\
4 & 1973,1 & 2010,3 & 1,85 \\
5 & 2204,5 & 2274,9 & 3,09 \\
6 & 2728,4 & 2824,5 & 3,40 \\
7 & 3042,7 & 3068,5 & 0,84 \\
8 & 3370,1 & 3407,9 & 1,11 \\
9 & 3701,8 & 3832,2 & 3,40 \\
10 & 4439,6 & 4443,2 & 0,08 \\
\hline
\end{tabular}


Da Tabela 4.2, observa-se uma boa aproximação para as freqüências pelo método de Rayleigh-Ritz.

O mesmo pode ser dito com relação aos modos de vibrar. Na Figura 4.42, apresenta-se os 8 primeiros modos de vibrar estimados pelo método de aproximação via Rayleigh-Ritz e o modelo em elementos finitos. Observa-se que há também uma boa correlação em relação aos modos de vibrar.

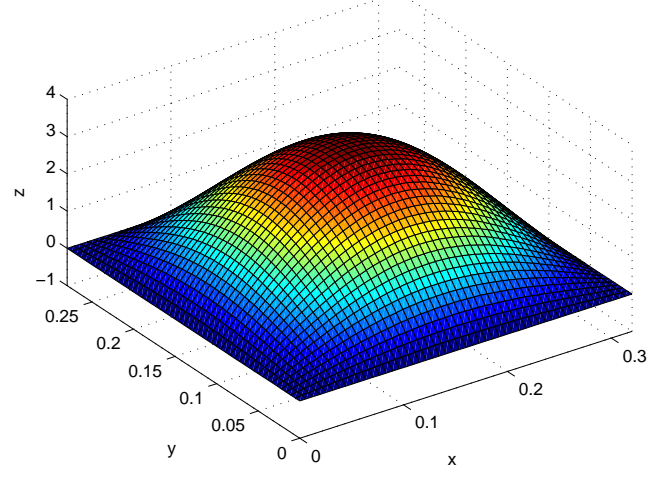

RR: $493,29 \mathrm{~Hz}$

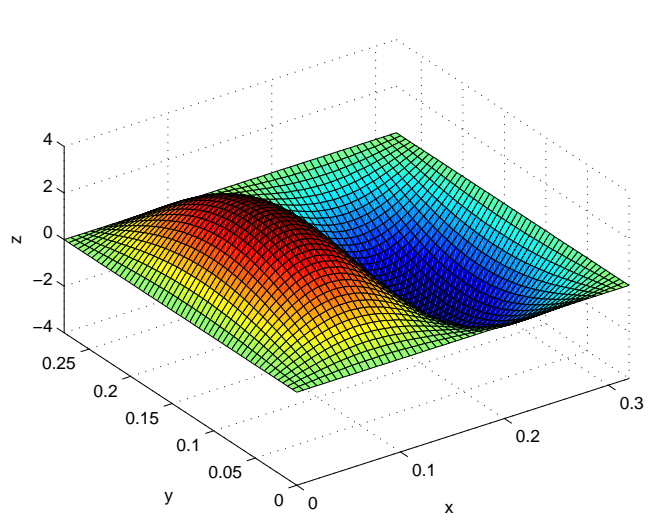

RR: $1135, \mathrm{OHz}$

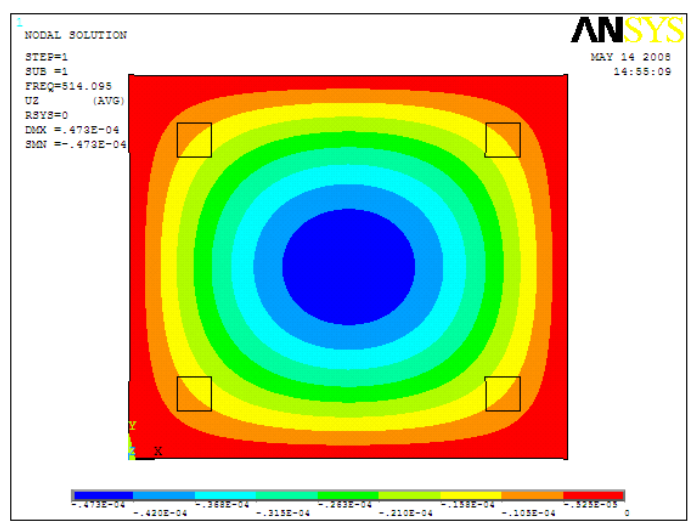

Ansys: $514,09 \mathrm{~Hz}$

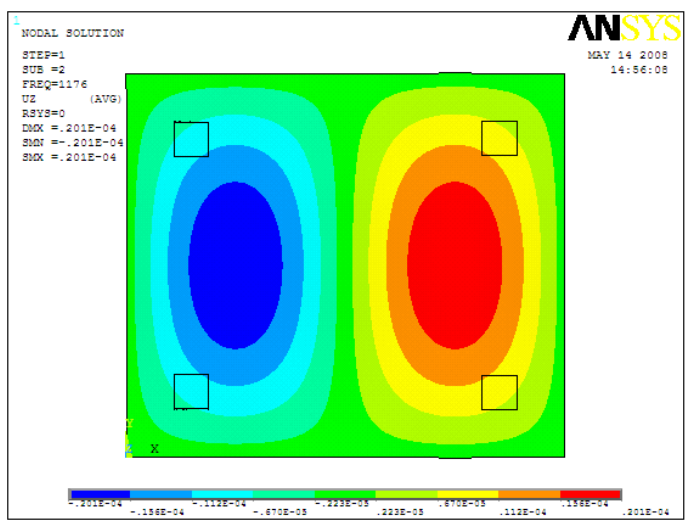

Ansys: $1176,0 \mathrm{~Hz}$ 


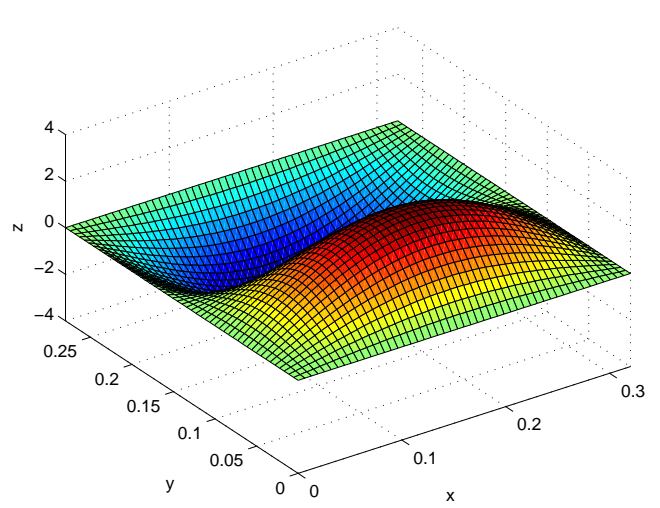

$R R: 1331,4 \mathrm{~Hz}$

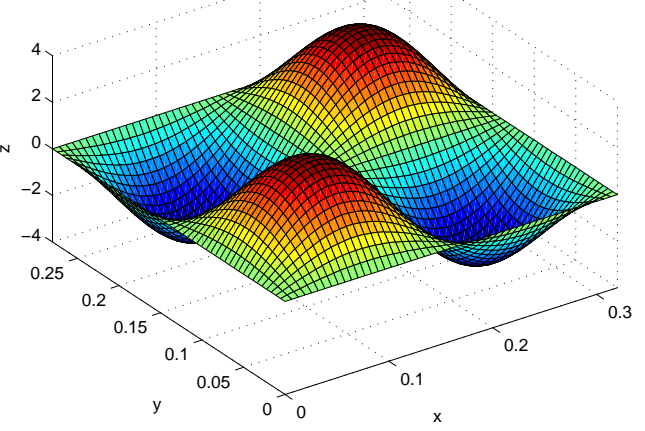

RR: $1973,1 \mathrm{~Hz}$

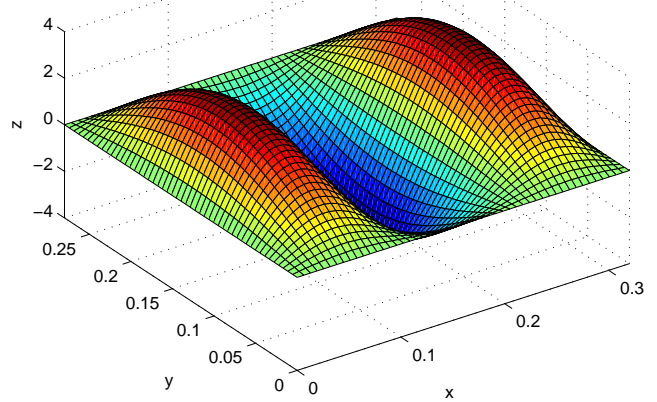

RR: $2204,5 \mathrm{~Hz}$

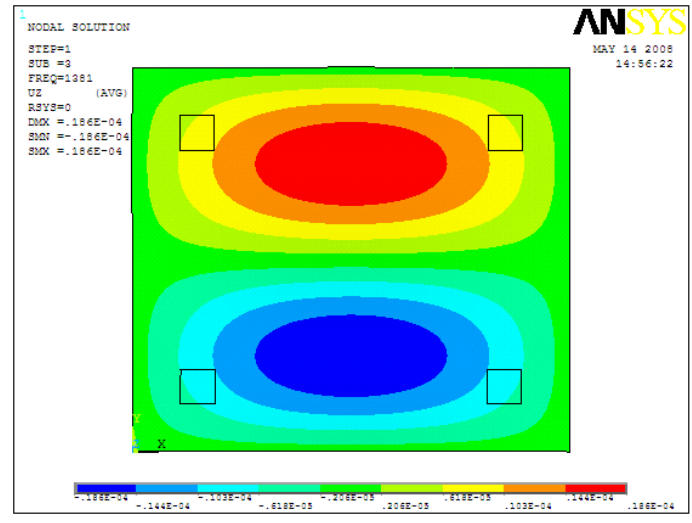

Ansys: $1380,9 \mathrm{~Hz}$

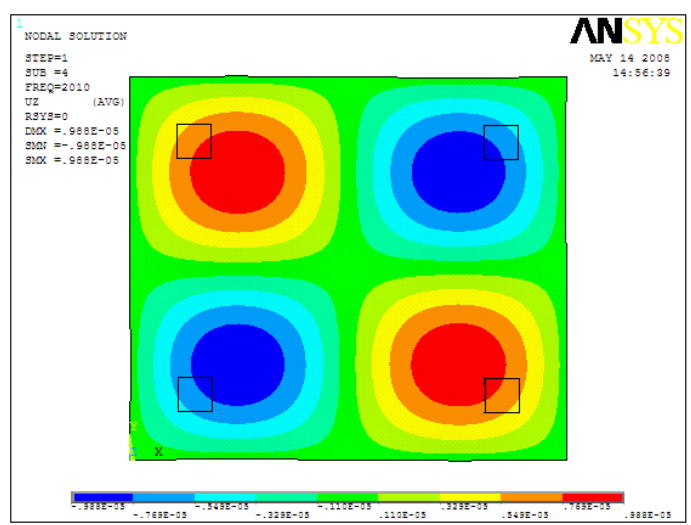

Ansys: $2010,3 \mathrm{~Hz}$

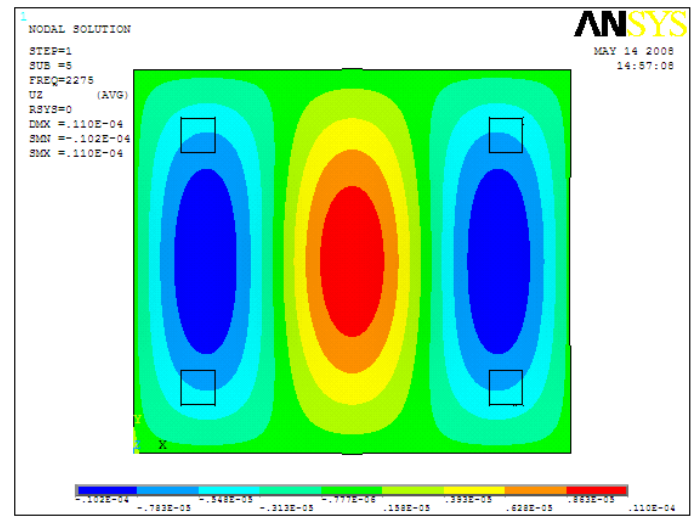

Ansys: $2274,9 \mathrm{~Hz}$ 


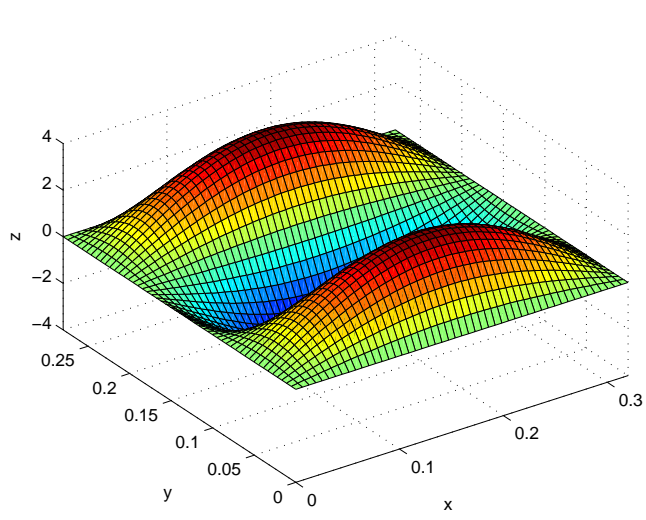

$R R: 2728,4 \mathrm{~Hz}$

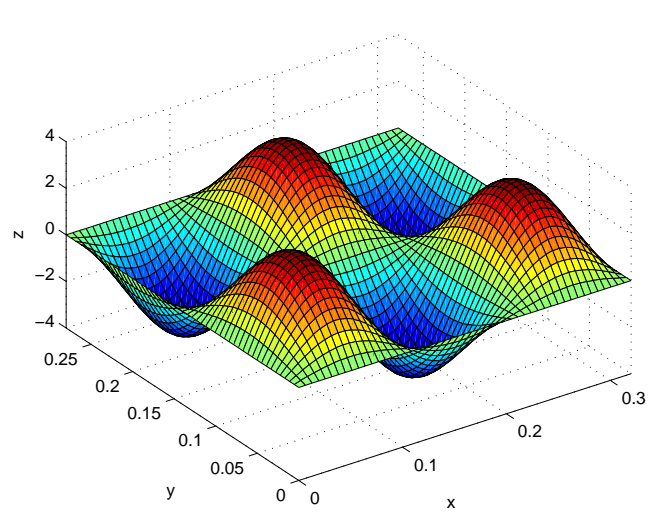

$R R: 3042,7 \mathrm{~Hz}$

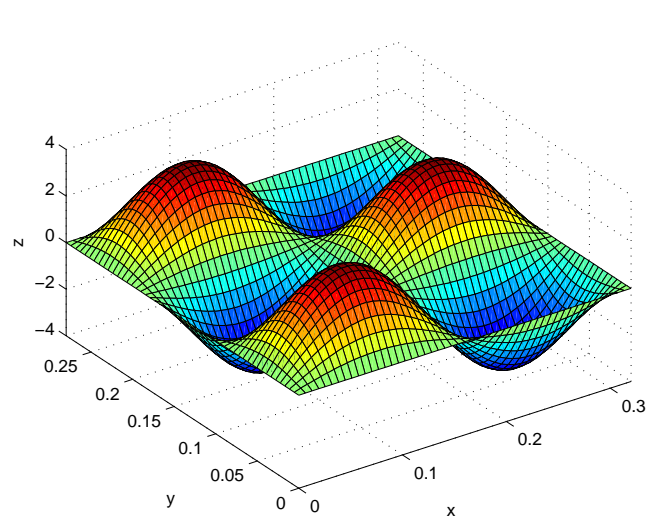

RR: $3370,1 \mathrm{~Hz}$

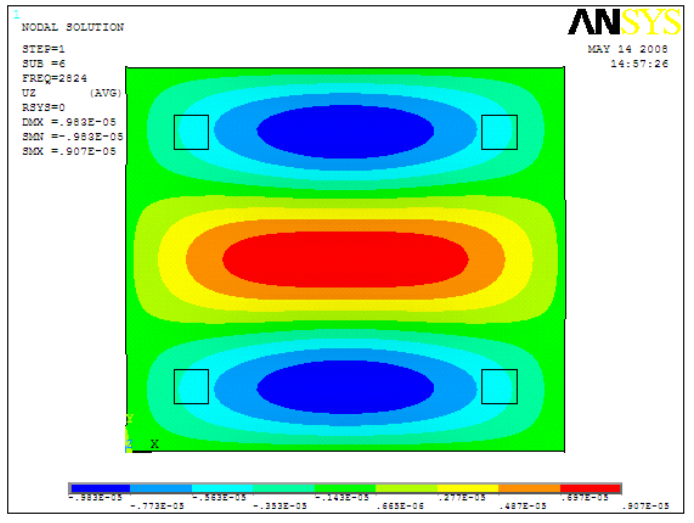

Ansys: $2824,5 \mathrm{~Hz}$

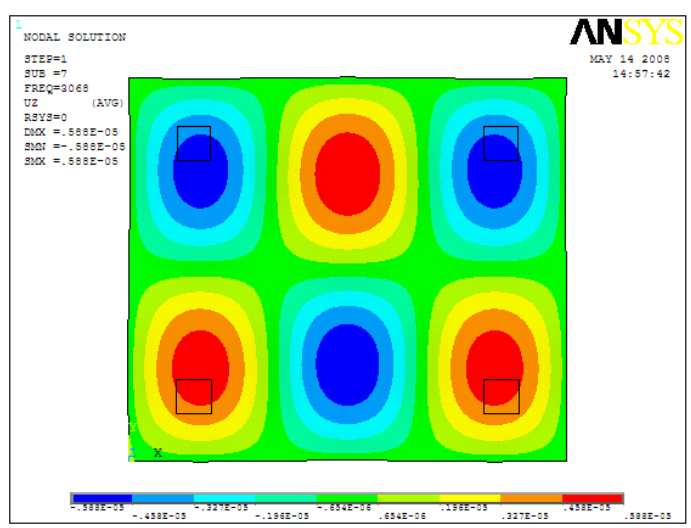

Ansys: $3068,5 \mathrm{~Hz}$

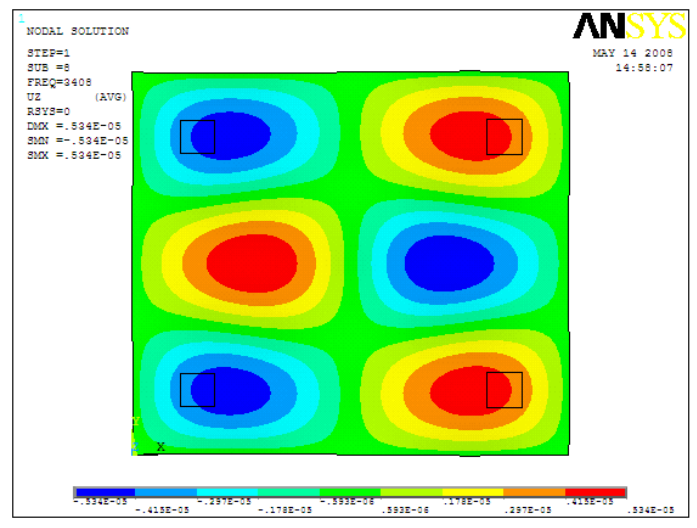

Ansys: $3407,9 \mathrm{~Hz}$

Figura 4.42: Modos de vibrar para placa com 4 bimorphs (Rayleigh-Ritz) 
O modelo em elementos finitos fornece ainda a resposta em termos da tensão elétrica resultante em cada sensor bimorph no domínio da freqüência (ver Figura 4.43). Utilizou-se aqui um incremento de $0,5 \mathrm{~Hz}$ no intervalo de 0 à $5000 \mathrm{~Hz}$ para construção das curvas.
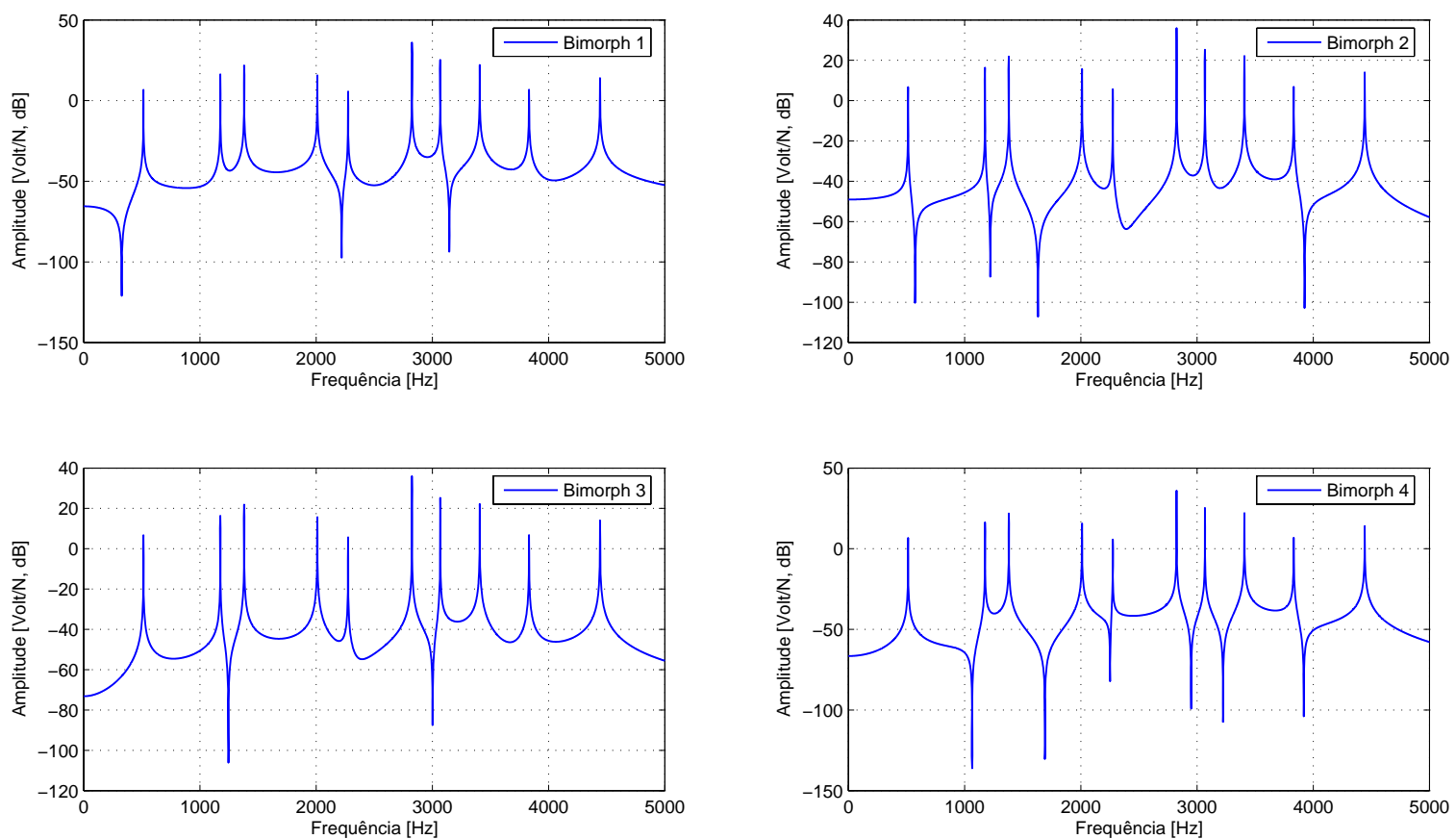

Figura 4.43: Respostas no domínio da freqüência para cada bimorph $(n=4)$

Determinados os modos de vibrar e as respostas em termos da tensão elétrica gerada em cada sensor bimorph, é possível através do método de aproximação por formas modais estimar as FRFs angulares para qualquer ponto da estrutura - ver Eq. (2.69).

Sendo assim, quatro pontos distintos na placa foram escolhidos para a avaliação da metodologia ao estimar as FRFs angulares. Ponto 1: $\left(x_{1}, y_{1}\right)=(200,25)$; ponto 2: $\left(x_{2}, y_{2}\right)=(100,50)$; ponto $3:\left(x_{3}, y_{3}\right)=(220,250)$ e ponto $4:\left(x_{4}, y_{4}\right)=(90,210)$. 
As figuras 4.44 à 4.47 ilustram os resultados obtidos.

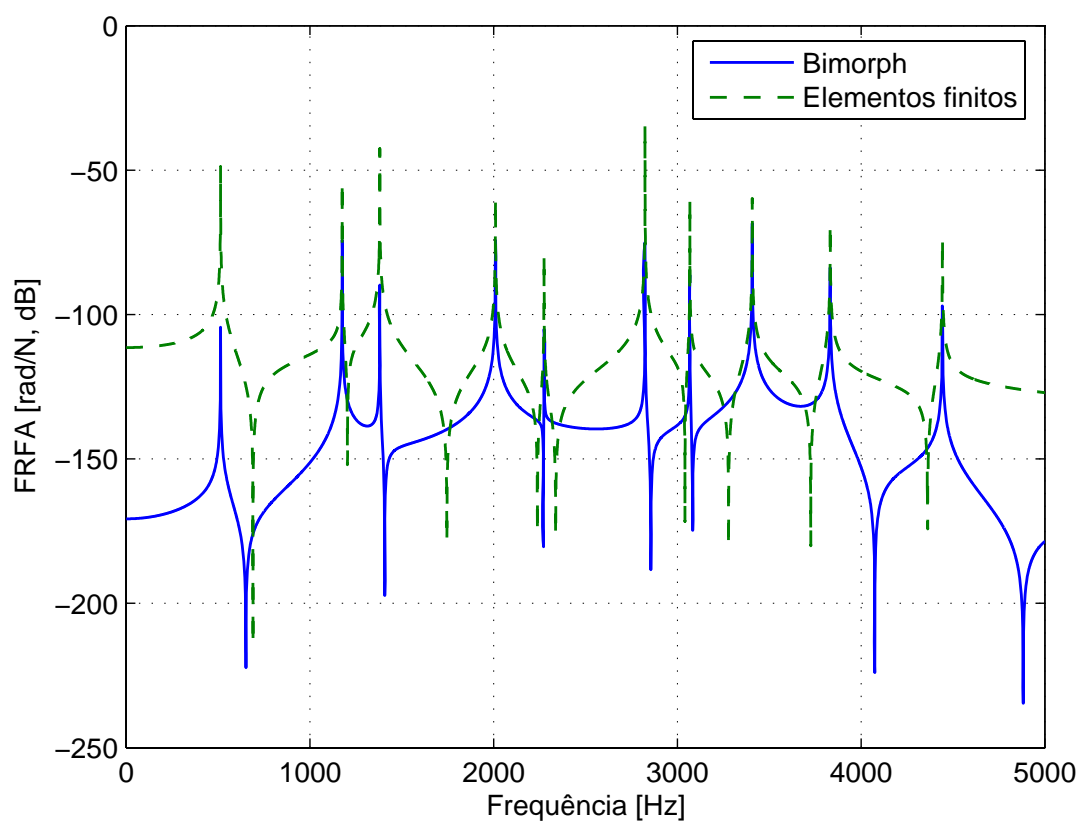

a) Rotação em $x$

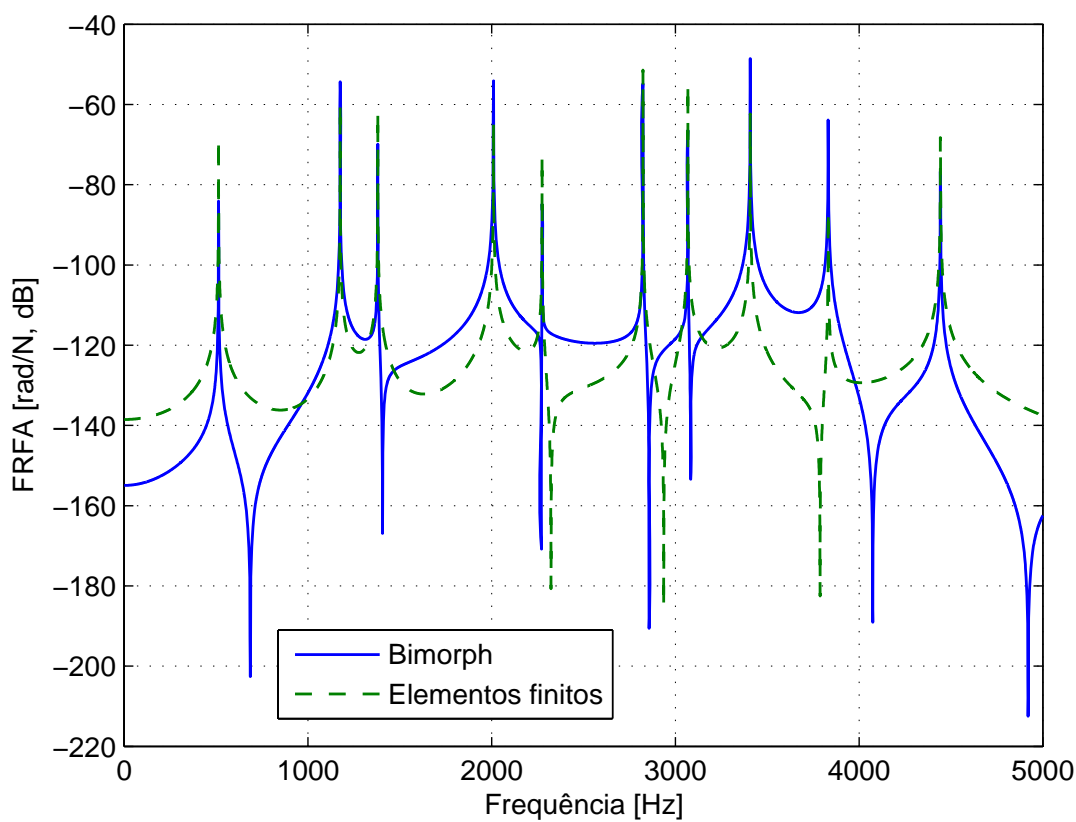

b) Rotação em y

Figura 4.44: Estimativa da FRFA: ponto $1(x=200, y=25)$ e $n=4$ 


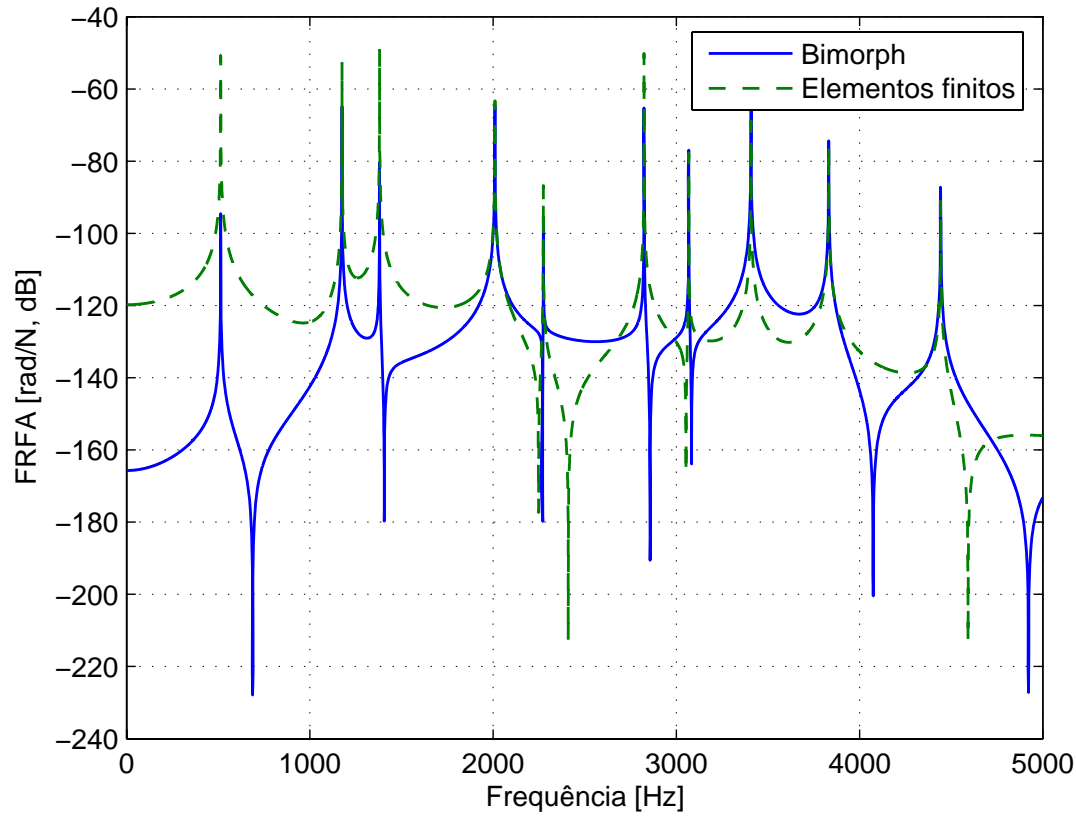

a) Rotação em $x$

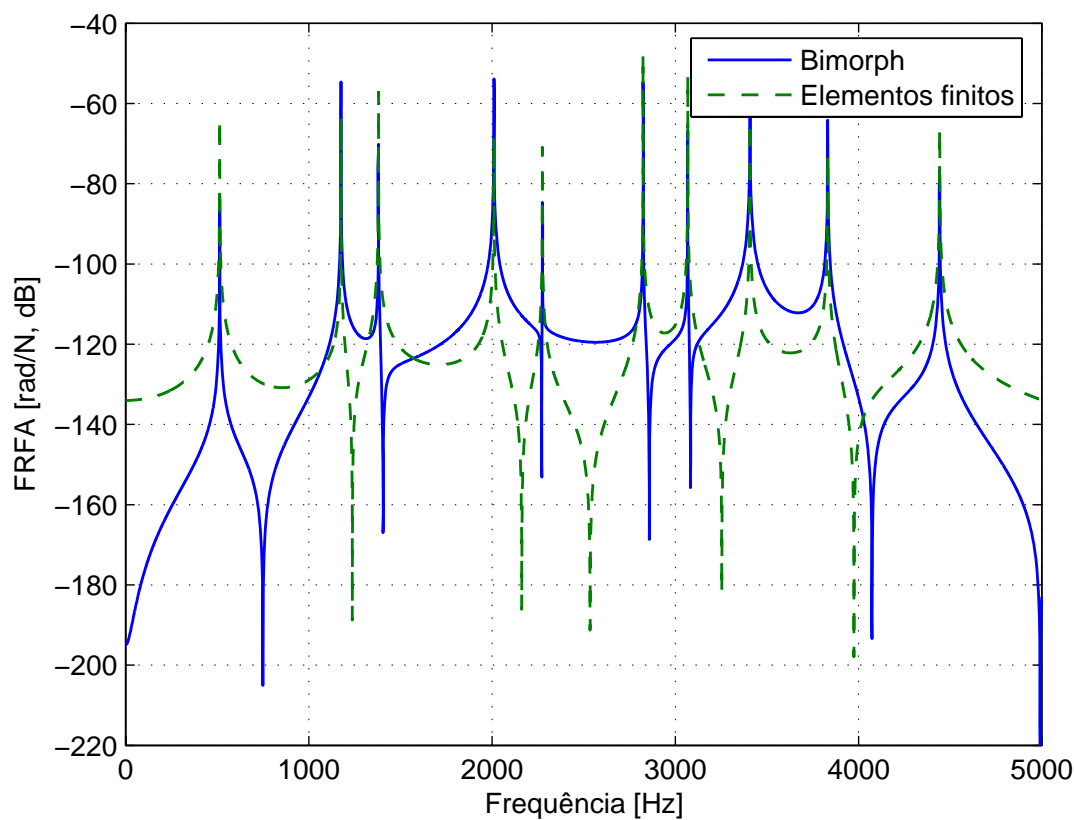

b) Rotação em y

Figura 4.45: Estimativa da FRFA: ponto $2(x=100, y=50)$ e $n=4$ 


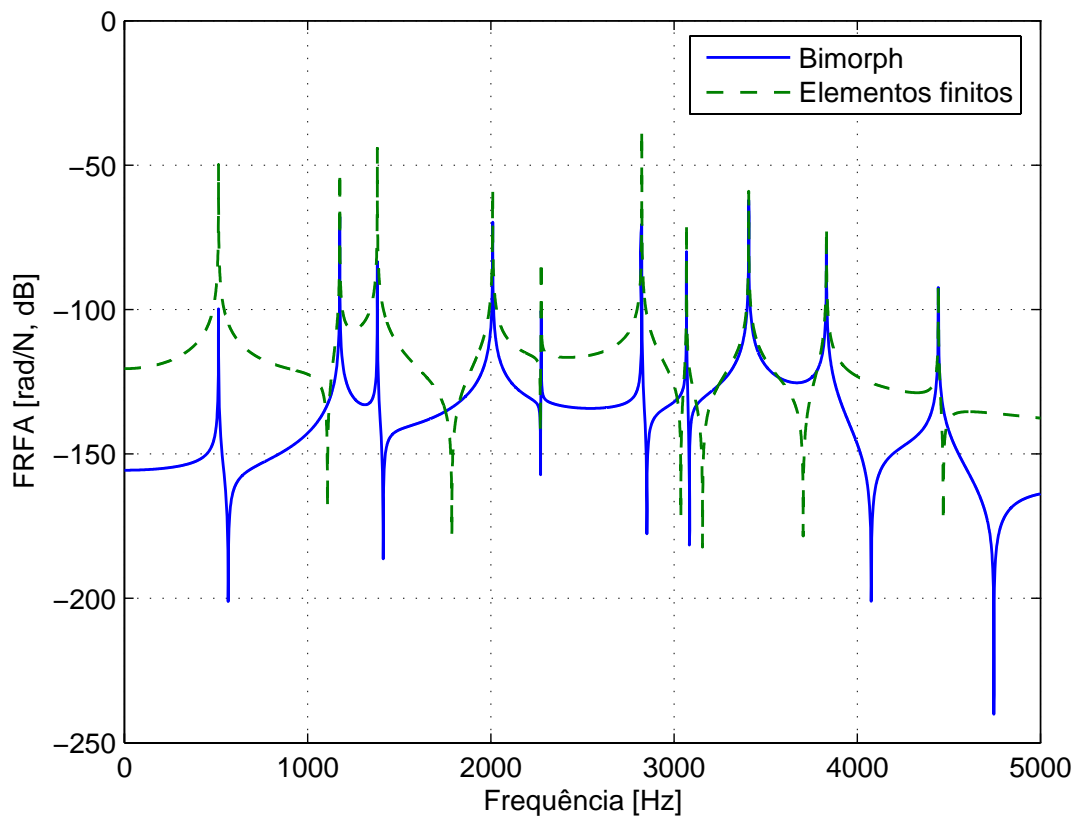

a) Rotação em $x$

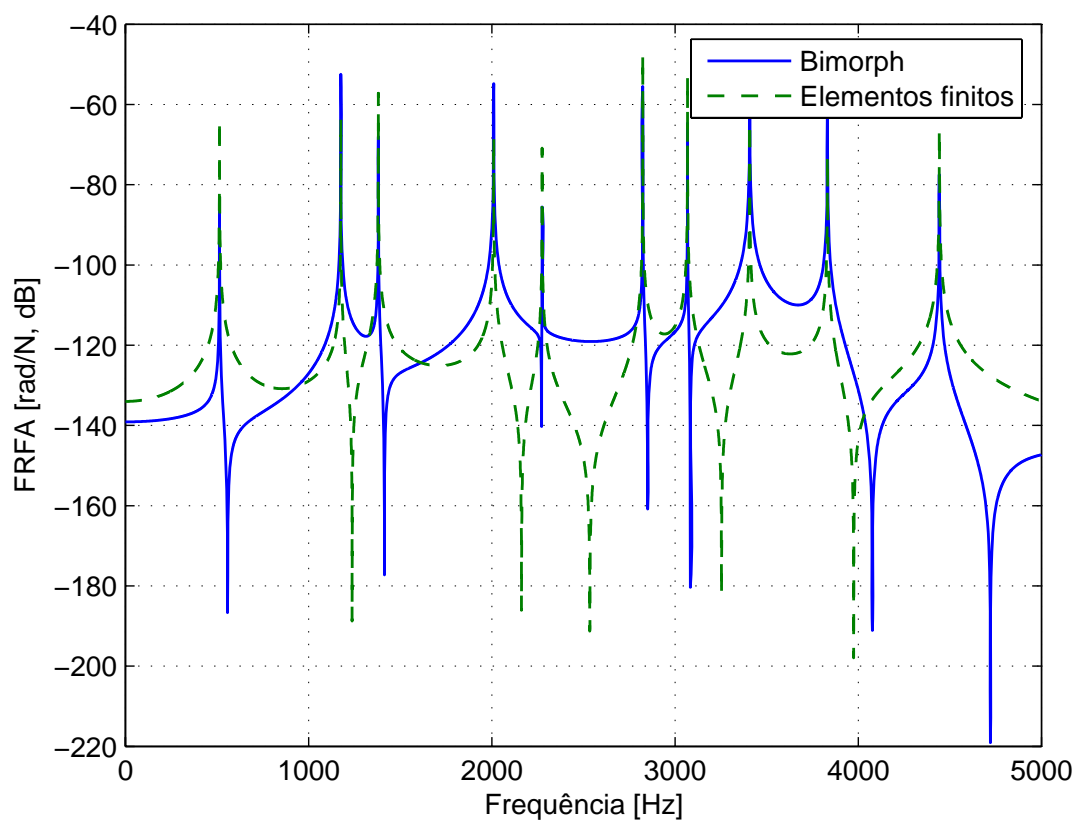

b) Rotação em y

Figura 4.46: Estimativa da FRFA: ponto $3(x=220, y=250)$ e $n=4$ 


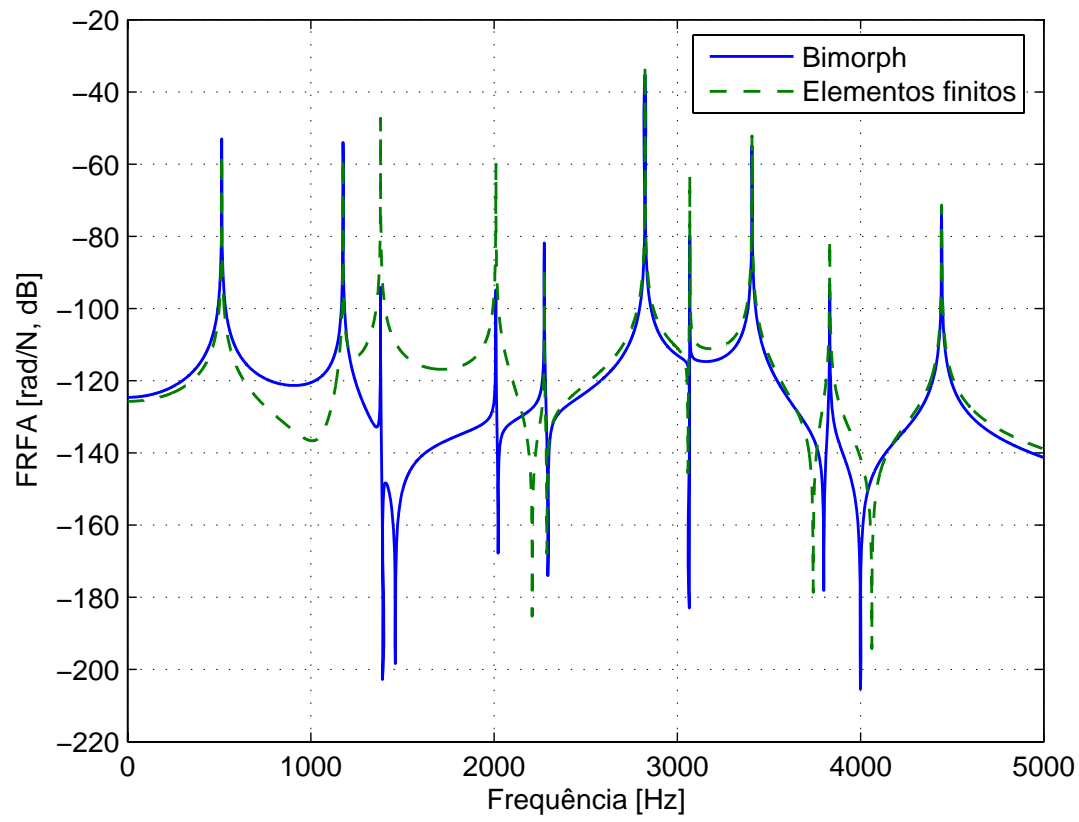

a) Rotação em $x$

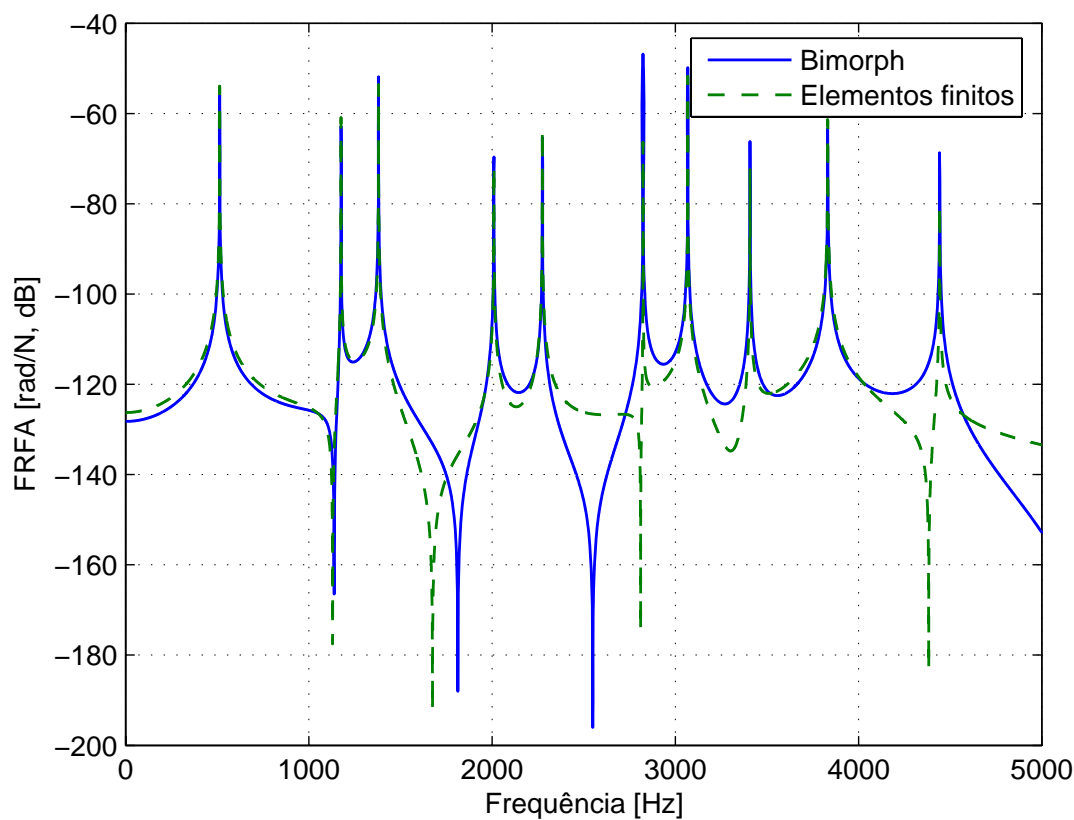

b) Rotação em y

Figura 4.47: Estimativa da FRFA: ponto $4(x=90, y=210)$ e $n=4$ 
Nota-se que os resultados obtidos não são satisfatórios, pois há uma grande divergência entre as FRFs angulares. Tal resultado pode ser explicado por uma falta de investigação acerca de um posicionamento e dimensionamento otimizado dos sensores. Além disso, com 4 bimorphs, apenas 4 modos de vibrar são utilizados na construção do campo de deslocamentos.

Em vista disso, uma nova configuração de sensores bimorphs foi proposta: 12 sensores bimorphs $(n=12)$ dispostos sobre a placa de acordo com a configuração ilustrada na Figura 4.48 (PAGANI JR; TRINDADE, 2007).
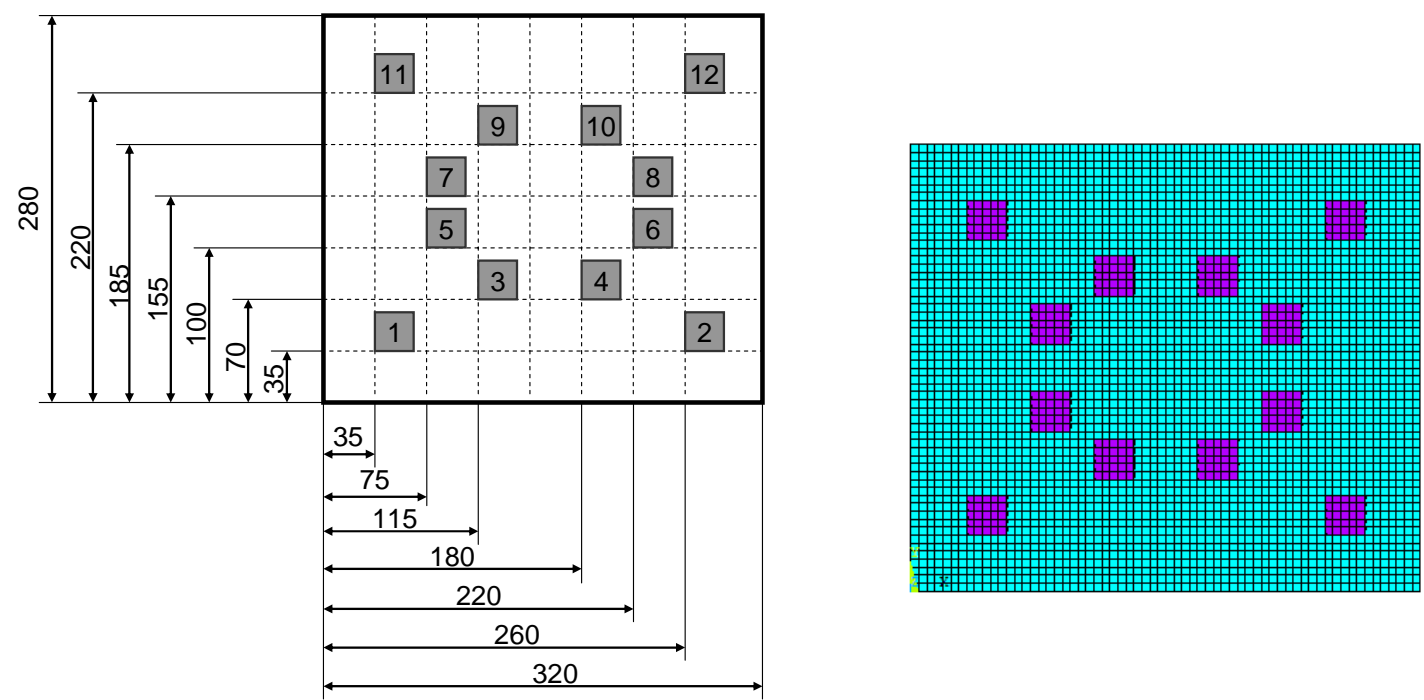

Figura 4.48: 4 bimorphs dispostos sobre a placa

Na Tabela 4.3 apresenta-se novamente um comparativo entre as freqüências naturais oriundas de ambos os modelos: elementos finitos e Rayleigh-Ritz.

A Figura 4.49 apresenta os 8 primeiros modos de vibrar estimados pelo modelo em elementos finitos. Os modos de vibrar estimados pelo método de Rayleigh-Ritz nesta configuração com 12 bimorphs são os mesmos vistos na Figura 4.42. 
Tabela 4.3. Comparação entre as freqüências naturais $(n=12)$

\begin{tabular}{cccc}
\hline & Rayleigh-Ritz & Elem. Finitos & $(\%)$ \\
\hline 1 & 493,29 & 490,28 & $-0,61$ \\
2 & 1135,0 & 1123,1 & $-1,06$ \\
3 & 1331,4 & 1324,3 & $-0,54$ \\
4 & 1973,1 & 1956,1 & $-0,87$ \\
5 & 2204,5 & 2228,3 & 1,07 \\
6 & 2728,4 & 2778,0 & 1,79 \\
7 & 3042,7 & 3017,7 & $-0,83$ \\
8 & 3370,1 & 3349,9 & $-0,60$ \\
9 & 3701,8 & 3724,2 & 0,60 \\
10 & 4439,6 & 4415,5 & $-0,55$ \\
\hline
\end{tabular}

Da tabela acima, observa-se uma boa aproximação para as freqüências pelo método de Rayleigh-Ritz.
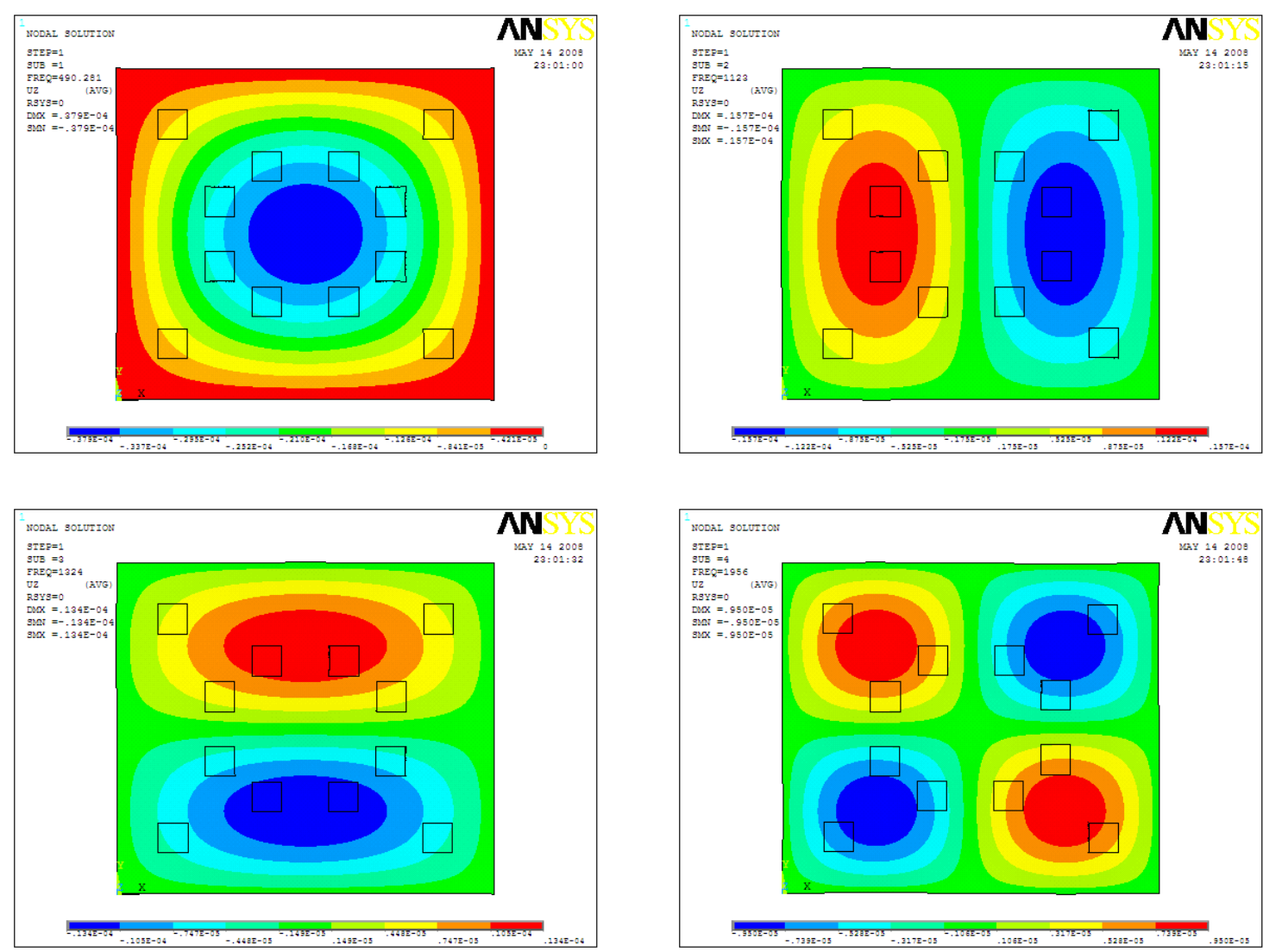

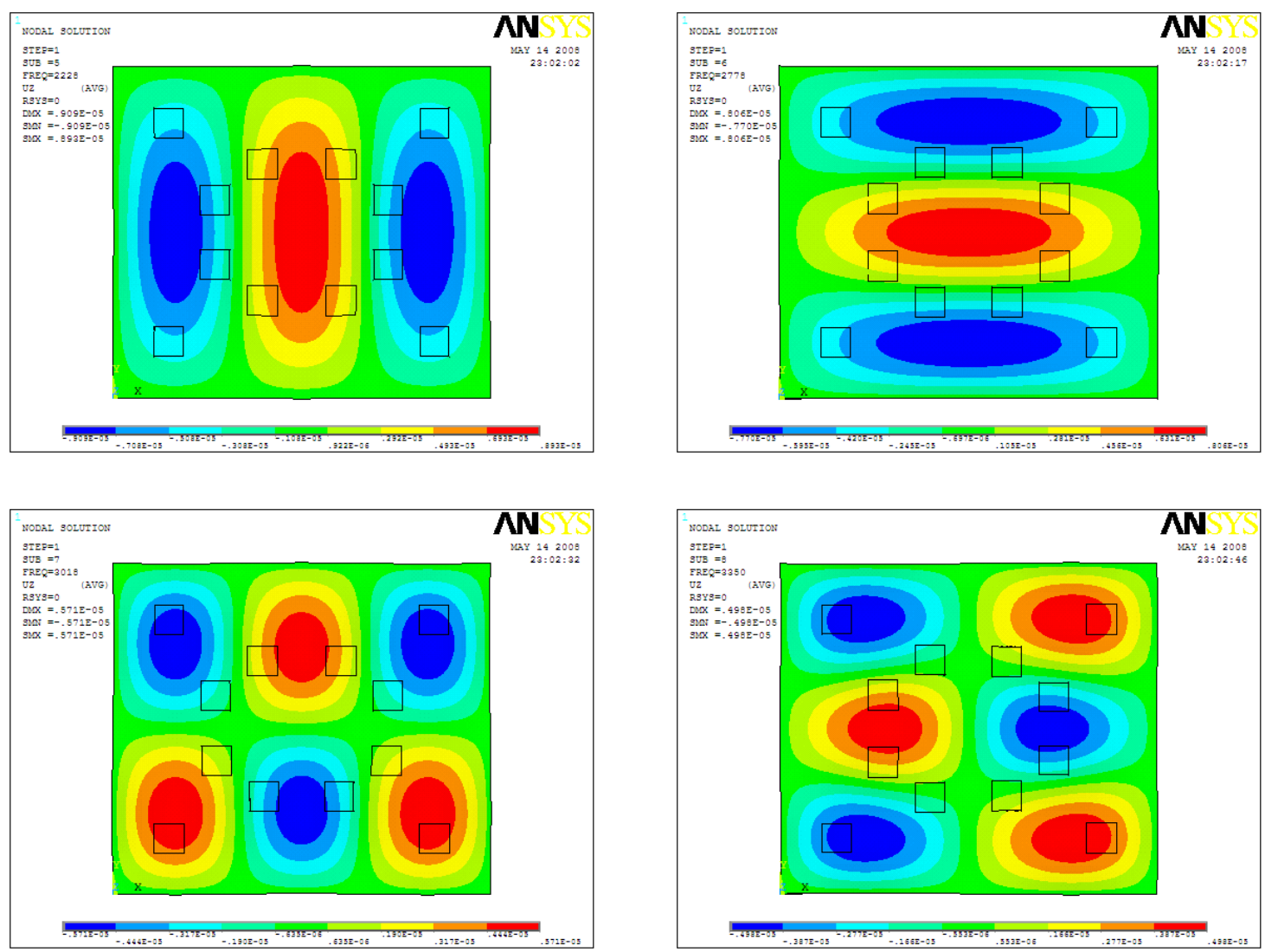

Figura 4.49: Modos de vibrar para placa com 12 bimorphs (Elementos finitos)

As amplitudes em tensão lidas para cada sensor bimorph no domínio da freqüência estão representadas na Figura 4.50.
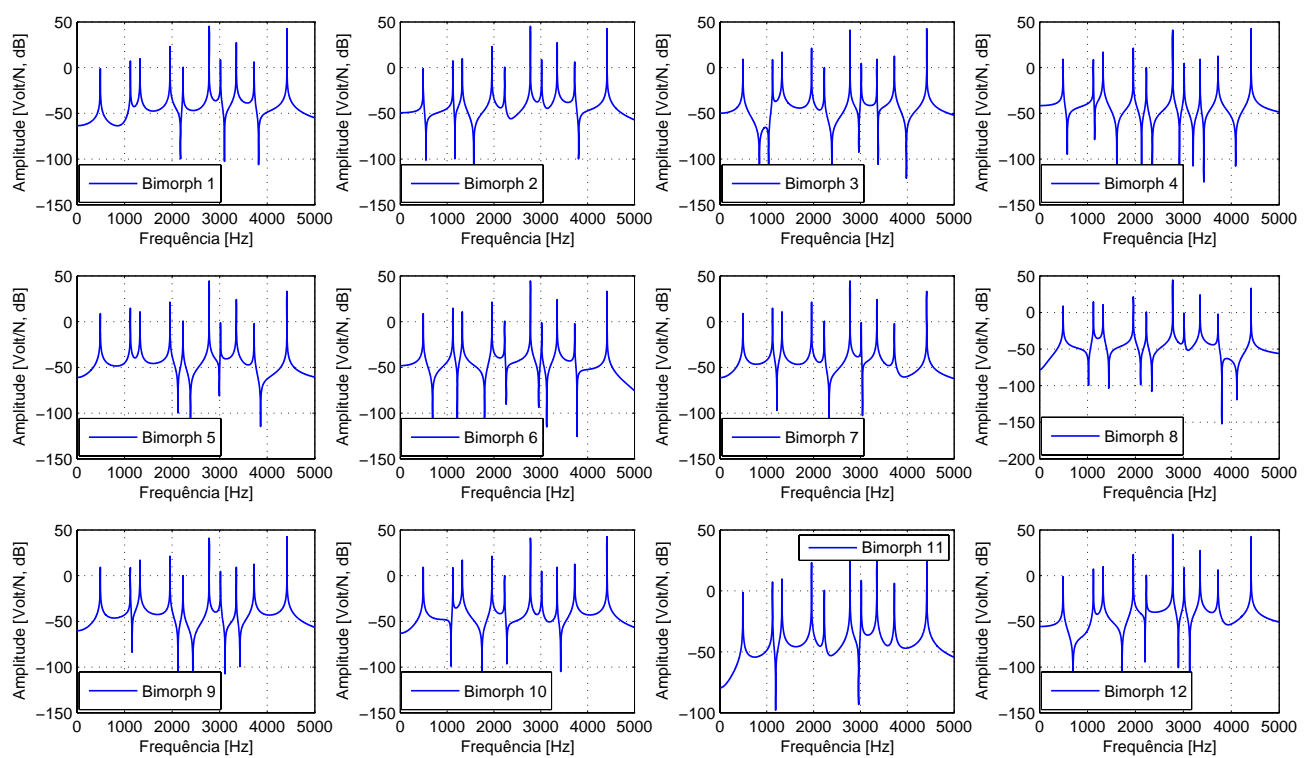

Figura 4.50: Respostas no domínio da freqüência para cada bimorph $(n=12)$ 
As figuras a seguir ilustram os resultados para a configuração com 12 bimorphs.

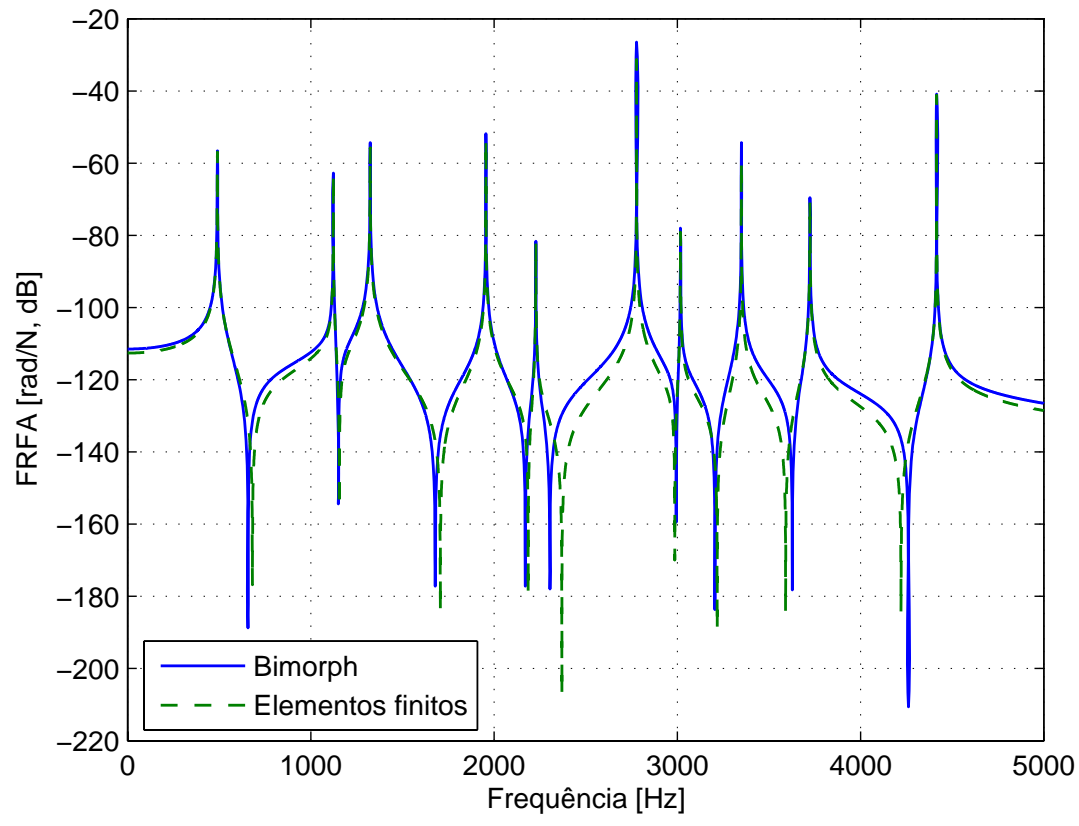

a) Rotação em $x$

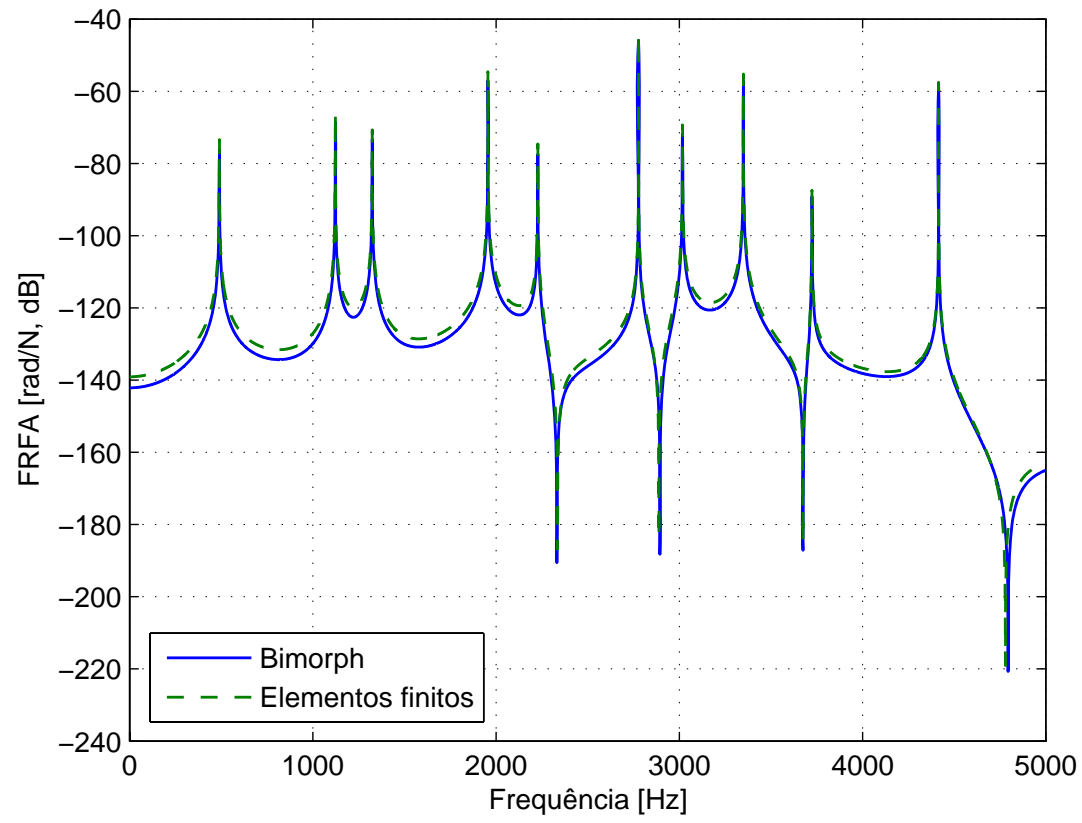

b) Rotação em y

Figura 4.51: Estimativa da FRFA: ponto $1(x=200, y=25)$ e $n=12$ 


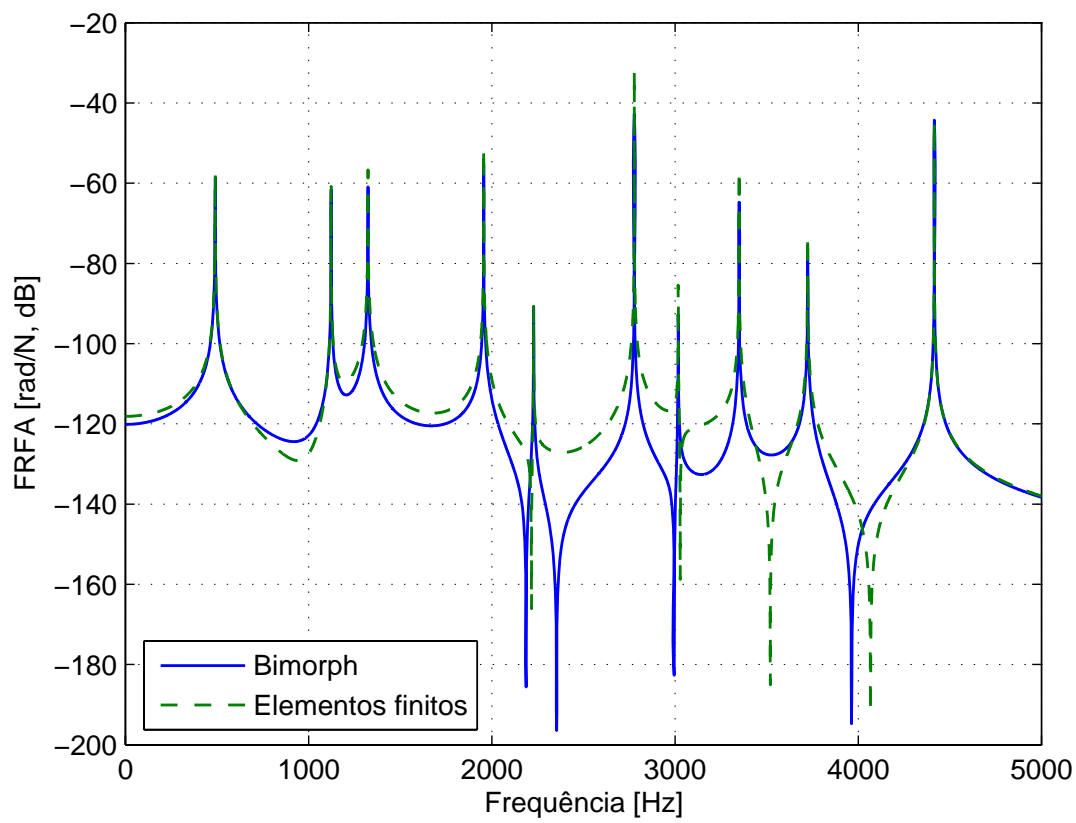

a) Rotação em $x$

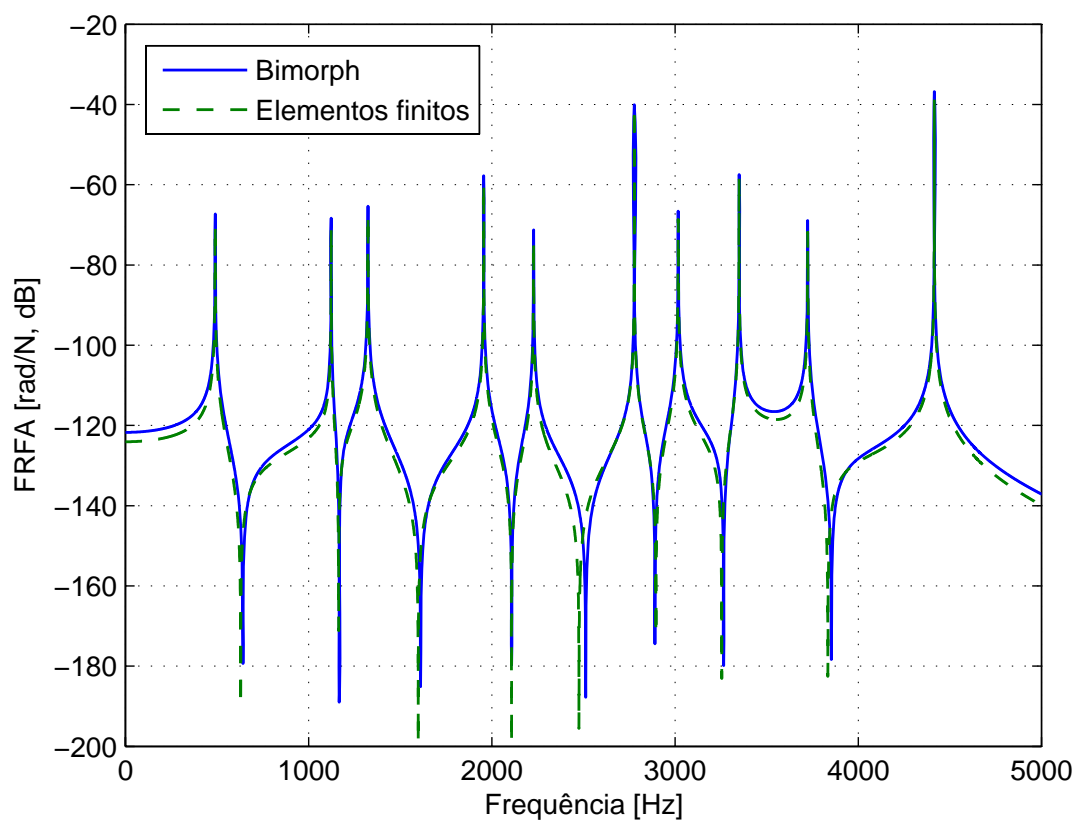

b) Rotação em y

Figura 4.52: Estimativa da FRFA: ponto $2(x=100, y=50)$ e $n=12$ 


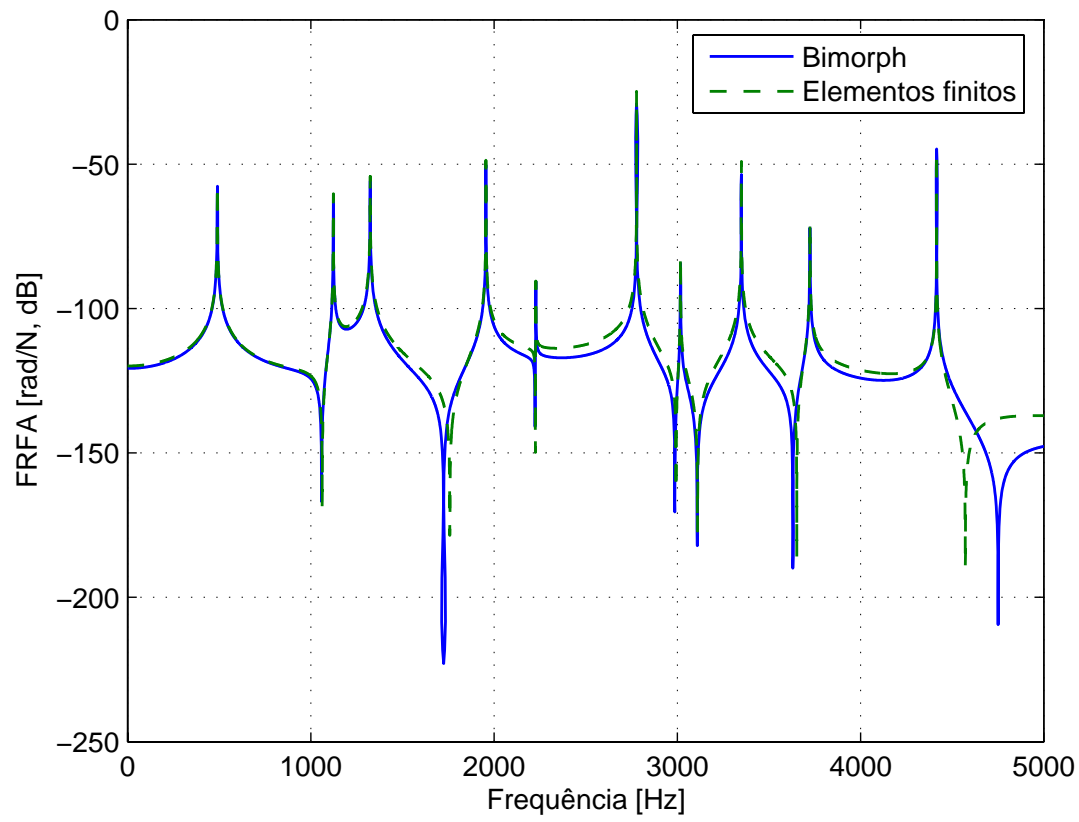

a) Rotação em $x$

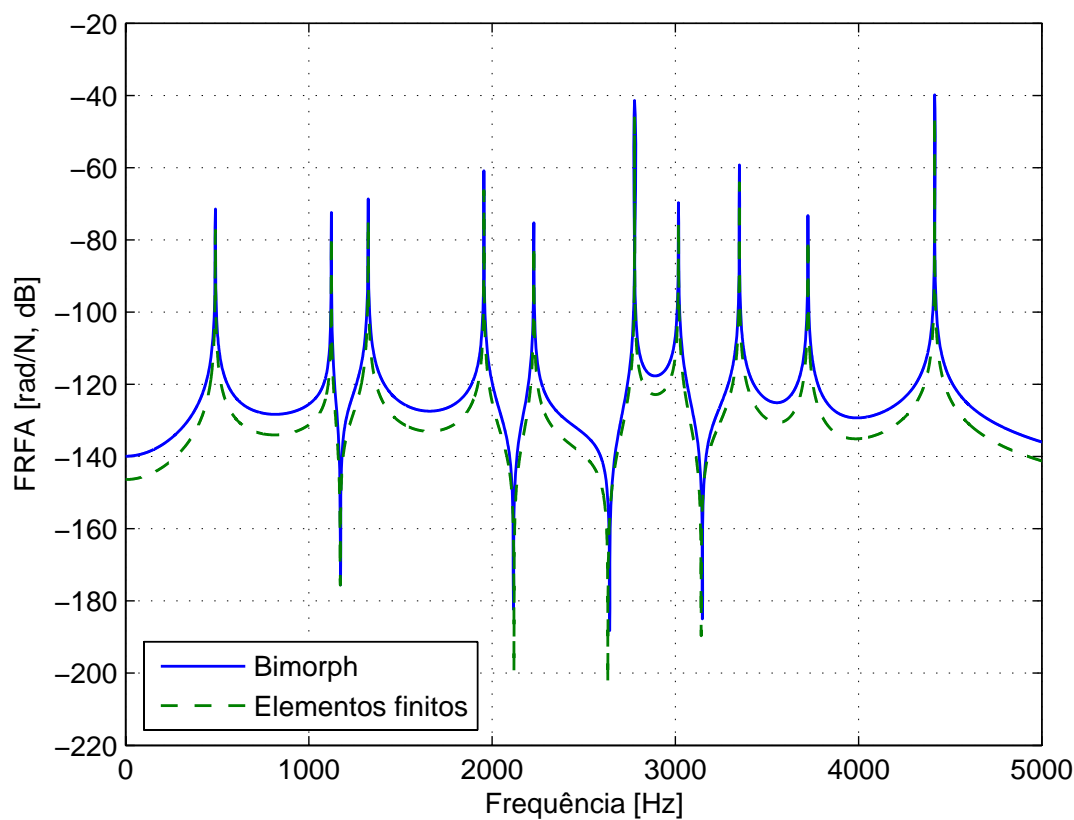

b) Rotação em y

Figura 4.53: Estimativa da FRFA: ponto $3(x=220, y=250)$ e $n=12$ 


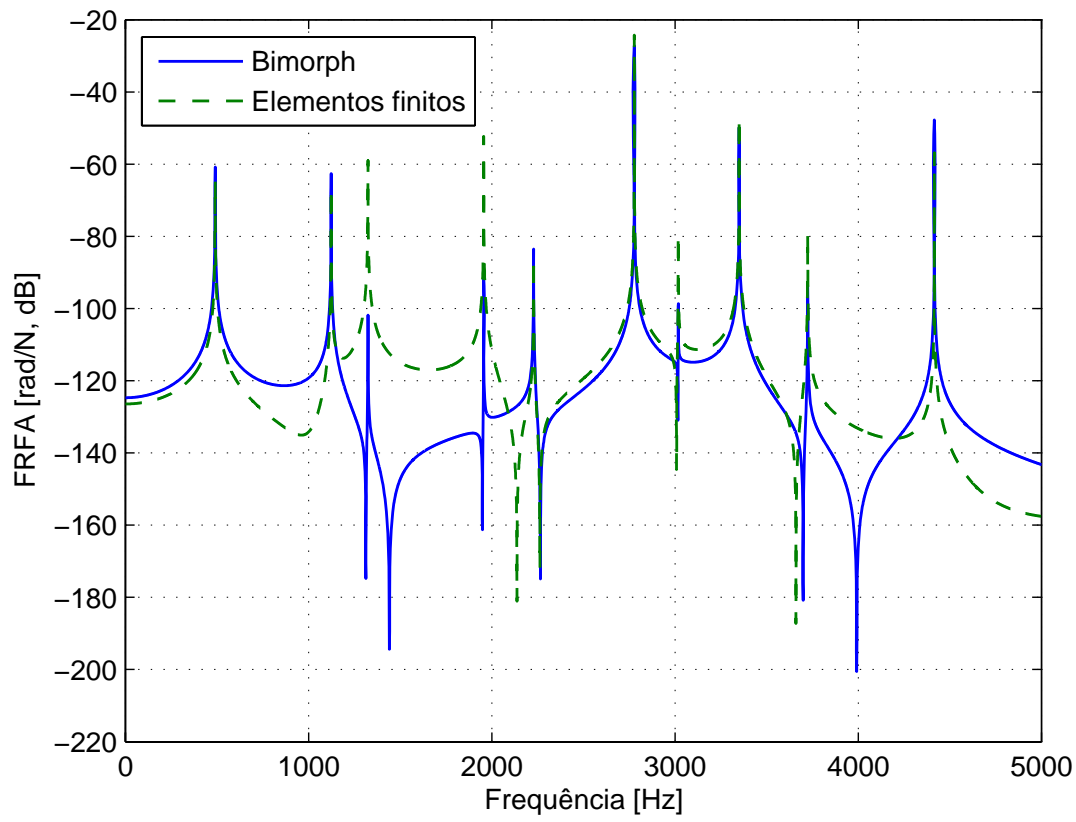

a) Rotação em $x$

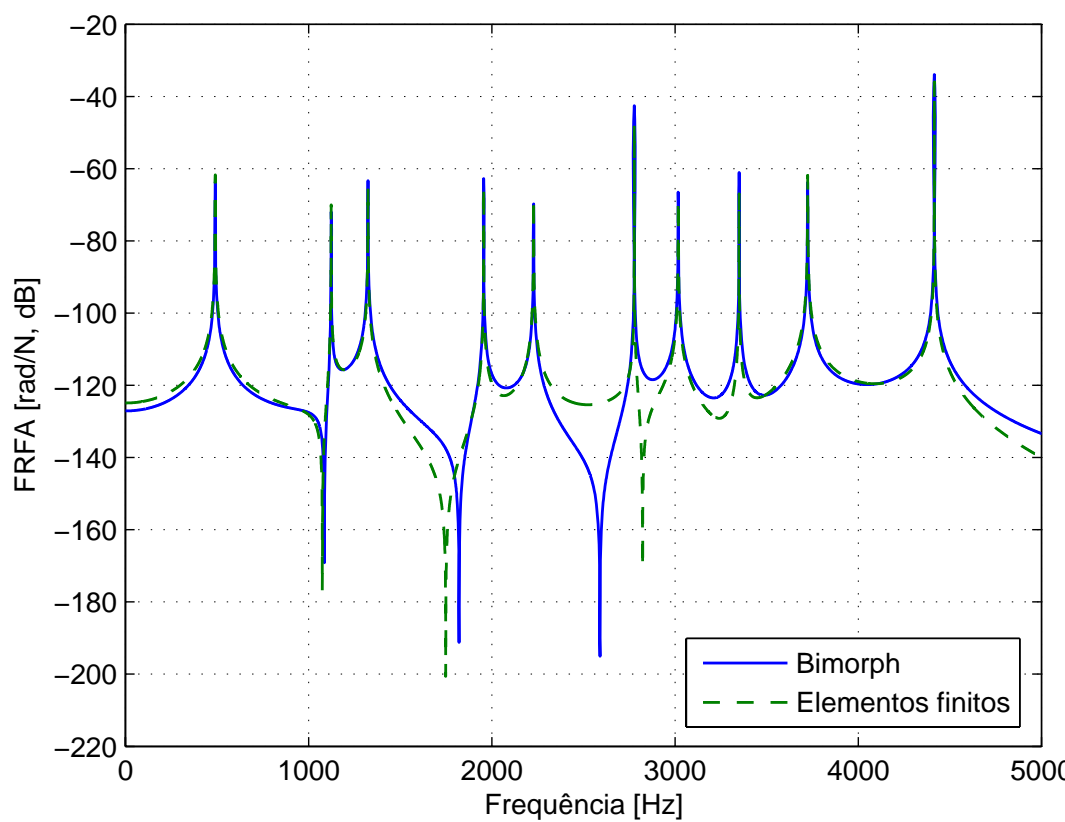

b) Rotação em y

Figura 4.54: Estimativa da FRFA: ponto $4(x=90, y=210)$ e $n=12$ 
As figuras acima apresentam as FRFs angulares estimadas através da utilização dos sensores bimorphs em comparação ao resultado oriundo diretamente do modelo em elementos finitos, onde os graus de liberdade de rotação nas direções $x$ e $y$ são diretamente medidos de acordo com o ponto de teste escolhido.

Em vista dos resultados obtidos, é possível afirmar que a utilização de mais modos de vibrar no método de aproximação melhora em muito as estimativas. No entanto, uma otimização quanto ao número de sensores, posição e dimensão de cada bimorph possa ainda reproduzir resultados tão bons como os ilustrados acima.

\subsubsection{AVALIAÇÃO DAS CONDIÇÕES DE CONTORNO ELÉTRICAS}

Duas condições de contorno elétricas foram consideradas no intuito de verificar a variação na rigidez da estrutura em função da mudança na condição de contorno elétrica:

1) Todas as pastilhas piezelétricas em circuito aberto. Nesta condição, os nós da base e do topo de cada bimorph são aterrados e todas as superfícies, superior e inferior, de cada camada piezelétrica respeitam a equipotencialidade.

A condição de equipotencialidade equivale a uma rede de eletrodos interconectados que tem por função escoar instantaneamente o acúmulo de carga gerado em regiões de maior tensão mecânica, uniformizando a tensão elétrica superficial induzida pelo acoplamento eletromecânico. Logo, as condições de contorno na superfície equipotencial são típicas de uma interface condutor-espaço livre. 
2) Todas as pastilhas piezelétricas em circuito fechado. Nesta segunda condição, todos os nós da base e do topo de cada pastilha piezelétrica são aterrados, de maneira que os potenciais elétricos sejam mantidos nulos. Sendo assim, a pastilha se comporta como um dispositivo em curto-circuito. Fisicamente, as cargas geradas escoam para fora da pastilha por meio de fios condutores, de maneira a mantê-la superficialmente descarregada.

Levando-se em conta as duas condições de contorno elétricas vistas acima, pode-se medir o grau de variação na rigidez da estrutura em função da mudança na condição de contorno. Isto é feito através do coeficiente efetivo de acoplamento eletromecânico (EMCC), o qual mede o potencial de conversibilidade das formas de energia, elétrica e mecânica, na estrutura, relativa à energia total distribuída no sistema (PAGANI JR; TRINDADE, 2007).

O EMCC pode ser definido pela diferença relativa entre as freqüências de ressonância da estrutura em condições elétricas de circuito aberto $\omega_{O C}$ e curto-circuito $\omega_{S C}$ conforme a equação a seguir (TRINDADE; BENJEDDOU, 2007):

$$
E M C C=\frac{\omega_{O C}^{2}-\omega_{S C}^{2}}{\omega_{O C}^{2}}
$$

A Tabela 4.4 fornece as freqüências de ressonância da estrutura para as duas condições de contorno elétricas descritas anteriormente e para os 10 primeiros modos vibrar no caso de 12 bimorphs presentes sobre a placa.

Conforme pode ser observado da Tabela 4.4, as freqüências em curto-circuito (SC) e circuito aberto (OC) são muito próximas, resultando em valores relativamente 
baixos de EMCC. Isto indica uma pequena variação na rigidez da estrutura em função da mudança na condição de contorno (PAGANI JR; TRINDADE, 2007).

Tabela 4.4. Freqüências naturais da placa sob condições de contorno elétricas diferentes

\begin{tabular}{cccc}
\hline & $\omega_{S C}$ & $\omega_{O C}$ & EMCC $(\%)$ \\
\hline 1 & 490,26 & 490,28 & 0,008 \\
2 & 1123,1 & 1123,1 & 0,000 \\
3 & 1324,2 & 1324,3 & 0,015 \\
4 & 1956,0 & 1956,1 & 0,010 \\
5 & 2228,2 & 2228,3 & 0,009 \\
6 & 2778,0 & 2778,0 & 0,000 \\
7 & 3017,6 & 3017,7 & 0,007 \\
8 & 3349,8 & 3349,9 & 0,006 \\
9 & 3724,1 & 3724,2 & 0,005 \\
10 & 4415,2 & 4415,5 & 0,014 \\
\hline
\end{tabular}




\section{CONCLUSÕES}

O desenvolvimento de um novo transdutor de baixo custo capaz de medir a curvatura local de estruturas do tipo viga foi apresentado em sua forma analítica e numérica. No caso de estruturas do tipo placa, apresentou-se a formulação analítica.

Em ambos os casos foi possível estabelecer uma relação direta entre a curvatura local da estrutura e a voltagem resultante do sensor bimorph.

Para estruturas do tipo viga, propuseram-se dois métodos de aproximação na estimativa da rotação em qualquer ponto de interesse da estrutura: polinomial, onde o campo de deslocamentos e, por sua vez, a rotação, é representado através de um polinômio de ordem $p$. Os coeficientes temporais são obtidos utilizando-se as condições de contorno, bem como, as leituras de curvatura local oriundas de cada sensor bimorph. Demonstrou-se que para uma viga cantilever, o grau do polinômio que aproxima a rotação em qualquer ponto da estrutura é igual $p=n+1$, onde $n$ é o número de sensores bimorph presente na estimativa.

O segundo método de aproximação apresentado utiliza formas modais na estimativa da rotação. A grande vantagem neste método de aproximação se baseia na possibilidade de utilização de polinômios de alta ordem na representação dos modos de vibrar. O mesmo não ocorre com a aproximação polinomial, pois esta é limitada a polinômios de ordem $p=n+2$ em termos do campo de deslocamentos. 
Novamente os coeficientes que descrevem a resposta da estrutura no tempo são obtidos através da imposiçãa das condições de contorno e da curvatura local para cada sensor bimorph posicionado sobre a estrutura. Para cada bimorph, o número de modos utilizados na aproximação é dado por $m=n+2$.

As análises demonstraram que para estimativas onde o ponto de medição da rotação está próximo da região de engaste, ocorre uma inversão entre o melhor método de aproximação. Para o caso de um único sensor posicionado até o meio da viga, a aproximação polinomial propicia resultados ligeiramente melhores em comparação ao método de aproximação por formas modais. No entanto, este fato se inverte quando o sensor é posicionado além do ponto central da viga e, neste caso, as diferenças entre os métodos se sobressaem.

Para pontos próximos à extremidade livre da viga, o que se observou é que a aproximação modal fornece sempre resultados melhores quando do posicionamento do bimorph.

Em termos da inclusão de mais bimorphs nas aproximações, foi possível estabelecer uma relação direta com a melhoria dos resultados, porém, sem uma percepção direta de qual método se comporta melhor de acordo com o posicionamento dos sensores bimorphs.

Outra análise efetuada corresponde à correção dos modos de vibrar devido à presença dos sensores ao longo da viga. Tal correção se mostrou importante quando se tem dimensões de sensores superiores à $s_{b}>15 \mathrm{~mm}$ e quando mais de um sensor é utilizado na aproximação. 
Os resultados obtidos foram comparados a outros oriundos de um modelo baseado no método dos elementos finitos demonstrando a viabilidade de uso deste sensor. Ficou evidente a influência da correção dos modos de vibrar na estimativa das funções de resposta em freqüência angulares.

Devido à extensa gama de possíveis soluções, propôs-se o estudo de um método de otimização. Neste trabalho, optou-se por uma otimização via algoritmos genéticos (AG) devido a sua simplicidade de implementação e aos bons resultados oriundos desta técnica. Alguns fatores revelaram-se importantes na melhoria dos resultados: (i) escolha por parte do AG do melhor método de aproximação; (ii) o número de bimorphs, como também, alguns parâmetros relacionados ao desempenho ao AG: (iii) a probabilidade de ocorrência de crossover (iv) a probabilidade de mutação, (v) tamanho da população e (vi) porcentagem de elitismo.

O estudo acerca dos parâmetros de desempenho do AG mostrou-se decisivo considerando os resultados finais obtidos, bem como, a função de avaliação (erro) introduzida neste trabalho. Um ganho considerável em termos de qualidade nas aproximações, bem como, o aumento da faixa de freqüência analisada, 0 à $1000 \mathrm{~Hz}$, foi alcançado.

Os resultados experimentais apresentados comprovaram ainda o desempenho da técnica, validando também o modelo numérico. No entanto, resultados apenas satisfatórios foram obtidos com a utilização do acelerômetro angular.

Para estruturas do tipo placa, apenas um único método de aproximação foi considerado: formas modais. Para a determinação dos modos de vibrar, por sua vez, 
utilizou-se o método de Rayleigh-Ritz, por se mostrar preciso e ao mesmo tempo simples em termos da sua programação.

Os resultados numéricos obtidos demonstraram que o número de modos de vibrar possui um peso significativo para a metodologia proposta. Foi possível observar que com o aumento do número de sensores, de 4 para 12 bimorphs, houve um aumento expressivo na qualidade dos resultados. Em ambos os casos, as freqüências de ressonância foram bem estimadas, porém, somente no segundo caso, as anti-ressonâncias também foram.

Outra análise feita levou em consideração as condições de contorno elétricas. Os resultados em termos do coeficiente efetivo de acoplamento eletromecânico (EMCC) demonstraram uma pequena variação na rigidez da estrutura em função da mudança na condição de contorno (curto-circuito e circuito aberto).

Por fim, os resultados aqui apresentados comprovaram a eficácia da metodologia proposta na estimativa de funções de resposta em freqüência angulares utilizando-se para tal um sensor baseado em pastilhas piezelétricas, aqui denominado por bimorph, para ambos os tipos de estruturas investigadas: viga engastada-livre e uma placa simplesmente apoiada.

\subsection{TRABALHOS FUTUROS}

Baseando-se nos resultados promissores envolvendo os sensores bimorph aplicados a estruturas do tipo viga, propõe-se a confecção de um novo algoritmo genético para a otimização das dimensões, com a possibilidade de variação da forma, e o posicionamento dos bimorphs no caso da estrutura do tipo placa. 
O estudo e desenvolvimento de um novo algoritmo genético permitirão ainda avaliar a qualidade da metodologia proposta. Propõe-se determinar o mínimo de sensores (quantidade) em vista do máximo desempenho em termos de uma estimativa global de FRFs angulares.

Ainda em termos de trabalhos futuros, projeta-se a avaliação experimental do transdutor bimorph para estruturas do tipo placa tendo em vista o procedimento de otimização, validando por fim a técnica e confirmando à aplicabilidade da metodologia proposta.

Por fim, considerando-se apenas o sensor bimorph, propõe-se o estudo de um método de calibração experimental confiável do mesmo. Desta forma, será possível descrever informações importantes concernentes ao sensor, como sensibilidade (direta e cruzada), bem como, adequá-lo a uma possível utilização em maior escala. 


\section{REFERÊNCIAS BIBLIOGRÁFICAS}

AJITSARIA, J.; CHOE, S. Y.; SHEN, D.; KIM, D. J. (2007). Modeling and analysis of a bimorph piezoelectric cantilever beam for voltage generation. Smart Materials and Structures, v. 16, p. 447-454.

ASHORY, M. R. (1999). High quality modal testing methods. Tese (Doutorado em Engenharia Mecânica), Imperial College of Science, Technology and Medicine, Londres.

AVITABILE, P.; O'CALLAHAN, J. (2003). Frequency response function for unmeasured translation and rotation DOFs for impedance modeling applications. Mechanical Systems and Signal Processing, v. 17, n. 4, p. 723-745.

BARUT, A.; MADENCl, E.; ANDERSON, T.; TESSLER, A. (2002). Equivalent singlelayer theory for a complete stress field in sandwich panels under arbitrarily distributed loading. Composite Structures, v. 58, p. 483-495.

BECKERT, W.; PFUNDTNER, G. (2002). Analysis of the deformational behaviour of a bimorph configuration with piezoelectric actuation. Smart Materials and Structures, v. 11, p. 599-609.

BELLO, M.; SESTIERI, A.; D' AMBROGIO, W.; LA GALA, F. (2003). Development of a rotation transducer based on bimorph PZTs. Mechanical Systems and Signal Processing, v. 17, n. 5, p. 1069-1081.

BENJEDDOU, A.; TRINDADE, M. A.; OHAYON, R. (1997). A unified beam finite element model for extension and shear piezoelectric actuation mechanisms. Journal of Intelligent Material Systems and Structures, v. 8, n. 12, p. 1012-1025.

BENJEDDOU, A.; TRINDADE, M. A.; OHAYON, R. (1999). New shear actuated smart structure beam finite element. AIAA Journal, v. 37, n. 3, p. 378-383.

BENJEDDOU, A.; DEÜ, J.-F.; LETOMBE, S. (2002). Free vibrations of simplysupported piezoelectric adaptive plates: an exact sandwich formulation. ThinWalled Structures, v. 40, p. 573-593.

BOKELBERG, E. H.; SOMMER, H. J.; TRETHEWEY, M. W. (1994a). A six-degree-offreedom laser vibrometer, Part I: Theoretical development. Journal of Sound and Vibration, v. 178, n. 5, p. 643-654. 
BOKELBERG, E. H.; SOMMER, H. J.; TRETHEWEY, M. W. (1994b). A six-degree-offreedom laser vibrometer, Part II: Experimental validation. Journal of Sound and Vibration, v. 178, n. 5, p. 655-667.

BREGANT, L.; SANDERSON, M. (2000). Rotational degree of freedom: A historical overview on techniques and methods. Proceedings of the International Seminar on Modal Analysis - ISMA25 - Leuven, Bélgica.

BRISSAUD, M. (2004). Modelling of non-symmetric piezoelectric bimorphs. Journal of Micromechanics and Microengineering, v. 14, p. 1507-1518.

BRUANT, I.; PROSLIER, L. (2005). Optimal Location of Actuators and Sensors in Active Vibration Control. Journal of Intelligent Material Systems and Structures, v. 16, p. 197-206.

BRUNSKOG, J. (2002). Acoustic Excitation and Transmission of Lightweight Structures. Tese (Doutorado em Engenharia Acústica), Lund University, Suécia, 138 páginas.

CAFEO, J. A.; TRETHEWEY, M. W.; SOMMER, H. J. (1992). Measurement and application of experimental rotational degrees of freedom for mode shape refinement. The International Journal of Analytical and Experimental Modal Analysis, v. 7, n. 4, p. 255-269.

CAO, Y, J.; WU, Q. H. (1999). Teaching Genetic Algorithm Using Matlab. Int. J. Elect. Eng. Educ., v. 36, p. 139-153.

CARBONARI, R. C.; SILVA, E. C. N.; NISHIWAKI, S. (2007). Optimum placement of piezoelectric material in piezoactuator design. Smart Materials and structures, v. 16 , p. 207-220.

CHARETTE, F.; BERRY, A.; GUIGOU, C. (1998). Active control of sound radiation from plate using a polyvinylidene fluoride volume displacement sensor. Journal of Acoustical Society of America, v. 103, n. 3, p. 1493-1503.

CHEN, S. Q.; WEI, H. J. (1984). Pattern Recognition. People's Communication Press, p. 5-20.

COSTA, L.; FIGUEIREDO, I.; LEAL, R.; OLIVEIRA, P.; STADLER, G. (2007). Modeling and numerical study of actuator and sensor effects for a laminated piezoelectric plate. Computers and Structures, v. 85, p. 385-403.

COSTA BRANCO, P. J.; DENTE, J. A. (2004). On the electromechanics of a piezoelectric transducer using a bimorph cantilever undergoing asymmetric sensing and actuation. Smart Materials and Structures, v. 13, p. 631-642.

DAS-GUPTA, D. K. (1998). Ferroelectric Ceramic/Polymer Bimorph Sensor for Strain Measurements in Laminates. Final Report, University of Wales, February. 
DE JONG, K. A. (1975). Analysis of the Behavior of a Class of Genetic Adaptive Systems. Tese (Doutorado) - College of Literature, Science and Arts, University of Michigan.

DHURI, K. D.; SESHU, P. (2006). Piezo actuator placement and sizing for good control effectiveness and minimal change in original system dynamics. Smart Materials and Structures, v 15, p. 1661-1672.

DUARTE, M. L. M. (1996). Experimentally-derived structural models for use in further dynamic analysis. Tese (Doutorado em Engenharia Mecânica), University of London, Imperial College of Science, Technology and Medicine, Londres.

DUARTE, M. L. M.; EWINS, D. J. (2000). Rotational degree of freedom for structural coupling analysis via finite-difference technique whit residual compensation. Mechanical Systems and Signal Processing, vol. 14, n. 2, p. 205-227.

EWINS, D. J. (1984). Modal testing: Theory and practice. $1^{\text {st }}$ Edition, Research Studies Press, London, United Kindgom.

EWINS, D. J.; INMAM, D. J. (2000). Structural Dynamics@ 2000: current status and future directions. Research Studies Press Ltd., Baldock, Hertfordshire, England.

FERRARIO, L.; TASCHINI, S.; EMMENEGGER, M.; BALTES, H.; KORVINK, J. G. (2003). A new computational method for piezoelectric plate modeling: application to membrane microsensors. DTIP (Design, Test, Integration \& Packaging) of MEMS/MOEMS, Cannes-Mandelieu, p. 121-126.

GIANNOPOULOS, G.; MONREAL, J.; VANTOMME, J. (2007). Snap-through buckling behavior of piezoelectric bimorph beams: I. Analytical and numerical modeling. Smart Materials and Structures, v. 16, p. 1148-1157.

GODOY, T. C. (2008). Modelagem de placas laminadas com materiais piezelétricos conectados a circuitos shunt resistivo-indutivo. Dissertação de Mestrado, Escola de Engenharia de São Carlos, Universidade de São Paulo, São Carlos.

GOLDBERG, D. E. (1989). Genetic Algorithms in Search, Optimization, and Machine Learning. New York: Addison-Wesley Publishing Company, Inc., 412 páginas.

GONG, Z.; LUO, Y.; SUN, L. (2005). Modality Analysis on PZT Bimorph Actuator. Proceedings of the IEEE - International Conference on Mechatronics \& Automation, Niagara Falls, Canada, p. 1863-1866, July.

GOPINATHAN, S. V.; VARADAN, V. V.; VARADAN, V. K. (2000). A review and critique of theories for piezoelectric laminates. Smart Materials and Structures, v. 9, p. 24-48.

HAN, J.-H.; LEE, I. (1999). Optimal placement of piezoelectric sensors and 
actuators for vibration control of a composite plate using genetic algorithms. Smart Materials and Structures, v. 8, p. 257-267.

HAMEY, C. S.; LESTARI, W.; QIAO, P.; SONG, G. (2004). Experimental Damage Identification of Carbon/Epoxy Composite Beams Using Curvature Mode Shapes. Structural Health Monitoring, v. 3, n. 4, p. 333-353.

HELDERWEIRT, S. et al. (2001). Application of accelerometer-based rotational degree of freedom measurements for engine subframe modelling. Proceedings of the $19^{\text {th }}$ International Modal Analysis Conference, IMAC 19, p. 1298-1304.

HEYLEN, W.; LAMMERNS, S.; SAS, P. (2000). Modal analysis: Theory and testing. KU Leuven, PMA, Leuven, Belgium.

HUANG, C.; LIN, Y. Y.; TANG, T. A. (2004). Study on the tip-deflection of a piezoelectric bimorph cantilever in the static state. Journal of Micromechanics and Microengineering, v. 14, p. 530-534.

IVARSSON, L; SANDERSON, M. A.; TROSHIN, A. G. (2000). Design, theory and validation of a low mass 6-d.o.f transducer. Journal of Sound and Vibration, v. 230, n. 3, p. 661-688, 2000.

JIANG, S.; LI, X.; GUO, S.; HU, Y.; YANG, J.; JIANG, Q. (2005). Performance of a piezoelectric bimorph for scavenging vibration energy. Smart Materials and Structures, v. 14, p. 769-774.

KOSHIGOE, S.; MURDOCK, J. W. (1993). A unified analysis of both active and passive damping for a plate with piezoelectric transducers. Journal of Acoustical Society of America, v. 93, n. 1, p. 346-355.

KULIKOV, G. M.; PLOTNIKOVA, S. V. (2005). Equivalent Single-Layer and Layerwise Shell Theories and Rigid-Body Motions - Part I: Foundations. Mechanics of Advanced Materials and Structures, v. 12, p. 275-283.

LEE, C.-K.; MOON, F. C. (1989). Laminated piezopolymer plates for torsion and bending sensors and actuators. Journal of Acoustical Society of America, v. 85, n. 6, p. 2432-2439.

LEE, C.-K. (1990). Theory of laminated piezoelectric plates for the design of distributed sensors/actuators. Part I: Governing equations and reciprocal relationships. Journal of Acoustical Society of America, v. 87, n. 3, p. 1144-1158.

LEE, C.-K.; CHIANG, W.-W.; O'SULLIVAN, T. C. (1991). Piezoelectric modal sensor/actuator pairs for critical active damping vibration control. Journal of Acoustical Society of America, v. 90, n. 1, p. 374-384.

LEE, S.-Y.; KO, B; YANG, W. (2005). Theoretical modeling, experiments and optimization of piezoelectric multimorph. Smart Materials and Structures, v. 14, p. 1343-1352. 
LI, Q.; LOVELL, M.; MEl, J.; CLARK, W. (2004). A Study of Displacement Distribution in a Piezoelectric Heterogeneous Bimorph. Journal of Mechanical Design, v. 126, p. 757-762, July.

LIM, S. C.; CHOI, S. B. (2007). Vibration control of an HDD disk-spindle system utilizing piezoelectric bimorph shunt damping: I. Dynamic analysis and modeling of the shunted drive. Smart Materials and Structures, v. 16, p. 891-900.

LIMA JR, J. J. (1999). Modelagem de Sensores e Atuadores Piezelétricos com aplicações em Controle Ativo de Estruturas. Tese (Doutorado). Universidade Estadual de Campinas.

LOFRANO, M. (2003). Técnicas de estimativa de FRFs angulares em análise modal experimental com aplicações a estruturas do tipo viga. Dissertação (Mestrado em Engenharia Mecânica), Escola de Engenharia de São Carlos, São Carlos, 152 páginas.

MEIROVITCH, L (1970). Elements of vibration analysis. New York: McGraw-Hill.

McCONNELL, K. G. (1995). Vibration testing: Theory and Practice. New York, Wiley \& Sons Inc.

MAIA, N. M. M. et al. (1997). Experimental modal analysis. Taunton, England, Research Studies Press Ltd, John Wiley \& Sons Inc.

MAURINI, C.; PORFIRI, M.; POUGET, J. (2006). Numerical methods for modal analysis of stepped piezoelectric beams. Journal of Sound and Vibration, v. 298, p. 918-933.

MAXWELL, N. D.; ASOKANTHAN, S. F. (2004). Modal characteristics of a flexible beam with multiple distributed actuators. Journal of Sound and Vibration, v. 269, p. 19-31.

MITCHELL, M. (1996). An Introduction to Genetic Algorithms. MIT Press, 205 páginas.

MONTALVÃO, D.; RIBEIRO, A. M. R.; MAIA, N. M. M.; SILVA, J. M. M. (2004).

Estimation of the rotational terms of the dynamic response matrix. Shock and Vibration 11, IOS Press, p. 333-350.

MONTURET, V.; NOGAREDE, B. (2002). Optimal dimensioning of a piezoelectric bimorph actuator. The European Physical Journal Applied Physics, v. 17, p. $107-$ 118.

MORRIS, C. J.; FORSTER, F. K. (2000). Optimization of a circular piezoelectric bimorph for a micropump driver. J. Micromech. Microeng., v. 10, p. 459-465.

MOTTERSHEAD, J. E.; KYPRIANOU, A.; OUYANG, H. (2005). Structural modification. Part I: rotational receptances. Journal of Sound and Vibration 284, p. 


\section{9-265.}

OLIVEIRA, L. P. R., VAROTO, P. S. (2002). On the Interaction Between the Vibration Exciter and the Structure Under Test in Vibration Testing. Journal of Sound and Vibration, p. 28-35.

OLIVEIRA, L. P. R. (2003). Interação entre excitadores de vibração e a estrutura sob estudo em ensaios com múltipla excitação. Dissertação (Mestrado em Engenharia Mecânica) - Programa de Pós-Graduação em Engenharia Mecânica, Escola de Engenharia de São Carlos - Universidade de São Paulo, São Carlos.

PAGANI Jr, C. C.; TRINDADE, M. A. (2007). Modelagem por elementos finitos de placas com sensores piezelétricos aplicada ao desenvolvimento de filtros modais. $\mathrm{X}$ Encontro de Modelagem Computacional, Nova Friburgo, IPRJ-UERJ.

PAGANI Jr, C. C.; TRINDADE, M. A. (2008). Projeto e Otimização do Desempenho de Filtros Modais Baseados em Redes de Sensores Piezelétricos. Anais do VIII Simpósio de Mecânica Computacional (SIMMEC), Belo Horizonte - MG.

PARK, G.; FARRAR, C. R.; DI SCALEA, F. L.; COCCIA, S. (2006). Performance assessment and validation of piezoelectric active-sensors in structural health monitoring. Smart Materials and Structures, v. 15, p. 1673-1683.

PIETRZAKOWSKI, M. (2007). Piezoelectric control of composite plate vibration: Effect of electric potential distribution. Computers and Structures (em fase de impressão).

QIU, Z.-C.; ZHANG, X.-M.; WU, H.-X.; ZHANG, H.-H. (2007). Optimal placement and active vibration control for piezoelectric smart flexible cantilever plate. Journal of Sound and Vibration, v. 301, p. 521-543.

RAHMOUNE, M.; BENJEDDOU, A.; OHAYON R.; OSMONT, D. (1998). New thin piezoelectric plate models. Journal of Intelligent Material Systems and Structures, $v$. 9, n. 12, p. 1017-1029.

RATCLIFFE, M. J.; LIEVEN, N. A. J. (1996). Measuring rotations using a laser doppler vibrometer. Proceedings of the $14^{\text {th }}$ International Modal Analysis Conference, IMAC, USA, p. 1002-1008.

SADRI, A. M.; WRIGHT, J. R.; WYNNE, R. J. (1999). Modelling and optimal placement of piezoelectric actuators in isotropic plates using genetic algorithms. Smart Materials and Structures, v. 8, p. 490-498.

SAMPAIO, R. P. C.; MAIA, N. M. M.; SILVA, J. M. M. (1999). Damage Detection Using the Frequency Response-Function Curvature Method. Journal of Sound and Vibration, v. 226, n. 5, p. 1029-1042.

SAWYER, C. B. (1931). The use of rochelle salt crystals for electrical reproducers and microphones. Proc. Inst. Radio Eng., v. 19, n. 11, p. 2020-2029. 
SILVA, D. C. C. M. (2003). Determinação de termos rotacionais da resposta dinâmica por técnicas de análise modal. Dissertação (Mestrado em Engenharia Mecânica) - Instituto Superior Técnico, Universidade Técnica de Lisboa, Portugal.

STEEL, M. R.; HARRISON, F.; HARPER, P. G. (1978). The piezoelectric bimorph: An experimental and theoretical study of its quasistatic response. J. Phys. D: Appl. Phys., v. 11, p. 979-989.

SZE, K. Y.; YANG, X.-M.; FAN, H. (2004). Electric assumptions for piezoelectric laminate analysis. International Journal of Solids and Structures, v. 41, p. 23632382.

TAI, H.; SEKI, J.; KIDA, T.; KOBAYASHI, T. (2004). Vibration-Type Viscometer Using a Triangular Bimorph Transducer - Measurement of High Viscosity by LowFrequency Operation. Japanese Journal of Applied Physics, v. 43, n. 5B, p. 30883089.

TANAKA, N.; SANADA, T. (2007). Modal control of a rectangular plate using smart sensors and smart actuators. Smart Materials and Structures, v. 16, p. 36-46.

TRINDADE, M. A. (2000). Controle Hybride Actif-Passif des Vibrations de Structures par des Matériaux Piézoélectriques et Viscoélastiques: Poutres Sandwich/Multicouches Intelligentes. Tese (Doutorado em Engenharia de Estruturas e Sistemas Acoplados) - Conservatoire National des Arts et Métiers.

TRINDADE, M. A.; BENJEDDOU, A.; OHAYON, R. (2001a). Finite element modelling of hybrid active-passive vibration damping of multilayer piezoelectric sandwich beams - part I: Formulation. International Journal for Numerical Methods in Engineering, v. 51, p. 835-854.

TRINDADE, M. A.; BENJEDDOU, A.; OHAYON, R. (2001b). Finite element modelling of hybrid active-passive vibration damping of multilayer piezoelectric sandwich beams - part II: System analysis. International Journal for Numerical Methods in Engineering, v. 51, p. 855-864.

TRINDADE, M. A.; BENJEDDOU, A. (2007). On the evaluation of effective electromechanical coupling coefficients for structures with piezoelectric elements. III ECOMAS Thematic Conference on Smart Structures and Materials, Gdansk, Polônia.

URGUEIRA, A. P. V. (1989). Dymanic analysis of coupled structures using experimental data. Tese (Doutorado), University of London, Imperial College of Science, Technology and Medicine, London.

VAROTO, P. S. (1994). An FE study of exciter - structure interaction in vibration testing. Proceedings of the XII International Modal Analysis Conference - IMAC, Honolulu.

VAROTO, P. S. (1996). The rules for the exchange and analysis of dynamic 
information in structural vibration. Tese (Doutorado em Engenharia Mecânica), lowa State University, lowa, 249 páginas.

WANG, S. Y. (2004). A finite element model for the static and dynamic analysis of a piezoelectric bimorph. International Journal of Solids and Structures, v. 41, p. 4075-4096.

WANG, S.; REN, Q.; QIAO, P. (2006). Structural Damage Detection Using Local Damage Factor. Journal of Vibration and Control, v. 12, n. 9, p. 955-973.

WU, T.; RO, P. I. (2004). Dynamic peak amplitude analysis and bonding layer effects of piezoelectric bimorph cantilevers. Smart Materials and Structures, v. 13, p. 203-210.

ZABIHOLLAH, A.; GANESAN, R.; SEDAGHATI, R. (2006). Sensitivity analysis and design optimization of smart laminated beams using layerwise theory. Smart Materials and Structures, v. 15, p. 1775-1784.

ZHANG, X.; ERDMAN, A. G. (2006). Optimal Placement of Piezoelectric Sensors and Actuators for Controlled Flexible Linkage Mechanisms. Transactions of ASME, v. 128, p. 256-260, April.

ZHU, W., ZHENG, N., WONG, C.-H. (2006). A Novel Stochastic Model for the Random Impact Series Method in Modal Testing. Department of Mechanical Engineering, University of Maryland, Baltimore, MD 21250.

ZIAEI-RAD, S.; MARTARELLI, M.; EWINS, D. J. (2000). Measuring RDOFs using laser doppler vibrometer. Proceedings of the International Seminar on Modal Analysis - ISMA25 - Leuven, Bélgica.

YOSHIMURA, T.; HOSOYA, N. (2000). FRF estimation on rotational degree of freedom by rigid block attachment. Proceedings of the International Seminar on Modal Analysis - ISMA25 - Leuven, Bélgica.

KISTLER INC. <www.kistler.com>. Acesso em: 28 mar. 2007.

MIDE TECHNOLOGY CORPORATION <www.mide.com/>. Acesso em 5 mar. 2007.

PI CERAMIC GmbH <www.piceramic.de/>. Acesso em 28 fev. 2007. 


\section{A. CÓDIGO EM MATLAB ${ }^{\circledR}$ PARA ESTRUTURAS DO TIPO VIGA}

A seguir, apresentam-se as rotinas desenvolvidas em ambiente Matlab ${ }^{\circledR}$ para a modelagem numérica do transdutor bimorph aplicado a estruturas do tipo viga.

\section{A.1. PROGRAMA PRINCIPAL}

$\%$ Main program \# 1.25

$\%$ Last modification: 20/09/07

clc; clear all; close all; clear memory;

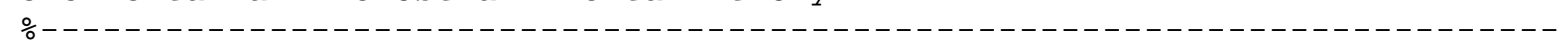

$\mathrm{b}=25 \mathrm{e}-3 ; \mathrm{kc}=0.83 ; \mathrm{L}=500 \mathrm{e}-3 ; \bmod \_i d=[1: 20] ;$ fdisp=0; fplot=0; frec=1;

$\mathrm{n}=8$; hv $=3 \mathrm{e}-3$; thick_sens $=0.5 \mathrm{e}-3$; thick_glue $=0.2 \mathrm{e}-3$; $\mathrm{dx}=5 \mathrm{e}-3$;

$\mathrm{dt}=2.5 \mathrm{e}-4 ; \mathrm{tf}=5.0$; popsize $=60 ; \mathrm{pc}=0.95 ; \mathrm{pm}=0.04$; elite=3;

ngerstop $=100$; rstop $=10.0$; bitsleng $=6$; bitspos $=8$;

for $n b=1: 3$

for $\mathrm{x} \_$out $=450.0: 0.050: \mathrm{L}$

$\%$ Saving values

if frec $==1$

eval(['fid=fopen( ' 'a_status_', int2str(nb), '_', int2str(x_out*1000), '.out' ', ''a' ');'])

fprintf(fid, '\%s\n', datestr(now));

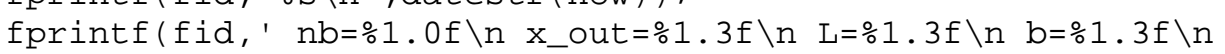

$h v=\% 1.3 f \backslash n^{\prime}, \mathrm{nb}$,

x_out, L, b, hv);

fprintf(fid, ' $k c=\% 1.2 f \backslash n$ thick_sens=\%1.5f $\backslash n$ thick_glue=\%1.5f $\backslash n$

$d x=\% 1.5 f \backslash n$

$d t=\% 1.5 f \backslash n$ tf $=\% 1.5 f \backslash n ', k c$, thick_sens, thick_glue, $d x, d t, t f)$;

fprintf(fid, ' popsize $=\% 1$. $0 f \backslash n$ pcros $=\% 1.3 f \backslash n$

pmut $=\% 1$. $3 f \backslash n^{\prime}$, popsize, pc, pm) ;

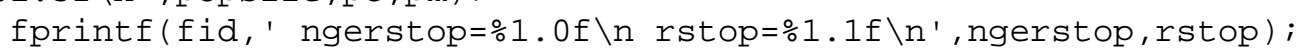

fclose(fid);

end

$\%$ GA: inital population

function

[popini]=initialise(popsize, nb, bitsleng,bitspos); \% Call INITIALIZE

[values]=dcode (popsize, popini,nb,bitsleng, bitspos,L); \% Call DCODE function

\% Loop: adding values (leng_sens, pos_sens) to POPINI

for $i=1: 2 * n b$

popini $(:, n b *$ bitsleng+nb*bitspos+i) $=\operatorname{values}(:, i)$; end

nger $=1 ; \operatorname{valger}(1,2)=50 ;$ contfig= $0 ; \%$ Initialization 
$\%$ GA: run until the result be acceptable

while $((\operatorname{valger}(:, 2)>$ rstop) \& (nger<=ngerstop))

tic

if nger $==1$

oldpop=popini;

start=1;

clear popini

else

oldpop=newpop ;

start=elite+1;

end

$\%$ Loop: determines the value for each pair: leng_sens and pos_sens

for $\mathrm{k}=$ start: length $(\operatorname{oldpop}(:, 1))$

contfig=contfig +1 ;

for $m=1: n b$ position input $(2 * m-1)=o l d p o p(k, n b *$ bitsleng+nb*bitspos+nb+m); \% Bimorph's

length input $(2 * m)=0 l d p o p(k, n b *$ bitsleng+nb*bitspos $+m) / 1 e 3 ; \%$ Bimorph's end

oldpop (k, nb*bitsleng+nb*bitspos $\left.+2{ }^{*} n b+1\right)=$ bimorph (input, fplot, fdisp, frec, $n$, BIMORPH $\mathrm{L}, \mathrm{b}, \mathrm{hv}, \mathrm{kc}$, mod_id, thick_sens, thick_glue, x_out, dx, dt,tf); \% Call

end

function

function

[oldpop]=sortpop(popsize, oldpop, nb, bitsleng, bitspos); \% Call SORTPOP

oldpop=oldpop (1: popsize, : );

wval(popsize, oldpop, nb, bitsleng, bitspos, eval([' ' 'gen_pop_' , int2str(nb), '_'

int2str(x_out*1000),'.out''']), nger); \% Call WVAL function

$\%$ values from BIMORPH function

valger (nger, 1) =max (oldpop ( :,nb*bitsleng+nb*bitspos+2*nb+1));

valger (nger , 2) =min (oldpop (:, nb*bitsleng+nb*bitspos+2*nb+1));

$\operatorname{valger}($ nger, 3$)=$ mean $($ oldpop $(:, n b *$ bitsleng+nb*bitspos+2*nb+1) );

$\%$ Saving values

eval(['fid=fopen(' 'gen_values_', int2str(nb), '_', int2str(x_out*1000), '.out ' ',

' 'a' '); $\left.\left.{ }^{\prime}\right]\right)$

fprintf(fid, '\%1.4f \%1.4f \%1.4f \n', valger(nger,1), valger(nger, 3), valger (nger, 2));

fclose(fid); Call

[newpop]=genetic (popsize, oldpop, nb, bitsleng, bitspos, pc, pm, elite);\%

\section{GENETIC function}

[values]=dcode (popsize, newpop(elite+1: elite+popsize, :), nb, bitsleng, bitspos, L); \% Call DCODE function

\% Loop: writting values into NEWPOP

for $i=1$ : popsize

for $j=1: 2^{*} n b$

newpop (elite+i,nb*bitsleng+nb*bitspos $+j)=\operatorname{values}(i, j)$;

end

nger=nger +1 ;

pack 


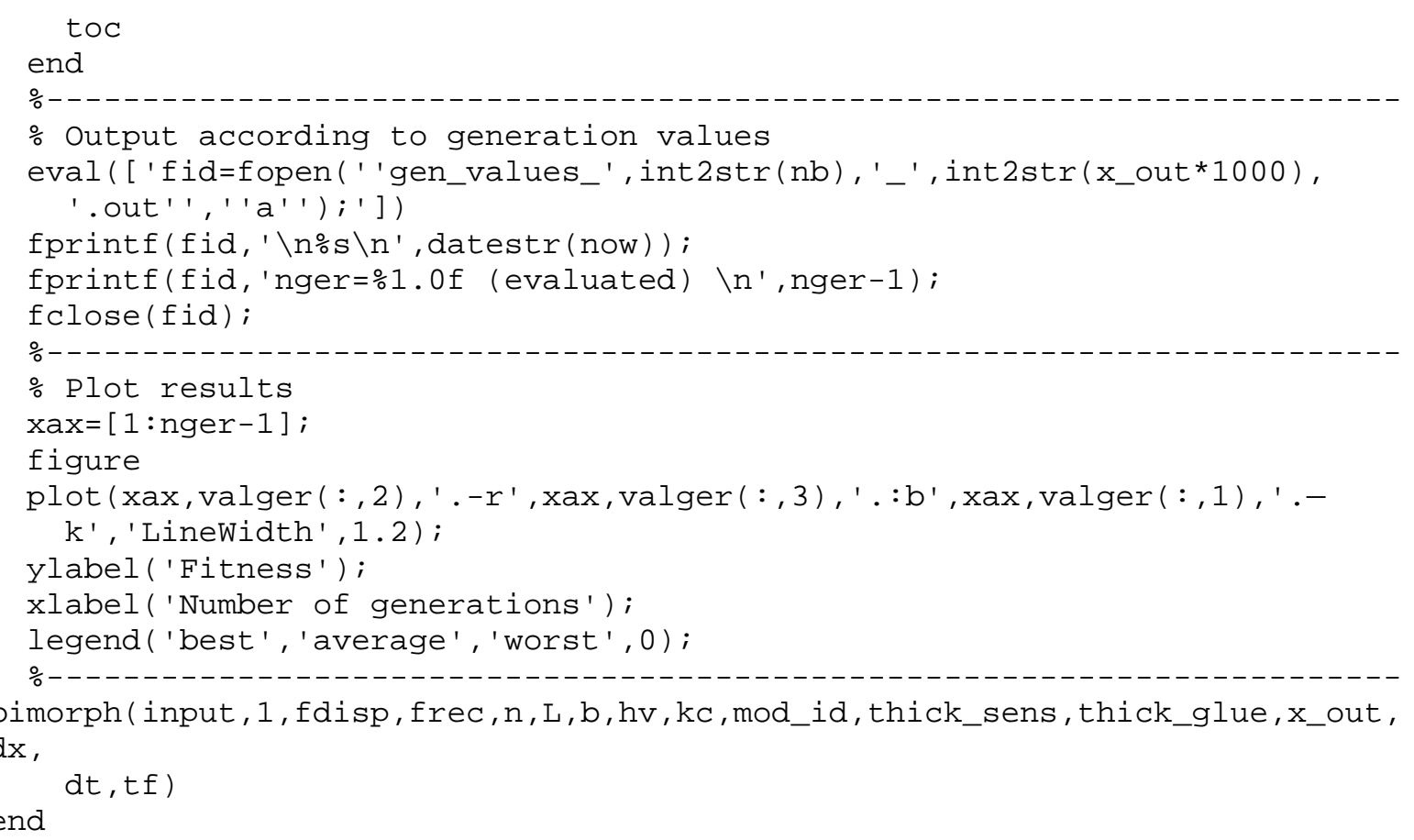

\section{A.2. FUNÇÃO INITIALISE}

$\%$ INITIALISE function \# 1.25

\% Description: creates random initial population

function [pop]=initialise(popsize, nb, bitsleng, bitspos);

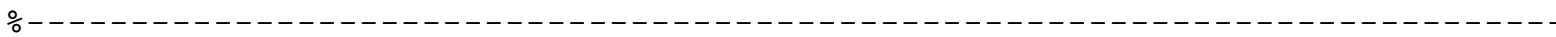

pop $=$ round $(r$ and (popsize, nb*bitspos+nb*bitsleng $))$;

\section{A.3. FUNÇÃO DCODE}

\% DCODE function \#1.25

\% Description: decodes values from genes

function [dcoded]=dcode(popsize, pop, nb, bitsleng, bitspos, L) ;

\%-

$\%$ Dcode

aleng $=5$; bleng $=68$;

for $i=1$ : popsize

$\%$ Bimorph's length

for contnb=1:nb $\operatorname{dcoded}(i$, contnb $)=\operatorname{sum}(2 . \wedge(\operatorname{size}(\operatorname{pop}(:),($ contnb -

1) *bitsleng+1: contnb*bitsleng), 2) -1:-1:0). *pop(i, (contnb -

$1) *$ bitsleng +1 : contnb*bitsleng $) *($ bleng -aleng $) /(2$. ^bitsleng -1$)+$ aleng ;

end

$\%$ Bimorph's position

for $m=n b+1: 2^{*} n b$

$\operatorname{dcoded}(i, m)=\operatorname{sum}\left(2 . \wedge\left(\operatorname{size}\left(\operatorname{pop}\left(:, n b^{*}\right.\right.\right.\right.$ bitsleng $+(m-n b-$

$1) *$ bitspos $+1: n b *$ bitsleng $+(m-n b) *$ bitspos $), 2)-1:-1: 0)$ * pop $(i, n b *$ bitsleng $+(m-$

$n b-1) *$ bitspos +1 : nb*bitsleng $+(m-n b) *$ bitspos $)) *(L-0.010) /(2 . \wedge$ bitspos -1$)$; end

end 


\section{A.4. FUNÇÃO BIMORPH}

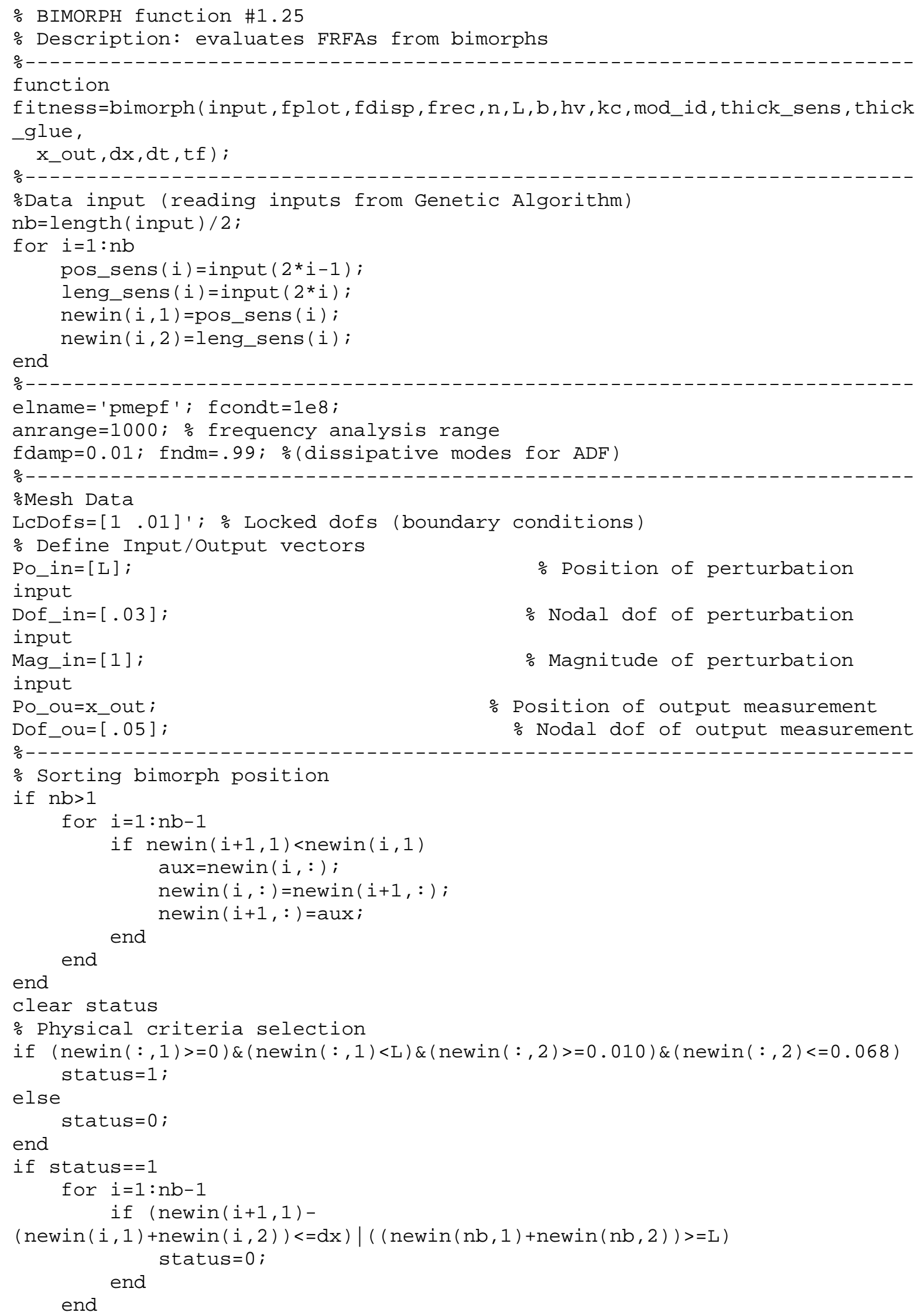


end

$\%$ Loop to determine RFRF from bimorph/cantilever beam

if status $==1$

\%Top layer

\%Sub-layers definition: begin from lower left sub-layer (PZT5H)

for $i=1: n b$

for $j=1: 2$

To_h $(i, j)=$ thick_sens;

To_p $(i, j)=$ pos_sens $(i)$;

To_a $(i, j)=$ leng_sens $(i)$;

\%aterial data

To_c11m $(i, j)=65.5 e 9$;

To_rho $(i, j)=7500$;

To_e31m $(i, j)=-23.2$;

end

To_epsm $(i, j)=1.54 \mathrm{e}-8$;

\%Core layer

\%Core center determines $z=0$, so that its thickness

$\%$ must be the same for all adjacent layers

Co_h $(i, 1)=$ thick_glue;

Co_p $(i, 1)=$ pos_sens $(i)$;

Co_a $(i, 1)=$ leng_sens $(i)$;

\%Core layer: material data

Co_c33m $(i, 1)=300 \mathrm{e} 9$;

Co_c55 $(i, 1)=100 \mathrm{e} 9$;

end

Co_rho $(i, 1)=1000$;

\%Bottom layer

\%Sub-layers definition: begin from upper left sub-layer

Bo_h $(1,1)=h v$;

Bo_p $(1,1)=0 \mathrm{e}-3$;

Bo_a $(1,1)=\mathrm{L}$;

$\%$ Material properties $==\mathrm{Alu}$

Bo_c11m $(1,1)=70.3 e 9$;

Bo_rho $(1,1)=2690$;

fe_ndelt

fe_ss

\% Finding DDLs

$L p=\operatorname{full}(\operatorname{nod}(1: \operatorname{size}(\operatorname{nod}, 1)-1,5)) ;$

ua $=\operatorname{real}(\operatorname{Tr})$; uf $=\operatorname{zeros}(\operatorname{size}(\operatorname{mdof}, 1), \operatorname{size}(\operatorname{Tr}, 2))$;

for $k d=1: \operatorname{size}(\operatorname{adof}, 1), i d=f i n d(\operatorname{mdof}(:)==\operatorname{adof}(k d)) ; \operatorname{uf}(i d,:)=$ $\mathrm{ua}(\mathrm{kd}, \mathrm{:})$; end

ws $=$ full $($ uf $($ find $(\operatorname{round}(100 *(\operatorname{mdof}-f i x(\operatorname{mdof})))==3),:))$;

$\%$ Plot excitation

$[\mathrm{y}, \mathrm{t}]=$ impulse $(\operatorname{ssp}(:, 1),[0: \mathrm{dt}: \mathrm{tf}])$;

if elname=='pmepf'

saidas=size $(\operatorname{ssp} . c, 1) ;$ sdesl=saidas $/ 2 ;$ spiezo=sdesl-1;

$\mathrm{sp}=\mathrm{spiezo} /\left(2{ }^{*} \mathrm{nb}\right)$;

$\mathrm{V} 12 \mathrm{~b}=$ zeros(length $(\mathrm{t}), \mathrm{nb}+2)$;

for $i=1: 2^{*} \mathrm{nb}$

$b V=1+i *[1: s p]$

end

$\operatorname{Vb}(:, i)=\operatorname{mean}\left(y(:, b V)^{\prime}\right) '$;

for $i=1: n b$ end

$\operatorname{V12b}(:, i)=V b(:, i)-V b(:, i+n b)$;

else 


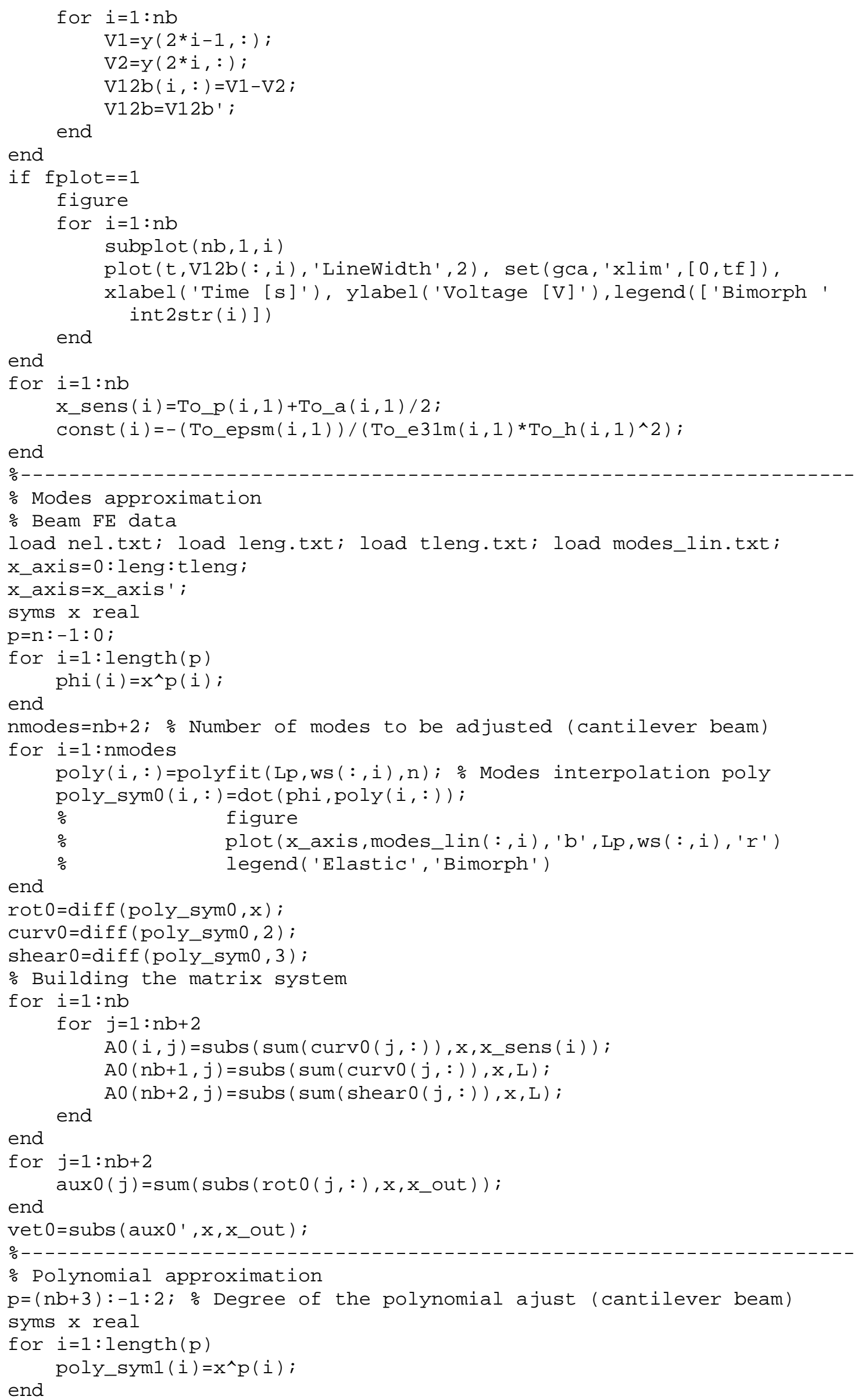




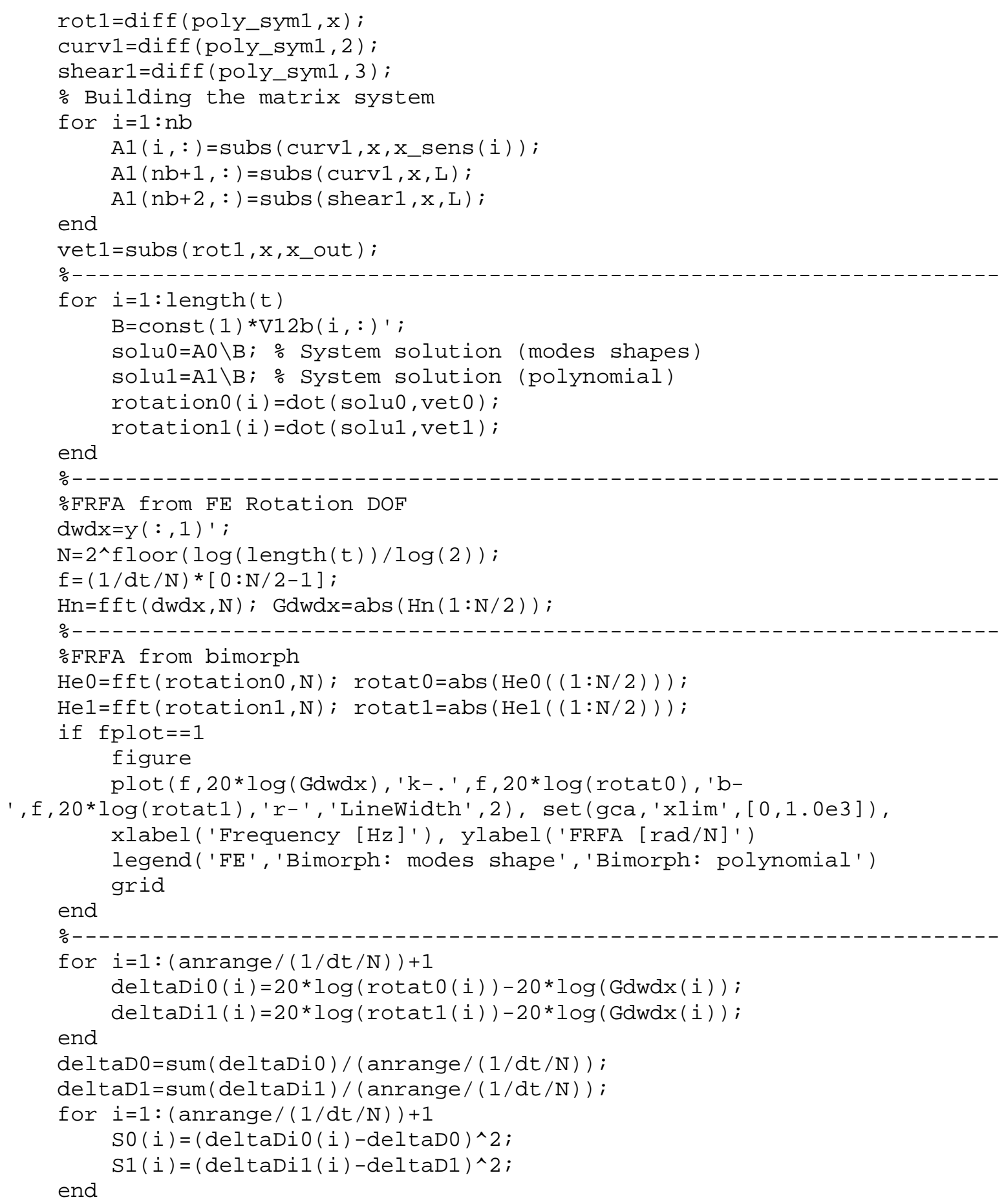

fitness $\theta=\operatorname{sqrt}((\operatorname{sum}(\mathrm{S} \Theta)) /($ anrange $/(1 / \mathrm{dt} / \mathrm{N})))+\operatorname{abs}(\operatorname{sum}($ deltaDi $\Theta)) /(($ anrange $/$ $(1 / \mathrm{dt} / \mathrm{N}))+1)$;

fitness1=sqrt (( sum(S1))/(anrange/(1/dt/N)))+abs ( sum(deltaDi1) $) /(($ anrange/

$(1 / \mathrm{dt} / \mathrm{N}))+1)$;

if fitness $0<$ fitness 1

fitness=fitness 0 ;

else

approx $=0$;

fitness=fitness1;

end

approx $=1$;

$\%$ - 


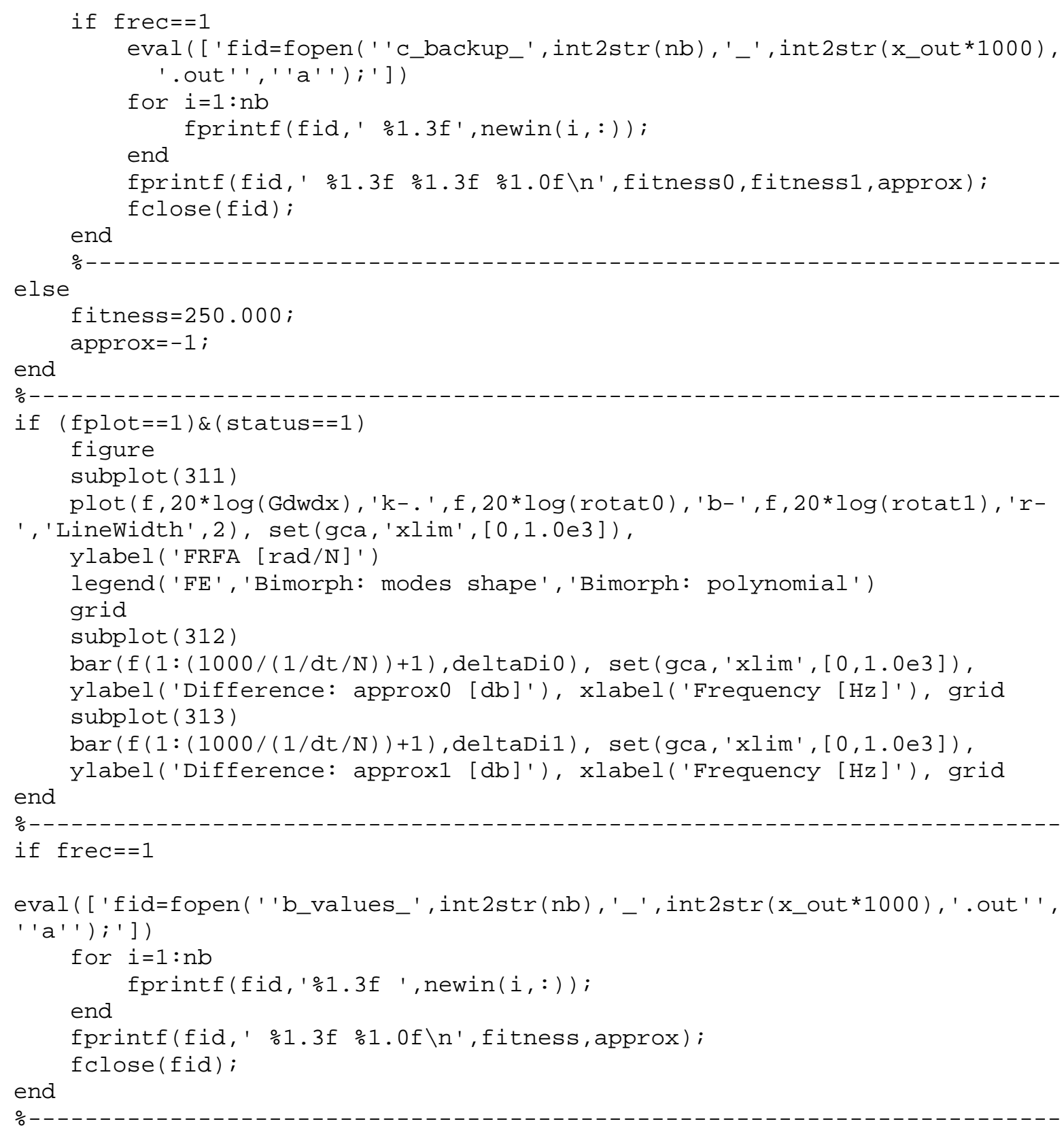

\section{A.5. FUNÇÃO GENETIC}

$\%$ GENETIC function \# 1.25

\% Description: genetic operators

\%- .

function [newpop]=genetic (popsize, oldpop, nb, bitsleng, bitspos, pc, pm, elite);

\%- $\ldots$

newpop=zeros (elite+popsize, nb*bitsleng+nb*bitspos+2*nb+1);

for $i=1$ : elite

for $j=1: n b *$ bitsleng $+n b *$ bitspos $+2{ }^{*} n b+1$

end newpop $(i, j)=0 l d p o p(i, j)$;

end

for $i=1: p o p s i z e / 2$

[parents]=select (popsize, nb, bitspos, bitsleng,oldpop); \% Call SELECT 
function

[childs]=crossover (popsize, nb, bitspos, bitsleng, parents,pc,pm); \% Call CROSSOVER function

for $j=1: n b$ *bitsleng+nb*bitspos newpop (elite $\left.+2^{*} i-1, j\right)=\operatorname{childs}(1, j)$;

end newpop $\left(\operatorname{elite}+2^{*} i, j\right)=\operatorname{childs}(2, j) ;$

end

\section{A.6. FUNÇÃO SELECT}

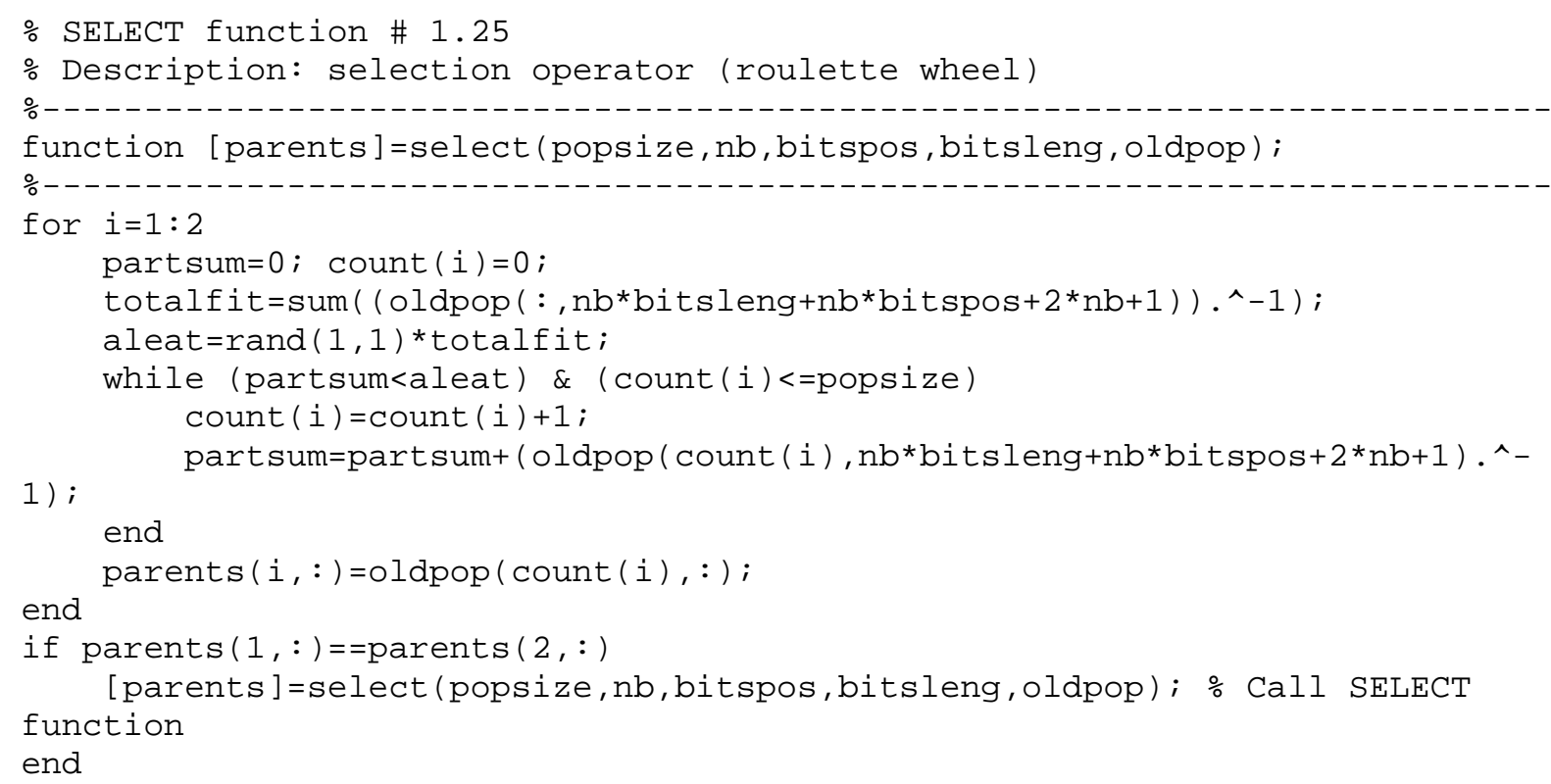

\section{A.7. FUNÇÃO CROSSOVER}

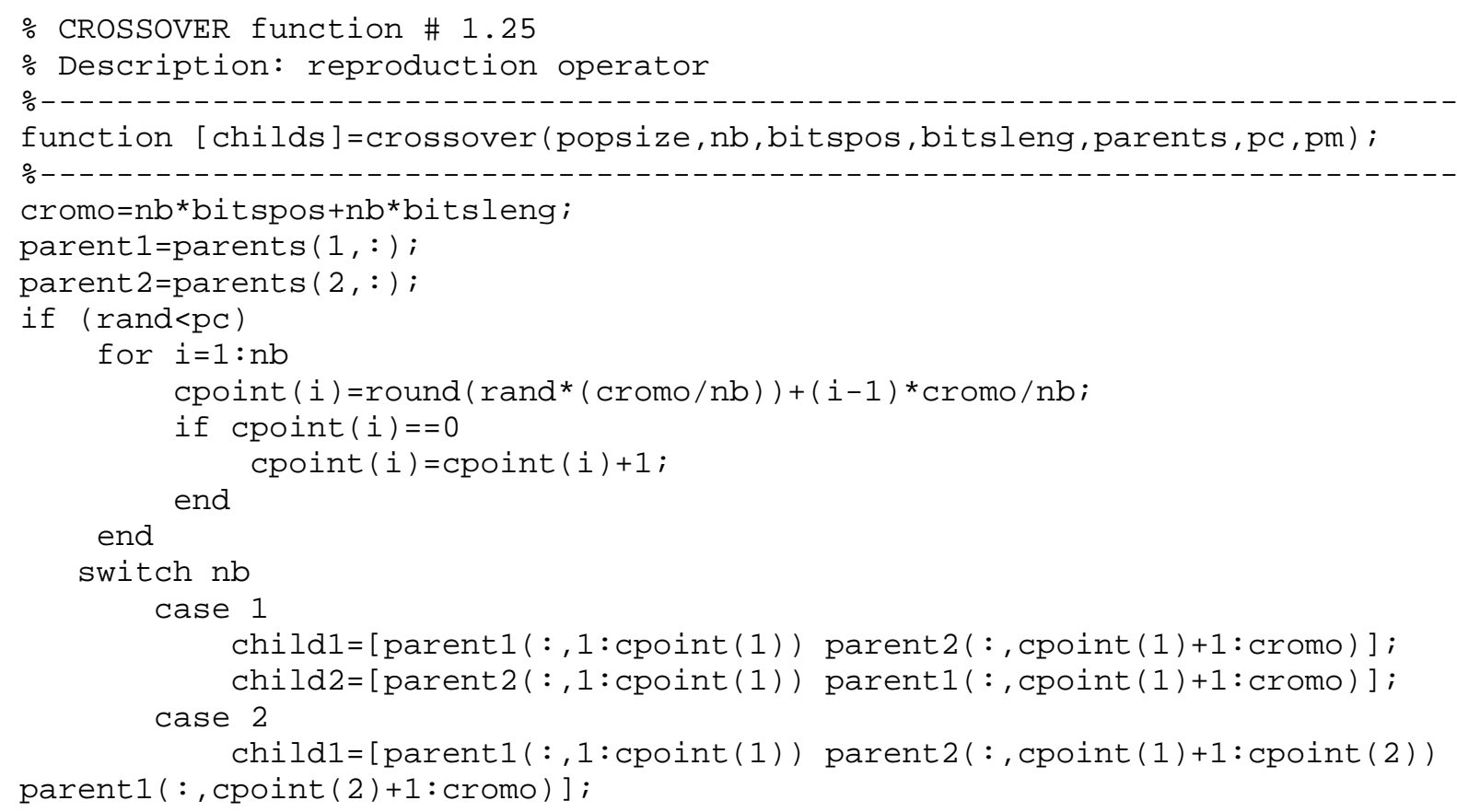




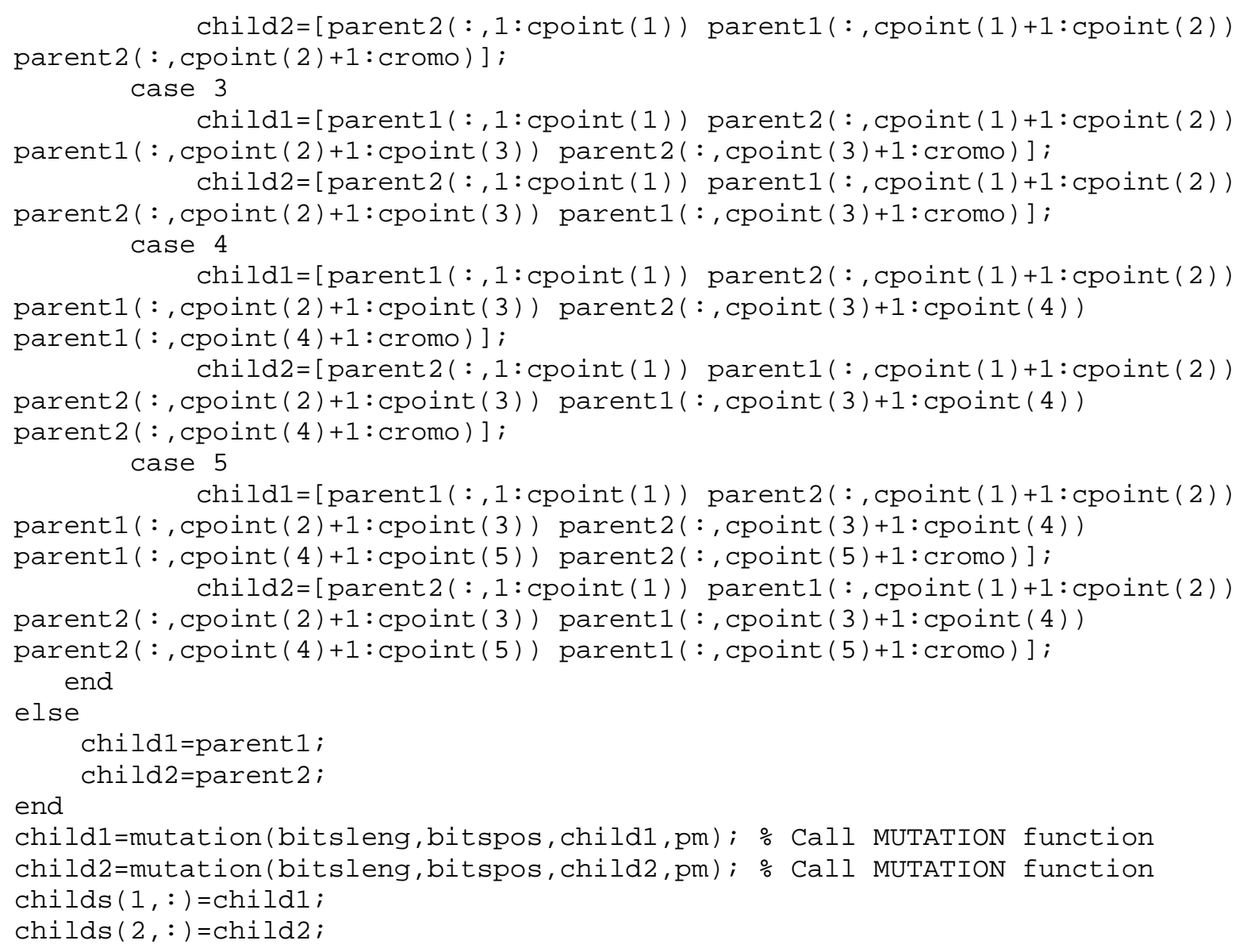

\section{A.8. FUNÇÃO MUTATION}

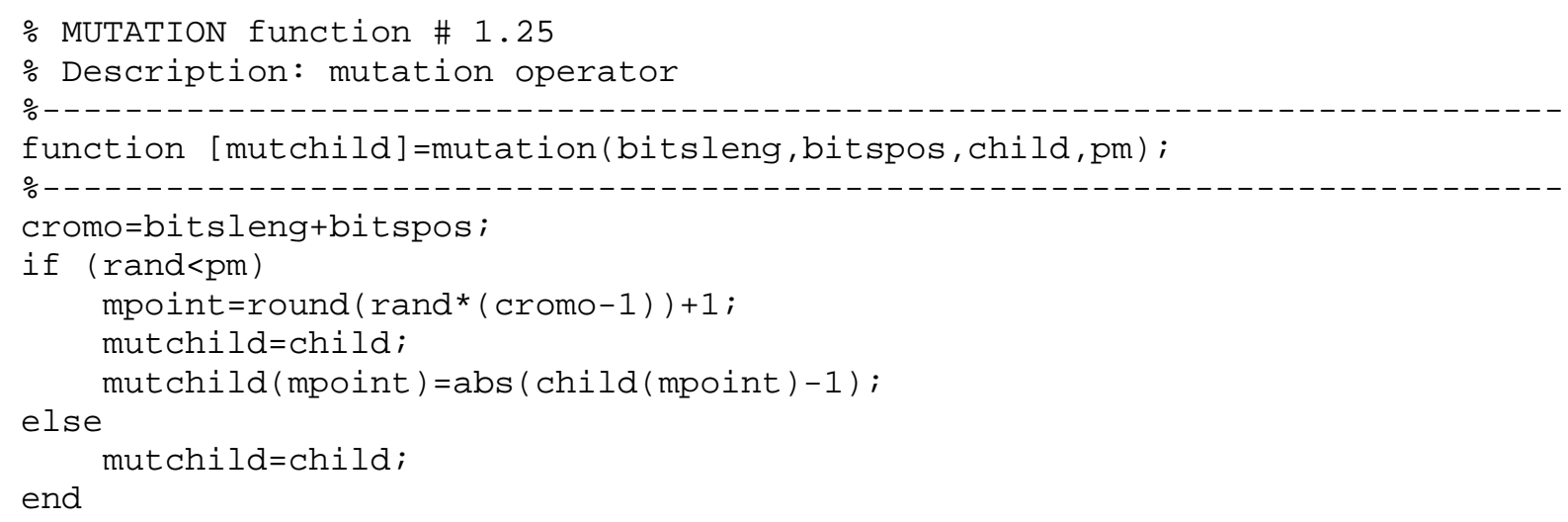

\section{A.9. FUNÇÃO WVAL}

$\%$ WVAL function \# 1.25

\% Description: write population 


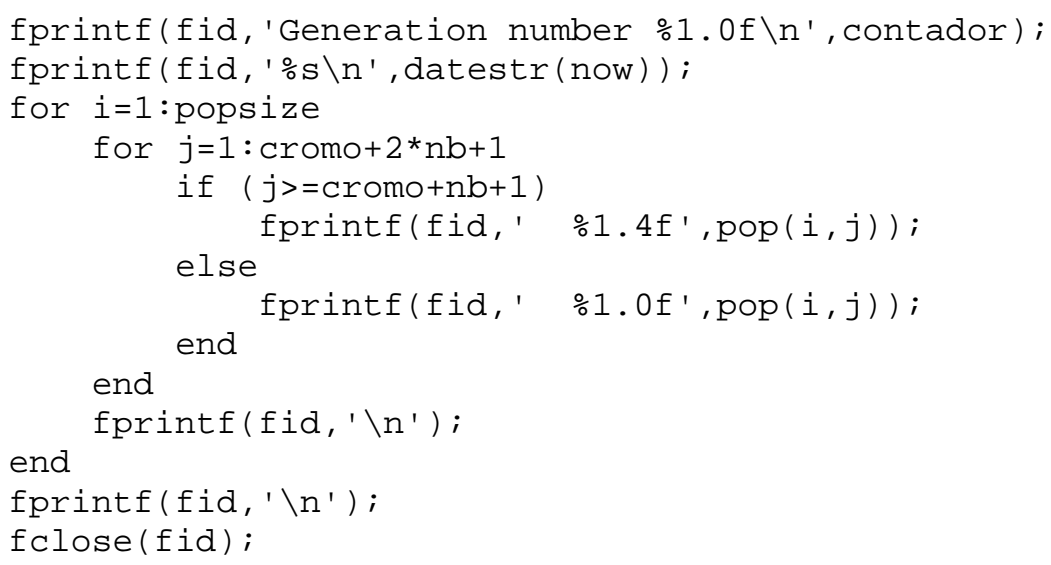

\section{A. 10. FUNÇÃO SORTPOP}

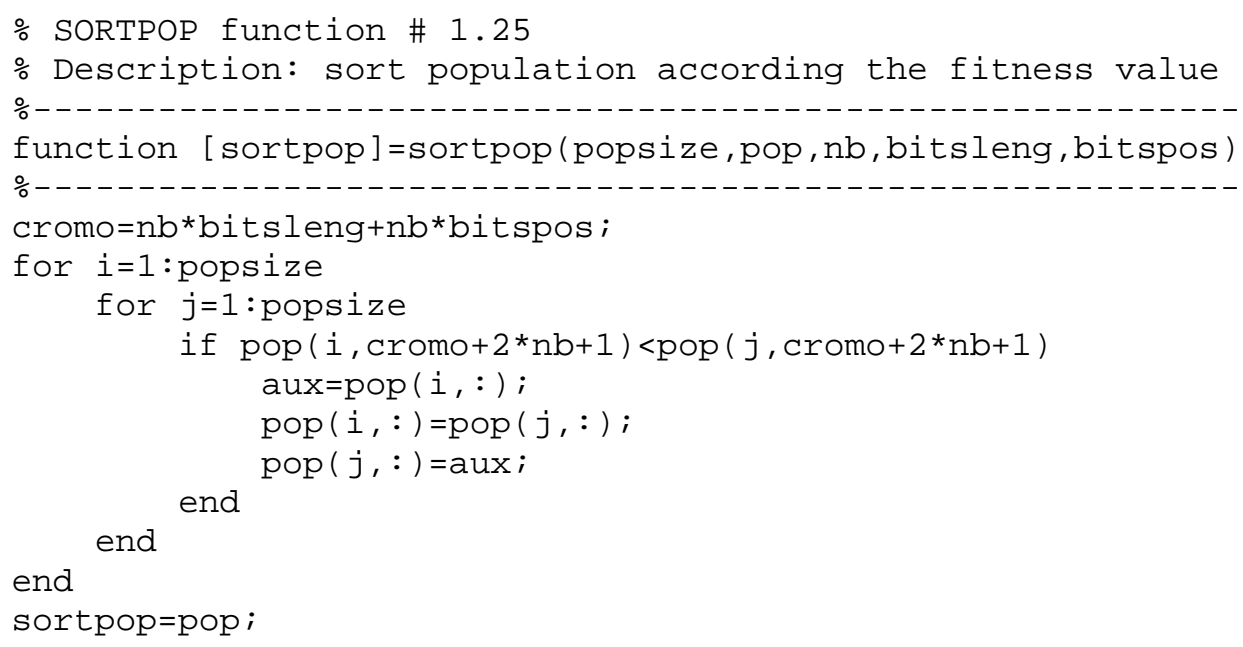




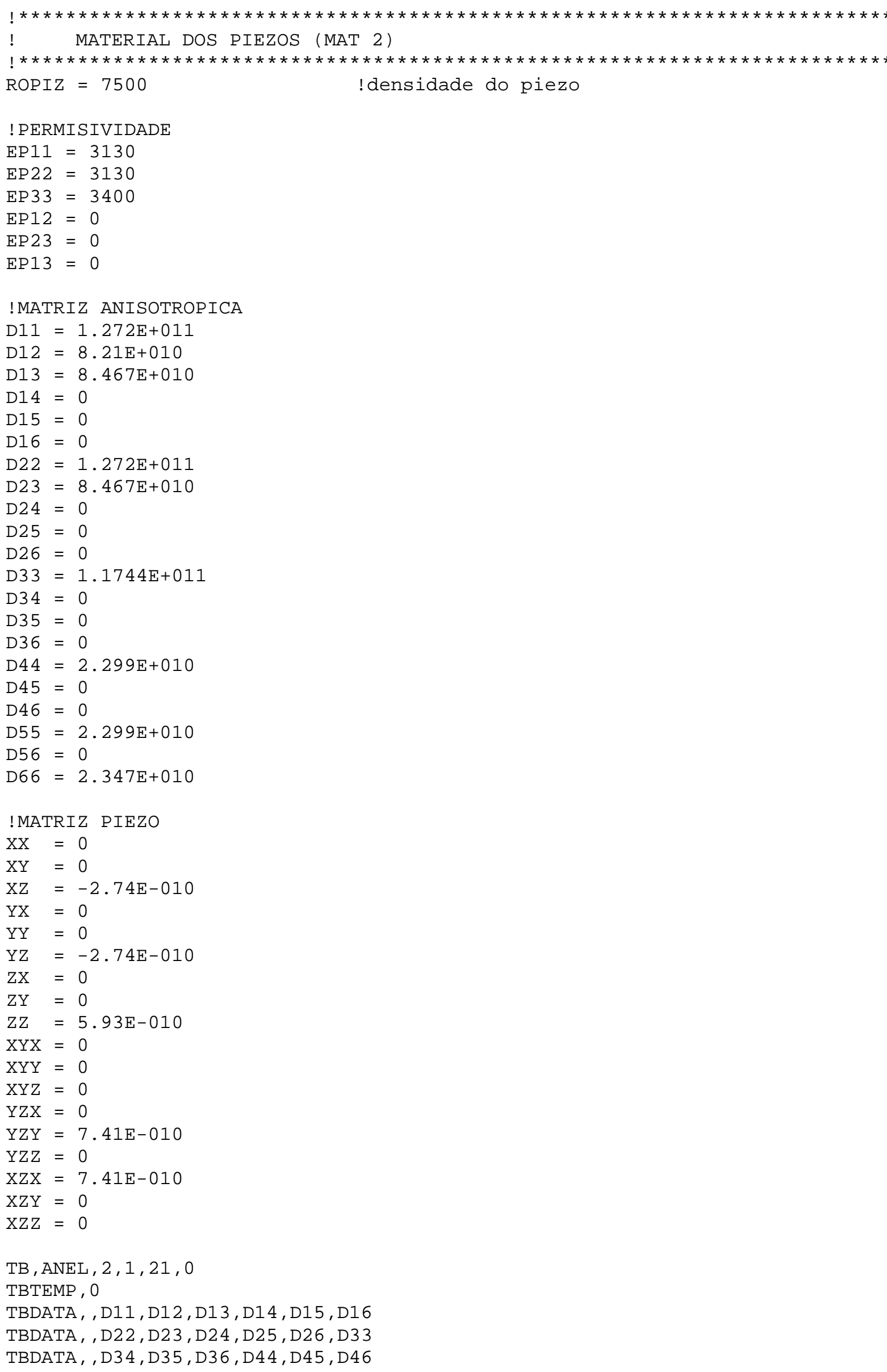


TBDATA, , D55, D56, D66, , ,

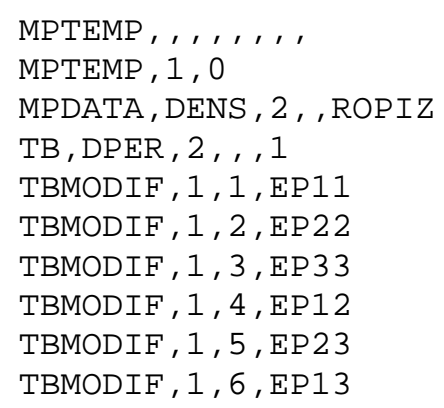


AMESH, ALL

ALLSEL, ALL
$1 * * * * * * * * * * * *$

! PIEZOS

! ************************************
! @@@@@@@@@@@@@@@@@@@@@@@@@@@@@@@@@@
! @@@@@@@@@@@@@@@@@@@@@@@@@@@@@@@@@@

! BIMORPH 1

!@@@@@@@@@@@@@@@@@@@@@@@@@@@@@@@@@@

!@@@@@@@@@@@@@@@@@@@@@@@@@@@@@@@@@@

!@@@@@@@@@@@@@@@@@@@@@@@@@@@@@@@@@@

! LOCALIZACAO DO PIEZO 1

!@@@@@@@@@@@@@@@@@@@@@@@@@@@@@@@@@@

$\begin{array}{ll}\text { NGRIDX1 }=7 & \text { ! numero de grid em X a partir da quina }(\odot, \odot) \\ \text { NGRIDY1 }=7 & \text { ! numero de grid em } Y \text { a partir da quina }(\odot, \odot)\end{array}$

POSX1 = INCX*NGRIDX1

POSY1 $=$ INCY $^{*}$ NGRIDY1

$\mathrm{K}$, , POSX1, POSY1, 0

KWPAVE, 5

RECTNG, $\odot$, LPIZ, $\odot$, BPIZ

$\mathrm{NZPIZ}=\mathrm{LPIZ} / \mathrm{INCX}$

LSEL, S, , , 5, 8, 1

LESIZE, ALL, , , NZPIZ

TYPE, 1

MAT, 1

MSHAPE, $0,2 \mathrm{D}$

MSHKEY, 1

ASEL, $S$, , , 2

AMESH, ALL

ALLSEL, ALL

!@@@@@@@@@@@@@@@@@@@@@@@@@@@@@@@@@@

! LOCALIZACAO DO PIEZO 2

!@@@@@@@@@@@@@@@@@@@@@@@@@@@@@@@@@@

$\mathrm{K}$, , POSX1, POSY1, HPIZ

KWPAVE, 10

RECTNG, $\odot$, LPIZ, $\odot$, BPIZ

LSEL, $S$, , $9,12,1$

LESIZE, ALL, , , NZPIZ

TYPE, 1

MAT, 1

MSHAPE, $\odot, 2 D$

MSHKEY, 1

ASEL, $S, 1,3$

AMESH, ALL

ALLSEL, ALL

!@@@@@@@@@@@@@@@@@@@@@@@@@@@@@@@@@@

!@@@@@@@@@@@@@@@@@@@@@@@@@@@@@@@@@@

! BIMORPH 2

! @@@@@@@@@@@@@@@@@@@@@@@@@@@@@@@@@@

!@@@@@@@@@@@@@@@@@@@@@@@@@@@@@@@@@@

!@@@@@@@@@@@@@@@@@@@@@@@@@@@@@@@@@@

! LOCALIZACAO DO PIEZO 1

!@@@@@@@@@@@@@@@@@@@@@@@@@@@@@@@@@@

NGRIDX2 $=52$

NGRIDY2 $=7$

! numero de grid em $X$ a partir da quina $(0,0)$

POSX2 = INCX*NGRIDX2

! numero de grid em $Y$ a partir da quina $(0, \odot)$

POSY2 $=$ INCY*NGRIDY2

$\mathrm{K}$, , POSX2, POSY2, $\odot$ 
KWPAVE, 15

RECTNG, $\odot$, LPIZ, $\odot$, BPIZ

LSEL, S, , , 13, 16, 1

LESIZE, ALL, , , NZPIZ

TYPE, 1

MAT, 1

MSHAPE, 0 , 2D

MSHKEY, 1

ASEL, S, , , 4

AMESH, ALL

ALLSEL, ALL

!@@@@@@@@@@@@@@@@@@@@@@@@@@@@@@@@@@

! LOCALIZACAO DO PIEZO 2

!@@@@@@@@@@@@@@@@@@@@@@@@@@@@@@@@@@

$\mathrm{K}$, , POSX2, POSY2, HPIZ

KWPAVE, 20

RECTNG, $\odot$, LPIZ, $\odot$, BPIZ

LSEL, S, , , 17, 20, 1

LESIZE, ALL, , , NZPIZ

TYPE, 1

MAT, 1

MSHAPE, $0,2 \mathrm{D}$

MSHKEY, 1

ASEL, $S$, , , 5

AMESH, ALL

ALLSEL, ALL

!@@@@@@@@@@@@@@@@@@@@@@@@@@@@@@@@@@ ! @@@@@@@@@@@@@@@@@@@@@@@@@@@@@@@@@@ ! BIMORPH 3

!@@@@@@@@@@@@@@@@@@@@@@@@@@@@@@@@@@ ! @@@@@@@@@@@@@@@@@@@@@@@@@@@@@@@@@@

! @@@@@@@@@@@@@@@@@@@@@@@@@@@@@@@@@@ ! LOCALIZACAO DO PIEZO 1

!@@@@@@@@@@@@@@@@@@@@@@@@@@@@@@@@@@
NGRIDX3 $=23$
! numero de grid em $X$ a partir da quina $(0,0)$
NGRIDY3 $=14$
! numero de grid em $Y$ a partir da quina $(\odot, \odot)$

POSX3 $=$ INCX ${ }^{*}$ NGRIDX3

POSY3 $=$ INCY ${ }^{*}$ NGRIDY3

$\mathrm{K}$, , POSX3, POSY 3,0

KWPAVE, 25

RECTNG, $\odot$, LPIZ, $\odot$, BPIZ

LSEL, $S,, 21,24,1$

LESIZE, ALL, , , NZPIZ

TYPE, 1

MAT, 1

MSHAPE, $\odot, 2 \mathrm{D}$

MSHKEY, 1

ASEL, $S, 1,6$

AMESH, ALL

ALLSEL, ALL

!@@@@@@@@@@@@@@@@@@@@@@@@@@@@@@@@@@

! LOCALIZACAO DO PIEZO 2

!@@@@@@@@@@@@@@@@@@@@@@@@@@@@@@@@@@

$\mathrm{K}$, POSX3, POSY3, HPIZ

KWPAVE, 30

RECTNG, $\odot$, LPIZ, $\odot$, BPIZ

LSEL, $S$, , 25, 28, 1

LESIZE, ALL, , , NZPIZ

TYPE, 1 
MAT, 1

MSHAPE, $\odot, 2 D$

MSHKEY, 1

ASEL, $S, 1,7$

AMESH, ALL

ALLSEL, ALL

! @@@@@@@@@@@@@@@@@@@@@@@@@@@@@@@@@@ !@@@@@@@@@@@@@@@@@@@@@@@@@@@@@@@@@@

! BIMORPH 4

!@@@@@@@@@@@@@@@@@@@@@@@@@@@@@@@@@@

!@@@@@@@@@@@@@@@@@@@@@@@@@@@@@@@@@@

!@@@@@@@@@@@@@@@@@@@@@@@@@@@@@@@@@@

LOCALIZACAO DO PIEZO 1

!@@@@@@@@@@@@@@@@@@@@@@@@@@@@@@@@@@

NGRIDX4 $=36 \quad$ ! numero de grid em $X$ a partir da quina $(\odot, \odot)$

NGRIDY4 $=14$

! numero de grid em $Y$ a partir da quina $(0,0)$

POSX4 $=$ INCX ${ }^{*}$ NGRIDX4

POSY4 $=$ INCY ${ }^{*}$ NGRIDY4

$\mathrm{K}$, , POSX4, POSY 4,0

KWPAVE, 35

RECTNG, $\odot$, LPIZ, $\odot$, BPIZ

LSEL, $S, 1,29,32,1$

LESIZE, ALL, , , NZPIZ

TYPE, 1

MAT, 1

MSHAPE, $\odot, 2 D$

MSHKEY, 1

ASEL, $S$, , , 8

AMESH, ALL

ALLSEL, ALL

!@@@@@@@@@@@@@@@@@@@@@@@@@@@@@@@@@@

! LOCALIZACAO DO PIEZO 2

!@@@@@@@@@@@@@@@@@@@@@@@@@@@@@@@@@@

$\mathrm{K}$, , POSX4, POSY4, HPIZ

KWPAVE, 40

RECTNG, $\odot$, LPIZ, $\odot$, BPIZ

LSEL, $S$, , , 33, 36, 1

LESIZE, ALL , , , NZPIZ

TYPE, 1

MAT, 1

MSHAPE, $\odot, 2 D$

MSHKEY, 1

ASEL, $S, 1,9$

AMESH, ALL

ALLSEL, ALL

!@@@@@@@@@@@@@@@@@@@@@@@@@@@@@@@@@@

!@@@@@@@@@@@@@@@@@@@@@@@@@@@@@@@@@@

! BIMORPH 5

!@@@@@@@@@@@@@@@@@@@@@@@@@@@@@@@@@@

!@@@@@@@@@@@@@@@@@@@@@@@@@@@@@@@@@@

!@@@@@@@@@@@@@@@@@@@@@@@@@@@@@@@@@@

! LOCALIZACAO DO PIEZO 1

!@@@@@@@@@@@@@@@@@@@@@@@@@@@@@@@@@@

NGRIDX5 $=15$

NGRIDY5 $=20$

! numero de grid em $X$ a partir da quina $(0,0)$

POSX5 = INCX*NGRIDX5

! numero de grid em $Y$ a partir da quina $(0,0)$

POSY5 $=$ INCY*NGRIDY5 


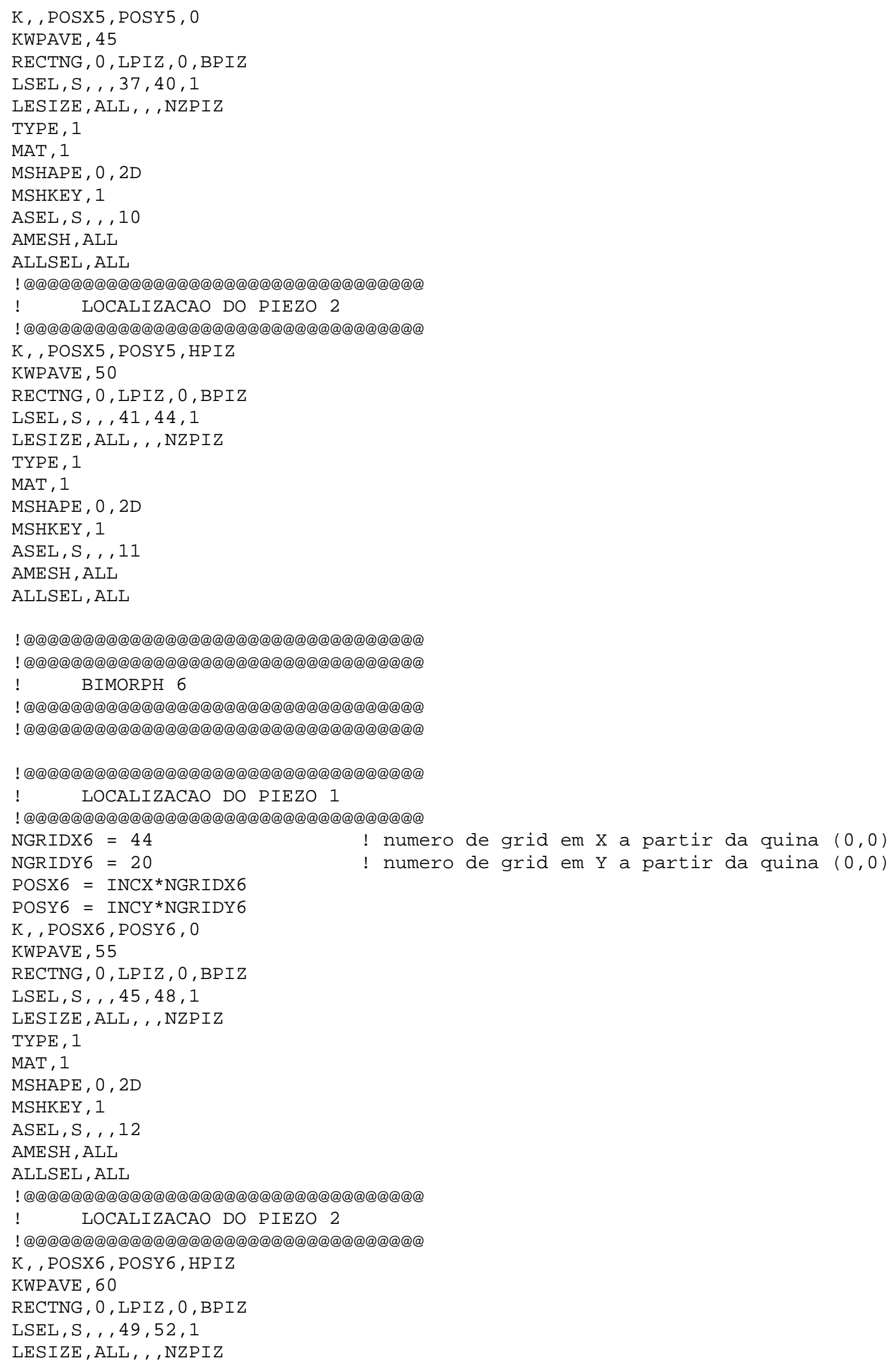


TYPE, 1

MAT, 1

MSHAPE, $0,2 \mathrm{D}$

MSHKEY, 1

ASEL, $S$, , , 13

AMESH, ALL

ALLSEL, ALL

!@@@@@@@@@@@@@@@@@@@@@@@@@@@@@@@@@@

!@@@@@@@@@@@@@@@@@@@@@@@@@@@@@@@@@@

! BIMORPH 7

!@@@@@@@@@@@@@@@@@@@@@@@@@@@@@@@@@@

!@@@@@@@@@@@@@@@@@@@@@@@@@@@@@@@@@@

!@@@@@@@@@@@@@@@@@@@@@@@@@@@@@@@@@@

! LOCALIZACAO DO PIEZO 1

!@@@@@@@@@@@@@@@@@@@@@@@@@@@@@@@@@@

NGRIDX7 = 15

! numero de grid em $X$ a partir da quina $(0,0)$

NGRIDY7 $=31$

! numero de grid em $Y$ a partir da quina $(\odot, \Theta)$

POSX7 $=$ INCX ${ }^{*}$ NGRIDX7

POSY7 $=$ INCY ${ }^{*}$ NGRIDY7

$\mathrm{K}$, , POSX7, POSY7, 0

KWPAVE, 65

RECTNG, $\odot$, LPIZ, $\odot$, BPIZ

LSEL, $S$, , ,53, 56, 1

LESIZE, ALL, , , NZPIZ

TYPE, 1

MAT, 1

MSHAPE, $\odot, 2 D$

MSHKEY, 1

ASEL, $S$, , , 14

AMESH, ALL

ALLSEL, ALL

!@@@@@@@@@@@@@@@@@@@@@@@@@@@@@@@@@@

! LOCALIZACAO DO PIEZO 2

!@@@@@@@@@@@@@@@@@@@@@@@@@@@@@@@@@@

$\mathrm{K}$, , POSX7, POSY7, HPIZ

KWPAVE, 70

RECTNG , $\odot$, LPIZ, $\odot$, BPIZ

LSEL, $S$, , ,57, 60, 1

LESIZE, ALL , , NZPIZ

TYPE, 1

MAT, 1

MSHAPE, $\odot, 2 \mathrm{D}$

MSHKEY, 1

ASEL, $S, ~, ~, 15$

AMESH, ALL

ALLSEL, ALL

!@@@@@@@@@@@@@@@@@@@@@@@@@@@@@@@@@@ !@@@@@@@@@@@@@@@@@@@@@@@@@@@@@@@@@@ ! BIMORPH 8

!@@@@@@@@@@@@@@@@@@@@@@@@@@@@@@@@@@ ! @@@@@@@@@@@@@@@@@@@@@@@@@@@@@@@@@@

!@@@@@@@@@@@@@@@@@@@@@@@@@@@@@@@@@@

! LOCALIZACAO DO PIEZO 1

!@@@@@@@@@@@@@@@@@@@@@@@@@@@@@@@@@@
NGRIDX8 $=44$
! numero de grid em $X$ a partir da quina $(\odot, \Theta)$
NGRIDY8 $=31$
! numero de grid em $Y$ a partir da quina $(0,0)$
POSX8 $=$ INCX*NGRIDX8 


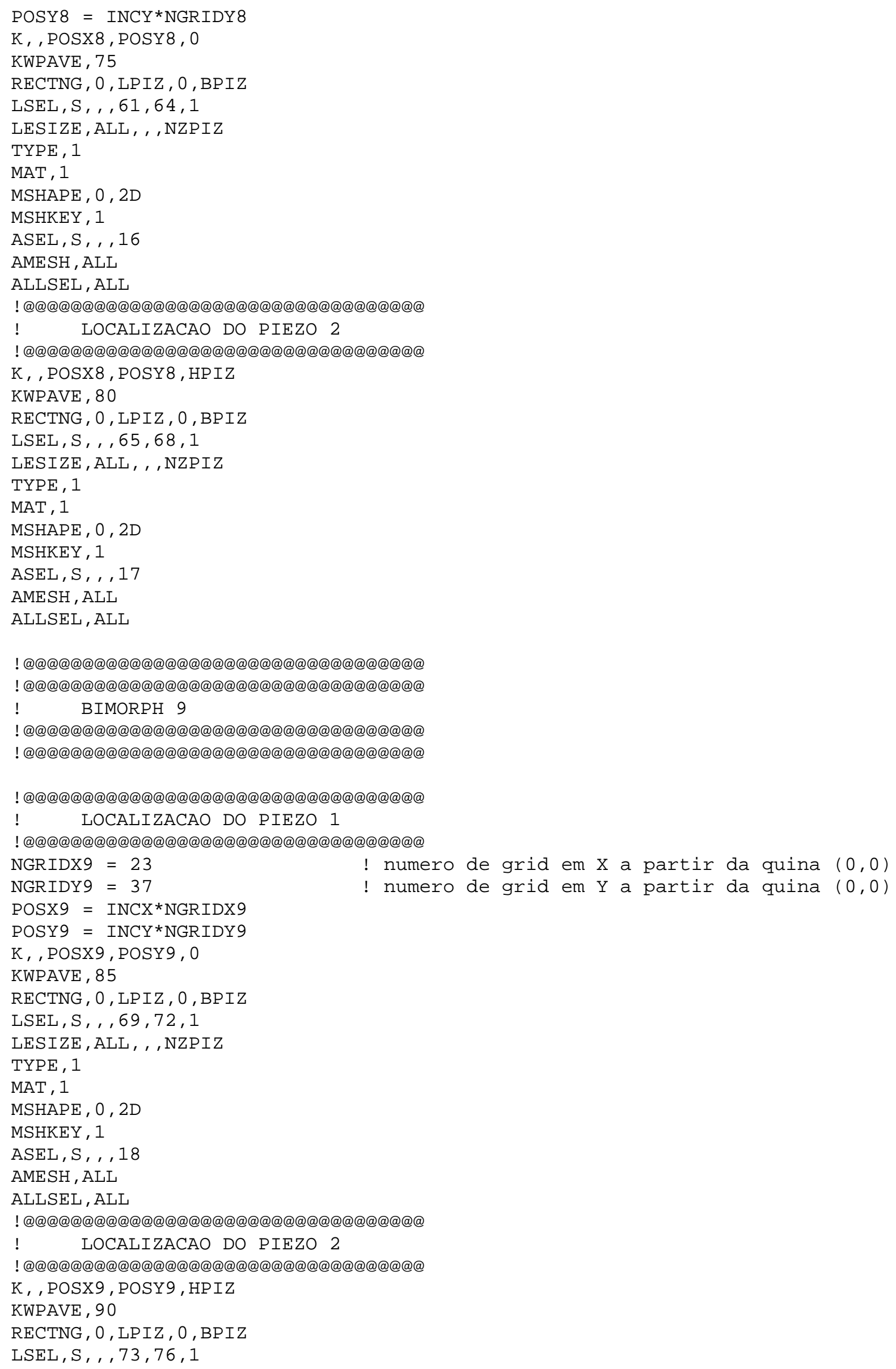




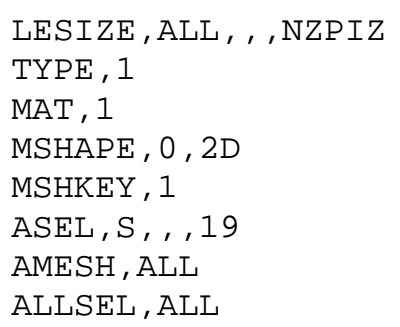

!@@@@@@@@@@@@@@@@@@@@@@@@@@@@@@@@@@ ! @@@@@@@@@@@@@@@@@@@@@@@@@@@@@@@@@@ 


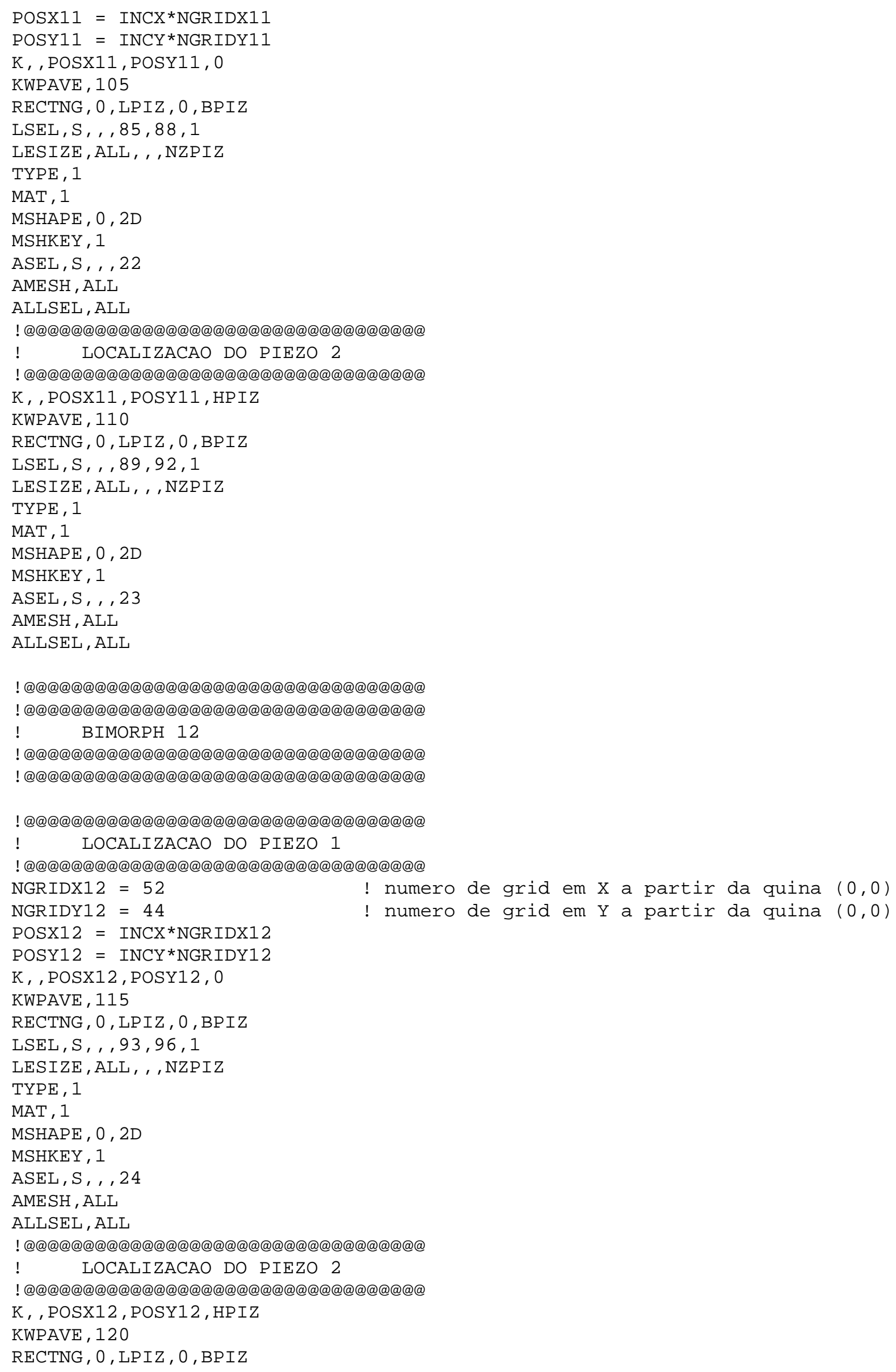


LSEL, S, , , 97, 100, 1

LESIZE, ALL, , , NZPIZ

TYPE, 1

MAT, 1

MSHAPE, $\odot, 2 D$

MSHKEY, 1

ASEL, S, , , 25

AMESH, ALL

ALLSEL, ALL

! \#\#\#\#\#\#\#\#\#\#\#\#\#\#\#

! EXTRUSAO PIEZOS

! \#\#\#\#\#\#\#\#\#\#\#\#\#\#\#

$\mathrm{AUX}=2$

EXTOPT, ESIZE, AUX, $\odot$,

EXTOPT, ACLEAR, 1

ASEL, $S, ~, ~, 2,25,1$

TYPE, 2

MAT, 2

VEXT, ALL, , , $\odot, \odot$, HPIZ

ALLSEL, ALL

EPLO

NUMMRG, KP, , , , LOW

NUMMRG, NODE, , , , LOW

NUMMRG, KP, , , , LOW

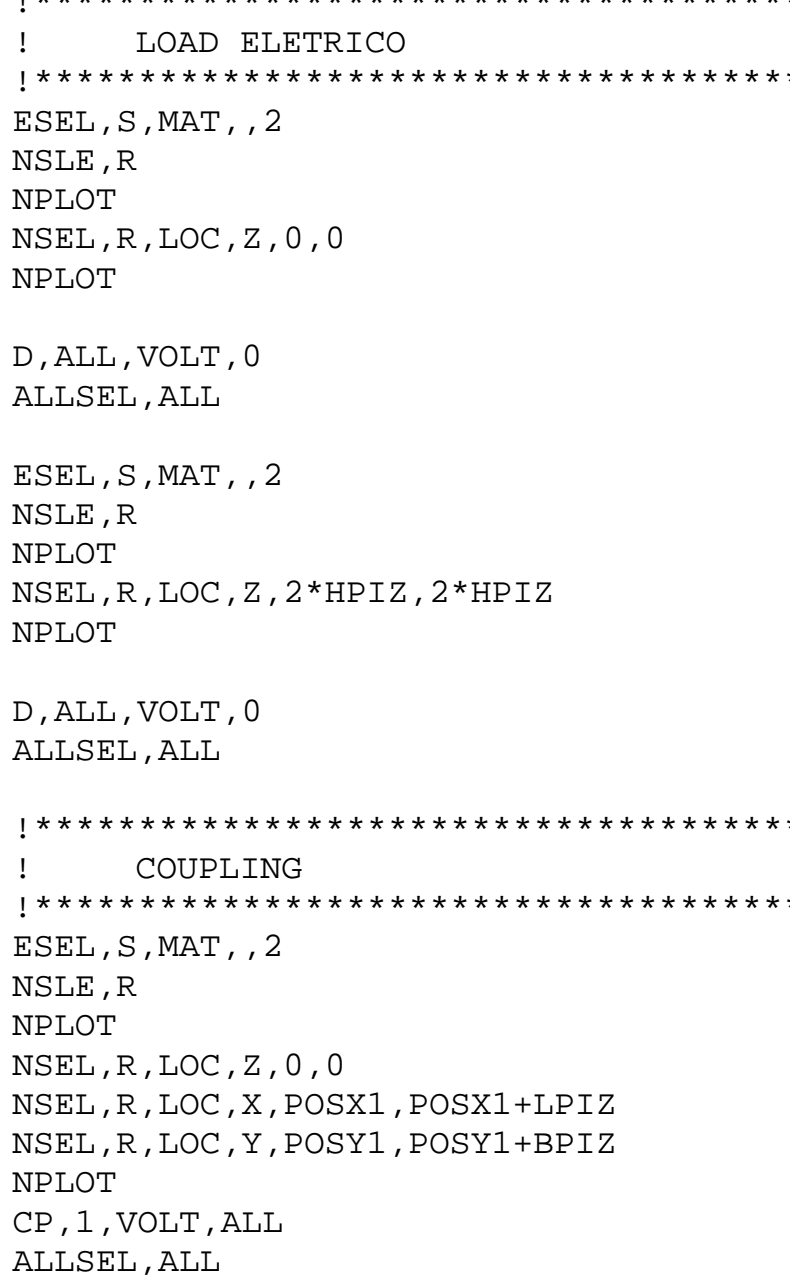

NSLE, $R$

NPLOT

NSEL, R, LOC , Z, $\odot, \odot$

NPLOT

$D, A L L, V O L T, \odot$

ALLSEL, ALL

ESEL, S, MAT, , 2

NSLE, $R$

NPLOT

NSEL, R, LOC , Z, 2*HPIZ, 2*HPIZ

NPLOT

$D, A L L, V O L T, \odot$

ALLSEL, ALL 
EPLO

ESEL, S, MAT, , 2

NSLE, $R$

NPLOT

NSEL, R, LOC , Z, $\odot, \Theta$

NSEL, R, LOC , X, POSX2, POSX2+LPIZ

NSEL, R, LOC, Y, POSY2, POSY2+BPIZ

NPLOT

$\mathrm{CP}, 2$, VOLT, ALL

ALLSEL, ALL

EPLO

ESEL, S, MAT, , 2

NSLE, $R$

NPLOT

NSEL, R, LOC , Z, $\odot, 0$

NSEL, R, LOC, X, POSX3, POSX3+LPIZ

NSEL, R, LOC, Y, POSY3, POSY3+BPIZ

NPLOT

$\mathrm{CP}, 3, \mathrm{VOLT}, \mathrm{ALL}$

ALLSEL, ALL

EPLO

ESEL, S, MAT, , 2

NSLE, $R$

NPLOT

NSEL, R, LOC , Z, $\odot, \Theta$

NSEL, R, LOC , X, POSX4, POSX4+LPIZ

NSEL, R, LOC, Y, POSY4, POSY4+BPIZ

NPLOT

CP, 4, VOLT, ALL

ALLSEL, ALL

EPLO

ESEL, S, MAT, , 2

NSLE, R

NPLOT

NSEL, R, LOC , Z, $\odot, 0$

NSEL, R, LOC, X, POSX5, POSX5+LPIZ

NSEL, R, LOC, Y, POSY5, POSY5+BPIZ

NPLOT

$\mathrm{CP}, 5$, VOLT, ALL

ALLSEL, ALL

EPLO

ESEL, S, MAT, , 2

NSLE, $R$

NPLOT

NSEL, R, LOC , Z, $\odot, 0$

NSEL, R, LOC, X, POSX6, POSX6+LPIZ

NSEL, R, LOC, Y, POSY6, POSY6+BPIZ

NPLOT

CP, 6, VOLT, ALL

ALLSEL, ALL

EPLO

ESEL, S, MAT, , 2

NSLE, R

NPLOT

NSEL, R, LOC , Z, $\odot, \odot$ 
NSEL, R, LOC , X, POSX7 , POSX7+LPIZ NSEL, R, LOC, Y, POSY7, POSY7+BPIZ NPLOT

CP, 7, VOLT, ALL

ALLSEL, ALL

EPLO

ESEL, S, MAT, , 2

NSLE, $R$

NPLOT

NSEL, R, LOC, Z, $\odot, \odot$

NSEL, R, LOC , X, POSX8, POSX8+LPIZ

NSEL, R, LOC, Y, POSY8, POSY8+BPIZ

NPLOT

$\mathrm{CP}, 8, \mathrm{VOLT}, \mathrm{ALL}$

ALLSEL, ALL

EPLO

ESEL, S, MAT, , 2

NSLE, $R$

NPLOT

NSEL, R, LOC, Z, $\odot, \odot$

NSEL, R, LOC , X, POSX9, POSX9+LPIZ

NSEL, R, LOC, Y, POSY9, POSY9+BPIZ

NPLOT

CP , 9, VOLT, ALL

ALLSEL, ALL

EPLO

ESEL, S, MAT, , 2

NSLE, R

NPLOT

NSEL, R, LOC, Z, $\odot, \odot$

NSEL, R, L0C , X, POSX10, P0SX10+LPIZ

NSEL, R, L0C, Y, P0SY10, P0SY10+BPIZ NPLOT

CP , 10, VOLT, ALL

ALLSEL, ALL

EPLO

ESEL, S, MAT, , 2

NSLE, R

NPLOT

NSEL, R, LOC , Z, $\odot, \odot$

NSEL, R, LOC , X, POSX11, P0SX11+LPIZ

NSEL, R, LOC , Y, P0SY11, P0SY11+BPIZ

NPLOT

CP, 11, VOLT, ALL

ALLSEL, ALL

EPLO

ESEL, S, MAT, , 2

NSLE, $R$

NPLOT

NSEL, R, LOC, Z, $\odot, \odot$

NSEL, R, LOC , X, P0SX12, P0SX12+LPIZ

NSEL, R, LOC , Y, POSY12, P0SY12+BPIZ

NPLOT

CP , 12, VOLT, ALL

ALLSEL, ALL

EPLO 


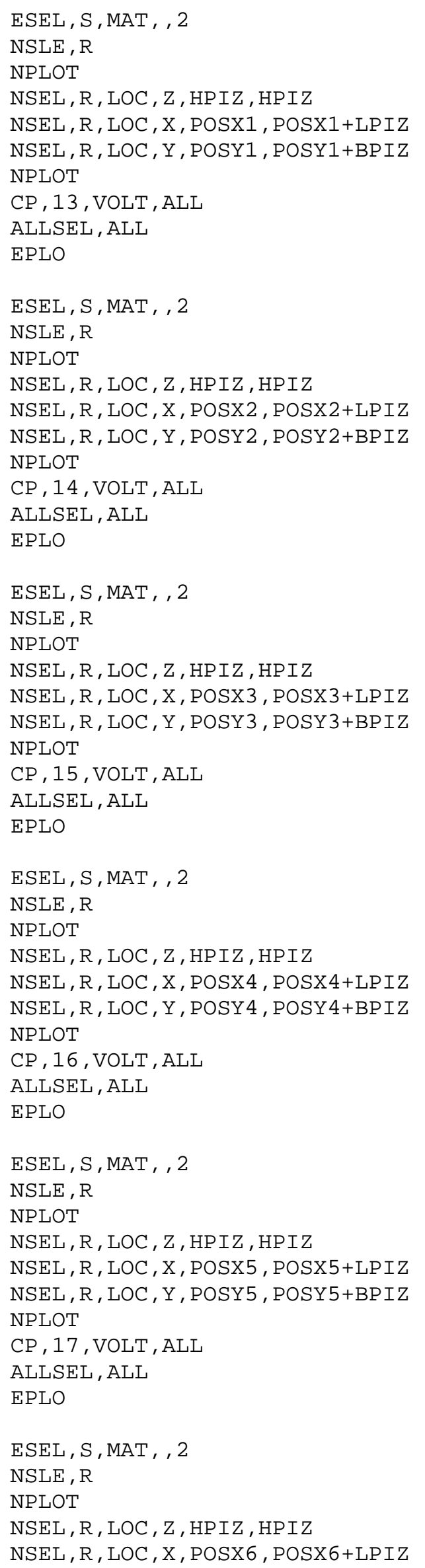


NSEL, R, LOC , Y , POSY6, POSY6+BPIZ NPLOT

CP, 18, VOLT, ALL

ALLSEL, ALL

EPLO

ESEL, S, MAT, , 2

NSLE, $\mathrm{R}$

NPLOT

NSEL, R, LOC , Z, HPIZ, HPIZ

NSEL, R, LOC , X, POSX7, POSX7+LPIZ

NSEL, R, LOC , Y, POSY7, POSY7+BPIZ

NPLOT

CP , 19, VOLT, ALL

ALLSEL, ALL

EPLO

ESEL, S, MAT, , 2

NSLE, $R$

NPLOT

NSEL, R, LOC, Z, HPIZ, HPIZ

NSEL, R, LOC , X, POSX8, POSX8+LPIZ

NSEL, R, LOC , Y, POSY8, POSY8+BPIZ

NPLOT

CP, 20, VOLT, ALL

ALLSEL, ALL

EPLO

ESEL, S, MAT, , 2

NSLE, $R$

NPLOT

NSEL, R, LOC , Z, HPIZ, HPIZ

NSEL, R, LOC , X, POSX9, POSX9+LPIZ

NSEL, R, LOC , Y, POSY9, POSY9+BPIZ

NPLOT

CP, 21, VOLT, ALL

ALLSEL, ALL

EPLO

ESEL, S, MAT, , 2

NSLE, R

NPLOT

NSEL, R, LOC , Z, HPIZ, HPIZ

NSEL , R, LOC , X, POSX10, POSX10+LPIZ

NSEL, R, LOC, Y, POSY10, POSY10+BPIZ

NPLOT

CP, 22, VOLT, ALL

ALLSEL, ALL

EPLO

ESEL, S, MAT, , 2

NSLE, R

NPLOT

NSEL, R, LOC, Z, HPIZ, HPIZ

NSEL, R, LOC , X, POSX11, POSX11+LPIZ

NSEL, R, LOC, Y, POSY11, P0SY11+BPIZ

NPLOT

CP, 23, VOLT, ALL

ALLSEL, ALL

EPLO 


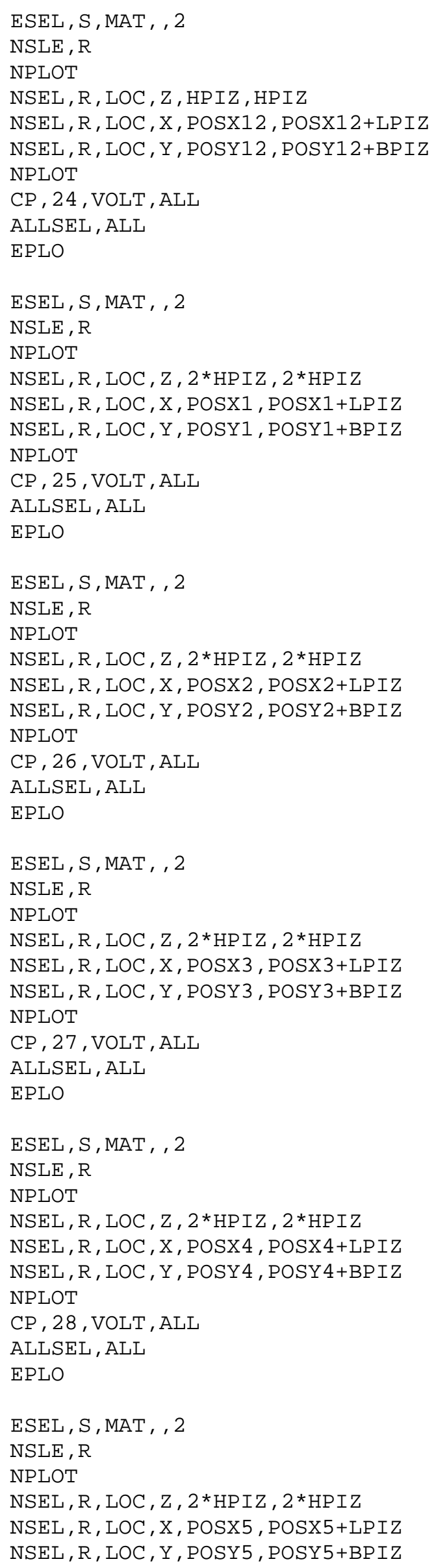


NPLOT

CP, 29, VOLT, ALL

ALLSEL, ALL

EPLO

ESEL, S, MAT, , 2

NSLE, $R$

NPLOT

NSEL, R, LOC , Z, 2*HPIZ, 2*HPIZ

NSEL, R, LOC , X, POSX6, POSX6+LPIZ

NSEL, R, LOC, Y, POSY6, POSY6+BPIZ

NPLOT

CP, 30, VOLT, ALL

ALLSEL, ALL

EPLO

ESEL, S, MAT, , 2

NSLE, R

NPLOT

NSEL, R, LOC , Z, 2*HPIZ, 2*HPIZ

NSEL, R, LOC , X, POSX7, POSX7+LPIZ

NSEL, R, LOC, Y, POSY7, POSY7+BPIZ

NPLOT

CP, 31, VOLT, ALL

ALLSEL, ALL

EPLO

ESEL, S, MAT, , 2

NSLE, $R$

NPLOT

NSEL, R, LOC , Z, 2 *HPIZ, 2*HPIZ

NSEL, R, LOC , X, POSX8, POSX8+LPIZ

NSEL, R, LOC, Y, POSY8, POSY8+BPIZ

NPLOT

$\mathrm{CP}, 32, \mathrm{VOLT}, \mathrm{ALL}$

ALLSEL, ALL

EPLO

ESEL, S, MAT, , 2

NSLE, $R$

NPLOT

NSEL, R, LOC , Z, 2*HPIZ, 2*HPIZ

NSEL, R, LOC , X, POSX9, POSX9+LPIZ

NSEL, R, LOC, Y, POSY9, POSY9+BPIZ

NPLOT

CP, 33, VOLT, ALL

ALLSEL, ALL

EPLO

ESEL, S, MAT, , 2

NSLE, $R$

NPLOT

NSEL, R, LOC , Z, 2*HPIZ, 2*HPIZ

NSEL, R, LOC, X, POSX10, P0SX10+LPIZ

NSEL, R, LOC, Y, POSY10, POSY10+BPIZ

NPLOT

$\mathrm{CP}, 34, \mathrm{VOLT}, \mathrm{ALL}$

ALLSEL, ALL

EPLO

ESEL, S, MAT, , 2 


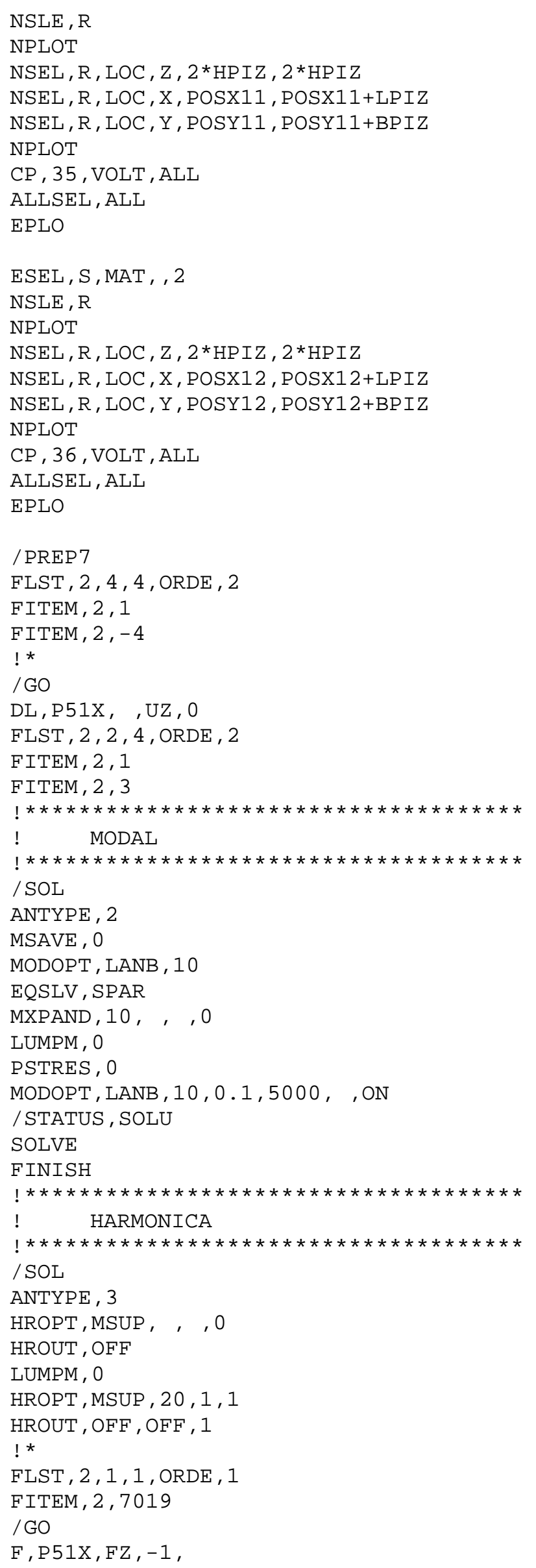


! *

HARFRQ, $\odot, 5000$,

NSUBST, 10000,

$\mathrm{KBC}, 1$

$!$ *

SOLVE

FINISH 